\title{
Tell me... why do you drink? : a study of drinking motives in adolescence
}

Citation for published version (APA):

Kuntsche, E. N. (2007). Tell me... why do you drink? : a study of drinking motives in adolescence.

[Doctoral Thesis, Maastricht University]. SFA-ISPA Press. https://doi.org/10.26481/dis.20071108ek

Document status and date:

Published: 01/01/2007

DOI:

10.26481/dis.20071108ek

Document Version:

Publisher's PDF, also known as Version of record

\section{Please check the document version of this publication:}

- A submitted manuscript is the version of the article upon submission and before peer-review. There can be important differences between the submitted version and the official published version of record.

People interested in the research are advised to contact the author for the final version of the publication, or visit the DOI to the publisher's website.

- The final author version and the galley proof are versions of the publication after peer review.

- The final published version features the final layout of the paper including the volume, issue and page numbers.

Link to publication

\footnotetext{
General rights rights.

- You may freely distribute the URL identifying the publication in the public portal. please follow below link for the End User Agreement:

www.umlib.nl/taverne-license

Take down policy

If you believe that this document breaches copyright please contact us at:

repository@maastrichtuniversity.nl

providing details and we will investigate your claim.
}

Copyright and moral rights for the publications made accessible in the public portal are retained by the authors and/or other copyright owners and it is a condition of accessing publications that users recognise and abide by the legal requirements associated with these

- Users may download and print one copy of any publication from the public portal for the purpose of private study or research.

- You may not further distribute the material or use it for any profit-making activity or commercial gain

If the publication is distributed under the terms of Article $25 \mathrm{fa}$ of the Dutch Copyright Act, indicated by the "Taverne" license above, 
TELL ME... WHY DO YOU DRINK?

A STUDY OF DRINKING MOTIVES IN ADOLESCENCE 


\section{sfa/ispa $R$ SFA-ISPA Press}

(C) Emmanuel Kuntsche, Lausanne, 2007.

No part of this book may be reproduced

in any form and by any means without

permission of the author.

ISBN 978-2-88183-127-0

Publisher: $\quad$ Swiss Institute for the

Prevention of Alcohol

and Drug Problems

Avenue Ruchonnet 14

CH 1003 Lausanne

www.sfa-ispa.ch

English editing: Elaine Sheerin, Lausanne

Cover illustration: Biff cartoons created by

Chris Garratt and Mick Kidd

Printed by: $\quad$ Publisprint, Renens $(\mathrm{CH})$

www.publisprint.com 


\title{
TELL ME... WHY DO YOU DRINK?
}

\section{A STUDY OF DRINKING MOTIVES IN ADOLESCENCE}

\author{
Proefschrift
}

ter verkrijging van de graad van doctor

aan de Universiteit Maastricht,

op gezag van de Rector Magnificus,

Prof. dr. G.P.M.F. Mols

volgens het besluit van het College van Decanen

in het openbaar te verdedigen op

donderdag 8 november om 12.00 uur

door

Emmanuel Nicolás Kuntsche

geboren op 20 augustus 1972

te Barcelona (Spanje) 


\section{Promotor}

Prof. Dr. Ronald A. Knibbe, University of Maastricht, Maastricht, the Netherlands

\section{Co-promotors}

Dr. Gerhard Gmel, Swiss Institute for the Prevention of Alcohol and Drug

Problems, Lausanne, Switzerland

Prof. Dr. Rutger C.M.E. Engels, Radboud University Nijmegen, Nijmegen, the Netherlands

\section{Expert committee}

Prof. Dr. Nanne de Vries, University of Maastricht, Maastricht, the Netherlands (chair)

Dr. Paul Lemmens, University of Maastricht, Maastricht, the Netherlands

Prof. Dr. Wim Meeus, University of Utrecht, Utrecht, the Netherlands

Prof. Dr. Sherry H. Stewart, Dalhousie University, Halifax, Canada

Prof. Dr. Reinout Wiers, University of Maastricht, Maastricht, the Netherlands 


\section{CONTENTS}

$\begin{array}{ll}\text { Chapter 1: General introduction } & \text { p. } 1\end{array}$

Chapter 2: The current state of knowledge I: Overview of empirical

p. 29 research on formal aspects and possible consequences of drinking motives

Chapter 3: The current state of knowledge II: Overview of empirical

p. 61 research on socio-demographic, personality, and contextual issues of drinking motives

Chapter 4: Replication and validation of the Drinking Motive

p. 85 Questionnaire Revised (DMQ-R, Cooper, 1994) among adolescents in Switzerland

Chapter 5: Drinking motives as mediators of the link between alcohol expectancies and alcohol use

Chapter 6: "I drink spirits to get drunk and block out my problems..." Beverage preference, drinking motives and alcohol use in adolescence

Chapter 7: Bullying and fighting among adolescents - Do drinking motives and alcohol use matter?

Chapter 8: Identifying enhancement and coping drinkers among risky drinking adolescents

p. 173

Chapter 9: General discussion

References

p. 223

Curriculum Vitae

p. 253

Acknowledgements 

Chapter 1

$=7$

General introduction 


\section{Alcohol use and adolescents}

The 2002 World Health Organization (WHO) report demonstrates that, after tobacco use and high blood pressure, alcohol use is the third leading risk factor of life years lost and premature death in established market economies, such as Switzerland and the Netherlands (World Health Organization, 2002). According to the current state of knowledge, alcohol use is one of several factors which have been shown to be responsible for more than 60 different causes of ill-health (Gutjahr \& Gmel, 2001).

Excessive alcohol use among young people has equally been shown to be associated with various adverse consequences and health problems, such as blackouts, unintended pregnancy, sexually transmitted diseases, accidents and injuries, involvement in violent acts like bullying and fighting, academic failure, low life satisfaction, depressive mood, and suicide attempts (e.g., Castilla, Barrio, Belza, \& de la Fuente, 1999; Gmel, Rehm, \& Kuntsche, 2003; Swahn, Simon, Hammig, \& Guerrero, 2004; Kuntsche \& Gmel, 2004; Windle, 2003; Hingson, Heeren, Zakocs, Kopstein, \& Wechsler, 2002; Perkins, 2002). However, despite the range of adverse consequences and associated health problems, over the last 20 years increased weekly alcohol consumption and drunkenness has been observed among adolescents in Switzerland (Kuntsche, 2001b, 2004c) and in most other European countries (Gmel, Rehm, \& Kuntsche, 2003; Hibell, Andersson, Bjarnason, Ahlström, Balakireva, Kokkevi, \& Morgan, 2004). For example, the proportion of 15- and 16- year olds in Switzerland who had been repeatedly drunk in 2002 was twice as high as in 1986 (Schmid, Delgrande Jordan, Kuntsche, \& Kuendig, 2003). In 2003, $40.7 \%$ of 15 -year olds and $43.5 \%$ of 16 -year olds in Switzerland had at least one risky drinking occasion (consumed five or more drinks in a row) in the 30 days prior to the survey (Kuntsche, Gmel, Wicki, Rehm, \& Grichting, 2006). Official records from every hospital in Switzerland reveal that 
1,294 10- to 23 -year olds in 2003 were brought to an emergency room and were diagnosed according to ICD-10 as suffering from alcohol intoxication; this is approximately 3.5 per day (Gmel \& Kuntsche, 2007). In the same age group and survey year, 172 adolescents were diagnosed as alcohol-dependent. The prevalence and upward trend are alarming, and should consequently provide an impetus for new policy measures and prevention efforts. However, if efforts to limit premature and excessive drinking among adolescents are to be a success, we must first understand why young people engage in heavy drinking.

One possible explanation for the high prevalence and upward trend might be that adolescents are simply not sufficiently informed about the risks of heavy drinking. However, empirical data demonstrate that in 2002 about $50 \%$ of boys and more than $60 \%$ of girls indicated that alcohol use was a risky activity with potential health consequences (Kuntsche, 2004b). Other risky activities such as skiing, skateboarding, riding a motorbike, or driving a car were rated as being much less dangerous, with the prevalence for riding a bicycle well below $10 \%$. It would seem then that the knowledge of potential health consequences does not deter adolescents from drinking frequently and excessively (Kuntsche, 2004b). Accordingly, information campaigns about the adverse consequences of excessive drinking were found to be ineffective in changing drinking behavior (e.g., Babor, Caetano, Casswell, Edwards, Giesbrecht, Graham, Grube et al., 2003). Adolescents, therefore, appear to have high levels of motivation to consume alcohol, despite their knowledge of the potential adverse consequences. If so, it is important to determine what these motivations actually are. What, then, are the reasons or the goals that adolescents seek to attain through drinking? 


\section{Theories of adolescent substance use}

In the last 30 years, several theories have been developed to explain the use of alcohol and other psychoactive substances in adolescence (for reviews, see Petraitis, Flay, \& Miller, 1995; White, 1996). According to White (1996) and Kandel (1980), the four most prominent examples are the problem behavior theory (Jessor \& Jessor, 1977), the social learning theory (Akers, 1977), the socialization theory (Kandel, 1980, 1974), and the self-derogation theory (Kaplan, 1975, 1980; for a validation of the self-derogation theory among adolescents in Germany and in Switzerland, see Kuntsche, 2001a and Kuntsche, Reitzle, \& Silbereisen, 2001). These theories share two points in common: each includes aspects of socialization or social learning and postulates that friends' use and/or attitudes about use are important determinants for individual substance use in adolescence.

Around the same time, Fishbein and Ajzen $(1975 ; 1980)$ developed their theory of reasoned action. This theory and its extension, the theory of planned behavior (Ajzen, 1985, 1988, 1991), is the most comprehensive and most widely applied theory of all cognitive-affective theories of adolescent substance use (Petraitis, Flay, \& Miller, 1995). However, both theories were not specifically developed as a comprehensive model of substance use behavior. Furthermore, they provide little explanation of the long-term causes of such behavior. Approximately ten years later, Cox and Klinger $(1988 ; 1990)$ developed their Motivational Model of Alcohol Use. A more detailed comparison between the Motivational Model and the theory of reasoned action and of planned behavior is given below.

\section{A short history of research on drinking motives}

Based on the Motivational Model, Cooper (1994) developed a four-dimensional questionnaire to assess adolescent drinking motives. Research on drinking motives, 
however, had already been undertaken in the late 1940s (Riley, Marden, \& Lifshitz, 1948). By the end of the 1960s, research on drinking motives was incorporated in quantitative studies of the general population (Cahalan, Cisin, \& Crossley, 1969) and college students (Jessor, Carman, \& Grossman, 1968) in the United States. The reasons for drinking, which these studies identified, were then classified into two broad categories: motives to escape or to cope with personal problems or negative emotional states, and motives to celebrate, to enjoy or to be sociable (e.g., Kuntsche, Rehm, \& Gmel, 2004; McCarty \& Kaye, 1984; Smith, Abbey, \& Scott, 1993). Subsequently, a more complex understanding of the subjective motivation for engaging in alcohol consumption was reached (e.g., Carman, Fitzgerald, \& Holmgren, 1983; Edwards, Hensman, \& Peto, 1973; Farber, Khavari, \& Douglass, 1980; Segal, Huba, \& Singer, 1980). Jung (1977), for example, found that among college students social drinkers with mature motives for drinking (e.g., on special occasions) drank less than drinkers with immature motives (e.g., to increase selfconfidence). Brown and Finn (1982) observed that most junior and senior highschool students drink to get drunk in order to enhance their feelings of pleasure. McCarthy and Kaye (1984) revealed a different motivational pattern for different types of drinkers: heavy drinkers scored high on avoidance, social, sensationseeking, and enjoyment reasons, moderate drinkers were primarily women who drank for enjoyment, and beer drinkers were primarily men with a strong endorsement of sensation-seeking motives.

However, like most research on adolescent alcohol use in the first half of the $20^{\text {th }}$ century (cf. White, 1996), these early studies on drinking motives were not based on a comprehensive theory concerning the motivational process that may underlie alcohol use. Their main aim was to collect information on subjective statements of why people think that they engage in alcohol use, which were often part and parcel of more broadly-based alcohol use surveys. Moreover, none of these studies placed 
drinking motives within a wider research context, i.e. to study drinking motives and their interplay with historical factors, past reinforcement from drinking, current factors, and expected effects. The Motivational Model of Alcohol Use provided a basis for a more comprehensive understanding of the reasons why young people engage in alcohol use (Cooper, 1994). In addition to an adequate grasp of drinking motives and the Motivational Model, it is therefore important to understand the general concept of motivation.

\section{Motivation: Definition, goal pursuit, and affective change}

Motivation is defined as a process of instigating, sustaining, and directing psychological or physical activities, including internal forces such as impulses, drives, and desires (Corsini, 2002). This process may operate consciously or unconsciously, psychologically or physiologically, and stimulates, maintains and directs behavior. Motivational factors are basic or immediate needs, interests, incentives, rewards, social drives, and personal drives, for example, security, selfesteem, fortune, or superiority. Thus, motivation can be described as the internal states of organisms (humans or animals) which lead to initiation, persistence, energy, and direction of behaviors towards specific goals (Klinger \& Cox, 2004).

According to Klinger and Cox (2004), the successful pursuit of goals is not just the most important thing in the life of humans and animals; it is ultimately the only factor that ensures survival. All living organisms must meet life's challenges: finding food, avoiding threatening situations, locating hospitable places to live, and reproducing themselves. To address these challenges, plants and animals have adopted different survival strategies. To satisfy their needs, plants depend on the particular environment where they are found. Their immobility requires the massive production of offspring to guarantee the survival of their species. Animals 
have the advantage of being mobile and therefore do not completely depend on one particular environment. However, there is a price to pay for this independence: they must find, pursue, and consume the substances and conditions that meet their needs. For animals, the most basic requirement for survival, therefore, is the successful pursuit of goals.

This pursuit requires complex individual elements. First, the information on a goal and how to obtain it has to be represented somehow in the brain. Otherwise, individuals would become distracted by other stimuli. Neuroscience, for example, has demonstrated that the destruction of specific areas of the brain leaves people unable to steadfastly pursue their goals and to lead a normal life (e.g., Damasio, 1994; Bechara, Damasio, Tranel, \& Damasio, 1997). In addition, goal pursuit requires more than memory, since individuals need to be sensitized to the goalrelated cues and to be ready to act without consciously thinking exclusively about the goal. These cues or stimuli can be external (e.g., a Ph.D. student who spies a keyword related to his thesis on the internet) or internal (e.g., thoughts or ideas). Sensitization means that encountering these cues increases the likelihood of responding to them consciously, either with goal-directed actions (e.g., searching for related articles and documents on the internet) or with mental activity (e.g., thinking about strategies how to proceed next). This offers individuals the most efficient way to seize opportunities to attain or continue to pursue their goals.

Goal pursuit can thus be described as a latent process that refers to the state of an individual between becoming committed to a particular goal and either attaining the goal or abandoning the pursuit (Klinger \& Cox, 2004). Regardless of how the goal pursuit ends, a representation of the goal and its pursuit remains stored in the memory. Goal attainment or resignation does not mean forgetting or deleting the goal-related information but rather inhibiting responses to all but the most salient cues related to it. A certain dish, for example, might remind a middle-aged man of 
a pretty waitress he had met long before marrying his wife. Or, coming across a keyword might remind a Ph.D. student of his Masters' thesis completed many years ago. The goal and its pursuit, or the memory of a former goal and its pursuit, therefore, is not consciously present at any given moment or situation, but can be activated and consciously reflected when a goal-related cue is encountered. With regard to engaging in alcohol use in adolescence, authors have gone as far as to argue that drinking is a rational, goal-directed action with which individuals selfdirect their decisions about engaging in this potentially risky behavior (see, Maggs, 1997, for an overview).

Goal pursuit is initiated by the affective change that people expect from attaining the goal. In other words, individuals strive for things or circumstances that will make them feel better, by either giving them pleasure or relieving their discomfort. Thus, the pursuit of an affective change constitutes the basic condition for individuals to recognize the value of a potential goal. Research has demonstrated that the intensity of affective responses to particular words is closely related to the degree to which these words were related to personal goal pursuit (Bock \& Klinger, 1986). Incentives are defined as potential goals, i.e. the objects, events, or circumstances through which a person expects that their realization will result in a desirable affective change (Klinger \& Cox, 2004). Generally, people are motivated either to acquire positive incentives to achieve a positive affective change (e.g., increased pleasure), or they strive to reduce negative incentives that create discomfort.

In any given moment or circumstance, individuals have to choose between a wealth of different incentives. There are, for example, assorted dishes in a restaurant, washing powders in a supermarket, and ways to proceed with a Ph.D. thesis. Yet, there are also assorted restaurants, supermarkets, and Ph.D. topics to choose from. Often people have clear preferences for choosing a particular goal and, as 
mentioned above, the process of becoming committed to this goal and attaining it, for example, going for lunch with a particular colleague at a particular hour to a particular restaurant and ordering a particular meal with a particular beverage, has become unconscious, either because there are strong preferences and/or because of established habits. However, even if choices in favor of particular goals and their pursuit have become a latent process for a given individual, the totality of potential choices in any given moment and circumstance is always there (the philosopher Jean-Paul Sartre (1976) even states that humans are condemned to live with this totality of choices).

However, the permanent availability of all potential choices does not mean that individuals are generally indifferent to a particular pursuit. Individuals are rather indifferent to making a particular decision if the value and cost of a range of alternatives are balanced (e.g., the more expensive the washing powder or dish, the better it is). Yet, individuals tend to have a clear preference for an incentive if they expect a high value and low costs compared to all other alternatives at a given moment and in the given circumstance (e.g., of the ten washing powders in a supermarket or ten dishes in a restaurant, the one which is subjectively rated as the best is also the cheapest). Thus, the fact that an individual chooses a particular incentive in a given situation (perhaps for the first time) can be explained by two important determinants: the value that the person attributes to the incentive compared to others and the subjective assessment of being able to attain the goal (expectancy). This is consistent with the Value*Expectancy-Theory (Feather, 1982), in which a choice is considered as product of the value and the expectancy of each alternative. Consequently, a person will generally choose the alternative with the highest value-expectancy product. Thus, the probability that an object or circumstance becomes a potential goal (incentive) depends on the amount and feasibility of the affective change that the individual expects to derive (Klinger, 
1977); it is the balance between value and cost needed to realize this value that makes an object an incentive. To be distracted, for example, might not have a great personal value but the feasibility is rather easy - one has only to switch on the television and an incentive may in turn emerge. In contrast, to write a Ph.D. thesis is supposed to be a complex endeavor that requires many years of study, restricted budget, and limited leisure time, but with its successful completion one might expect career opportunities, professional respect, financial returns, and self-worth, thereby also transforming it into an incentive. However, other people will not be motivated to pursue such a goal because they either do not expect to succeed or they do not attribute such a high value to the goal. Of course, incentives can change over time even if the original goal has yet to be attained. Generally, motivation is likely to be stronger when individuals pursue goals that they expect to attain in the near future than those with a longer attainment period. In addition, people may overestimate the intensity and duration of expected change and underestimate the costs to attain the goal. Nevertheless, expected affective change remains the most reliable determinant of goal choice (Klinger \& Cox, 2004).

\section{Description of the Motivational Model}

The desire to drink alcohol and even to get drunk can be a strong motivator for behavior. When individuals expect that drinking alcohol will result in desirable affective changes, alcohol use becomes a positive incentive. This starts an internal motivational process which directs a person's attention, thoughts, emotions, and behavior towards drinking as a goal.

Based on these considerations, Cox and Klinger (1988; 1990) developed their Motivational Model of Alcohol Use, which assumes that a person makes a decision about whether or not he or she will consume alcohol. The decision to drink is a 
combination of emotional and rational processes in that the decision is made on the basis of the affective change that the person expects to achieve by drinking compared with not drinking. As mentioned above, effective goal pursuit can be described as a latent process in which individuals are sensitized to the goal-related cues and are ready to act without consciously thinking exclusively about the goal. In fact, a person does not have to be aware of either having made a decision to drink or the factors affecting this decision. In most cases, decisions about drinking are mostly unconscious and automatized. However, this does not mean that the decision or its underlying motivational process could not be consciously reflected when individuals encounter cues which push them to reflect on their reasons for consumption. A girl, for example, might drink to be more sociable and to better enjoy a mixed-sex party. However, when she perceives that this results in unintended intimate contact with boys, she might stop drinking or leave the party. Cox and Klinger (1988) stress that the decision to drink is voluntary and individuals can exercise control over it.

According to the model, the decision to drink is embedded in historical factors, past reinforcement from drinking, current factors, and expected effects (Figure 11). Historical factors relate to the nature of past experiences with alcohol use, which influence the current motivation of individuals to drink. Historical factors are grouped in three categories: biochemical reactivity to alcohol, personality characteristics, and the socio-cultural environment. Obviously, there are biochemical mechanisms that are driven by the genetic disposition of individuals and that determine how individuals react physically to alcohol intake. This comprises, for example, the way in which individuals metabolize alcohol and is related to the level of metabolic enzymes in the body. People with insufficient enzymes metabolize alcohol more slowly and thus experience stronger negative physical effects associated with drinking than people with an adequate level of 
these enzymes. Personality characteristics (e.g., non-conformity, impulsivity, extraversion, sensation-seeking, or neuroticism) are supposed to constitute salient ways in which individuals differ in their motivational styles (McCrae \& John, 1992), and authors argue that it is important to include drinking motives when studying the link between personality characteristics and alcohol-related outcomes (Cooper, 1994; Stewart \& Devine, 2000). This is discussed in further detail below.

Figure 1-1: Assumptions of the Motivational Model (Cox \& Klinger, 1988, 1990)

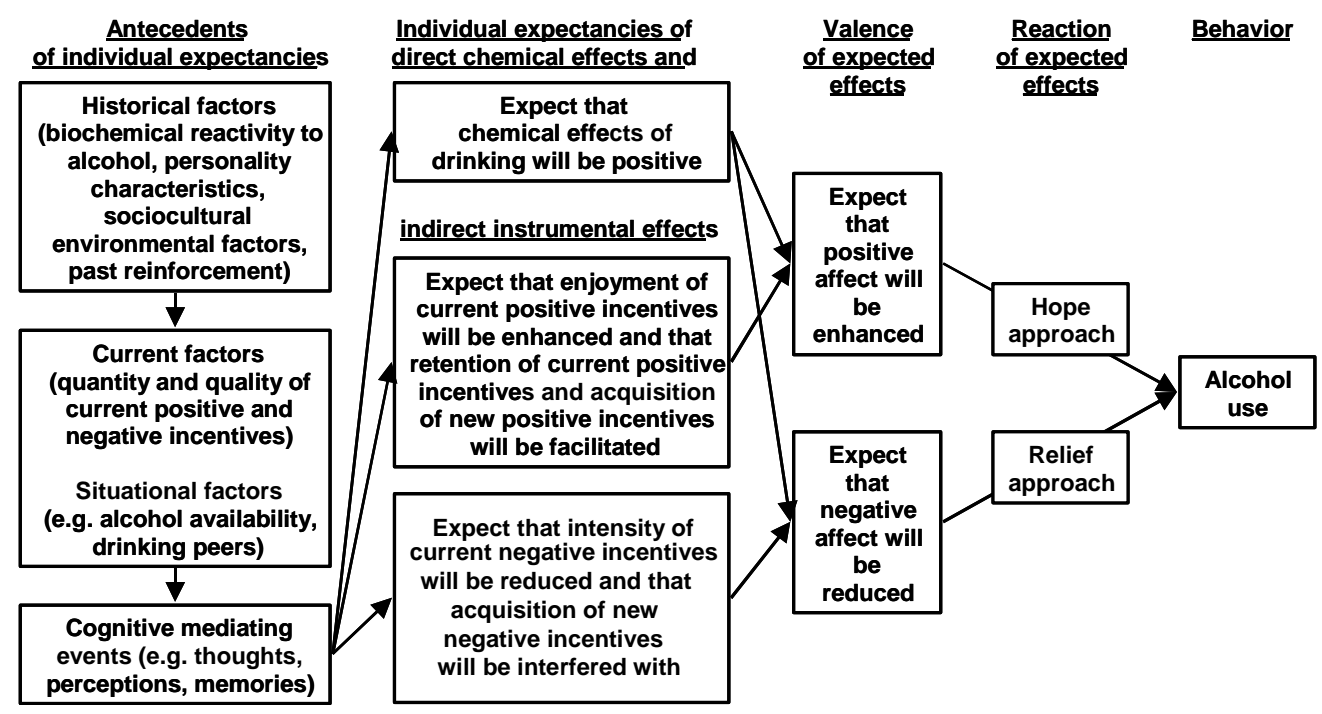

Socio-cultural and socio-environmental factors include culture-specific drinking styles, as well as drinking habits of the proximal social environment such as parents or peers. Since the work of MacAndrew and Edgerton (1969), it is recognized that drunken behavior does not have the same effects across all societies. For example, alcohol consumption has a more important role in the etiology of problem behavior in so-called dry countries like the US and Nordic 
countries in which mainly beer and spirits are consumed and drunkenness is generally considered as a "time out" behavior than in wet, wine-drinking countries, in which alcohol consumption is integrated into everyday life and where young people become acquainted with alcohol use earlier, but within a family context (Lenke, 1990; Room, 2001). In the family context, studies have demonstrated that adolescents adopt parental heavy drinking habits, even if they perceive the negative consequences of their parents' drinking (e.g., Kuntsche \& Meyer, 2002). Affiliation with alcohol-consuming peers has been shown to be strongly linked to adolescent alcohol use (Hawkins, Catalano, \& Miller, 1992; Kandel, 1996; Petraitis, Flay, \& Miller, 1995). This association between adolescent and peer alcohol use is due to both selection and socialisation processes: like-minded adolescents will join together and social interaction will reinforce (new) behaviors to increase similarity among peer group members (e.g., Kandel, 1996; Engels, Knibbe, De Vries, Drop, \& Van Breukelen, 1999). Furthermore, if a person has had positive experiences from drinking in the past, he or she will be reinforced to drink in the future, i.e. when faced with a choice between having a drink or not, this person is more likely than others to decide to drink.

Apart from socio-environmental characteristics, situational factors include the features of the immediate and physical environment where individuals find themselves when they decide whether to drink or not, such as whether alcohol is available or being exposed to a large number of people who drink. Current factors include all other areas of incentives, for example during leisure time and at work. Drinking, therefore, might occur when individuals aim to obtain particular emotional effects that they are unable to obtain through non-chemical incentives. Cognitive mediating events include people's thoughts, perceptions, and memories that determine the nature of personal expectations about the supposed chemical and instrumental impact of alcohol use on their affect. These expectations are related to 
short- and long-term experiences with alcohol. Some people, for example, might tend to overemphasize the (positive) short-term effect while neglecting the (negative) long-term consequences.

Historical, current, and cognitive factors are the basis for individual expectancies both in terms of the direct chemical effects of alcohol intake and the indirect instrumental effects. An example of instrumental effects is when an individual expects that drinking will enhance a positive affect because it leads to peer approval. The probability that alcohol use becomes an incentive also depends on the amount and feasibility of the affective change (i.e. the value) that the individual expects to derive from it. Multiplication with the value that the individual attributes to the incentive alcohol use results in a hope approach, e.g., to enhance positive moods, or a relief approach, e.g., to mitigate negative consequences. Both approaches will eventually lead to alcohol use.

\section{Similarities between the Motivational Model and the Theory of Planned}

\section{Behavior}

In their review of theories of adolescent substance use, Petraitis, Flay, and Miller (1995) identified the theory of reasoned action (Fishbein \& Ajzen, 1975; Ajzen \& Fishbein, 1980) or to its extension, the theory of planned behavior (Ajzen, 1985, 1988, 1991), as the most comprehensive and most widely applied theories of all cognitive-affective theories of adolescent substance use. Although Cox and Klinger $(1988 ; 1990 ; 2002 ; 2004)$ do not refer to these two theories, there are some similarities between the Motivational Model and the theory of planned behavior. As in the original theory of reasoned action, the central variable in this theory is the intention of individuals. In both theories, intentions are defined as motivational factors to perform a certain behavior. In the theory of planned behavior, there are 
three determinants for intentions. First, attitudes are a mathematical function of both the personal consequences (i.e. costs and benefits) that individuals expect from the behavior under consideration (e.g., alcohol use) and the affective value that they place on those consequences. This is consistent with the Value*Expectancy-Theory (Feather, 1982), which also plays a central role in the Motivational Model. Ajzen (1991) states that the motivation to achieve a goal is assumed to combine multiplicatively the expectancy of success with the incentive value of success; this is very similar to the definition of motivation in the Motivational Model.

Second, according to the theory of planned behavior (Ajzen, 1985, 1988, 1991), intentions also depend on the social norms of the behavior under consideration. Social normative beliefs are based on the individual's perception that others want him or her to perform this behavior and on the affective motivation to comply with the wishes or beliefs of these people. Although not identical to social normative beliefs, the Motivational Model acknowledges that there are indirect instrumental effects of alcohol use. In the conceptualization of drinking motives (Cooper, 1994), which is described in detail below, these indirect instrumental effects are understood as the affective change that individuals expect to derive from their proximal social environment (i.e. their parents or peer groups).

The third determinant for intentions is perceived behavioral control, which is consistent with Bandura's concept of perceived self-efficacy (Bandura, 1977; 1982). It concerns personal judgments of how well one can execute courses of actions required to attain a certain goal. The Motivational Model also includes such an element, since the probability that alcohol use becomes a potential goal (an incentive) depends on the amount and feasibility of the affective change that the individual expects to derive from it. However, in the Motivational Model the 
feasibility is directly integrated in the individual's benefit-cost evaluation and determines whether something becomes an incentive or not.

To conclude, it appears that the term "intention" as used in the theory of planned behavior is similar to the hope-relief approach of the Motivational Model, in the sense that both result from the multiplication of expected personal consequences and the personal value placed on these consequences. However, it appears that intentions in the theory of planned behavior are mainly rational and conscious, whereas the hope-relief approach can be described as a latent process and that decisions about drinking in the Motivational Model can also be made automatically and unconsciously. Attitudes and the perceived behavior control in the theory of planned behavior appear to be similar to the interplay between individual expectancies and the valence of expected effects in the Motivational Model. Although subjective norms in the theory of planned behavior are not identical to individual expectations of indirect instrumental effects of alcohol use in the Motivational Model, one aspect of instrumental effects of alcohol use is to obtain access to or be accepted by alcohol-consuming peer groups in adolescence (e.g., Cooper, 1994). In this way, the individual motivation to consume alcohol depends also on the individual's perception that others want him or her to perform this behavior and on the affective motivation to comply with the wishes or beliefs of these people. In this sense, it is similar to the subjective norms described in the theory of planned behavior.

Despite these similarities, the Motivational Model is both wider in scope and more specific than the theory of planned behavior. The Motivational Model is more specific because, although it adopts a motivational perspective that can be applied to different kind of behaviors, it aims to provide a comprehensive explanation for one specific behavior (i.e. alcohol use) and not for behavior in general. It is wider in scope because it takes into account variables (e.g., biochemical reactivity to 
alcohol, personality characteristics, and the socio-cultural environment in which people live) before an individual reaches the point when he or she deliberates about the benefits and costs that he or she expects to obtain from drinking. Although the theory of planned behavior also acknowledges the existence of historical factors such a past reinforcement of a particular task (Ajzen, 1991), less explicit account is taken of these factors and the way they influence expectancies than in the Motivational Model. Furthermore, the affective change obtained from attaining a goal is less explicitly taken into account in the theory of planned behavior. The Motivational Model assumes that a certain behavior becomes a potential goal (an incentive) when the individual expects an affective change from attaining this goal, because individuals generally strive for things or circumstances that will make them feel better, by either giving them pleasure or relieving their discomfort. Also, the decision to engage in alcohol use does not necessarily have to be a volitional act; people must not necessarily have the conscious intention to do so but must be sensitized to the goal-related cues and ready to act without consciously thinking exclusively of the goal. Actually, the decision to drink is a combination of emotional and rational processes in that the decision is made on the basis of the affective change that the person expects to achieve by drinking compared with not drinking. In fact, a person does not have to be aware of either having made a decision to drink or the factors affecting this decision. In most cases, decisions about drinking are actually unconscious and automatized. Fourth, the Motivational Model incorporates aspects of the self-regulation theory (e.g., Carver \& Scheier, 1998). As mentioned above, regardless of how the pursuit ends, a representation of the goal and its pursuit remains stored in the memory. In this way, a feedback process is established, since deliberation on the benefits and costs that the individual expects to obtain from drinking will also depend on past reinforcement from drinking (cf. Figure 1-1). 


\section{Alcohol expectancies, drinking motives, and the Motivational Model of Alcohol Use}

According to the Motivational Model, the concept of drinking motives is based on the assumption that people drink in order to attain certain valued outcomes (Cooper, 1994). It also assumes that drinking behavior is motivated by different needs or serves different functions, and that specific drinking motives are associated with a unique pattern of precursors and consequences. Heavy drinking, for example, is more likely among people who experience stress and drink for coping motives, as well as those whose friends drink heavily and who drink for social motives themselves (Abbey, Smith, \& Scott, 1993). In other words, drinking motives or reasons represent a subjectively derived decisional framework for alcohol use that is based on personal experience, situation and expectancies (Carpenter \& Hasin, 1998b; Cox \& Klinger, 1988).

Expectancies, on the other hand, are defined as beliefs about the positive or negative behavioral, emotional and cognitive effects of alcohol intake (Baer, 2002; Quigley \& Marlatt, 1996). Wiers, Hoogeveen, Sergeant, and Gunning (1997) defined expectancies as a "probability held by the individual that a particular reinforcement will occur as a function of a specific behavior". It appears that to hold a particular expectancy is a commensurate condition of drinking, because an individual must have a particular expectancy before alcohol is consumed to achieve the desired effect, but that he or she will not necessarily drink to achieve a desired effect simply because the corresponding expectancy is endorsed (Cooper, 1994). In contrast, as described in the Motivational Model of Alcohol Use (Cox \& Klinger, 1988, 1990), having a particular motive or reason is a necessary condition for drinking, conceptualized by the final decision to drink or not to drink. 
As mentioned above, the Motivational Model assumes that a person decides to drink alcohol based on the affective change that he or she expects to achieve by drinking compared with not drinking. The affective change can either be related to the direct chemical effects of alcohol, e.g., tension reduction or mood enhancement, or the indirect effects such as peer acceptance. Historical, current, situational, and cognitive factors are the basis for individual expectancies, both in terms of the chemical effects of alcohol intake, e.g., mood enhancement, and the non-chemical effects, e.g., to celebrate with friends or to enjoy meals. The result of all expected effects (labeled valence in the Motivational Model) can either be positive (to enhance positive moods) or negative (to avoid or attenuate negative experiences). The source of these expected effects can also be either internal (in respect to the personal affective change) or external (in respect to the given social environment). Accordingly, four categories of drinking motives emerge as final antecedents of drinking behavior (see Figure 1-2 for a graphical representation): drinking to enhance positive mood or well-being (enhancement: positive, internal), to obtain social rewards (social: positive, external), to attenuate or to avoid negative emotions (coping: negative, internal), and to avoid social rejection (conformity: negative, external). By adopting a specific reason for drinking, the decision for engaging in alcohol consumption is made. For example, people decide to drink because it gives them a pleasant feeling or because it helps them when depressed or nervous. 
Figure 1-2: Alcohol expectancies, drinking motives, and alcohol use according to assumptions of the Motivational Model (taken from Kuntsche, Knibbe, Gmel, \& Engels, 2005)

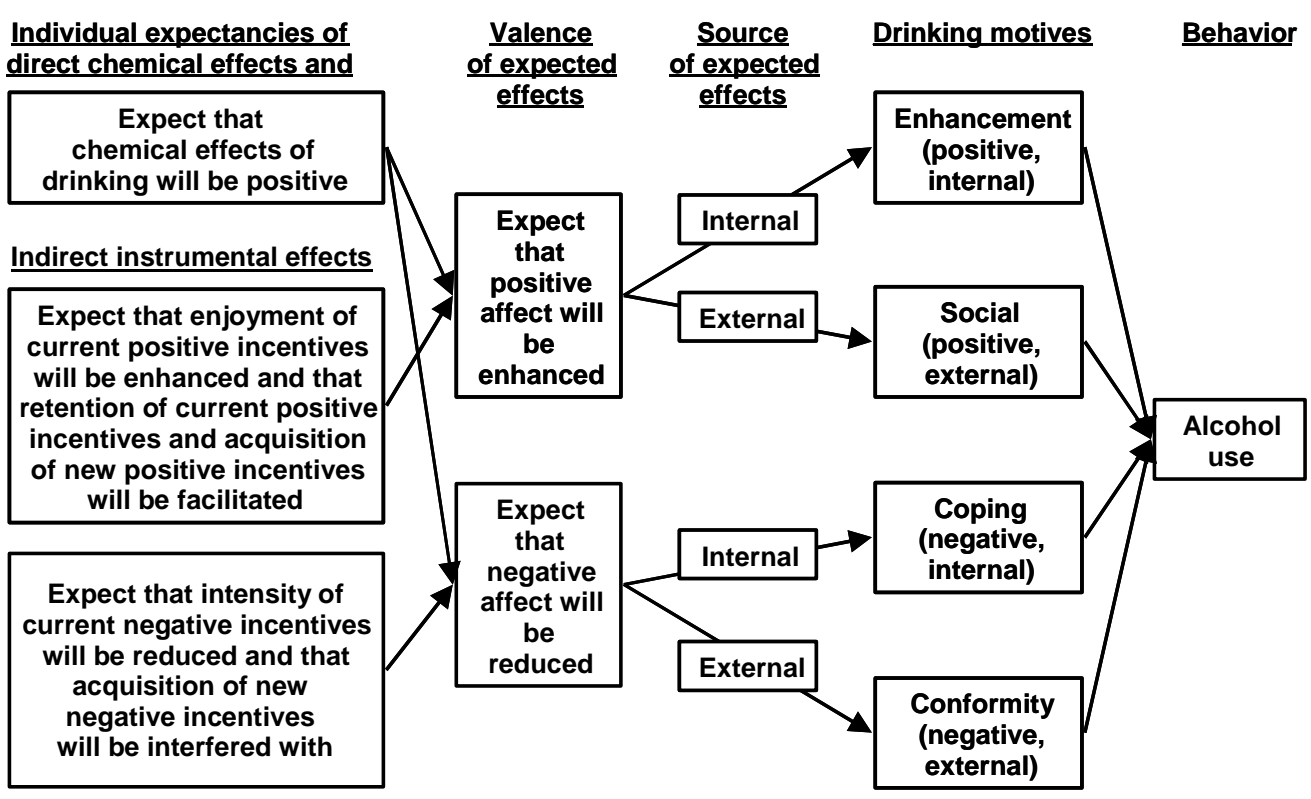

Based on these considerations, Cooper developed her Drinking Motive Questionnaire Revised (DMQ-R) in 1994 to assess drinking motives, particularly among adolescent populations. The DMQ-R reliably measures the four drinking motive categories of enhancement (internal, positive), coping (internal, negative), social (external, positive), and conformity (external, negative) among 13- to 19year olds in the US (for a more detailed description of the DMQ-R see Chapter 4). At present, the DMQ- $\mathrm{R}$ is the most frequently applied multidimensional instruments to assess drinking motives in North America. However, since 1994 a 
variety of other instruments to assess drinking motives have been used alongside the DMQ-R (see Chapter 2 for a detailed discussion).

In their recently published Handbook of Motivational Counseling, Cox and Klinger (2004) acknowledge Cooper's (1994) work to test the conceptual validity of the source*valence matrix in their Motivational Model. However, they also underline some differences between their Motivational Model (Cox \& Klinger, 1988, 1990) and the conceptualization of drinking motives in the DMQ-R (Cooper, 1994). They describe, for example, that individual expectancies of indirect instrumental effects of alcohol use have a broader meaning in the Motivational Model than the external sources of expected effects in the DMQ-R (i.e. social and conformity motives Cox \& Klinger, 2004). Another difference is that the Motivational Model stresses that a person makes a decision about whether or not he or she will consume alcohol, whereas the DMQ-R assesses the relative frequency of drinking for four conceptually different drinking motive domains, given a certain amount of drinking occasions for each individual. In other words, the DMQ-R assesses each individual aspect of a person's overall motivation to engage in drinking.

\section{Rationale of the present work}

From both a conceptual point of view and in terms of prevention, the factors that are most proximate to drinking are particularly important. These factors are not only supposed to be more easily accessible for prevention efforts than most of the more distal ones, but they also tend to reflect or include distal factors such as culture, situation, or personality (Cox \& Klinger, 1988, 1990). Drinking motives are defined as the final decision whether to drink or not to drink and therefore the most proximal factor for engaging in drinking (Carpenter \& Hasin, 1998b; Cooper, 1994). In other words, drinking motives are the final pathway to alcohol use, i.e. 
the gateway through which more distal influences, such as alcohol expectancies, are mediated (Catanzaro \& Laurent, 2004; Cooper, 1994; Cronin, 1997; Kuntsche, Knibbe, Gmel, \& Engels, 2007). However, in the last 25 years, there has been overwhelming research on alcohol expectancies but few studies on drinking motives (Baer, 2002, a literature search in Medline conducted in December 2003 revealed 45 hits for the quoted phrase "drinking motives", 81 for "reasons for drinking" and 217 for "alcohol expectancies").

It therefore appears that the relevance and importance of drinking motives for understanding adolescent alcohol use and heavy drinking is underestimated in current adolescent and alcohol research. This might have several reasons:

1. Although, as mentioned above, research on drinking motives has a long tradition dating back to the late 1940s (e.g., Riley, Marden, \& Lifshitz, 1948) right up to the late 1980s, there has been no comprehensive theory on how to understand and measure drinking motives. Consequently, a variety of motive instruments without any theoretical basis has been developed and is still in use today.

2. The heterogeneity of drinking motive conceptualization and assessment makes it difficult to compare the results of one study with another. In addition, no attempt has been made to comprehensively summarize the research evidence which has emerged from these heterogeneous studies.

3. Research on drinking motives originated in the US (e.g., Riley, Marden, \& Lifshitz, 1948; Cahalan, Cisin, \& Crossley, 1969; Jessor, Carman, \& Grossman, 1968) and remained nearly exclusively a North American research topic. 
Hence, to advance and promote an adequate understanding of adolescent drinking motives and their relevance for alcohol use and other problem behaviors, four major research tasks appear to be crucial. These are:

1. to summarize current empirical evidence on young people's drinking motives and to identify weaknesses and gaps in current drinking motive research.

2. to study theoretical aspects of the Motivational Model, such as (a) how to measure drinking motives, more specifically whether the DMQ-R which was developed in the US can be replicated in a European sample and (b) whether the effect of alcohol expectancies on drinking is, as the Model assumes, mediated by motives.

3. to extend current knowledge of adolescents' drinking motives, for example by demonstrating the relevance of drinking motives in the link between beverage preference and adolescent alcohol use or in the link between alcohol use and violence.

4. with prevention approaches in mind, to develop procedures to identify homogenous groups among adolescents who drink heavily, based on their motivation to engage in drinking.

\section{Outline and advanced organizer}

According to the identified four major research tasks, the present work (1) summarizes current knowledge and identifies research gaps, (2) seeks to replicate and validate for the first time outside North America a theoretically based instrument to measure drinking motives, as well as to test a basic assumption of the Motivational Model, (3) investigates the relevance of drinking motives (a) in explaining aspects of alcohol use and violent behaviors and (b) in the prevention of excessive drinking among adolescents by identifying and classifying excessively 
drinking adolescents into homogenous groups based on their motivation to engage in drinking.

Chapters 2 and 3 aim to give a comprehensive overview of empirical evidence on young people's drinking motives published in the last 15 years, i.e. from 1989 onwards, the year after the development of the Motivational Model of Alcohol Use (Cox \& Klinger, 1988). Chapter 2 concentrates on the formal aspects of drinking motives (issues of definition, measurement and classification), and on the possible consequences (alcohol use, related problems, and other problem behaviors). Chapter 3 concentrates on possible antecedents of drinking motives among young people. These concern factors that do not result in specific behaviors like heavy drinking or delinquency, but are related to the individual or the given situation. It attempts to provide information on the generalities/specificities of drinking motives (e.g., Do drinking motives differ according to gender? Are prevalence and associations of drinking motives comparable between different countries and drinking cultures? Do drinking motives change over time?). Chapter 3 also explores the validity of these motives (e.g., How strong is the association between drinking for social motives and drinking in social situations? How strong is the association between drinking motives and personality traits which have been shown to be remarkably stable across cultures and developmental periods?). Both chapters aim to identify gaps in the research on drinking motives among young people.

Chapter 4 presents new empirical evidence and has two central aims. The first is to replicate the four-dimensional structure of the DMQ- $R$ in a nationally representative sample from Switzerland, while the second is to validate the relevance of distinguishing drinking motives by examining the links with expected consequences, alcohol use, as well as alcohol-related and other problems. This is the first time that the most widely used drinking motive questionnaire has been 
tested in a sample outside North America. Additionally, the present sample of Swiss adolescents offers the opportunity to study cultural differences within one country, by comparing adolescents living in the German-speaking part with those living in the French- and Italian-speaking ones. This is important as it will provide an indication of whether the DMQ-R could also be a sound and useful instrument to assess drinking motives in other European countries.

In Chapter 5, a basic assumption of the Motivational Model (Cox \& Klinger, 1988, 1990) is tested, namely that the link between alcohol expectancies and alcohol use is mediated by drinking motives. More precisely, the aim of this chapter is to confirm that coping motives mediate the link between tension reduction expectancies and different measures of alcohol use. It also aims to test if enhancement motives mediate the link between positive change expectancies and improved ability expectancies and alcohol use. A further objective is to investigate whether social motives mediate the link between changes in social behavior expectancies and alcohol use. In addition, the study examines whether drinking motives mediate the link between expectancies and alcohol use in general (i.e. when the different motive and expectancy items respectively were added together to produce an overall score).

Chapter 6 deals with the motivation behind adolescents' preferences for a particular alcoholic beverage and whether this motivation modifies the relation between beverage preference and drinking patterns. It examines whether a particular beverage is better suited to achieve valued outcomes. For example, adolescents who drink for enhancement motives, e.g., to have fun and to get drunk, might prefer beverages which are cheap are therefore allow them to drink high quantities over those which contain a high degree of pure alcohol, thus enabling them to get drunk faster. Chapter 6 specifically tests whether the association between beverage preference (beer, spirits, wine, and alcopops) and adolescent 
alcohol use (drinking levels and risky drinking occasions) is mediated or moderated by drinking motives (enhancement, social, conformity, and coping).

Chapter 7 extends the possible consequences of adopting particular drinking motives by investigating direct and indirect links (through alcohol use) between drinking motives and violent behaviors (i.e. bullying and fighting). The study detailed in Chapter 7 was designed in such a way as to overcome the various limitations of current research on the link between drinking motives and violent behaviors, namely that (1) violent behaviors are often combined in one indicator variable with other problem behaviors in adolescence such as truancy or academic failure; (2) the assessment of violent behaviors is often exclusively alcoholattributed (e.g., how often have you been involved in a fight because of your drinking?), which might create associations because of individuals who admit consumption and attribute consequences to their drinking (Gmel, Rehm, Room, \& Greenfield, 2000; Rehm \& Gmel, 1999); and (3) alcohol use levels are often not taken into account in studies which explore the link between motives and aggressive behaviors, making it impossible to determine whether particular motives increase alcohol consumption and are thus indirectly associated with violence among adolescents, or whether a particular motive itself directly explains violent behaviors.

Chapter 8 contains an analytical approach to the identification and classification of risky single occasion drinking adolescents according to their motivation to engage in drinking. Although previous studies which classified adolescents into enhancement and coping drinkers were either based on median splits (Cooper, Frone, Russell, \& Mudar, 1995) or standard deviations and z-scores (Stewart, Hall, Wilkie, \& Birch, 2002), no approach used information from the DMQ-R to classify all risky single occasion drinking (RSOD) adolescents in a given sample into homogenous risk groups and validated the accuracy of the classification by another 
classification method and external predictors. The aim of this study therefore is to develop and validate an analytical approach that uses the DMQ-R as a diagnostic tool to identify RSOD adolescents and classify them according to homogenous risk groups. Such a classification procedure might be important in terms of targeting specific prevention programs, such as life skills training or social influence programs, at these homogenous risk groups.

The last chapter summarizes and discusses the main findings that emerge from Chapters 2 to 8 . In addition, special attention is given to how drinking motives can be measured, the nature of drinking motives, how drinking motives can be used in prevention approaches, the tasks of future research, as well as ideas that go beyond drinking motives and other explicit alcohol-related cognitions. 


\section{Chapter 2}

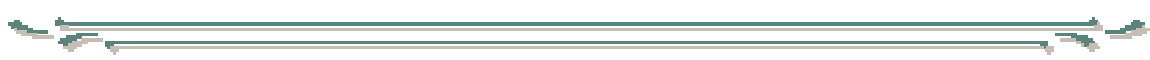

The current state of knowledge I:

Overview of empirical research on the formal aspects and possible consequences of drinking motives ${ }^{1}$

\footnotetext{
${ }^{1}$ This chapter is based on Kuntsche, E., Knibbe, R., Gmel, G., \& Engels, R. (2005). Why do young people drink? A review of drinking motives. Clinical Psychology Review, 25(7), 841-861.
} 


\section{SUMMARY OF CHAPTER 2}

This chapter reviews evidence of the drinking motives of adolescents and young adults as well as their links with possible consequences over the last 15 years. To this end, a computer-assisted search of relevant articles was conducted. Results revealed that most young people reported drinking for social motives, some indicated enhancement motives, and only a few reported coping motives. Social motives appear to be associated with moderate alcohol use, enhancement with heavy drinking, and coping motives with alcohol-related problems. However, the measurement of motives was found to be highly heterogeneous: 10 to 40 items were grouped into between 2 and 10 dimensions and sometimes the same items occurred in several dimensions. Future studies should therefore use well-defined, theoretically-based, homogenous instruments to disentangle cultural and measurement differences across surveys. 


\section{INTRODUCTION}

Excessive alcohol use has been shown to be associated with various adverse consequences and health problems such as fatal and non-fatal injuries, blackouts, suicide attempts, unintended pregnancy, sexually transmitted diseases, academic failure, and violence (see Gmel, Rehm, \& Kuntsche, 2003; Hingson, Heeren, Zakocs, Kopstein, \& Wechsler, 2002; Perkins, 2002, for reviews). Since initiation into alcohol use (e.g., Johnston, O'Malley, Bachman, \& Schulenberg, 2004) and excessive drinking (e.g., Gmel, Rehm, \& Kuntsche, 2003; Tucker, Orlando, \& Ellickson, 2003) mostly occurs in adolescence, it is crucial that prevention efforts are in place during this life period or even before (e.g., Hawks, Scott, McBride, Jones, \& Stockwell, 2002; James, Moore, \& Gregersen, 1996). However, if efforts to limit premature and excessive drinking among adolescents are to be a success, it is necessary to understand the antecedents and etiology of drinking behavior. In this regard, the motivation for engaging in drinking is one important aspect. Theorists regard drinking motives as the final common pathway to alcohol use, i.e. the gateway through which more distal influences are mediated (Cooper, 1994; Cox \& Klinger, 1988). Indeed, empirical research demonstrates that drinking motives, for example, are more closely associated with alcohol use than alcohol expectancies (Cronin, 1997). Although drinking motives are associated with drinking in different situational contexts, they explain a substantial amount of variance in alcohol use besides situational factors like drinking circumstance, location, day of the week, group size, type of relationship, local norms and residence (Kairouz, Gliksman, Demers, \& Adlaf, 2002).

The concept of drinking motives is based on the assumption that people drink in order to attain certain valued outcomes (Cooper, 1994; Cox \& Klinger, 1988). It also assumes that drinking behavior is motivated by different needs or serves 
different functions, and that specific drinking motives are associated with a unique pattern of precursors and consequences. Heavy drinking, for example, is particularly likely among people who experience stress and drink for coping motives, as well as those whose friends drink heavily and who drink for social motives themselves (Abbey, Smith, \& Scott, 1993). In other words, drinking motives or reasons represent a subjectively derived decisional framework for alcohol use, based on personal experience, situation and expectancies (Carpenter \& Hasin, 1998b; Cox \& Klinger, 1988).

Expectancies, on the other hand, are defined as beliefs about the positive or negative behavioral, emotional and cognitive effects of alcohol intake (Baer, 2002; Quigley \& Marlatt, 1996). Wiers and colleagues (1997) defined expectancies as a "probability held by the individual that a particular reinforcement will occur as a function of a specific behavior". It appears that to hold a particular expectancy is a commensurate condition of drinking because an individual must have a particular expectancy before alcohol will be consumed to achieve the desired effect, but that he or she will not necessarily drink to achieve a desired effect simply because the corresponding expectancy is endorsed (Cooper, 1994). In contrast, as described in the Motivational Model of Alcohol Use (Cox \& Klinger, 1988, 1990), to have a particular motive or reason is a necessary condition for drinking; this is conceptualized by the final decision to drink or not to drink.

The Motivational Model assumes that a person makes a decision about whether or not he or she will consume alcohol. The decision to drink is a combination of emotional and rational processes in that the decision is made on the basis of the affective change that the person expects to achieve by drinking compared with not drinking. The affective change can either be related to the direct chemical effects of alcohol, e.g., tension reduction or mood enhancement, or the indirect effects, such as peer acceptance. In fact, a person does not have to be aware of either having 
made a decision to drink or the factors affecting this decision. In most cases, decisions about drinking are even unconscious and automated.

According to the model, the decision to drink is embedded in historical and current factors, expected effects, and drinking motives (Figure 2-1). Historical factors relate to biochemical reactivity to alcohol (e.g., the genetic disposition to react positively or negatively to alcohol), personality characteristics (e.g., nonconformity, impulsivity, extraversion, sensation seeking, or self-derogation), sociocultural and environmental factors (e.g., culture-specific drinking styles), and past reinforcement from drinking. Current factors are associated with quality of life in terms of the quantity and quality of prevailing positive and negative incentives for drinking and situational factors (e.g., if alcohol is available or being exposed to people who drink).

Figure 2-1: Antecedents, alcohol expectancies, drinking motives, and alcohol use according to assumptions of the Motivational Model of Alcohol Use

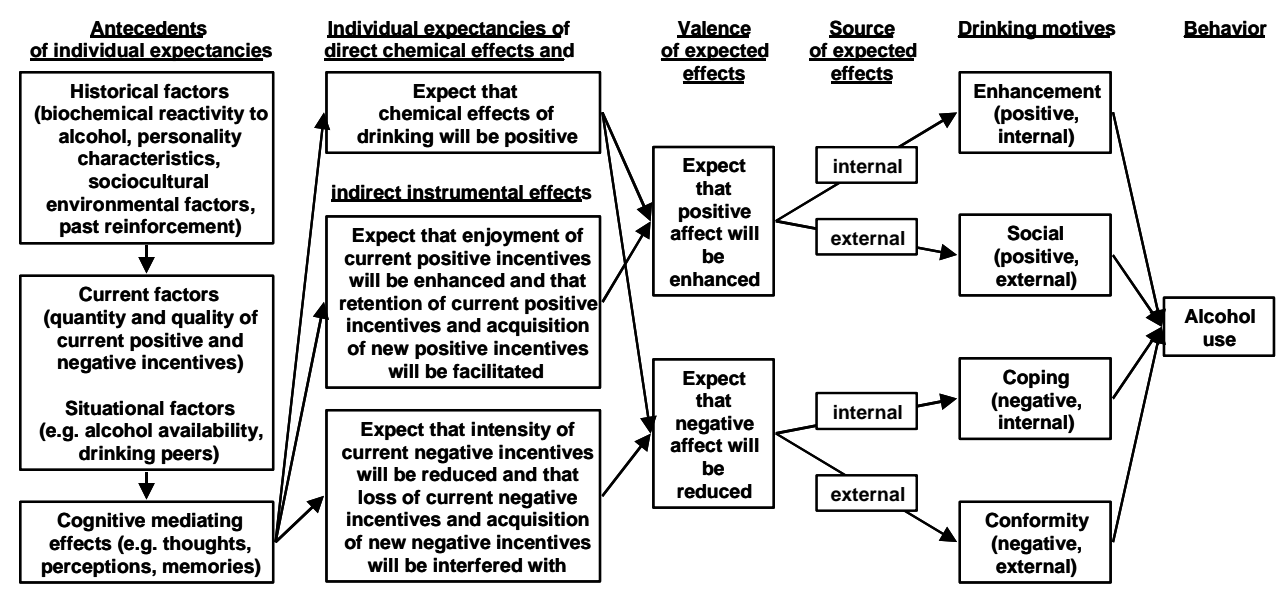


Historical, current, situational, and cognitive factors are the basis for individual expectancies both in terms of the chemical effects of alcohol intake, e.g., mood enhancement, and the non-chemical effects, e.g., to celebrate with friends or to enjoy meals. The result of all expected effects (labeled valence in the Motivational Model) can either be positive (to enhance positive moods) or negative (to avoid or attenuate negative experiences). The source of these expected effects can further be either internal (regarding the personal affective change) or external (regarding the individual social environment). Accordingly, four categories of drinking motives emerge as final antecedents of drinking behavior: drinking to enhance positive mood or well-being (enhancement: positive, internal), to obtain social rewards (social: positive, external), to attenuate negative emotions (coping: negative, internal), and to avoid social rejection (conformity: negative, external). The adoption of a specific reason for drinking implies that the decision for engaging in alcohol consumption is made.

Although there is a long tradition of research (e.g., Edwards, Hensman, \& Peto, 1973; Jung, 1977; Riley, Marden, \& Lifshitz, 1948) and profound theoretical considerations (e.g., Cox \& Klinger, 1988, 1990; Cooper, 1994), no systematic attempt has been made to summarize recent evidence on drinking motives. The aim of this paper is to review the recent empirical research on adolescents' and young adults' drinking motives because if efforts to limit premature and excessive drinking are to succeed, research on these age groups is particularly important. More specifically, the paper concentrates on formal aspects of drinking motives (issues of definition, measurement and classification), and on the possible consequences (alcohol use, related problems, and other problem behaviors). 


\section{MeTHODS}

A computer-assisted literature search was conducted using the keywords "reason" or "reasons" or "motive" or "motives" or "motivation" and "alcohol" or "drinking" or "drunk" or "drunkenness" and "adolescents" or "adolescence" or "juvenile" or "young people". "Current Contents", "ERIC Database", "ETOH", "Medline", "PsychInfo", "Sociological Abstracts", and "Swetsnet" were used as databases, together with the internal library system of the Swiss Institute for Prevention of Alcohol and Drug Problems. The search strategy was to include articles published only in English. The literature search was restricted to publications from 1989 onwards, the year after the development of the Motivational Model of Alcohol Use (Cox \& Klinger, 1988) and to the age group of 10- to 25-year olds.

During the first stage more than 100 articles were identified. Since the review focuses on alcohol use and related problems among adolescents in general, articles on motives to abstain from drinking, on particular drinking motives (e.g., reasons for ending drinking games), and based on particular populations (e.g., women with eating disorders or rural Arab youth) were excluded. Since studies on drinking motives are sometimes integrated into wider studies of young people's drinking and not explicitly labeled as drinking motives or reasons, all identified articles were crosschecked for other yet unidentified studies. The article was based on a total of 82 articles.

The present review intends to give a comprehensive overview of empirical evidence on young people's drinking motives published in the last 15 years. In some cases, however, key or exemplary studies based on the general population (including adolescents or young adults) or published before 1989 are highlighted, where no recent or age group-specific evidence was found. 


\section{RESULTS}

\section{Formal aspects of drinking motives}

\section{Motives and reasons - different terms, same meaning?}

In the literature, the terms "drinking motives" and "reasons for drinking" are used interchangeably (Baer, 2002; Stewart \& Chambers, 2000; Stewart \& Devine, 2000). In English dictionaries (e.g., Cambridge University, 2001; Oxford University Press, 2001), motives appear to be more broadly defined than reasons, whereby the latter provide explanations or judgments for events based on practical facts. Similarly, in psychology, reasons are defined as an intellectual process involved in considering the totality of a situation or an explanation for a behavior (Corsini, 2002). Motives are more broadly defined as conscious or unconscious reasons for behavior that directs a person's energies towards a goal (cf. Cooper, 1994; Cox \& Klinger, 1988).

Although it appears that reasons and motives have roughly the same meaning, there are some subtle differences. Accordingly, drinking reasons appear to imply a rational process based on practical facts, whereas drinking motives appear to be more general and also incorporate unconscious and automatized causes. When describing the results of numerous studies in this review, it can lead to misunderstandings when using the two expressions interchangeably. Therefore, we suggest using the term "reason" to describe a specific drinking reason that is not part of a broader classification, such as drinking to help fall asleep or to gain greater sexual pleasure. "Motives" characterize items in specific motive categories, factors, or dimensions, such as social or coping motives. Under these motivational dimensions, all specific motives that serve the according purpose are subsumed. 


\section{Approaches to measure drinking motives}

There are various ways and instruments to measure drinking motives. A first group of studies adopted a qualitative approach, i.e. they simply asked young people why they drink. The resulting answers were subsequently classified into categories of commonly indicated reasons, like drinking to get drunk or to be part of a peer group. Only five studies could be identified that fall into this category (Alvarez \& del Rio, 1994; Boys, Marsden, \& Strang, 2001; Kloep, Hendry, Ingebrigtsen, Glendinning, \& Espnes, 2001; Lo \& Globetti, 2000; Palmqvist, Martikainen, \& vonWright, 2003).

A second group of studies collected several items on drinking reasons from previous research without explicitly classifying them into broader motive categories, factors or dimensions. In this category, nine studies could be identified (De Micheli \& Formigoni, 2002; Feldman, Harvey, Holowaty, \& Shortt, 1999; Jerez \& Coviello, 1998; Klein, 1992; Montgomery, Benedicto, \& Haemmerlie, 1993; Neff, 1997; Plant, Bagnall, \& Foster, 1990; Rutledge \& Sher, 2001; Webb, Getz, Baer, \& McKelvey, 1999).

A third group of studies developed their own multidimensional questionnaire to measure drinking motives (e.g., Bradley, Carman, \& Petree, 1991; Carpenter \& Hasin, 1998b; Cronin, 1997; Haden \& Edmundson, 1991; Kairouz, Gliksman, Demers, \& Adlaf, 2002; Karwacki \& Bradley, 1996; Labouvie \& White, 2002; Stewart \& Power, 2002; Weinberger \& Bartholomew, 1996; Windle, 1996). In these developments, scales consisting of 10 to 40 items grouped into between 2 and 10 categories, dimensions, or factors were analyzed (see Table 2-1). 
Table 2-1: Overview of multidimensional instruments to measure drinking motives

\begin{tabular}{l} 
Name (abbreviation, author) \\
\hline Definitions of Alcohol Scale \\
(DAS, Mulford \& Miller, 1960) \\
Dinking Context Scale (O'Hare, \\
1997) \\
Drinking Motivations Scale \\
(Bailly, 1987)
\end{tabular}

Drinking Motive Questionnaire $\&$ Windle, 1992)

Drinking Motive Questionnaire Revised (DMQ-R, Cooper, 1994) (DMQ, Cooper, Russell, Skinner,

\author{
Items, categories (labels) \\ 18 items, 2 categories \\ (social/celebratory, \\ personal/deficiency) \\ Original 22 items reduced to 9 \\ items in 3 categories (convivial \\ drinking, negative coping, \\ intimate drinking)
}

40 items, 4 categories (positive social, personal psychological, dominance power, assertiveness power)

15 items, 3 categories (social, coping, enhancement)

20 items, 4 categories (social, coping, enhancement, conformity)

42 items, 8 categories

Inventory of Drinking Situations - Short Form (IDS-42, Annis, 1984) (unpleasant emotions, physical discomfort, pleasant emotions, testing personal control, urges and temptations to drink, conflict with others, social pressure to

Studies
(Connors, O'Farrell, \& Cutter,
1990)

(O'Hare, 2001)

(Bailly, Carman, \& Forslund, 1991)

(Carrigan, Samoluk, \& Stewart, 1998; Colder, 2001; Colder \& O'Connor, 2002; Cooper, Frone, Russell, \& Mudar, 1995; Cooper, Agocha, \& Sheldon, 2000; Gire, 2002; Kassel, Jackson, \& Unrod, 2000; Novak, Burgess, Clark, Zvolensky, \& Brown, 2003;

Stewart \& Chambers, 2000;

Stewart \& Zeitlin, 1995;

MacLean \& Lecci, 2000)

(Comeau, Stewart, \& Loba,

2001; Cooper, 1994; Cooper,

Frone, Russell, \& Mudar, 1995;

Cooper, Agocha, \& Sheldon,

2000; Hussong, 2003; Lecci,

MacLean, \& Croteau, 2002;

Loukas, Krull, Chassin, \& Carle,

2000; MacLean \& Lecci, 2000;

McNally, Palfai, Levine, \&

Moore, 2003; Read, Wood,

Kahler, Maddock, \& Palfai, 2003;

Simons, Correia, \& Carey, 2000;

Stewart \& Devine, 2000;

Stewart, Loughlin, \& Rhyno,

2001; Stewart \& Power, 2002;

Wild, Hinson, Cunningham, \&

Bacchiochi, 2001)

(Carey, 1993, 1995; Carrigan,

Samoluk, \& Stewart, 1998) 
Table 2-1 continued

\begin{tabular}{|c|c|c|}
\hline Name (abbreviation, author) & Items, categories (labels) & Studies \\
\hline $\begin{array}{l}\text { No specific instrument name } \\
\text { (items based e.g. on Barnes, } \\
\text { 1981; Jessor, Carman, \& } \\
\text { Grossman, 1968) }\end{array}$ & $\begin{array}{c}11 \text { items, } 2 \text { categories (social, } \\
\text { coping) }\end{array}$ & $\begin{array}{c}\text { (Bradizza, Reifman, \& Barnes, } \\
\text { 1999) }\end{array}$ \\
\hline $\begin{array}{l}\text { No specific instrument name } \\
\text { (items based e.g. on Jessor, } \\
\text { Carman, \& Grossman, 1968) }\end{array}$ & $\begin{array}{c}40 \text { items, } 4 \text { categories (positive } \\
\text { social, personal/psychological, } \\
\text { personal power, } \\
\text { warmth/affection) }\end{array}$ & (Karwacki \& Bradley, 1996) \\
\hline $\begin{array}{l}\text { No specific instrument name } \\
\text { (items based on Cahalan, Cisin, } \\
\text { \& Crossley, 1969; Farber, } \\
\text { Khavari, \& Douglass, 1980) }\end{array}$ & $\begin{array}{c}7 \text { items, } 2 \text { categories (dinking to } \\
\text { cope with stress, drinking for } \\
\text { social reasons) }\end{array}$ & (Abbey, Smith, \& Scott, 1993) \\
\hline $\begin{array}{l}\text { No specific instrument name } \\
\text { (items based on Carman, } \\
\text { Fitzgerald, \& Holmgren, 1983) }\end{array}$ & $\begin{array}{c}19 \text { items, } 2 \text { categories } \\
\text { (negative/personal, } \\
\text { positive/social) }\end{array}$ & $\begin{array}{c}\text { (Bradley, Carman, \& Petree, } \\
\text { 1991; Bradley, Carman, \& } \\
\text { Petree, 1992) }\end{array}$ \\
\hline $\begin{array}{l}\text { No specific instrument name } \\
\text { (items based on Cooper, } \\
\text { Russell, Skinner, \& Windle, } \\
\text { 1992) }\end{array}$ & $\begin{array}{c}13 \text { items, } 2 \text { categories (coping, } \\
\text { social) }\end{array}$ & $\begin{array}{c}\text { (Windle, 1996; Windle \& Windle } \\
\text { 1996) }\end{array}$ \\
\hline $\begin{array}{l}\text { No specific instrument name } \\
\text { (items based on Goodwin, 1990; } \\
\text { Haden \& Edmundson, 1991) }\end{array}$ & $\begin{array}{c}10 \text { items; } 2 \text { categories (personal, } \\
\text { social) }\end{array}$ & $\begin{array}{c}\text { (Montgomery, Benedicto, \& } \\
\text { Haemmerlie, 1993) }\end{array}$ \\
\hline $\begin{array}{l}\text { No specific instrument name } \\
\text { (items based on Johnston \& } \\
\text { O'Malley, 1986; Schulenberg, } \\
\text { Wadsworth, O'Malley, Bachman, } \\
\text { \& Johnston, 1996) }\end{array}$ & $\begin{array}{l}\text { number of items not indicated in } \\
\text { the method section, } 2 \text { categories } \\
\text { (reduce negative affect, drinking } \\
\text { to get drunk scale) }\end{array}$ & (McCabe, 2002) \\
\hline $\begin{array}{l}\text { No specific instrument name } \\
\text { (items based on Johnston, } \\
\text { O'Malley, \& Bachman, 1984) }\end{array}$ & $\begin{array}{c}13 \text { items, } 3 \text { categories } \\
\text { (increasing positive affect, } \\
\text { decreasing negative affect, } \\
\text { social facilitation) }\end{array}$ & $\begin{array}{c}\text { (Weinberger \& Bartholomew, } \\
1996)\end{array}$ \\
\hline $\begin{array}{l}\text { No specific instrument name } \\
\text { (items based on Johnson, } \\
\text { Schwitters, Wilson, Nagoshi, \& } \\
\text { McClearn, 1985) }\end{array}$ & $\begin{array}{l}\text { number of items not indicated in } \\
\text { the method section, } 2 \text { categories } \\
\text { (celebratory/social facilitation, } \\
\text { pathological/self-medication) }\end{array}$ & $\begin{array}{c}\text { (Nagoshi, Nakata, Sasano, \& } \\
\text { Wood, 1994) }\end{array}$ \\
\hline $\begin{array}{l}\text { No specific instrument name (no } \\
\text { specific author indicated) }\end{array}$ & $\begin{array}{l}10 \text { items; } 2 \text { categories (personal } \\
\text { motivation, social motivation) }\end{array}$ & (Haden \& Edmundson, 1991) \\
\hline $\begin{array}{l}\text { No specific instrument name (no } \\
\text { specific author indicated) }\end{array}$ & $\begin{array}{l}15 \text { items, } 10 \text { categories (to be } \\
\text { sociable/polite, to comply with } \\
\text { others, to feel good, to help you } \\
\text { relax, to forget your worries, to } \\
\text { feel less inhibited or shy, to get } \\
\text { high or drunk, to celebrate, to } \\
\text { enjoy the taste or add to the } \\
\text { enjoyment of a meal, other) }\end{array}$ & $\begin{array}{c}\text { (Kairouz, Gliksman, Demers, \& } \\
\text { Adlaf, 2002) }\end{array}$ \\
\hline
\end{tabular}


Table 2-1 continued

\begin{tabular}{|c|c|c|}
\hline Name (abbreviation, author) & Items, categories (labels) & Studies \\
\hline $\begin{array}{l}\text { No specific instrument name (no } \\
\text { specific author indicated) }\end{array}$ & $\begin{array}{l}33 \text { items, } 3 \text { categories (social, } \\
\text { disinhibition, suppression) }\end{array}$ & (Labouvie \& Bates, 2002) \\
\hline $\begin{array}{l}\text { No specific instrument name (no } \\
\text { specific author indicated) }\end{array}$ & $\begin{array}{l}30 \text { items, } 5 \text { categories } \\
\text { (belonging, coping, pleasure, } \\
\text { creativity, aggression) }\end{array}$ & $\begin{array}{c}\text { (Novacek, Raskin, \& Hogan, } \\
1991 \text { ) }\end{array}$ \\
\hline $\begin{array}{l}\text { No specific instrument name (no } \\
\text { specific author indicated) }\end{array}$ & $\begin{array}{c}16 \text { items, } 4 \text { categories (coping, } \\
\text { sociable, social confidence, } \\
\text { enjoy) }\end{array}$ & (Smith, Abbey, \& Scott, 1993) \\
\hline $\begin{array}{l}\text { No specific instrument name (no } \\
\text { specific author indicated) }\end{array}$ & $\begin{array}{l}16 \text { items, } 5 \text { categories (to party, } \\
\text { for enjoyment, to be social, to } \\
\text { cope, to alleviate tension) }\end{array}$ & (Stewart \& Power, 2002) \\
\hline $\begin{array}{l}\text { Reason for Drinking Scale (RFD, } \\
\text { Cronin, 1997) }\end{array}$ & $\begin{array}{c}25 \text { items, } 3 \text { categories (social } \\
\text { camaraderie, mood } \\
\text { enhancement, tension reduction) }\end{array}$ & (Cronin, 1997) \\
\hline $\begin{array}{l}\text { Reasons for Drinking } \\
\text { Questionnaire (RFDQ, Farber, } \\
\text { Khavari, \& Douglass, 1980) }\end{array}$ & $\begin{array}{l}14 \text { items, } 2 \text { categories (negative } \\
\text { reinforcement, positive } \\
\text { reinforcement) }\end{array}$ & (Carey \& Correia, 1997) \\
\hline $\begin{array}{l}\text { Reasons for Drinking Scale } \\
\text { (RDS, Carpenter \& Hasin, } \\
\text { 1998b) }\end{array}$ & $\begin{array}{c}35 \text { items, } 4 \text { categories (negative } \\
\text { affect, enjoyment, social } \\
\text { facilitation, social pressure) }\end{array}$ & $\begin{array}{c}\text { (Carpenter \& Hasin, 1998a, } \\
\text { 1998b; Carpenter \& Hasin, } \\
\text { 1999) }\end{array}$ \\
\hline $\begin{array}{l}\text { Social Context of Drinking } \\
\text { Scales (SCDS, Thombs, Beck, \& } \\
\text { Pleace, 1993) }\end{array}$ & $\begin{array}{l}32 \text { items, } 6 \text { categories (social } \\
\text { facilitation, peer acceptance, } \\
\text { emotional pain, family drinking, } \\
\text { sex seeking, motor vehicle) }\end{array}$ & $\begin{array}{c}\text { (Beck, Thombs, Mahoney, \& } \\
\text { Fingar, 1995) }\end{array}$ \\
\hline
\end{tabular}

Finally, a fourth group of studies used previously developed, evaluated, and established questionnaires, such as the Drinking Motive Questionnaire (DMQ, Cooper, Russell, Skinner, \& Windle, 1992), the Drinking Motive Questionnaire Revised (DMQ, Cooper, 1994), the Reasons for Drinking Questionnaire (RFDQ, Farber, Khavari, \& Douglass, 1980), the Reasons for Drinking Scale (RDS, Carpenter \& Hasin, 1998b), and the Social Context of Drinking Scales (SCDS, Thombs, Beck, \& Pleace, 1993). Among these multidimensional instruments, the Drinking Motive Questionnaire in its original or revised form is the most commonly used. 


\section{Multidimensional classifications}

Table 2-1 gives a comprehensive overview of multidimensional instruments to measure drinking motives. All the instruments listed in Table 2-1 were identified by using the search terms "reason", "reasons", "motive", "motives", and "motivation". However, some scales such as the Drinking Context Scale, the Inventory of Drinking Situations, and the Social Context of Drinking Scales appear at first glance to measure other constructs than drinking motives. Nevertheless, a closer look at the items integrated in these scales shows that aspects which are otherwise subsumed under certain motive categories are in fact measured. The item "When I'm feeling sad, depressed, or discouraged" from the Negative Coping category in the Drinking Context Scale (O'Hare, 1997), for example, can also be found in the Coping subscale of the Drinking Motive Questionnaire (DMQ, Cooper, Russell, Skinner, \& Windle, 1992) and in the Negative Affect subscale of the Reasons for Drinking Scale (RDS, Carpenter \& Hasin, 1998b). The subscales "Unpleasant Emotions", "Pleasant Emotions", "Pleasant Times with Others", and "Social Pressure to Drink" of the Inventory of Drinking Situations (IDS-42, Annis, 1984) show strong similarities with the dimensions "Coping", "Enhancement", "Social" and "Conformity" of the Drinking Motives Questionnaire Revised (DMQR, Cooper, 1994). The subscale "Social Facilitation" of the Social Context of Drinking Scales (SCDS, Thombs, Beck, \& Pleace, 1993) appears to be similar to the motive subscales used by Carpenter \& Hasin (1998b), by Nagoshi, Nakata, Sasano, and Wood (1994), or by Weinberger \& Bartholomew (1996).

Traditionally, reasons for drinking have been grouped into two broad categories: drinking to be sociable, to celebrate, to have a good time, or to enhance one's social confidence on the one hand, and drinking to cope, to escape, or to avoid or regulate unpleasant emotions on the other (McCarty \& Kaye, 1984; Smith, Abbey, \& Scott, 1993). Cox \& Klinger $(1988 ; 1990)$ proposed the characterization of 
drinking motives according to the valence (positive or negative) and source (internal or external) of the outcomes individuals expect to achieve by drinking. Crossing these two dimensions results in four categories of motives: drinking to enhance positive mood or well-being (positive, internal), to obtain social rewards (positive, external), to cope with negative emotions (negative, internal), and to avoid social rejection (negative, external, also labeled "conformity"). Taken together, all studies used a "coping" dimension and one or more other dimensions. Concerning these other dimensions, "social" or "enhancement" motives or both were most frequently included.

Item batteries measuring drinking to cope, to escape, or to avoid or regulate unpleasant emotions are labeled as coping motives (Cooper, Russell, Skinner, \& Windle, 1992; Cooper, 1994; Windle, 1996), coping with negative affect motives (Carpenter \& Hasin, 1998b), drinking to cope with stress (Abbey, Smith, \& Scott, 1993), drinking to reduce negative affect (McCabe, 2002), tension reduction (Cronin, 1997; Rutledge \& Sher, 2001), drinking to ease tension (Stewart \& Power, 2002), relief drinking (Palmqvist, Martikainen, \& vonWright, 2003; Poikolainen, Tuulio-Henriksson, Aalto-Setälä, Marttunen, \& Lönnqvist, 2001), personal reasons (Montgomery, Benedicto, \& Haemmerlie, 1993), negative personal motives (Bradley, Carman, \& Petree, 1991; Bradley, Carman, \& Petree, 1992), escape motives (Neff, 1997), pathological/self-medication reasons (Nagoshi, Nakata, Sasano, \& Wood, 1994), and suppression reasons (Labouvie \& Bates, 2002). The present chapter refers to these reasons as "coping motives".

Drinking motivated by social reasons was labeled positive-social use of drinking (Bradley, Carman, \& Petree, 1991; Karwacki \& Bradley, 1996), social facilitation (Carey, 1993, 1995; Carrigan, Samoluk, \& Stewart, 1998; Carpenter \& Hasin, 1998b; Weinberger \& Bartholomew, 1996; Nagoshi, Nakata, Sasano, \& Wood, 1994), social motives (Cooper, Russell, Skinner, \& Windle, 1992; Cooper, 1994); 
social camaraderie (Cronin, 1997), social motivation subscale (Haden \& Edmundson, 1991), to be sociable/polite (Kairouz, Gliksman, Demers, \& Adlaf, 2002), social reasons (Labouvie \& Bates, 2002), to be social (Stewart \& Power, 2002), and social drinking motives (Windle \& Windle, 1996). Some studies further distinguish between positive and negative social motives. While labels for positive motives are listed above, negative social motives (e.g., drinking to fit in a peer group, not to feel left out, because of peer pressure) were labeled conformity motives (Cooper, 1994), social pressure to drink (Carey, 1993, 1995; Carrigan, Samoluk, \& Stewart, 1998), to comply with others (Kairouz, Gliksman, Demers, \& Adlaf, 2002), social pressure (Carpenter \& Hasin, 1998b), and peer acceptance (Beck, Thombs, Mahoney, \& Fingar, 1995). Since in most identified instruments, social motives were not separated into rewarding and rejection-avoiding motives, both categories were treated together in the following paragraphs and called "social motives".

Items measuring drinking to experience positive feelings, for kicks or excitement, to get high, or because it tastes good were classified as pleasant emotions (Carey, 1993, 1995; Carrigan, Samoluk, \& Stewart, 1998), drinking for enjoyment (Carpenter \& Hasin, 1998b; Smith, Abbey, \& Scott, 1993; Stewart \& Power, 2002), to enhance positive mood (Cooper, Russell, Skinner, \& Windle, 1992; Cooper, 1994), for mood enhancement (Cronin, 1997), to feel good (Kairouz, Gliksman, Demers, \& Adlaf, 2002), to increase positive affect (Weinberger \& Bartholomew, 1996), and drinking to get drunk (Kairouz, Gliksman, Demers, \& Adlaf, 2002; McCabe, 2002). Such reasons are called "enhancement motives" in the following.

These three broad categories to classify drinking motives appear to be comparable across studies, even if there are differences in terms of the labels and number of items used. However, the different formulations and classifications of items make 
it difficult to compare studies that do not use the same instrument to assess drinking motives. Based on a specific connotation, a question can be classified according to different motive dimensions. Drinking to relax or to get drunk, for example, can be considered as a coping motive if one subsumes that relaxation or drunkenness is needed when someone is tense. Relaxation or drunkenness, on the other hand, can be considered as an enhancement motive if one subsumes these are positive sensations that can be enhanced. In addition, drinking to relax or to get drunk is also likely to appear in a social context. Therefore, in studies where the items were classified a posteriori and on an empirical basis by means of an explorative factor analysis (e.g., Cronin, 1997; Haden \& Edmundson, 1991; Novacek, Raskin, \& Hogan, 1991; Smith, Abbey, \& Scott, 1993; Weinberger \& Bartholomew, 1996), the same items can occur under different dimensions only because the respective populations in the studies (e.g., adolescents compared to college students or US college students compared to Canadian college students) attribute different meanings to the same items. Also, when the items were classified a priori on a theoretical basis and confirmed by using a confirmatory factor analysis (e.g., Bradizza, Reifman, \& Barnes, 1999; Cooper, 1994; Labouvie \& Bates, 2002; Carpenter \& Hasin, 1998b), the same items can occur under different dimensions because the respective researchers attribute divergent connotations.

Consequently, motives that are quite similar in name may differ substantially in the items used to indicate this particular motive and vice versa. In other words, a particular item may, depending on the study, be subsumed under a different type of motive. In the Reasons for Drinking Scale (RFD, Cronin, 1997) and in the Social Context of Drinking Scales (SCDS, Thombs, Beck, \& Pleace, 1993; Beck, Thombs, Mahoney, \& Fingar, 1995), the item "drinking to get high or drunk" was part of the social motivation for the drinking subscale, whereas other instruments subsumed this item under enhancement motives (Carpenter \& Hasin, 1998b; 
Cooper, Russell, Skinner, \& Windle, 1992; Cooper, 1994; MacLean \& Lecci, 2000; Weinberger \& Bartholomew, 1996). In the study of Labouvie \& Bates (2002), the items "it tastes good" and "to have fun and enjoy things better" were classified as social motives whereas other instruments subsumed the items under enhancement motives (Carpenter \& Hasin, 1998b; Cooper, Russell, Skinner, \& Windle, 1992; Cooper, 1994; MacLean \& Lecci, 2000; Smith, Abbey, \& Scott, 1993). In the study by Weinberger and Bartholomew (1996), the items "to have a good time with friends" and "to celebrate social occasions" was part of the enhancement motive subscale, whereas other instruments subsumed these items under social motives (Cooper, Russell, Skinner, \& Windle, 1992; Cooper, 1994; Haden \& Edmundson, 1991; Montgomery, Benedicto, \& Haemmerlie, 1993; MacLean \& Lecci, 2000; Smith, Abbey, \& Scott, 1993). For the dimensions of other instruments, only examples (e.g., Abbey, Smith, \& Scott, 1993; Carey \& Correia, 1997; Stewart \& Power, 2002; Windle, 1996; Windle \& Windle, 1996) or no item information (e.g., Bradley, Carman, \& Petree, 1991; Kairouz, Gliksman, Demers, \& Adlaf, 2002; Karwacki \& Bradley, 1996) are given, making it unclear whether they can be compared with other instruments.

These different classifications become particularly important when the different motive dimensions were used to predict alcohol use and related problems (see below). In the following study, however, we maintained the broad classification of coping, social, and enhancement motives, and analyzed the classification of the items only when contradictory evidence emerged.

\section{Conclusion of formal aspects}

Drinking motive research is highly heterogeneous, making it difficult to compare studies. First, the terms "motive" and "reason" are used interchangeably in the 
literature. We suggest, however, that "reason" can be used to describe a specific drinking reason, whereas "motive" refers to items included in broader motive categories. Second, four different ways to assess drinking reasons and motives were identified (qualitatively via single items, and the development and replication of multidimensional scales). Third, even among studies that used multidimensional classifications (see Table 2-1) a high degree of heterogeneity was found: 54 studies used 25 different instruments to analyze 10 to 40 items that were grouped into 2 to 10 categories. Fourth, studies with similar dimensions used different items, and studies with similar items differ in relation to the dimensions under which particular items were subsumed. This was mainly due to how the classifications were created: theoretically-based and a priori versus empiricallybased and a posteriori. When comparing results from studies that use different instruments, it is particularly important to examine which items are subsumed under a certain motive dimension. Future studies should, however, use multidimensional instruments that are based on theoretical assumptions and validated by means of confirmatory factor analysis in different samples, since the motive classifications in such instruments do not depend on the specific sample characteristics and are therefore comparable across studies. In this respect, the Drinking Motive Questionnaire Revised (DMQ-R, Cooper, 1994) is a good example because its development was based on the Motivational Model of Alcohol Use (Cox \& Klinger, 1988, 1990) and confirmed in different samples (e.g., MacLean \& Lecci, 2000; Stewart, Loughlin, \& Rhyno, 2001). 


\section{Possible consequences of indicating drinking motives}

\section{Alcohol use}

In general, most adolescents drink for social reasons or for enhancement reasons (in the sense of enjoyment). In a study of 13- to 18-year olds in Argentina, for example, $80 \%$ drank for enjoyment reasons and only $7 \%$ to improve bad mood, $4.6 \%$ to be accepted by peers, and $1 \%$ to relax or to escape boredom (Jerez \& Coviello, 1998). Among 14- to 16-year olds in the UK, drinking to make a party more enjoyable was the most often reported reason (e.g., 94.4\% of the male heavy drinkers indicated that reason, Plant, Bagnall, \& Foster, 1990). In a Canadian study, most college students drank to enjoy the taste $(24.9 \%)$, to celebrate $(21.3 \%)$ or to be sociable $(16.9 \%)$, whereas only $2.1 \%$ drank to forget worries or to feel less shy (Kairouz, Gliksman, Demers, \& Adlaf, 2002). Stewart \& Power (2002) identified eight different drinking clusters among US high school students. While the level of endorsement of different reasons varied between groups, drinking to party was the most prevalent in all groups, directly followed by drinking for enjoyment. Among US college students, drinking to celebrate was also the most prevalent reason, directly followed by enjoyment of taste (Klein, 1992). Among 14- to 18-year olds in Canada, the three most prominent reasons for drinking were "to get in a party mood" (18\%), "because I enjoy it" $(16 \%)$, and "to get drunk" (10\%, Feldman, Harvey, Holowaty, \& Shortt, 1999). Among 15- to 17-year olds in Hong Kong, however, drinking to have fun was the most prevalent reason for girls, while boys drank mainly to feel the effects of alcohol (Lo \& Globetti, 2000).

As most young people drink for social facilitation, to improve social gatherings, or to get in a party mood, social motives are associated with moderate drinking in most studies (e.g., Cooper, 1994; Feldman, Harvey, Holowaty, \& Shortt, 1999; Kairouz, Gliksman, Demers, \& Adlaf, 2002; Kassel, Jackson, \& Unrod, 2000; 
Weinberger \& Bartholomew, 1996; Windle, 1996; Windle \& Windle, 1996). Among young adults in the US, social motives were negatively associated with drinking intensity in multiple models ( $\beta=-.25$, Labouvie \& Bates, 2002). US college students who drank for social motives were less likely to use alcohol excessively than those who drank for enhancement or coping motives $(r=-.18$, Karwacki \& Bradley, 1996).

Enhancement motives in the sense of feeling the effects of alcohol appear to be highly endorsed by heavy drinkers (e.g., Kairouz, Gliksman, Demers, \& Adlaf, 2002). Among US college students, heavy drinkers (defined as having seven or more drinks on an average drinking occasion) scored significantly higher on drinking to enhance pleasant emotions $(\mathrm{M}=3.03)$ than light $(\mathrm{M}=2.09)$ or moderate $(\mathrm{M}=2.61)$ drinkers (Carey, 1993). In a study among US college students, heavy episodic drinkers scored highest on the created "drinking to get drunk" scale, which contained enhancement motives (McCabe, 2002). In a discriminant analysis, drinking to get drunk was the reason that discriminated best between moderate and heavy drinking among US college students (Billingham, Parrillo, \& Gross, 1993). Heavy drinkers aged between 14 and 18 in Canada were more likely to state that they drink "to get drunk" (22\%) than moderate drinkers (7\%, Feldman, Harvey, Holowaty, \& Shortt, 1999).

Consequently, when items such as "I like the feeling of drunkenness" or "I drink to get high" were integrated in enhancement motive scales, these were most closely associated with heavy drinking (Carpenter \& Hasin, 1998b; Cooper, 1994; Weinberger \& Bartholomew, 1996). When "drinking to get drunk" was not part of the enjoyment/enhancement scale, this scale was only a weak predictor of heavy drinking ( $\beta<.10$, Smith, Abbey, \& Scott, 1993). If drinking to get drunk or to get high was subsumed with other motives under the label "social camaraderie" (Cronin, 1997) or "social facilitation" (Beck, Thombs, Mahoney, \& Fingar, 1995), 
these batteries were the best predictor for average drinks per occasion, frequency of binge episodes (having five drinks or more per occasion), and frequency of drinking days. They also discriminated best between low and high intensity drinkers, with a high endorsement among high intensity drinkers.

Coping motives also appear to be associated with heavy drinking (Cooper, Agocha, \& Sheldon, 2000; Labouvie \& Bates, 2002; Montgomery, Benedicto, \& Haemmerlie, 1993). In the US, tension reduction drinking motives were associated with heavy drinking in each year of college ( $\beta>.30$, Rutledge \& Sher, 2001). Anglo-, African-, and Mexican Americans had all more drinks on a typical occasion and more frequently indicated having five drinks or more when indicating escape motives, independently of their cultural origin (Neff, 1997). In a US population study including persons aged between 21 and 86, the frequency of heavy drinking was highest among those reporting a high endorsement of coping motives and a high level of perceived stress (Abbey, Smith, \& Scott, 1993). In one study among US college students, however, drinking to attenuate negative affects was not significantly associated with heavy episodic drinking $(\beta<.01$, McCabe, 2002).

Apart from the specific relation between the different motive dimensions and alcohol use, young people tend to indicate drinking motives in general. This means that in all studies in which correlations between the different motive dimensions were reported, positive associations were found (see Table 2-2 for an overview). Consequently, apart from the different types of drinking motives, it appears that the total number of reasons is associated with higher levels of alcohol use. In a study among US college students, motivation for drinking in general was associated with high levels of drinking (Weinberger \& Bartholomew, 1996). In this study, frequency of drinking was correlated with all three motivation dimensions measured. The correlation, however, was higher for positive affect enhancement 
$(\mathrm{r}=.32)$ and coping with negative affects $(\mathrm{r}=.29)$ compared to social facilitation $(\mathrm{r}=.10)$. In another study among US college students, the total number of drinking motives was correlated with the quantity-frequency index of drinking $(\mathrm{r}=.22$, Karwacki \& Bradley, 1996).

Table 2-2: Overview of correlations between different motive dimensions according to the study in which they were reported

\begin{tabular}{lccc}
\hline Study & social and coping \\
motives & $\begin{array}{c}\text { Correlation between } \\
\text { social and } \\
\text { enhancement } \\
\text { motives }\end{array}$ & $\begin{array}{c}\text { enhancement and } \\
\text { coping motives }\end{array}$ \\
\hline Bradizza, Reifman, \& Barnes (1999) & .61 & & \\
Carey \& Correia, 1997) & .44 & .68 & .66 \\
Cooper, Russell, Skinner, \& Windle & .47 & .68 & .46 \\
(1992) & .46 & .45 & .69 \\
Cooper (1994) & .42 & & \\
Labouvie \& Bates (2002) & .39 & & \\
O'Hare (2001) & .35 & & \\
Smith, Abbey, \& Scott (1993) & .32 & & \\
Windle \& Windle (1996) & & & \\
\hline
\end{tabular}

The total number of drinking reasons also appears to differentiate between types of drinkers. Among US college students, heavy drinkers indicated more motives than moderate drinkers (Montgomery, Benedicto, \& Haemmerlie, 1993). Similarly, in a study among US high school students (Stewart \& Power, 2002), heavy multiplecontext drinkers who tended to drink heavily and frequently in a socially appropriate context (e.g., with friends or family at parties) and in a risky context (e.g., drinking at school, drinking in cars and drinking alone or with strangers) reported the highest level in all 5 motive categories (drinking to party, for enjoyment, to ease tension, to cope, and to be social). Among 14- to 16-year olds in 
England, heavy drinkers who reported the highest level of alcohol consumption at the last drinking occasion scored higher than other drinkers on all drinking reasons surveyed, with the exception of the "to find out what it's like" reason (Plant, Bagnall, \& Foster, 1990).

However, no study was found that classified young people according to the number of drinking reasons or that tried to identify homogenous groups of young people who drink mainly for specific motives. Due to the high intercorrelation of the different motive dimensions (cf. Table 2-2), it appears difficult to disentangle young people who drink mainly for coping but sometimes also for enhancement motives from those who drink mainly for enhancement motives but sometimes also for coping motives. Nevertheless, it appears sensible to target specific prevention approaches to homogenous risk groups and their specific needs and deficits (e.g., Kuntsche \& Gmel, 2004; Masterman \& Kelly, 2003); drinking motives as most proximal antecedents of alcohol use (Cooper, 1994; Cox \& Klinger, 1988) appear to be of particular importance in this respect.

\section{Alcohol-related problems}

Drinking to cope with negative emotional states is particularly associated with alcohol problems (e.g., Cooper, Frone, Russell, \& Mudar, 1995; McNally, Palfai, Levine, \& Moore, 2003; Simons, Correia, \& Carey, 2000; Windle \& Windle, 1996). Among 14- to 16-year olds in the US, for example, problem drinkers (defined as heavy drinkers who also indicated five or more alcohol-related problems such as missing school due to drinking) scored higher on coping motives $(M=15.0)$ than abstainers $(M=9.7)$ or light $(M=10.0)$, moderate $(M=11.4)$, and heavy ( $M=12.0)$ drinkers (Windle, 1996). Among Canadian college students, a moderation effect was found; only a weak association between neuroticism and 
alcohol problems (measured by the Rutgers Alcohol Problem Index) was found among those who did not indicate drinking to cope. However, a strong association was noted among those who indicated drinking to cope (Stewart, Loughlin, \& Rhyno, 2001). Similarly, among US college students, the relation between a negative-self score and alcohol problems (measured by the Young Adult Alcohol Problems Screening Test) was moderated by coping motives (McNally, Palfai, Levine, \& Moore, 2003). In a multiple model, controlled for age, sex, and the quantity-frequency drinking index, coping motives $(\beta=.38)$, but not social $(\beta=.16)$ or enhancement $(\beta=.05)$ motives, were significantly related to drinking problems among US college students (Kassel, Jackson, \& Unrod, 2000). Furthermore, there is evidence that coping motives are associated with alcohol dependence in adulthood (Carpenter \& Hasin, 1998a, 1998b; Carpenter \& Hasin, 1999). It is argued that, while effective in the short term, drinking to cope as a way to compensate for deficits in problem-focused coping leads to adverse long-term consequences, because the discrepancies that foster negative affects have never been adequately addressed (Cooper, Frone, Russell, \& Mudar, 1995; Kassel, Jackson, \& Unrod, 2000).

Mixed evidence was found for the association between enhancement motives and alcohol problems. Whereas some studies found that, in addition to coping motives, enhancement motives (including drinking to get drunk or similar items) were a second strong predictor for alcohol problems among adolescents and young adults in North America (Cooper, 1994; Cooper, Agocha, \& Sheldon, 2000; Cronin, 1997; Labouvie \& Bates, 2002), others failed (Read, Wood, Kahler, Maddock, \& Palfai, 2003; Simons, Correia, \& Carey, 2000). Some studies found a strong association between enhancement motives and alcohol problems on the bivariate level that did not remain significant when adjusting for coping motives in multiple 
analyses (Carey \& Correia, 1997; Cooper, Frone, Russell, \& Mudar, 1995; Kassel, Jackson, \& Unrod, 2000).

Social drinkers are less likely to experience alcohol-related problems (e.g., Cooper, 1994; Simons, Correia, \& Carey, 2000; Stewart, Loughlin, \& Rhyno, 2001; Windle, 1996). Among young adults in the US, social motives were even negatively associated with drinking problems in multiple models ( $\beta=-.13$, Labouvie \& Bates, 2002).

\section{Other problem behaviors}

There is evidence that academic performance relates to drinking motives. Social (r>.22) and coping ( $r>37)$ motives were correlated with low expectations of academic achievement among US college students (Bradley, Carman, \& Petree, 1991). Among 16- to 18-year old high school students in the US, both social ( $\mathrm{r}=-$ $.10, p<.01)$ and coping $(r=-.17, p<.01)$ drinking motives were negatively correlated with academic performance (measured by grade point average, Windle \& Windle, 1996). However, as both studies were based on correlations, the results were not adjusted for drinking levels. Thus, the unique contribution of drinking motives to low academic achievement remains unclear.

In addition, drinking motives appear to affect social relations and law-abiding behavior. Among US college students, coping motives were correlated with scores on the social complications of drinking scale, which includes destruction of property, accidents, damage to social relationships, absence from or drinking at school or work, and trouble with the authorities (Bradley, Carman, \& Petree, 1992; Karwacki \& Bradley, 1996). With regard to social motives, the evidence is mixed. Bradley, Carman, and Petree (1992) found a positive association between social drinking motives and social complications ( $r>10)$, whereas for Karwacki \& 
Bradley (1996) it was negative ( $\mathrm{r}=-.35)$. In addition, social drinking motives predicted significantly delinquent activity in multiple regressions among 16-to 18year old high school students in the US ( $\beta=.09$, Windle \& Windle, 1996).

\section{Conclusion of possible consequences}

Most young people report drinking for social reasons or enjoyment. Accordingly, social reasons were found to be negatively related to heavy drinking and alcoholrelated problems. Enhancement motives in particular were associated with heavy drinking. These results, however, depend on whether drinking to get drunk and similar items are part of the relevant enhancement motive scale. If enhancement motives only cover aspects such as drinking for enjoyment, to make a party more enjoyable, or because it tastes good, then enhancement motives are likely to be associated with moderate drinking. If drinking to get drunk, high or intoxicated or to feel the effects of alcohol is included in enhancement (or otherwise labeled) scales, then enhancement motives are likely to be associated with heavy drinking. This demonstrates the importance of the use of theoretically-based and internationally validated questionnaires to enhance comparability of findings across studies and to judge the impact of other limitations (see below), such as the use of different reference populations (last month or last year drinkers only vs. the inclusion of abstainers) or the use of highly selective samples (e.g., college freshmen from one US university or poly-drug users in London).

In addition, enhancement motives appear to be associated with alcohol-related problems but are only mediated by coping motives. When coping motives are controlled, the direct association between enhancement motives and alcohol problems is likely to become weaker or vanish. Drinking to cope was found to be associated not only with heavy drinking but also with alcohol-related problems in 
particular. It is argued that, while effective in short term, drinking to cope as a way to compensate for deficits in problem-focused coping leads to adverse long-term consequences because the discrepancies that foster negative affects have never been adequately addressed (Cooper, Frone, Russell, \& Mudar, 1995; Kassel, Jackson, \& Unrod, 2000).

Apart from the different types of drinking motive, the total number of reasons was found to be associated with higher levels of alcohol use. There are indications that adolescents and young adults drink for different reasons depending on the situation (Cooper, 1994; Kairouz, Gliksman, Demers, \& Adlaf, 2002). Accordingly, when young people indicate several reasons for their drinking or score highly on different motive dimensions, they are likely to drink in a variety of situations, and thus show higher levels of alcohol use.

In addition, evidence was found that coping and social drinking motives are associated with other forms of problem behavior such as low academic achievement, social complications, and delinquency. As the results stem from cross-sectional research, in terms of coping motives, social complications can be seen as precursors to drinking to cope with social disappointments, rejection, and loneliness. This points to the fact that during adolescence different problem behaviors occur in clusters (e.g., Basen-Engquist, Edmundson, \& Parcel, 1996; Jessor \& Jessor, 1977), including alcohol use for coping, school problems and violence. Although drinking for social motives was found to be associated with moderate drinking levels, they were also associated with low academic achievement and delinquency. The social context in which young people drink seems to be important. Delinquency is likely if drinking occurs in the company of deviant peers (e.g., Fergusson, Swain-Campbell, \& Horwood, 2002; Rossow, Pape, $\&$ Wichstrom, 1999). In the same way, a tendency towards delinquency was found to be associated with academic failure (Kaplan, Peck, \& Kaplan, 1994). 


\section{DISCUSSION}

To summarize, most young people reported drinking for social motives, some indicated enhancement motives and only a few reported coping motives. Concerning potential outcomes, social motives appear to be associated with moderate alcohol use, enhancement with heavy drinking and coping motives with alcohol-related problems.

There are, however, some considerable gaps in the research on drinking motives among young people. Apart from the definition-related problems, different theoretically- and empirically- based measures were used, even in recently published studies (e.g., Bradizza, Reifman, \& Barnes, 1999; Carrigan, Samoluk, \& Stewart, 1998; Cronin, 1997; Gire, 2002; Kairouz, Gliksman, Demers, \& Adlaf, 2002; Labouvie \& Bates, 2002; McCabe, 2002; O'Hare, 2001; Stewart \& Power, 2002). Although it seems that at least two of the three motive categories "social" (positive, external), "enhancement" (positive, internal), and "coping" (negative, internal) are integrated in all multidimensional instruments, motives to avoid social rejection (negative, external) are often neglected. This was the case even though negative external motives were shown to form an independent motive dimension among adolescents and young adults (Cooper, 1994; MacLean \& Lecci, 2000). Another problem is that the same items can occur under different dimensions, simply because researchers or participants attribute different meanings to the same items. This becomes crucial when predicting alcohol consumption. The item "drinking to get high or drunk", for example, appears to be a powerful predictor for heavy drinking but was part of enhancement as well as social motivation subscales.

Nevertheless, the classification of drinking reasons according to underlying dimensions appears to be a promising approach. Based on the Motivational Model of Alcohol Use (Cox \& Klinger, 1988), Cooper (1994) provided a four- 
dimensional questionnaire (DMQ-R) according to the valence (positive or negative) and source (internal or external) of the outcomes individuals expect to achieve by drinking; at the present time it is the most frequently used questionnaire in North America (see Table 2-1). The use of theoretically based questionnaires with well-defined items is particularly important, since the prevailing heterogeneity of research in this field restricts the comparability of findings and makes it difficult to reach firm conclusions.

Most research on drinking motives used highly specific populations. More than four out of five studies were based on samples from North America, and more than half of all identified studies used North American college students as research participants. In addition, among the very rare studies coming from countries outside North America, none were found that used a multidimensional approach to measure drinking motives. Therefore, the above results may be limited to the specific populations of adolescents and young adults in North America and the particular drinking culture in these two countries (e.g., Kuntsche, Rehm, \& Gmel, 2004). Studies from other countries therefore are needed to identify the significance of the implication of cultural origins in drinking motives.

Studies also differ in terms of the population groups to which their results refer. Some studies only looked at current drinkers who indicated alcohol use in the last 30 days, in the last 12 months or in a lifetime (e.g., Connors, O'Farrell, \& Cutter, 1990; Cooper, Russell, Skinner, \& Windle, 1992; Cooper, 1994; Kassel, Jackson, \& Unrod, 2000; Stewart \& Zeitlin, 1995; Comeau, Stewart, \& Loba, 2001; Stewart, Loughlin, \& Rhyno, 2001; Stewart \& Devine, 2000; Carey, 1993; Karwacki \& Bradley, 1996; Abbey, Smith, \& Scott, 1993; Labouvie \& Bates, 2002; Smith, Abbey, \& Scott, 1993). In other studies, no information was found on whether abstainers were excluded (e.g., O'Hare, 2001; Colder \& O'Connor, 2002; Windle \& Windle, 1996; Montgomery, Benedicto, \& Haemmerlie, 1993; Weinberger \& 
Bartholomew, 1996; Haden \& Edmundson, 1991; Novacek, Raskin, \& Hogan, 1991; Cronin, 1997; Carey \& Correia, 1997; Beck, Thombs, Mahoney, \& Fingar, 1995). In some studies, abstainers were explicitly included, e.g., by asking "if you do not drink, we would like to know how important each reason would be to you if you were to start drinking" (Bradizza, Reifman, \& Barnes, 1999; McCabe, 2002; Nagoshi, Nakata, Sasano, \& Wood, 1994). Different reference populations are another obstacle when comparing the results of the studies. It is possible, for example, that drinking motives mainly discriminate between drinkers and abstainers (in the last 30 days or 12 months, or in a lifetime) and have other implications for drinkers exclusively. Therefore, studies should clearly indicate their reference population and discuss the implications of their sample selection.

Another shortcoming is the fact that most evidence comes from cross-sectional survey research. No study was found that applies an experimental approach to research drinking motives, and only three studies were identified that predicted alcohol-related outcomes in follow-ups, based on a multidimensional measure of drinking motives. Among 13- to 16-year olds in the US, social motives predicted both the onset and continuation of alcohol misuse (including 5+ drinking and drunkenness) five and six years later (Bradizza, Reifman, \& Barnes, 1999). At first glance, these results appear to contradict the findings of most cross-sectional research. Although "drinking to get drunk" or similar items were not included in the social motive scale, the item "to see if I can hold it better than the other kids" indicate excessive drinking in the peer group and might be responsible for the causal link with alcohol misuse. Among US college freshmen, enhancement motives were associated with alcohol use and coping motives with alcohol problems in cross-sectional multiple models (Read, Wood, Kahler, Maddock, \& Palfai, 2003). Longitudinally, however, no motive dimension predicted alcohol use or problems from the freshmen to the sophomore years of college. In a general 
population survey of 18- to 65-year olds in the US, coping motives predicted DSMIV alcohol dependence diagnosis one year later but not enhancement motives (Carpenter \& Hasin, 1998a). In this study, neither coping nor enhancement motives predicted DSM-IV alcohol abuse diagnosis one year later.

An explanation for these contradictory results could be that motives affect drinking only in the onset phase and not the continuation to drink. It appears that motives are particularly important in adolescence when drinking starts and less important in adulthood when drinking habits are already established. However, it appears that the stability of the association between motives and drinking also depends on the kind of motives. Authors, for example, argue that the internally generated motives, i.e. enhancement and coping, that are most strongly related with personality traits (enhancement with extraversion, coping with neuroticism, e.g., Cooper, Agocha, \& Sheldon, 2000; Loukas, Krull, Chassin, \& Carle, 2000; Stewart \& Devine, 2000; Stewart, Loughlin, \& Rhyno, 2001) are more consistently related to alcohol use across drinking situations than external motives such as drinking to enhance social pleasure or to avoid social rejection (Cooper, 1994; Kairouz, Gliksman, Demers, \& Adlaf, 2002). However, since longitudinal evidence is rare, it is impossible to determine the long-lasting effects of different drinking motives on different alcohol-related outcomes in different age groups. Experimental and cross-lagged panel studies are needed to clarify causal links.

The aim of this chapter was to give an overview of empirical research on formal aspects and possible consequences of drinking motives. The next chapter provides information on specific subgroups of young people who drink for particular motives. 


\section{Chapter 3}

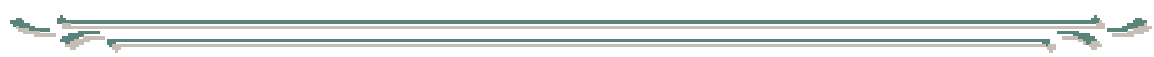

The current state of knowledge II:

Overview of empirical research on socio-demographic, personality, and contextual issues of drinking motives ${ }^{2}$

\footnotetext{
${ }^{2}$ This chapter is based on Kuntsche, E., Knibbe, R., Gmel, G., \& Engels, R. (2006). Who drinks and why? A review of socio-demographic, personality, and contextual issues behind the drinking motives in young people. Addictive Behaviors, 31(10), 1844-1857.
} 


\section{SUMMARY OF CHAPTER 3}

The aim was to review the empirical research carried out over the last 15 years on the characteristics of young people (10- to 25-year olds) who have specific motives for drinking. In a computer-assisted search of relevant literature, 82 studies were identified. Concerning demographic factors, a developmental trend was found general, undifferentiated drinking motives in late childhood and early adolescence towards more gender-specific drinking motives in subsequent years. With regard to personality factors, two specific patterns can be distinguished: extraversion and sensation-seeking correlates with enhancement motives, while neuroticism and anxiety correlate most strongly with coping motives. For contextual factors, drinking motives were found to vary across countries but not among different ethnic groups in the same culture. Based on these results, preventive strategies should take into account general, undifferentiated drinking motivation in late childhood, and social and enhancement motives in adolescence, particularly among boys. Findings on personality indicate that it would useful to focus on extraverted, sensation-seeking boys who drink for enhancement motives and neurotic, anxious girls who drink for coping motives. 


\section{INTRODUCTION}

Research on drinking motives among adolescents has a long tradition (e.g., Edwards, Hensman, \& Peto, 1973; Jung, 1977; Riley, Marden, \& Lifshitz, 1948). In 1988, Cox and Klinger developed their Motivational Model of Alcohol Use (Cox \& Klinger, 1988), based on the assumption that people drink in order to attain certain valued outcomes, and that persons make decisions about whether to drink or not. These decisions are a combination of emotional and rational processes, in that the decisions are made on the basis of the affective change that persons expect to achieve by drinking compared with not drinking. The affective change can either be related to the direct chemical effects of alcohol, e.g., tension reduction or mood enhancement, or the indirect effects, e.g., peer acceptance. In other words, drinking motives represent a subjectively derived decisional framework for alcohol use that is based on personal experience, situation and expectancies (Carpenter \& Hasin, 1998b; Cox \& Klinger, 1988).

A previous review revealed that most adolescents reported drinking for social motives, some indicated enhancement motives and only a few reported coping motives (Kuntsche, Knibbe, Gmel, \& Engels, 2005). Concerning potential outcomes, social motives appeared to be associated with moderate alcohol use, enhancement with heavy drinking, and coping motives with reported alcoholrelated problems besides heavy drinking. The results of empirical research on the characteristics of young people who drink for specific motives have yet to be summarized. The extent to which a review of empirical studies would show consistent associations between drinking motives and socio-demographic characteristics would enhance the validity of the drinking motive concept. Furthermore, it would allow researchers to delineate specific risk groups in terms of the combination of drinking motives and personality characteristics for which 
more tailored interventions should be developed. In fact, authors argue that by identifying and collecting information on the specific needs that alcohol meets for particular individuals, preventive strategies may be more effectively designed (Cooper, 1994; Miller, 1996). Gottfredson and Wilson (2003) conclude from their review of the characteristics of effective school-based substance abuse prevention that the evidence points to greater effectiveness by targeting higher risk youths than by targeting the general population (see also Masterman \& Kelly, 2003).

The aim of this paper is to review the empirical research over the last 15 years for possible antecedents of drinking motives. These concern factors that do not result in specific behaviors such as heavy drinking or delinquency, but are related to the individual or the given situation. It attempts to provide information on the generalities/specificities of drinking motives (e.g., Do drinking motives differ according to gender? Are prevalence and associations of drinking motives comparable between different countries and drinking cultures? Do drinking motives change over time?) and on their validity (e.g., How strong is the association between drinking for social motives and drinking in social situations? How strong is the association between those drinking motives and personality traits which were shown to be remarkably stable across cultures and life times?). The factors mentioned in the relevant studies can be classified in three different categories: socio-demographic (gender, age, trends over time), personality (sensation seeking, low inhibitory control, extraversion, conscientiousness, neuroticism, agreeableness, anxiety sensitivity) and contextual factors (drinking situations, culture). 


\section{MeTHODS}

A computer-assisted literature search was conducted using the keywords "reason" or "reasons" or "motive" or "motives" or "motivation" and "alcohol" or "drinking" or "drunk" or "drunkenness" and "adolescents" or "adolescence" or "juvenile" or "young people". "Current Contents", "ERIC Database", "ETOH“, "Medline“, "PsychInfo", "Sociological Abstracts", and "Swetsnet" were used as databases, together with the internal library system of the Swiss Institute for Prevention of Alcohol and Drug Problems. The search strategy included only articles published in English. The literature search was restricted to publications from 1989 onwards, the year after the development of the Motivational Model of Alcohol Use (Cox \& Klinger, 1988) and to the age group of 10- to 25-year olds.

During the first phase more than 100 articles were identified. The review focuses solely on drinking motives, therefore studies on motives to abstain where excluded. Similarly, the study is concerned with common drinking motives as well as with general population studies of children, adolescents and young adults. For this reason, those dealing exclusively with specific motives (e.g., reasons for ending drinking games) or among particular subpopulations (e.g., reasons for drinking among women with eating disorders or among rural Arab youth) were similarly excluded. Since studies on drinking motives are sometimes integrated into broader studies on young people's drinking in general and therefore often do not explicitly use keywords related to drinking motives or reasons, all identified articles were crosschecked for other yet unidentified studies. In total, the present chapter drew on 82 articles.

The aim of the review is to give an overview of empirical evidence published in the last 15 years on the drinking motives of young people. However, when no 
information from recent studies was available, key or exemplary studies from other populations or those published before 1989 are highlighted.

\section{RESULTS}

\section{Demographics and trends}

\section{Gender and age}

The distinction between different motive categories does not emerge until adolescence. Webb, Getz, Baer, and McKelvey (1999) found that 12 items measuring social and coping motives among $6^{\text {th }}$ graders loaded on two different factors emerged, while among $5^{\text {th }}$ graders only one motive factor was observed. Thus, the difference between social and coping motives as the most general distinction between motive categories (McCarty \& Kaye, 1984; Smith, Abbey, \& Scott, 1993) appears to occur for the first time in early adolescence. In later adolescence and early adulthood, most authors found three or more motive categories (for a review see Kuntsche, Knibbe, Gmel, \& Engels, 2005).

Gender differences seem to emerge during adolescence. In her study, Cooper (1994) did not find any gender differences at the age of 13 and 14, but did find a stronger increase in social and enhancement motives among boys in subsequent years. At age 18 and 19, boys endorsed social and enhancement motives more strongly than girls (Cooper, 1994; Jerez \& Coviello, 1998). Among university students, there is strong evidence that social (Carrigan, Samoluk, \& Stewart, 1998; Gire, 2002; Montgomery, Benedicto, \& Haemmerlie, 1993; Simons, Correia, \& Carey, 2000; Smith, Abbey, \& Scott, 1993; Theakston, Stewart, Dawson, Knowlden-Loewen, \& Lehman, 2002; Wild, Hinson, Cunningham, \& Bacchiochi, 
2001) and enhancement drinkers tend be male (Gire, 2002; Kairouz, Gliksman, Demers, \& Adlaf, 2002; Lo \& Globetti, 2000; Smith, Abbey, \& Scott, 1993; Stewart, Zeitlin, \& Samoluk, 1996; Wild, Hinson, Cunningham, \& Bacchiochi, 2001).

Gender differences in coping motives shift from early adolescence to adulthood. In a study among 13- to 19-year olds, girls score higher on coping motives than boys in early adolescence (13-15 years), whereas in late adolescence (18-19 years) the opposite was observed (Cooper, 1994). Studies among college students found no gender differences in relation to coping motives among younger students (18-21 years in mean: Carey \& Correia, 1997; Nagoshi, Nakata, Sasano, \& Wood, 1994; Stewart, Loughlin, \& Rhyno, 2001; Wild, Hinson, Cunningham, \& Bacchiochi, 2001), but among older students (23 years in mean) men scored higher on coping motives than women (Gire, 2002).

\section{Trends over time}

To our knowledge, only one study investigated trends in adolescent drinking motives over time. This research, carried out in Finland, repeatedly measured drinking motives among 14-16 year olds in 1984 and in 1999 (Palmqvist, Martikainen, \& vonWright, 2003). It revealed that on the one hand the percentage of adolescents indicating coping motives (e.g., drinking to cope with bad feelings, to relieve stress, or to avoid social rejection) decreases, while the percentage indicating enhancement motives (e.g., drinking to feel good, to get drunk or simply for its own sake) increased. 


\section{Conclusion on demographics and trends}

A developmental trend appears to exist - general, undifferentiated drinking motives in late childhood and early adolescence towards more gender-specific drinking motives in subsequent years. In late adolescence, for example, boys score higher on social and enhancement motives, while no gender differences were found in early adolescence; among older college students, men scored higher on coping motives whereas no differences were found among younger college students. Concerning trends over time, one study revealed a shift over the last 20 years towards a decrease in coping motives and an increase in enhancement motives among adolescents from Northern Europe.

\section{Personality issues}

In their Motivational Model of Alcohol Use, Cox and Klinger (1988; 1990) suggested that drinking motives are the most proximal antecedents of alcohol use, whereas other variables such as personality factors influence alcohol use by way of their associations with drinking motives. As personality factors are supposed to constitute salient ways in which individuals differ in their motivational styles (McCrae \& John, 1992), authors argue that it is important to include drinking motives when studying the link between personality characteristics and alcoholrelated outcomes (Cooper, 1994; Stewart \& Devine, 2000).

Accordingly, by reviewing literature on the characteristics of young people who drink for particular motives, several studies were found that treated the link between personality factors and drinking motives. The former can be classified into four broad categories: sensation seeking and low inhibitory control, dimensions of the five-factor model of personality, anxiety sensitivity, and other personalityrelated factors. 


\section{Sensation seeking and low inhibitory control}

Enhancement motives are defined as drinking to enhance positive emotional states and were assessed by items such as drinking because it is exciting or because it is fun. Accordingly, studies found that enhancement motives are associated with sensation-seeking (Comeau, Stewart, \& Loba, 2001; Cooper, Frone, Russell, \& Mudar, 1995), defined as a personality factor that refers to the desire for intense and novel experiences (Zuckerman, 1994). Additionally, enhancement motives were shown to be associated with low inhibitory control (Colder \& O'Connor, 2002), and low suppression of aggression (Weinberger \& Bartholomew, 1996). In a study among 13- to 19-year olds in the US, impulsivity - defined as responding immediately to urges and desires - was positively correlated with enhancement motives ( $\mathrm{r}=.19$, Cooper, Agocha, \& Sheldon, 2000). However, in this study, impulsivity was not identified as a significant predictor of enhancement motives when extraversion and neuroticism (see below) were taken into account in a multivariate regression analysis.

Extraversion, conscientiousness, neuroticism, agreeableness, and openness as dimensions of the five-factor model of personality

The five-factor model of personality (Costa \& McCrae, 1992) is an organization of five remarkably robust personality constructs and identifies salient ways in which individuals differ in their emotional, interpersonal, experiential, attitudinal, and motivational styles (McCrae \& John, 1992). The four factors of high extraversion, low conscientiousness, high neuroticism, and low agreeableness in this model were shown to be related to specific drinking motives.

Drinking to enhance positive emotional states was shown to be associated with high levels of extraversion which was defined as gregariousness, sociability, and 
high levels of activity and excitement-seeking (Cooper, Agocha, \& Sheldon, 2000; Stewart \& Devine, 2000; Theakston, Stewart, Dawson, Knowlden-Loewen, \& Lehman, 2002). It was argued that extraverted individuals are sensitive to positive affective stimuli and therefore more likely to engage in enhancement-motivated alcohol use (Gray, 1982; Stewart \& Devine, 2000).

Studies demonstrate that North American college students who drank to enhance positive emotional states scored low on conscientiousness - defined as responsibility, dependability and will to achieve (Loukas, Krull, Chassin, \& Carle, 2000; Stewart \& Devine, 2000; Stewart, Loughlin, \& Rhyno, 2001; Theakston, Stewart, Dawson, Knowlden-Loewen, \& Lehman, 2002). It was argued that low self-discipline and low deliberation make individuals who also score low on conscientiousness more likely to engage in short-term incentive activities, such as heavy drinking, and less likely to consider the long-term consequences of this behavior (Stewart, Loughlin, \& Rhyno, 2001). Some studies additionally found a correlation between coping motives and low conscientiousness $(r=.22$, Loukas, Krull, Chassin, \& Carle, 2000; r=.19, Stewart \& Devine, 2000; r=.15, Theakston, Stewart, Dawson, Knowlden-Loewen, \& Lehman, 2002). However, this relation did not remain significant when enhancement motives were statistically controlled for (Loukas, Krull, Chassin, \& Carle, 2000; Theakston, Stewart, Dawson, Knowlden-Loewen, \& Lehman, 2002).

There is strong evidence that drinking to cope with negative emotional states is associated with high levels of neuroticism - defined as emotional lability, hypersensitivity to criticism, self-doubt, and a tendency to dwell on the negative (Cooper, Agocha, \& Sheldon, 2000; Loukas, Krull, Chassin, \& Carle, 2000; Stewart \& Devine, 2000; Stewart, Loughlin, \& Rhyno, 2001). Neurotic individuals who are vulnerable to experiences of negative affect may place more importance on the use of alcohol to alleviate such feelings (Loukas, Krull, Chassin, \& Carle, 
2000). Alcohol use is only one of several maladaptive coping strategies employed by neurotic individuals in an attempt to deal with their frequent experiences of negative affect (Stewart, Loughlin, \& Rhyno, 2001). Neuroticism was also found to be correlated to social ( $\mathrm{r}=.20$, Stewart \& Devine, 2000) and enhancement motives ( $\mathrm{r}=.09$, Cooper, Agocha, \& Sheldon, 2000). However, Loukas, Krull, Chassin, and Carle (2000) found that although neuroticism was correlated with all motive dimensions measured in their study ( $\mathrm{r}_{\text {coping }}=.44, \mathrm{r}_{\text {enhancement }}=.20, \mathrm{r}_{\text {social }}=.22$ ), only coping motives remained significant after having statistically controlled for other motive dimensions.

In addition to neuroticism, coping motives were shown to be associated with low levels of agreeableness - defined as trust, compliance, good interpersonal relationships (Loukas, Krull, Chassin, \& Carle, 2000; Stewart, Loughlin, \& Rhyno, 2001). It was argued that individuals who score low in agreeableness (i.e. characterized by hostility, self-centeredness, and indifference to others) are likely to experience interpersonal conflicts (Suls, Martin, \& David, 1998) and violence (Heaven, 1996), and thus may use alcohol to cope with the elevated levels of social distress they encounter (Loukas, Krull, Chassin, \& Carle, 2000).

For openness, the fifth dimension of the five-factor model of personality (Costa $\&$ McCrae, 1992), no significant relation to any drinking motive dimension was found (Stewart \& Devine, 2000; Stewart, Loughlin, \& Rhyno, 2001).

\section{Anxiety sensitivity}

Individuals who score high on anxiety sensitivity are characterized by displaying fears concerning the potential negative consequences of anxiety symptoms, such as the fear of physical illness, social embarrassment, or loss of mental control (Reiss, Peterson, Gursky, \& McNally, 1986). For example, an individual with high anxiety 
sensitivity might perceive a rapid heart rate as a sign of an impending heart attack. In contrast, individuals who score low in anxiety sensitivity would perceive such bodily symptoms as essentially inconsequential.

Several studies demonstrate that drinking to cope with negative emotional states is associated with high levels of anxiety sensitivity (Comeau, Stewart, \& Loba, 2001; Stewart \& Zeitlin, 1995; Stewart, Karp, Pihl, \& Peterson, 1997; Stewart, Zvolensky, \& Eifert, 2002). Authors argue that anxiety-sensitive individuals use alcohol due to its anxiolytic properties to control the symptoms that they fear. In contrast, students with low anxiety sensitivity drink primarily for social or enhancement motives (Comeau, Stewart, \& Loba, 2001; Stewart, Karp, Pihl, \& Peterson, 1997). Additionally, one study found that the relation between anxiety sensitivity and coping motives was stronger among female college students in Canada (Stewart \& Zeitlin, 1995). Another study revealed that the correlations between trait anxiety and coping motives were stronger for those Canadian high school students with high anxiety sensitivity than for those with lower anxiety sensitivity (Comeau, Stewart, \& Loba, 2001). The authors argue that adolescents who are frequently anxious would be more motivated to attempt to control their anxiety through drinking alcohol if they also greatly feared anxiety symptoms. However, one study indicates that the relation between anxiety sensitivity and coping motives is moderated by experiential avoidance - defined as suppression or acceptance of negative emotional states (Stewart, Zvolensky, \& Eifert, 2002). Authors argue that the increased likelihood of coping-motivated drinking among individuals with high anxiety sensitivity can be explained by their greater attempts in general to control aversive inner experiences. 


\section{Other personality-related issues}

Coping motives in particular appear to be linked to a number of other personalityrelated issues. In one study, for example, US college students with a negative selfimage scored higher on coping motives (McNally, Palfai, Levine, \& Moore, 2003). This result is consistent with research on neuroticism (see above) and depression (see below). Particularly among male college students, coping motives were correlated with alienation (Bradley, Carman, \& Petree, 1991) - defined as feelings of helplessness, frustration, despair, and social isolation in the sense of being rejected, excluded or repudiated in social relations (Jessor, Graves, Hanson, \& Jessor, 1968).

Looking more closely at the different facets of the neurotic personality, Stewart and Devine (2000) found that depression was most strongly correlated with coping motives among Canadian college students. Windle and Windle (Windle \& Windle, 1996) also found a correlation between coping motives and depression among US high school students and concluded that coping motives, which typically have been viewed as alcohol-specific in terms of their relevance to dysfunctional behavior, highlight the potential predictive value of this dimension in multiple domains of adolescent functioning.

\section{Conclusion on personality issues}

Concerning drinking motives, two types of adolescents and young adults with a particular personality appear to exist. First, those who drink for enhancement motives were shown to be extraverted, impulsive, and aggressive. They tend to be sensation seekers, to have low inhibitory control, low levels of responsibility and a weak will to achieve. Second, those who drink for coping motives were shown to be neurotic and to have a low level of agreeableness and a negative views of the 
self. Table 3-1 provides an overview of the most important findings. It reveals that personality factors are mainly related to enhancement (internal, positive in the terminology of Cox \& Klinger, 1988) or coping drinking motives (internal, negative in the terminology of Cox \& Klinger, 1988). Authors argue that personality factors are less relevant for external motives (social motives: external, positive; conformity: external, negative) because they are more context-dependent and less stable over time (Cooper, 1994; Stewart \& Devine, 2000). Indeed, associations between personality factors and social or conformity motives tend to be weak and failed to be significant when statistically controlled for enhancement and coping motives (Loukas, Krull, Chassin, \& Carle, 2000; Stewart \& Devine, 2000; Theakston, Stewart, Dawson, Knowlden-Loewen, \& Lehman, 2002).

Table 3-1: Overview of the most important findings of the link between personality factors and drinking motives.

\begin{tabular}{|c|c|c|}
\hline Personality domain & $\begin{array}{l}\text { Drinking motive } \\
\text { dimension }\end{array}$ & Study \\
\hline High sensation-seeking & enhancement & Comeau et al., 2001; Cooper et al., 1995 \\
\hline Low inhibitory control & enhancement & Colder \& O'Connor, 2002 \\
\hline $\begin{array}{l}\text { Low suppression of } \\
\text { aggression }\end{array}$ & enhancement & Weinberger \& Bartholomew, 1996 \\
\hline High extraversion & enhancement & $\begin{array}{l}\text { Cooper et al., 2000; Stewart \& Devine, 2000; } \\
\text { Theakston et al., } 2002\end{array}$ \\
\hline Low conscientiousness & enhancement & $\begin{array}{c}\text { Loukas et al., 2000; Stewart \& Devine, 2000; Stewart } \\
\text { et al., 2001; Theakston et al., } 2002\end{array}$ \\
\hline High neuroticism & coping & $\begin{array}{c}\text { Cooper et al., 2000; Loukas et al., 2000; Stewart \& } \\
\text { Devine, 2000; Stewart et al., } 2001\end{array}$ \\
\hline Low agreeableness & coping & Loukas et al., 2000; Stewart et al., 2001 \\
\hline High anxiety sensitivity & coping & $\begin{array}{c}\text { Comeau et al., 2001; Stewart \& Zeitlin, 1995; Stewart } \\
\text { et al., 1997; Stewart et al., } 2002\end{array}$ \\
\hline High depression & coping & Stewart \& Devine, 2000; Windle \& Windle, 1996 \\
\hline Negative self views & coping & McNally et al., 2003 \\
\hline Alienation & coping & Bradley et al., 1991 \\
\hline
\end{tabular}




\section{Contextual issues}

\section{Situational context}

Only one study reports associations between drinking motives and drinking in different situational contexts (Cooper, 1994). This study shows that social drinkers drank more frequently at mixed-sex parties but not at home, in bars or together with family members, while enhancement drinkers drank with same-sex friends, at friends' homes, and in bars, and coping drinkers drank at home but not at parties or with their family. These results are highly consistent with the given drinking motive dimensions. Social drinkers, for example, are defined as people who drink in a social context and not alone at home, while one would expect that enhancement drinkers are likely to avoid drinking in the company of their family but seek out same-sex friends for company and whose drinking contexts are marked by little social control. Another study among Canadian college students confirms that young people drink for different reasons depending on the drinking situation (Kairouz, Gliksman, Demers, \& Adlaf, 2002). In fact, the reasons given added $8.1 \%$ of explained variances in the variation of alcohol intake between situations, compared to the model including only the characteristics of the drinking setting, such as circumstance, location, day of the week, group size, type of relationship, local norms and residence. However, the study failed to reveal the particular reasons why students drink in particular situations.

\section{Cultural context}

There is a remarkable similarity across cultures in terms of the drinking motives of adolescents. Most drink for social or enhancement reasons in the sense of enjoyment. For example, in a study among 13- to 18-year olds in Argentina 80\% 
drank for enjoyment reasons and only $7 \%$ to improve their bad mood, $4.6 \%$ to be accepted by peers, and 1\% to relax or to escape boredom (Jerez \& Coviello, 1998). Among 14- to 16-year olds in the UK, drinking to make a party more enjoyable was the most frequently reported reason (Plant, Bagnall, \& Foster, 1990). Among US college students, drinking to celebrate was the most common reason given (Klein, 1992; Stewart \& Power, 2002). In a Canadian study, most college students drank to enjoy the taste $(24.9 \%)$, to celebrate $(21.3 \%)$ or to be sociable $(16.9 \%)$, whereas only $2.1 \%$ drank to forget worries or to feel less shy (Kairouz, Gliksman, Demers, \& Adlaf, 2002). Among 14- to 18 -year olds in Canada, the three most prominent reasons for drinking were "to get in a party mood" (18\%), "because I enjoy it" (16\%), and "to get drunk" (10\%, Feldman, Harvey, Holowaty, \& Shortt, 1999). Among 15- to 17-year olds in Hong Kong, drinking to have fun was the most prevalent reason for girls, while boys drank mainly to feel the effects of alcohol (Lo \& Globetti, 2000; Kuntsche, Knibbe, Gmel, \& Engels, 2005, for a more extensive description).

There are, however, a number of exceptions indicating that in some cases reasons for drinking are culture-specific. In a Spanish study of regular drinkers, the most frequently reported reasons for drinking were "I like the taste", "it is a custom/social habit", and "it helps my digestion" (Alvarez \& del Rio, 1994). That Spanish drinkers indicate mainly custom- and meal-related reasons may be linked to the fact that, in southern European countries, alcohol, particularly wine, is often moderately consumed at mealtimes (see Fahrenkrug \& Gmel, 1998; Room \& Mäkelä, 2000, for reviews). While these examples came from countries with distinctive drinking cultures, one study failed to find differences in the relation between drinking motives and drinking patterns among different ethnic groups in the same country (Neff, 1997). In this study, Anglo-, African-, and MexicanAmericans all had more drinks on a typical occasion and more frequently indicated 
having five drinks or more when stating escape motives, independently of their cultural origin.

Two studies were identified that directly compare drinking motives and drinking patterns in samples from different countries. A cross-national study among US and Japanese college students revealed that in both countries social motives were more frequently indicated than coping motives. However, US students scored higher on social motives than their Japanese peers. No differences in coping motive scores were found (Nagoshi, Nakata, Sasano, \& Wood, 1994). In another cross-national study, US college students scored higher on coping motives, whereas Nigerian students scored higher on social motives (Gire, 2002). The author interprets the results in respect to the general attitude in African cultures to subordinate individual goals in favor of group goals.

Apart from prevalence differences across a number of countries, it appears that the classification of drinking motives (cf. Cox \& Klinger, 1988) as enhancement (internal, positive), coping (internal, negative), social (external, positive), and conformity (external, negative) is relatively stable across cultures. Results of the Drinking Motive Questionnaire Revised (DMQ-R, Cooper, 1994) reveal strong similarities in the motive structure between adolescents and college students (MacLean \& Lecci, 2000) and between adolescents from the US (Cooper, 1994), Canada (Comeau, Stewart, \& Loba, 2001), and Switzerland (Kuntsche, Knibbe, Gmel, \& Engels, 2006a).

\section{Conclusion on contextual issues}

Drinking motives are associated with drinking in different situational contexts (Cooper, 1994; Kairouz, Gliksman, Demers, \& Adlaf, 2002) and, in accordance with existing theories, these relations are as to be expected (Cox \& Klinger, 1988; 
1990). For example, the finding which stated that social drinkers tended to drink in a social context and not alone at home demonstrates the validity and discreteness of drinking motive dimensions. In addition to the fact that most adolescents drink for social or enjoyment reasons, some indication was found that drinking motives are culturally embedded. Prevalence of particular drinking motives were found between quite distinct cultures (Nigeria vs. US, Japan vs. US) but not between different ethnic groups living in the same country. It appears that a particular drinking culture in a country affects the different ethnic groups that live in that country and their drinking motives. There are two underlying factors which might explain the differences in drinking motives between countries. Social motives appear to be prominent in collectivistic countries (Nigeria vs. US) or in countries where there is a wealth of social activities and social opportunities or pressure to drink (US vs. Japan). Particularly among freshmen in the US, social modeling, peer pressure and easy availability of alcohol may stimulate students to drink frequently (Baer, 1994). This and the particular residence system for college students in the US (living in Greek social organizations or in fraternity or sorority houses, see Baer, 2002 for a review) may result in higher levels of social motives in the US than in Japan. Apart from prevalence, there does not appear to be, any differences in the classification of drinking motives into the four categories of enhancement, coping, social, and conformity.

\section{DISCUSSION}

\section{Specificity of drinking motives}

There appears to be a developmental trend whereby one general drinking motive is indicated in late childhood and early adolescence while two or more specific 
drinking motives are given in late adolescence and in adulthood. Accordingly, gender differences in relation to indicating drinking motives appear to develop accordingly. In late adolescence, boys score higher on social and enhancement motives whereas no differences were found in early adolescence; after college men scored higher on coping motives, whereas no differences were found when they entered college. This is consistent with the fact that during adolescence drinking patterns, such as risky single occasion drinking related to particular drinking motives, i.e. enhancement and coping motives (for a review, see Kuntsche, Knibbe, Gmel, \& Engels, 2005), increase generally with age but are steeper among males (Kuntsche, Gmel, Wicki, Rehm, \& Grichting, 2006; Kuntsche, Rehm, \& Gmel, 2004). Studies among college students found no gender differences in terms of coping motives among younger students (18-21 years in mean, Carey \& Correia, 1997; Nagoshi, Nakata, Sasano, \& Wood, 1994; Stewart, Loughlin, \& Rhyno, 2001; Wild, Hinson, Cunningham, \& Bacchiochi, 2001). However, among older students (23 years in mean), men scored higher on coping motives than women (Gire, 2002). In adolescence and during college freshman years, indicating coping motives was found to be more strongly associated with excessive alcohol use among females than among males (Beck, Thombs, Mahoney, \& Fingar, 1995; Bradizza, Reifman, \& Barnes, 1999; Stewart \& Zeitlin, 1995; Windle, 1996). However, after the freshman years and when entering the workplace in their midtwenties male heavy drinking tallied more with coping motives than with female heavy drinking (Rutledge \& Sher, 2001).

Indicating specific drinking motives may also be influenced by the drinking culture (e.g., Gire, 2002; Nagoshi, Nakata, Sasano, \& Wood, 1994) but not by different sub-cultures (ethnicities) in the same (drinking) culture (Neff, 1997). Only one such study reported differences in the association between drinking motives and alcohol use. In the US, students scored higher on social motives and their drinking 
was more strongly correlated with social motives than in Japan (Nagoshi, Nakata, Sasano, \& Wood, 1994). This is supposed to be related to the social and environmental characteristics of universities in the US (Baer, 1994; 2002). For coping motives that are internal by nature (Cox \& Klinger, 1988; Cooper, 1994), no differences in scores and associations were found. Likewise, no differences were found across cultures in terms of the classification of drinking motives according to the four categories of enhancement, coping, social, and conformity.

However, studies on drinking motives are still rare outside North America. Actually, more than four out of five studies identified in this review used samples from North American countries and more than half of all identified studies used North American college students as research participants. Therefore, studies from other countries and particularly cross-national comparisons and studies that use longitudinal designs or multiple age groups are needed. Another obstacle is the heterogeneity in drinking motive measurement (for details, see Kuntsche, Knibbe, Gmel, \& Engels, 2005). Future studies, therefore, should use well-defined, theoretically-based, homogenous instruments to disentangle cultural and possible measurement differences across surveys.

\section{Drinking motive personality types}

Taken all together, two types of adolescents and young adults with a particular personality, drinking motive structure and alcohol-related outcomes appear to exist. First, those who drink for enhancement motives were shown to be extravert, impulsive, and aggressive. They tend to be sensation-seekers, and to have low inhibitory control, low levels of responsibility and a weak will to achieve. Furthermore, enhancement drinkers are likely to be male (see above) and to use alcohol excessively, including the consumption of high quantities on single 
occasions (for a review, see Kuntsche, Knibbe, Gmel, \& Engels, 2005). It would appear that these young people like and actively seek to feel drunk as well as other extreme sensations due to their extraverted, risk-seeking personality.

Second, those who drink for coping motives were shown to be neurotic and to have a low level of agreeableness and a negative view of the self. They tend to have difficulties identifying and describing emotions, as well as being fearful of anxietyrelated sensations. Furthermore, coping drinkers tend to be female (at least in early and mid adolescence, see above) and to experience alcohol-related problems besides their heavy drinking (for a review, see Kuntsche, Knibbe, Gmel, \& Engels, 2005). Apparently, these young people cumulate personal problems due to their oversensitive, anxiety-fearing personality and they tend to use alcohol as a means to cope with them. However, while effective in the short term, drinking to cope as a way of compensating for deficits in problem-focused coping leads to greater adverse long-term consequences, because the discrepancies that foster negative affects are never adequately addressed (Cooper, Frone, Russell, \& Mudar, 1995; Kassel, Jackson, \& Unrod, 2000).

This classification, however, is limited due to the fact that the measurement of drinking motive differs between studies and that the evidence comes exclusively from North America and more than two thirds of the participants were college students. Although personality factors and their relations to drinking patterns were shown to be relatively invariant across cultures (e.g., Cook, Young, Taylor, \& Bedford, 1998; Kjærheim, Mykletun, \& Halvorsen, 1996; Vollrath \& Torgersen, 2002) and across developmental stages (e.g., Gotham, Sher, \& Wood, 1997; McCrae, Costa, Terracciano, Parker, Mills, De Fruyt, \& Mervielde, 2002), the existence of particular combinations of gender, personality factors, drinking motives, drinking patterns, and alcohol-related consequences in the sense of a joint pattern across cultures and developmental stages has yet to be proved. 


\section{The usefulness of drinking motives for research and prevention}

In this review, several indications for the validity of the drinking motive concept were found. First, results of the association between specific drinking motives and drinking situations (Cooper, 1994) are highly consistent with the definition of these drinking motives (Cox \& Klinger, 1988). Second, in several studies, drinking motives were consistently related to specific personality traits which were shown to be remarkably invariant across cultures (e.g., Cook, Young, Taylor, \& Bedford, 1998; Kjærheim, Mykletun, \& Halvorsen, 1996; Vollrath \& Torgersen, 2002) and stable across the life-span (e.g., Gotham, Sher, \& Wood, 1997; McCrae, Costa, Terracciano, Parker, Mills, De Fruyt, \& Mervielde, 2002). Third, like drinking styles, the indication of particular drinking motives appears to be culture-specific (e.g., Gire, 2002; Nagoshi, Nakata, Sasano, \& Wood, 1994). Together with the fact that drinking motives emerge at the same time as the development of genderspecific drinking patterns and associated problems from early adolescence to early adulthood, these results demonstrate the validity of the drinking motive concept and its usefulness for research on the etiology of alcohol use, heavy drinking, and alcohol-related problems in adolescence and beyond.

In addition, drinking motives appear to be an interesting concept for targeting prevention programs which specifically target at-risk adolescents (Stewart, Conrod, Marlatt, Comeau, Thush, \& Krank, 2005). Gottfredson and Wilson (2003) conclude from their review of the characteristics of effective school-based substance abuse prevention that the evidence suggests that targeting higher risk youths may yield greater effects than targeting the general population (see also Masterman \& Kelly, 2003). Yet, even at-risk adolescents, such as risky single occasion drinkers, do not appear to be a homogeneous group. Kuntsche and Gmel (2004), for example, found that social and solitary risky single occasion (or binge) drinkers differ in terms of the combination of their associated problems and 
conclude that preventive efforts, like competence-enhancing and social resistance programs, should be tailor made to the given problem constellation (see also Turrisi, Padilla, \& Wiersma, 2000). Current developments in prevention and early intervention highlight the need to include the interplay between the underlying personality and motivational factors of risky alcohol use in adolescence (Stewart, Conrod, Marlatt, Comeau, Thush, \& Krank, 2005).

Authors argue that the identification and collection of information on the specific needs that alcohol serves for particular individuals may lead to the design of more effective preventive strategies (Cooper, 1994; Miller, 1996). This review found that drinking motivations differ according to gender and age, and that prevention approaches should be tailored accordingly. For example, attention to drinking motivation in general is relevant in late childhood, social and enhancement motives in early adolescence and coping motives in late adolescence and early adulthood. The findings on personality would appear to favor tailored interventions in adolescence which focus on two risk groups: (a) extravert, sensation-seeking boys who drink for enhancement motives and (b) neurotic, anxious girls who drink for coping motives. 


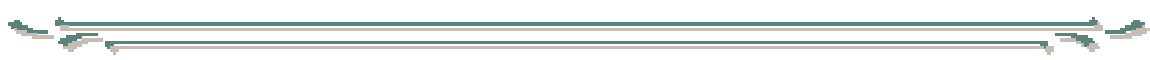

\section{Replication and validation of the Drinking Motive}

Questionnaire Revised (DMQ-R, Cooper, 1994) among adolescents in Switzerland $^{3}$

\footnotetext{
${ }^{3}$ This chapter is based on Kuntsche, E., Knibbe, R., Gmel, G., \& Engels, R. (2006). Replication and validation of the Drinking Motive Questionnaire Revised (DMQ-R, Cooper, 1994) among adolescents in Switzerland. European Addiction Research, 12(3), 161-167.
} 


\section{SUMMARY OF CHAPTER 4}

This chapter has two aims: (1) to replicate the four-dimensional structure of the DMQ-R in a national representative sample from Switzerland and (2) to validate the relevance of distinguishing drinking motives by examining the relations with expected consequences, alcohol use, as well as alcohol-related and other problems. Confirmatory factor analysis and linear structural equation models were estimated based on answers of $5,6178^{\text {th }}$ to $10^{\text {th }}$ graders (mean 15.1 years; $S D=.95$ ). The results confirm the four-dimensional factor structure in general, as well as among sub-populations defined by gender, age, and linguistic region. It could also be confirmed that enhancement motives followed by coping motives were strongly related to alcohol use and heavy drinking, whereas conformity motives were negatively related. Coping motives were related to problems independent of whether they were assessed as alcohol-related or not, while enhancement motives were associated solely with alcohol-related problems. In sum, the results demonstrate the robustness of the DMQ-R and its usefulness for assessing drinking motives among European adolescents from different cultural backgrounds. 


\section{INTRODUCTION}

Alcohol use is known to be determined by a large variety of factors that are found both within the individual (e.g., genetic disposition, personality characteristics, cognitions) and in his environment (e.g., factors on the level of the society, neighborhood, families, peer groups, drinking situations, see Ham \& Hope, 2003; Hawkins, Catalano, \& Miller, 1992; Kuntsche, Rehm, \& Gmel, 2004, for reviews). From both the conceptual point of view and in terms of prevention, the factors most proximate to drinking are of strategic importance. These are not only supposed to be more easily accessible for prevention efforts than most distal factors, but also tend to reflect or include such distal factors as culture, situation, or personality (Cox \& Klinger, 1988, 1990). Drinking motives are defined as the final decision to drink or not, and therefore the most proximal factor for engaging in drinking (Carpenter \& Hasin, 1998b; Cooper, 1994; Cox \& Klinger, 1988, 1990). In other words, drinking motives are the final pathway to alcohol use, i.e. the gateway through which more distal influences, such as personality characteristics, are mediated (Catanzaro \& Laurent, 2004; Cooper, Frone, Russell, \& Mudar, 1995; Cronin, 1997). On the other hand, however, drinking motives depend on past reinforcement achieved through drinking (Cox \& Klinger, 1988, 1990) and might also be used as justification for a certain drinking style. From both a conceptual and practical point of view, the relevance of drinking motives for understanding adolescent drinking is probably underestimated, partly due to the fact that until now most studies using drinking motives have been restricted to North America (Kuntsche, Knibbe, Gmel, \& Engels, 2005).

The central focus of this study is the measurement and relevance of drinking motives among adolescents in a multilingual European country. More specifically, it aims to replicate and validate a drinking motive instrument that was developed in 
the US and based on the Motivational Model of Alcohol Use (Cox \& Klinger, 1988, 1990). This model assumes that drinking motives can be classified according to two underlying dimensions which reflect the valence (positive or negative) and the source (internal or external) of the outcomes individuals expect to achieve by drinking. Thus, individuals are supposed to drink to obtain positive outcomes (positive reinforcement) or to avoid negative consequences (negative reinforcement). In addition, they may be motivated by internal rewards like enhancement of a desired internal emotional state or by external rewards like social approval or acceptance. Crossing these two dimensions results in four different drinking motive categories: (a) internally generated, positive reinforcement motives (drinking to enhance positive mood), (b) externally generated, positive reinforcement motives (drinking to obtain social rewards), (c) internally generated, negative reinforcement motives (drinking to reduce negative emotions), and (d) externally generated, negative reinforcement motives (drinking to avoid social rejection).

Based on these considerations, Cooper (Cooper, 1994) developed the Drinking Motive Questionnaire Revised (DMQ-R) for use among adolescents. It reliably measures the four drinking motive categories of enhancement (internal, positive), coping (internal, negative), social (external, positive), and conformity (external, negative) among 13- to 19-year olds in the US. At present, the DMQ-R is the most frequently used multidimensional instrument to assess drinking motives in North America (for a review, see Kuntsche, Knibbe, Gmel, \& Engels, 2005). To our knowledge, however, no study exists that has used the DMQ-R to assess drinking motives outside North America. However, as alcohol consumption and drinking patterns among adolescents vary widely across cultures (e.g., Hibell, Andersson, Bjarnason, Ahlström, Balakireva, Kokkevi, \& Morgan, 2004), it remains unclear if 
adolescent drinking motives follow the same patterns and are associated with the same alcohol outcomes as in the US.

This paper has two aims: (1) to replicate the four-dimensional structure of the DMQ-R in a national representative sample from Switzerland and (2) to validate the relevance of distinguishing drinking motives by examining the relations with expected consequences, alcohol use, as well as alcohol-related and other problems. A confirmation of the DMQ-R factor structure and its potential to predict alcohol use and problems would confirm the strategic importance of motives to understand adolescents' drinking and to develop effective interventions to prevent harm caused by this behavior.

Apart from the confirmation of the four-dimensional structure in a national representative sample, the present investigation seeks to determine the equivalence of the factor structure in different subpopulations. In her study among 13- to 19year olds in the US, Cooper (Cooper, 1994) found no differences in factor structure according to gender, age, and race. Likewise, we expect no structural differences according to gender and age in Switzerland. Additionally, the present sample of Swiss adolescents offers the opportunity to study cultural differences in one country by comparing adolescents living in the German-speaking part with those living in the French- and Italian-speaking ones. Evidence of such a structural equivalence would indicate that the DMQ-R could be a sound and useful instrument to assess drinking motives in other European countries.

The second aim was to validate the relevance of distinguishing drinking motives by examining the relations with expected consequences, alcohol use, and problems attributed or not attributed to alcohol. Per definition, enhancement drinkers drink to enhance internal positive feelings, social drinkers drink to have fun in a social context, and coping drinkers drink to alleviate problems. Accordingly, to validate 
the relevance of drinking motives, it is hypothesized that enhancement motives are related to fun enhancement expectations, social motives to social improvement expectations, and coping motives to problem-alleviating expectations (cf. Catanzaro \& Laurent, 2004; Cooper, Frone, Russell, \& Mudar, 1995; Cronin, 1997; Read, Wood, Kahler, Maddock, \& Palfai, 2003).

Concerning alcohol use, the literature shows that the internally generated motives, enhancement and coping, are most strongly related to personality traits (enhancement with extraversion, coping with neuroticism, e.g., Cooper, Agocha, \& Sheldon, 2000; Loukas, Krull, Chassin, \& Carle, 2000; Stewart \& Devine, 2000; Stewart, Loughlin, \& Rhyno, 2001). Thus, drinkers with internal motives will be more consistent across drinking situations in how they drink than drinkers with mainly external motives, thereby resulting in higher levels of alcohol consumption (Cooper, 1994). Since conformity drinkers consume alcohol only when they are motivated by the presence of drinking adolescents, it is assumed that they have lower drinking levels than drinkers with other motives. In this study, we hypothesize that enhancement and coping motives are more strongly associated with the usual frequency and quantity of alcohol use as well as to heavy drinking than social motives. We further expect that conformity motives are negatively associated with these drinking indicators.

Since coping motives are defined by the decision to drink to cope with problems, we hypothesize that coping motives are related to problems in general (i.e. problems not attributed to alcohol such as poor academic performance, see e.g., Windle \& Windle, 1996) and to those attributed to alcohol, since deficits in problem-focused coping have never been adequately addressed (Cooper, Frone, Russell, \& Mudar, 1995; Kassel, Jackson, \& Unrod, 2000). Due to higher levels of alcohol use among enhancement drinkers, we expect enhancement motives to be 
related to alcohol-attributed problems, such as involvement in violent acts, and risky or regretted sexual intercourse.

\section{METHODS}

\section{Study design}

Data from Swiss participation in the "European School Survey Project on Alcohol and Drugs" (ESPAD: Hibell, Andersson, Bjarnason, Ahlström, Balakireva, Kokkevi, \& Morgan, 2004), which has been conducted every four years since 1995 in European countries, were used for the present analysis. In 2003, the Swiss Institute for the Prevention of Alcohol and Drug Problems (SIPA) and the Addiction Research Institute (ARI) for the first time conducted the survey for Switzerland together with 34 other European countries.

Present data were collected by means of a paper-pencil questionnaire which was sent to schools to be administered to each pupil in the relevant classes between the end of April and the end of June 2003. To avoid systematic dropouts, the exact date of the distribution of the questionnaires was not communicated to the school boards ahead of time. Teachers who administered the questionnaires in the classroom were advised only to respond to adolescents' queries about the procedure and to guarantee the independent completion of the questionnaire without interference from classmates. The time frame for filling out the questionnaires was one school lesson (about 45 minutes). According to the Helsinki Declaration (World Medical Association (WMA), 2002), the students could freely choose to participate and confidentiality was ensured at all stages of the study. 


\section{Measures}

An interdisciplinary research group from the participating countries developed the ESPAD questionnaire (Hibell, Andersson, Bjarnason, Ahlström, Balakireva, Kokkevi, \& Morgan, 2004) including expected personal consequences and usual frequency of alcohol use, 5+ drinking, and problems. Countries were free to include additional questions to the ESPAD core questionnaire. In Switzerland, the Drinking Motive Questionnaire (DMQ-R, Cooper, 1994) and a question concerning the usual quantity of alcohol use was included. The resulting questionnaire was translated under the supervision of SIPA into the three languages most frequently spoken in Switzerland: German, French, and Italian.

\section{Drinking Motives}

The Drinking Motive Questionnaire Revised (DMQ-R, Cooper, 1994) is a 20-item self-report measure of the relative frequency of drinking for four conceptually and empirically distinct reason dimensions (i.e. enhancement, social, conformity, and coping motives). Participants were instructed to consider all the times they have drunk alcohol and to indicate how many occasions they have drunk for each given motive. Each dimension consists of 5 items and is rated on a relative frequency scale ranging from "Never" (coded as 1) to "Almost always" (coded as 6). The exact wording of all items is given in Table 4-1.

\section{Expected personal consequences of alcohol use}

The items stem from the original ESPAD questionnaire. The question was "How likely is it that each of the following things would happen to you personally, if you drink alcohol?" with the items "Have a lot of fun", "Feel more friendly and 
outgoing", and "Forget my problems". The answer categories varied from "Very unlikely" (coded as 1) to "Very likely" (coded as 5).

\section{Alcohol use}

For the usual frequency of alcohol use, the questions asked the number of drinking occasions in the last 30 days with answer categories "0", "1-2", "3-5", "6-9", "1019", “20-39" and "40 or more". Midpoints of categories were used and 45 occasions for the upper category (40 times plus half range to mid-point of adjacent category).

Usual quantity of alcohol use assessed the total amount of standard drinks of any alcoholic beverage (beer, wine, spirits, and alcopops as examples) consumed at a typical occasion. The answer categories were "less than 1 drink", "1 drink", "2 drinks", "3 drinks", "4 drinks" and "5 or more drinks". Midpoints of categories were used and 0.5 drinks for the lower and 5.5 drinks for the upper category (5 times plus half range to mid-point of adjacent category).

$5+$ drinking. The question was "Think back once more over the last 30 days. How many times (if any) have you had five or more drinks in a row?" with the answer categories "None", “1”, “2”, “3-5", "6-9" and "10 or more times". Midpoints of categories were used and 11.25 occasions for the upper category (10 times plus half range to mid-point of adjacent category).

Drinking problems (alcohol-attributed and non-attributed in the ESPAD core questionnaire)

Poor academic performance (not alcohol-attributed). The students were asked "Which of the following best describes your average grade at the end of the last 
school term?". The answers were coded 1 for the best possible grade to 6 for the worst, thereby enabling an assessment of poor academic performance.

Violence and sexual intercourse (alcohol-attributed questions). The question was "Have you ever had any of the following problems due to your alcohol consumption?". The students could indicate if they ever experienced a "Scuffle or fight", "Damage to objects or clothing you owned", and "Victimized by robbery or theft". These three questions were added up to a violence summary score (value range: 0 to 3). The two questions "Engaged in sexual intercourse you regretted the next day" and "Engaged in sexual intercourse without a condom" were added to a risky sexual intercourse summary score (value range: 0 to 2 ).

\section{Sample and missing value imputation}

Random cluster sampling was used, based on a list of all classes of Swiss schools from $8^{\text {th }}$ to $10^{\text {th }}$ grade compiled by the Swiss Federal Statistical Office, where the classes served as the primary sampling unit. The overall response rate was $83.1 \%$. The sample can be considered as representative for all $8^{\text {th }}, 9^{\text {th }}$ and $10^{\text {th }}$ graders in public schools in the German-, French-, and Italian-speaking regions of Switzerland. Since drinking motives were exclusively assessed among drinkers, those who did not indicate at least one drinking occasion in the last 12 months $(\mathrm{n}=1415,19.7 \%)$ were excluded. When a student did not answer one or two questions on drinking motives, the missing values were replaced by means of Markov Chain Monte Carlo (MCMC) estimates (Congdon, 2003; Hox, 2002). MCMC is a simulation method in the Bayesian tradition. Starting with the prior distribution of observed values, random draws of missing values conditional on an item and individual parameters of observed values are taken. The individual missing value is imputed by randomly selecting a value from this conditional 
distribution for the given individual and his or her observed item response pattern. The procedure is iterative and uses Markov Chains until convergence of the posterior distribution. The advantage of such an imputation method is that the information of observed values for an individual is taken into account, i.e. imputation is conditional on individuals that have the same response pattern on all but the missing items. Thus, a maximum of information for an individual from other items of the drinking motive questionnaire was used. The program LISREL 8.51 (Jöreskog \& Sörbom, 2001) was applied for missing value imputation.

All students who failed to answer more than two questions on drinking motives $(\mathrm{n}=71 ; 1.2 \%)$ were excluded from the analysis. All students who failed to answer questions about expected personal consequences and alcohol use and related consequences were also excluded $(\mathrm{n}=90 ; 1.6 \%)$. The analyzed data consists of 5,61712 - to 18 -year old students $\left(40.7 \% 8^{\text {th }}\right.$ graders, $45.9 \% 9^{\text {th }}$ graders, and $13.4 \%$ $10^{\text {th }}$ graders) of which $49.0 \%$ were boys and $70.9 \%$ came from the Germanspeaking part (22.3\% French-speaking and 6.7\% Italian-speaking). The mean age of the total sample was 15.1 years $(\mathrm{SD}=.95)$. More information about the ESPAD survey in Switzerland can be found in Gmel, Rehm, Kuntsche, Wicki, and Grichting (2004) or in the relevant chapter of the international report (Hibell, Andersson, Bjarnason, Ahlström, Balakireva, Kokkevi, \& Morgan, 2004).

\section{Statistical Analysis}

A confirmatory factor analysis (Muthén \& Muthén, 2004; Ullman, 2001) was used to confirm the four-dimensional factor structure (enhancement, social, conformity, and coping motives, Cooper, 1994) in the present sample of 12- to 18-year old students in Switzerland. Errors were allowed to correlate so as to compensate for answer tendencies and sub-dimensional item relations that were previously 
detected by an exploratory factor analysis (EFA) using a randomly selected subsample. To evaluate the overall model fit, the comparative fit index (CFI), the nonnormed fit index (NNFI), the root mean square error of approximation (RMSEA), and the standardized root mean square residual (SRMR) were used. The CFI and the NNFI are related to the total variance accounted for in the model, and the aim is to arrive at values close to 1, e.g., higher than .90 (Bentler \& Bonett, 1980; Hu \& Bentler, 1999; Ullman, 2001). The RMSEA and the SRMR are related to the residual variance, and the aim is to arrive at values close to 0 , e.g., smaller than .08 (Browne \& Cudeck, 1993; Hu \& Bentler, 1999; Ullman, 2001). Internal consistencies of each drinking motive dimension were assessed by using Cronbach's Alpha.

To determine the equivalence of factor structure in different subgroups, the fourdimensional measurement model was first estimated freely between males and females, older (15 to 18 years) and younger students (12 to 14 years, median split), as well as between German-speaking and French/Italian-speaking students (since the latter are both minorities in Switzerland and have rather similar cultural backgrounds, these students were grouped together and compared with their German-speaking peers). Subsequently, the factor loadings were set as equal between the groups, and the CFI, the NNFI, the RMSEA and the SRMR of the fixed models were compared with the fit indices obtained in the freely estimated models.

To confirm the validity of the DMQ-R in the present sample of Swiss adolescents, three multivariate linear structural equation models (LSEM) were estimated. In the first model, the three personal expected consequences of alcohol use were the dependent variables. In the second model, the three alcohol use measures were the dependent variables and in the third model, the three drinking problems were the dependent variables. In all models, the latent variables of enhancement, social, 
conformity, and coping motives as well as gender and age were the independent variables.

EFA, CFA, and LSEM were performed using the software Mplus 3.11 (Muthén \& Muthén, 2004). This program has the advantage of directly adjusting the analysis for the sampling design effect of clusters (school classes).

\section{RESULTS}

\section{Replication of the four-dimensional factor structure}

The results of the confirmatory factor analysis revealed high and homogenous item loadings on their specified factors (Table 4-1). One exception is the item 'drinking to be sociable' which had a rather low item loading. The mean values of enhancement and social items were generally higher than those of conformity and coping. Lowest scores were found for conformity. Exceptions are 'drinking to be sociable' which had a rather low mean, and drinking to cheer up when in a bad mood, which had a rather high mean. Items with the highest scores concerned drinking to celebrate special occasions, because it is fun, and because it makes social gatherings more fun. The drinking motive factors are highly correlated. The highest correlations were found between enhancement and social motives, followed by enhancement and coping. The fit of the model - around .90- with CFI and NNFI values is satisfactory; the RMSEA value is below .08 and SRMR value is about .08 . Internal consistencies of the drinking motive dimensions varied from $\alpha=.82$ to $\alpha=.88$. 
Table 4-1: Results of a Confirmatory Factor Analysis (standardized item loadings), item means, inter-factor correlations, and internal consistencies

\begin{tabular}{|c|c|c|c|c|c|}
\hline How often do you drink ... & Enhan. & Social & Confor. & Coping & Means (SD) \\
\hline because you like the feeling? & .76 & & & & $2.82(1.55)$ \\
\hline because it's exciting? & .67 & & & & $2.61(1.49)$ \\
\hline to get high? & .67 & & & & $2.23(1.56)$ \\
\hline because it gives you a pleasant feeling? & .81 & & & & $2.62(1.52)$ \\
\hline because it's fun? & .76 & & & & $3.41(1.75)$ \\
\hline because it helps you enjoy a party? & & .78 & & & $2.72(1.58)$ \\
\hline to be sociable? & & .39 & & & $1.58(1.03)$ \\
\hline because it makes social gatherings more fun? & & .84 & & & $3.01(1.68)$ \\
\hline because it improves parties and celebrations? & & .82 & & & $2.88(1.70)$ \\
\hline to celebrate a special occasion with friends? & & .57 & & & $3.86(1.58)$ \\
\hline because your friends pressure you to drink? & & & .56 & & $1.35(0.82)$ \\
\hline $\begin{array}{l}\text { so that others won't kid you about not } \\
\text { drinking? }\end{array}$ & & & .67 & & $1.33(0.88)$ \\
\hline you drink to fit in with a group you like? & & & .74 & & $1.32(0.85)$ \\
\hline to be liked? & & & .78 & & $1.35(0.86)$ \\
\hline so you won't feel left out? & & & .82 & & $1.39(0.94)$ \\
\hline to forget your worries? & & & & .79 & $1.91(1.31)$ \\
\hline $\begin{array}{l}\text { because it helps you when you feel depressed } \\
\text { or nervous? }\end{array}$ & & & & .83 & $1.91(1.30)$ \\
\hline to cheer up when you're in a bad mood? & & & & .82 & $2.05(1.36)$ \\
\hline $\begin{array}{l}\text { because you feel more self-confident or sure } \\
\text { of yourself? }\end{array}$ & & & & .53 & $1.77(1.21)$ \\
\hline to forget about your problems? & & & & .83 & $1.91(1.40)$ \\
\hline Correlation with the factor "Social" & .92 & & & & \\
\hline Correlation with the factor "Conformity" & .29 & .37 & & & \\
\hline Correlation with the factor "Coping" & .59 & .54 & .45 & & \\
\hline Internal consistencies (Cronbach's $\alpha$ ) & .85 & .82 & .87 & .88 & \\
\hline
\end{tabular}

Note. All factor loadings are significant at the $0.1 \%$ error level; model fit: $\mathrm{CFI}=.920, \mathrm{NNFI}=.897$, RMSEA $=.062$, SRMR $=.079$

To assess if the four-dimensional model of drinking motives is also valid for different subgroups, the confirmatory factor analysis was estimated for gender and age groups and linguistic regions separately. Subsequently, the factor loadings in 
each model were fixed to be equal between the groups. In all three conditions, allowing the parameters to vary between the groups did not improve the model fit considerably (Table 4-2).

Table 4-2: Model fit according to gender, age, and linguistic region

\begin{tabular}{lcccc}
\hline & CFI & NNFI & RMSEA & SRMR \\
\hline Gender (boys vs. girls) & & & & \\
Unconstrained model & .915 & .896 & .063 & .081 \\
Fixed model & .915 & .901 & .061 & .082 \\
Age groups (12-14 vs. 15-18) & & & & \\
Unconstrained model & .917 & .898 & .062 & .081 \\
Fixed model & .918 & .904 & .060 & .081 \\
Linguistic region & & & & \\
(German vs. French/ltalian speaking) & & & & .083 \\
Unconstrained model & .909 & .888 & .066 & .084 \\
Fixed model & .907 & .892 & .065 & .084 \\
\hline
\end{tabular}

\section{Relations to expected consequences and alcohol use and related problems}

For validation purposes, a linear structural equation model was estimated with the four drinking motives as independent variables, and different expected personal consequences of alcohol use as dependent variables. The results reveal that enhancement and social motives were positively related to the opinion that fun is likely to be the result of drinking, whereas conformity and coping motives were negatively related to this opinion (Table 4-3). Social motives in particular were related to the opinion that feeling more friendly and outgoing is a likely consequence of drinking. Coping motives were positively related but conformity motives negatively related to the opinion that drinking alcohol is likely to help 
forget problems. The explained variance of expected personal consequences varied from 19 to 44 percent.

Table 4-3: Drinking motives as predictors of expected personal consequences, alcohol use, and drinking problems (standardized Betas of the estimated three multiple-multivariate linear structural equation models)

\begin{tabular}{|c|c|c|c|c|c|}
\hline & Enhan. & Social & Conform. & Coping & $\mathrm{R}^{2}$ \\
\hline \multicolumn{6}{|l|}{ Expected person. consequences ${ }^{1}$} \\
\hline Have a lot of fun & $.43^{* * *}$ & $.32^{* * *}$ & $-.12^{* * *}$ & $-.08^{* * *}$ & $43.9 \%$ \\
\hline Feel more friendly and outgoing & .01 & $.35^{\star * *}$ & $.07^{\star * *}$ & $.09^{* \star *}$ & $19.1 \%$ \\
\hline Forget my problems & -.02 & .06 & $-.12^{\star \star \star}$ & $.64^{\star \star *}$ & $37.4 \%$ \\
\hline \multicolumn{6}{|l|}{ Alcohol use ${ }^{2}$} \\
\hline Usual frequency & $.25^{\star \star \star}$ & .06 & $-.06^{\star \star}$ & $.12^{\star \star \star}$ & $16.4 \%$ \\
\hline Usual quantity & $.34^{\star \star \star}$ & $.25^{\star \star *}$ & $-.15^{\star \star \star}$ & $.06^{* *}$ & $37.5 \%$ \\
\hline 5+ drinking & $.37^{\star \star \star}$ & .00 & -.05 & $.15^{\star \star *}$ & $23.0 \%$ \\
\hline \multicolumn{6}{|l|}{ Drinking problems ${ }^{3}$} \\
\hline Academic $^{4}$ & -.05 & .09 & -.03 & $.19^{\star \star \star}$ & $5.0 \%$ \\
\hline Violence $^{5}$ & $.17^{\star \star}$ & -.02 & .00 & $.12^{\star \star \star}$ & $7.1 \%$ \\
\hline Sexual $^{5}$ & $.19^{\star *}$ & -.06 & -.01 & $.12^{\star \star \star}$ & $5.1 \%$ \\
\hline $\begin{array}{l}\text { Note. All models were adjusted } \\
{ }^{2} \mathrm{CFI}=.918, \text { RMSEA }=.056 ; \\
\text { attributed; } * \mathrm{p}<.05, * * \mathrm{p}<.01\end{array}$ & $\begin{array}{l}\text { gender } \\
\mathrm{I}=.916 \\
\mathrm{p}<.001\end{array}$ & $\begin{array}{l}\text { age; } \\
\mathrm{EA}=.\end{array}$ & $\begin{array}{l}\text { del fit: }{ }^{1}{ }^{1} \\
;{ }^{4} \text { non-alc }\end{array}$ & $\begin{array}{l}=.914, \\
\text { ol attrib }\end{array}$ & $\begin{array}{r}\mathrm{EA}=.05 \\
5 \text { alcoh }\end{array}$ \\
\hline
\end{tabular}

To determine associations with different alcohol use measures, a second linear structural equation model was estimated. Enhancement and coping motives were positively related to the usual frequency of alcohol intake. Enhancement and social motives were positively related and conformity motives negatively related to the usual quantity. The frequency of having five drinks or more on single occasions was significantly linked to enhancement and coping motives. The explained variance of alcohol use varied from 16 to 37 percent. 
A third model was estimated for problems. In this model, only coping motives were positively related to all three problems. Enhancement motives were positively associated with alcohol-related violence and sexual problems. For social and conformity motives, no relation to drinking problems was found. The explained variance was between 5 and 7 percent.

\section{DISCUSSION}

The first aim of the present study was to confirm the structure of the DMQ-R in a sample of adolescents outside North America. The results of the confirmatory factor analysis showed that the specified four-factor model had an acceptable model fit (e.g., Bentler \& Bonett, 1980; Browne \& Cudeck, 1993; Hu \& Bentler, 1999; Ullman, 2001). Additionally, the internal consistency of each drinking motive dimension was good-to-excellent, and comparable to those reported in the Cooper study (Cooper, 1994). Also in relation to how high items load on the motive dimensions, there is a remarkable similarity between the two studies. For example, in both studies the items "makes social gatherings more fun" and "improves parties and celebrations" had the highest loadings on the factor "social motives" and the item "be sociable" had the lowest. Furthermore, the inter-factor correlations were similar. Both in our study and in that by Cooper, the highest correlation was found between enhancement and social motives and the lowest between enhancement and conformity motives.

The present study also aimed to determine the structural equivalence in different sub-groups. When fixing the factor loadings between the sub-groups no substantial differences in the different fit indices emerged. Since the NNFI takes degrees of freedom into account, the gain of degrees of freedom when fixing the factor loadings between sub-groups resulted in a very slight increase in NNFI values. 
Taken together, the four-dimensional structure of the DMQ-R was found to be invariant not only among males and females and among older and younger adolescents but also among adolescents living in the German-speaking part and those living in the French- and Italian-speaking parts. Apart from confirming the results Cooper found among adolescents in the US more than 10 years ago, this also demonstrates the robustness of the DMQ-R and its usefulness for the assessment of drinking motives among other European adolescents from different cultural backgrounds.

Concerning the validation of drinking motives, the results confirm that enhancement but not conformity or coping motives are related to fun enhancement expectations. Social motives are strongly linked to social improvement expectations, while coping but not conformity motives are linked to problemalleviating expectations (cf. Catanzaro \& Laurent, 2004; Cooper, Frone, Russell, \& Mudar, 1995; Cronin, 1997; Read, Wood, Kahler, Maddock, \& Palfai, 2003). Equally consistent are the results that enhancement motives are related to all drinking measures used in the study, that conformity motives are negatively related to frequency and quantity of drinking, and that coping motives were particularly related to 5+ drinking (cf. Cooper, 1994; Cooper, Frone, Russell, \& Mudar, 1995; Cronin, 1997). These results are not only consistent with previous research but also confirm the pertinence of distinguishing these four drinking motive categories when predicting expected consequences and different alcohol use patterns.

In this study we distinguished between alcohol-attributed and non-attributed problems. The results confirm that coping motives were related to problems independent of whether they were assessed to be alcohol-related or not (Cooper, 1994; Cooper, Frone, Russell, \& Mudar, 1995; Cronin, 1997; Kassel, Jackson, \& Unrod, 2000; Windle \& Windle, 1996). It might be the case that adolescents who have initial problems (e.g., poor academic performance) and start drinking for cope 
motives end up with other problems, such as involvement in violent acts and risky or regretted sexual intercourse as consequence of their alcohol consumption. In this way, a vicious cycle can be established since the deficits in problem-focused coping have never been adequately addressed (Cooper, Frone, Russell, \& Mudar, 1995; Kassel, Jackson, \& Unrod, 2000). However, the cross-sectional data used in the present study did not allow for such a causal succession in time to be addressed. Additionally, the results show that enhancement motives were related to alcoholattributed problems but not to non-attributed ones. It seems that enhancement drinkers do not have problems in general, but have problems related to their high levels of alcohol consumption; this is confirmed by the strong association between enhancement motives and different measures of alcohol use.

Another interesting point concerns the differences between enhancement and social motives. Although both dimensions are highly correlated, they show different associations with most of the dependent variables investigated. This was because in multiple regression models all independent variables are mutually adjusted. In other words, the coefficients indicate the increase, for example, in alcohol use or in drinking problems, assuming all other variables are equal. Thus, accounting for a particular social motive level, enhancement motives were associated with 5+ drinking. On the other hand, when a particular enhancement motive level is factored in, no association with social motives can be shown. However, in bivariate analyses (results not presented), social motives were also related to drinking frequency, 5+ drinking and alcohol-attributed problems, because enhancement motives are "hidden" due to the high correlation of both. This demonstrates the importance of analyzing the different motive dimensions in a mutually-adjusted way to arrive at the specific effect of a particular motive dimension on alcohol use, drinking problems and other variables. 
To conclude, the present study provides evidence for the usefulness of the DMQ-R among adolescents in Switzerland and similar drinking cultures in Europe. The results not only confirmed the appropriateness four-dimensional factor structure in general but also among boys and girls, among 12- to 14-year olds and 15- to 18year olds, and among adolescents living in the German-speaking part and those living in the French- and Italian-speaking parts of Switzerland. Additionally, the results are highly consistent with those obtained in a sample of adolescents in the US more than 10 years ago (Cooper, 1994). This makes us optimistic that the DMQ-R, which is the most frequently applied multidimensional questionnaire to assess drinking motives among adolescents in North America (for a review, see Kuntsche, Knibbe, Gmel, \& Engels, 2005), is a valid and reliable instrument for assessing adolescent drinking motives in other European countries.

Besides research, the present results should also be relevant for prevention. The Motivational Model of Alcohol Use that was originally developed to understand the goals and incentives of alcoholics (Cox \& Klinger, 1990) was also shown to help improve the motivational structure of young people and to reduce their substance use via motivational counseling (Cox \& Klinger, 2002). Current developments in prevention and early intervention also consider the interplay between the personality and motivational factors which underlie risky alcohol use among adolescents (Stewart, Conrod, Marlatt, Comeau, Thush, \& Krank, 2005). Consequently, the present validation of the DMQ-R in a multi-linguistic sample should contribute to the identification of adolescents at risk from alcohol problems in Europe and to the design of appropriate preventive strategies. 


\section{Chapter 5}

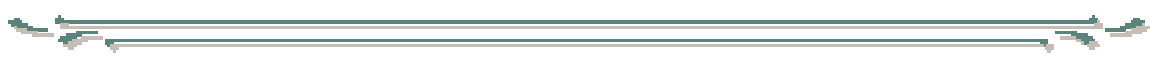

Drinking motives as mediators

of the link between alcohol expectancies and alcohol use ${ }^{4}$

${ }^{4}$ This chapter is based on Kuntsche, E., Knibbe, R., Engels, R., \& Gmel, G. (2007). Drinking motives as mediators of the link between alcohol expectancies and alcohol use among adolescents. Journal of Studies on Alcohol and Drugs, 68(1), 76-85. 


\section{SUMMARY OF CHAPTER 5}

The objective was to test whether the link between alcohol expectancies and alcohol use (drinking frequency, usual quantity, 5+ drinking) is mediated by drinking motives. Linear structural equation models were estimated based on a national representative sample of $5,6168^{\text {th }}, 9^{\text {th }}$ and $10^{\text {th }}$ graders in Switzerland (mean age 15.1 years, $\mathrm{SD}=1.0$ ). The results showed that in most cases a perfect mediation occurred, i.e. although all expectancy and motive dimensions were related to all alcohol use measures in multivariate models, the expectancy link in multiple multivariate models was reduced to zero, and the motive link remained basically the same. One exception was the tension reduction expectancy scale, which included aspects other than problem-coping that were still related to alcohol consumption, even when coping motives were controlled for. To conclude, given the consistency of the results across different alcohol expectancies, across drinking motives and across alcohol use measures, the present study provides evidence to support one basic assumption of the Motivational Model of Alcohol Use, namely that drinking motives are the most proximate factor which precedes alcohol use. In other words, drinking motives are the gateway through which more distal influences, such as alcohol expectancies, are mediated. 


\section{INTRODUCTION}

Among social-cognitive factors, alcohol expectancies and drinking motives are often described as two equivalent determinants of alcohol use and problematic drinking among young people (see Baer, 2002; and Ham \& Hope, 2003, for reviews). However, both are conceptually different: "Expectancies are people's beliefs about what will happen if they (or other people) drink alcohol, whereas motives are the value placed on the particular effects they want to achieve, which motivate them to drink" (Cox \& Klinger, 2004, p. 124). In other words, an individual who expects a desired effect from alcohol consumption will not necessarily drink to achieve the desired effect simply because the corresponding expectancy is endorsed (Cooper, 1994).

The Motivational Model of Alcohol Use assumes that each person (consciously or unconsciously) makes a decision about whether he or she will consume alcohol (Cox \& Klinger, 1988, 1990). According to the model, the decision to drink is embedded in historical factors (e.g., genetic disposition), personality characteristics (e.g., extraversion, sensation-seeking), socio-cultural factors (e.g., drinking styles), environmental factors (e.g., alcohol availability), situational and current factors (e.g., reinforcement from recent drinking), alcohol expectancies and lastly drinking motives. Thus, drinking motives are assumed to be the final path towards alcohol use, i.e. the gateway through which more distal influences, such as alcohol expectancies, are mediated (Catanzaro \& Laurent, 2004; Cooper, Frone, Russell, \& Mudar, 1995; Cronin, 1997). In terms of prevention, e.g., to identify adolescents who are prone to problematic drinking, it is important to confirm empirically whether drinking motives are more closely related to frequent and excessive drinking than alcohol expectancies (Kuntsche, Knibbe, Gmel, \& Engels, 2006a). The aim of the current study is to test whether the association between particular 
alcohol expectancies and different alcohol use measures in adolescence is mediated by particular drinking motives.

Numerous studies demonstrated that both alcohol expectancies and drinking motives are related to alcohol use (for reviews, see Baer, 2002; Ham \& Hope, 2003; Jones, Corbin, \& Fromme, 2001; Kuntsche, Knibbe, Gmel, \& Engels, 2005). However, few studies empirically addressed both the associations between the two concepts and their links to alcohol use (Catanzaro \& Laurent, 2004; Cooper, Frone, Russell, \& Mudar, 1995; Cronin, 1997; Nagoshi, Nakata, Sasano, \& Wood, 1994; Read, Wood, Kahler, Maddock, \& Palfai, 2003). For example, studies demonstrated that drinking motives could explain the variance in different alcohol use measures, such as drinking frequency and usual quantity and frequency of 5+ drinking and drunkenness, even when alcohol expectancies were controlled for (Nagoshi, Nakata, Sasano, \& Wood, 1994), but they could not prove the inverse (Cronin, 1997). In general, it appears that three dimensions are relevant for the comparison of expectancies and motives. First, enhancement expectancies (measured by such dimensions as "drinking alcohol makes me feel chilled out or friendly") were shown to be related to enhancement motives (e.g., "drinking to have fun or to get high"), which in turn were related to alcohol use (Cooper, Frone, Russell, \& Mudar, 1995; Read, Wood, Kahler, Maddock, \& Palfai, 2003). The same has been shown for tension reduction expectancies and coping motives (Cooper, Frone, Russell, \& Mudar, 1995). However, we could only identify one study that empirically tested whether tension reduction expectancies in particular were mediated by coping motives (Catanzaro \& Laurent, 2004). To our knowledge, no study has tested the mediation of drinking motives with regard to the link between general expectancies and alcohol use, or between specific expectancies and motives other than tension reduction and coping. For example, no study was found which investigated associations between social expectancies and social 
motives, even though the latter is the motive which is most frequently cited by young people (Kuntsche, Knibbe, Gmel, \& Engels, 2005).

Based on a national representative sample, the present study aims to confirm that coping motives mediate the link between tension reduction expectancies and different measures of alcohol use. It also aims to test if enhancement motives mediate the association of alcohol use and positive change expectancies with improved ability expectancies. A further objective is to investigate whether social motives mediate the link between changes in social behavior expectancies and alcohol use. In addition, the study examines whether drinking motives mediate the link between expectancies in general (both measured by total scores) and alcohol use. Statistically, mediation occurs when the following three criteria are satisfied (Baron \& Kenny, 1986): (a) variations in alcohol expectancies significantly account for variations in drinking motives; (b) variations in drinking motives significantly account for variations across alcohol use measures; and (c) any significant association between alcohol expectancies and alcohol use disappears (i.e. statistically non-significant) when drinking motives are included simultaneously in a model together with expectancies. Here, the clearest demonstration of mediation occurs when the link is reduced to zero or close to zero.

\section{METHODS}

\section{Study design}

The data base used for the analyses is part of the "European School Survey Project on Alcohol and Drugs" (ESPAD: Hibell, Andersson, Bjarnason, Ahlström, Balakireva, Kokkevi, \& Morgan, 2004), which has been conducted every four 
years since 1995 in about 30 European countries. In 2003, the Swiss Institute for Prevention of Alcohol and Drug Problems (SIPA) and the Addiction Research Institute (ARI) jointly conducted the survey for Switzerland for the first time.

The present data were collected by means of a paper-pencil questionnaire which was sent to schools to be administered to each pupil in the relevant classes between the end of April and the end of June 2003. To avoid systematic dropouts, the exact date of the distribution of the questionnaires was not communicated to the school boards ahead of time. Teachers who administered the questionnaires in the classroom were advised only to respond to adolescents' queries about the procedure and to guarantee the independent completion of the questionnaire without interference from classmates. The time frame for filling out the questionnaires was one school lesson (about 45 minutes). According to the Helsinki Declaration (World Medical Association (WMA), 2002), the students could freely choose to participate and confidentiality was ensured at all stages of the study.

\section{Measures}

An interdisciplinary research group from the participating countries developed the core ESPAD questionnaire (Hibell, Andersson, Bjarnason, Ahlström, Balakireva, Kokkevi, \& Morgan, 2004) and the Norwegian Short Form of the Alcohol Expectancy Questionnaire for Adolescents (Aas, 1993) and the adolescent version of the Drinking Motive Questionnaire (DMQ-R, Cooper, 1994) was added for the Swiss survey. Subsequently, the resulting questionnaire was translated into the three languages most frequently spoken in Switzerland: German, French, and Italian. Back-translations were conducted to guarantee the accuracy of the national language versions. 


\section{Alcohol Expectancies}

The Norwegian Short Form (Aas, 1993; Aas, Klepp, Laberg, \& Aarø, 1995; Aas, Leigh, Anderssen, \& Jakobsen, 1998) was derived from the original Alcohol Expectancy Questionnaire for Adolescents (AEQ-A: Christiansen, Goldman, \& Inn, 1982; Brown, Christiansen, \& Goldman, 1987), which is a widely used instrument in research on alcohol-related cognitions among adolescents (e.g., Aas, 1993; Leigh, 1989); it measures seven alcohol expectancy dimensions. For the comparison with coping, enhancement, and social drinking motives, the following four alcohol expectancy dimensions were used: tension reduction expectancies (4 items: "it is easier to open up and speak about one's feelings after drinking alcohol", "people become more friendly and less formal when they drink alcohol", "alcohol makes people relax" and "one doesn't have to think about mistakes one has made when one is inebriated"), global positive change expectancies (6 items, e.g., "most people become happy and feel good when they drink alcohol"; "people will come up with new and exciting things more easily when they drink alcohol"), improved cognitive and motor abilities expectancies ( 3 items, e.g., "it is easier for people to say what they are really thinking after becoming inebriated"; "one becomes better able to pursue a person one is attracted to when one is inebriated"), and changes in social behavior expectancies (5 items, e.g., "it is O.K. to drink alcohol because then one can join in with others who are having fun"; "parties become more fun when alcoholic beverages are consumed there"). The items in the AEQ-A are formulated in sentences describing the expected effects of drinking alcohol, with response categories which ranged from strongly disagree (coded as 1) to strongly agree (coded as 4). The internal consistencies of the four alcohol expectancy dimensions $\left(\alpha_{\text {tension reduction exp. }}=.56, \alpha_{\text {positive change exp. }}=.65, \alpha_{\text {improved abilities }}\right.$ exp. $=.42$, and $\left.\alpha_{\text {social behavior exp. }}=.60\right)$ are only slightly inferior to those reported by Aas (1993, Alphas between .48 and .72). To assess the impact of alcohol expectancies 
in general, the items on the different scales were added together to produce a summary score $(\alpha=.83)$. That the internal consistency of the subscales is rather low can be attributed to the fact that few items were used to measure one dimension (Aas, 1993).

\section{Tension Reduction Expectancies (revised)}

Since one aim of the study was to replicate the findings of Catanzaro and Laurent (2004), we compared the AEQ-A tension reduction measurement with the relevant items in the Alcohol Outcome Expectancy Questionnaire (AOEQ: Leigh \& Stacy, 1993), which was used in the aforementioned study. Since considerable differences in the formulation of the items in the two questionnaires were found, for more strict comparison with the Catanzaro and Laurent (2004) study, we replaced items of the AEQ-A (NSF) tension reduction battery to match the three tension reduction items of the AOEQ more closely ("I feel less stressed", "it takes away my negative moods and feelings", and "I am able to take my mind off my problems"). The revised AEQ-A (NSF) tension reduction battery comprises the three items: "one doesn't have to think about mistakes one has made when one is inebriated", "people can better control their moods when inebriated", and "annoyances and worries disappear when drinking alcohol". Although this revised tension reduction scale consists of only three items, it actually has a slightly higher internal consistency $(\alpha=.61)$ than the original scale $(\alpha=.56)$.

\section{Dinking Motives}

The Drinking Motive Questionnaire Revised (DMQ-R: Cooper, 1994) is the most widely used instrument to assess drinking motives among young people (for a 
review, see Kuntsche, Knibbe, Gmel, \& Engels, 2005). It measures the relative frequency of drinking for conceptually and empirically distinct dimensions. For the comparison with alcohol expectancies, three dimensions were chosen (conformity motives were excluded): coping motives (e.g., drinking to cheer up or to forget your worries), enhancement motives (e.g., drinking because it's fun or to get high), and social motives (e.g., drinking to celebrate a special occasion with friends or because it makes social gatherings more fun). Participants were instructed to consider every occasion when they drank alcohol and to indicate for each item on how many of these occasions they had consumed alcohol for the particular motive. Each scale consisting of five items had to be rated on a relative frequency scale, ranging from never (coded as 1) to almost always (coded as 6). The internal consistencies of the three scales are: $\alpha_{\text {coping }}=.88, \alpha_{\text {enhancement }}=.85$, and $\alpha_{\text {social }}=.82$. To assess the impact of drinking motives in general, the 15 items were added together to produce a summary score. Detailed information on the measurement properties of the DMQ-R among adolescents in Switzerland can be found in Kuntsche, Knibbe, Gmel, and Engels (2006a).

\section{Alcohol use}

For the frequency of alcohol use, the question concerned the number of drinking occasions in the last 30 days with answer categories "0", "1-2", "3-5", "6-9", "1019", "20-39" and "40 or more". Midpoints of categories were used, with 45 occasions used for the upper category (40 times plus half range to mid-point of adjacent category).

Usual quantity when drinking assessed the total number of standard drinks of any alcoholic beverage (beer, wine, spirits, and alcopops as examples) consumed at a typical occasion. The answer categories were "less than 1 drink", "1 drink", "2 
drinks", "3 drinks", "4 drinks" and "5 or more drinks". Midpoints of categories were used, with 0.5 drinks for the lower category and 5.5 drinks for the upper category (5 times plus half range to mid-point of the adjacent category).

$5+$ drinking. The question was "Think back once more over the last 30 days. How many times (if any) have you had five or more drinks in a row?" with the answer categories "none", "1", "2", "3-5", "6-9" and "10 or more times". Midpoints of categories were used and 11.25 occasions for the upper category (10 times plus half range to mid-point of the adjacent category).

\section{Sample and missing value imputation}

Random cluster sampling was used, based on a list of all $8^{\text {th }}$ to $10^{\text {th }}$ grade classes in public schools, where the classes served as the primary sampling unit. From the original sample of 473 classes, 65 (13.7\%) did not send back their questionnaires within the set time limit of three months (i.e. $86.3 \%$ response rate at class level). Only $4.1 \%$ of the students in the participating classes did not complete the survey because they were absent due to illness or truancy, or because they simply refused to take part (i.e. $95.9 \%$ response rate at the individual level). This resulted in an overall response rate of $83.1 \%$. The final sample of 7,193 adolescents can be considered as representative for all $8^{\text {th }}, 9^{\text {th }}$ and $10^{\text {th }}$ graders in public schools in the three main linguistic regions (German, French, and Italian) of Switzerland. Since drinking motives were exclusively assessed among drinkers, those who did not indicate at least one drinking occasion in the last 12 months $(n=1415,19.7 \%)$ were excluded.

When a student did not answer one or two questions on drinking motives or on alcohol expectancies $(n=637,11.0 \%)$, the missing values were replaced by means of Markov Chain Monte Carlo (MCMC) estimates (Congdon, 2003; Hox, 2002). 
The advantage of this imputation method is that the information of observed values for an individual is taken into account; imputation is conditional on the fact that individuals have the same response pattern on all but the missing items. Thus, a maximum of information for each individual item in the expectancy or motive questionnaire was used. The LISREL 8.51 program (Jöreskog \& Sörbom, 2001) was used for missing value imputations.

All students who failed to answer more than two questions on drinking motives or on alcohol expectancies $(\mathrm{n}=105 ; 1.8 \%)$ were excluded from the analysis. All students who failed to answer questions on alcohol use were also excluded ( $\mathrm{n}=57$; $1.0 \%$ ). The analyzed data consist of 5,616, 12-to 18-year old alcohol-using students $\left(40.6 \% 8^{\text {th }}\right.$ graders, $46.0 \% 9^{\text {th }}$ graders, and $13.4 \% 10^{\text {th }}$ graders $)$, of which $49.0 \%$ were boys; $70.9 \%$ of them came from German-speaking Switzerland $(29.1 \%$ from the French- or Italian-speaking part). The mean age of the total sample was 15.1 years $(\mathrm{SD}=1.0)$.

\section{Statistical Analysis}

As mentioned in the Introduction, the hypothesis that the link between alcohol expectancies and alcohol use is mediated through drinking motives is confirmed when three criteria are satisfied (Baron \& Kenny, 1986). Figure 5-1 provides a graphical representation of the different regression models estimated in three steps. First, to test the expected association of expectancies and motives, we performed regression models with the different alcohol expectancies (tension reduction (original AEQ-A (NSF) scale), tension reduction (revised scale), global positive change, improved cognitive and motor abilities, and changes in social behavior as independent variables; the relevant drinking motives (coping, enhancement, and social) were taken as dependent variables. Due to the strong links between alcohol 
expectancies and drinking motive scales (e.g., global positive change and changes in social behavior expectancies or enhancement and social motives, Aas, 1993; Kuntsche, Knibbe, Gmel, \& Engels, 2006a), we also estimated a regression model with the alcohol expectancy summary score as an independent variable and the drinking motive summary score as a dependent variable.

Second, to test the predicted association of expectancies, motives, and alcohol use, we performed different linear structural equation models separately, applying a particular alcohol expectancy (tension reduction, global positive change, improved cognitive and motor abilities, changes in social behavior, and the alcohol expectancy summary score), and a particular drinking motive (coping, enhancement, social, and the drinking motive summary score) as independent variables; all three alcohol use outcomes (frequency of drinking, usual quantity, and 5+ drinking) were taken as dependent variables in a series of latent structural equation models.

Third, the anticipated association between expectancies and alcohol use should become non-significant when drinking motives are included in a model together with expectancies; the strongest demonstration of mediation should occur when the link is reduced to zero or close to zero. To test this assumption, we performed multiple multivariate linear structural equation models with a given alcohol expectancy and a given drinking motive (e.g., tension reduction expectancies and coping drinking motives) used as independent variables, while all three alcohol use outcomes were dependent variables. 
Figure 5-1: Three steps to test the mediation of drinking motives in the link between alcohol expectancies and alcohol use
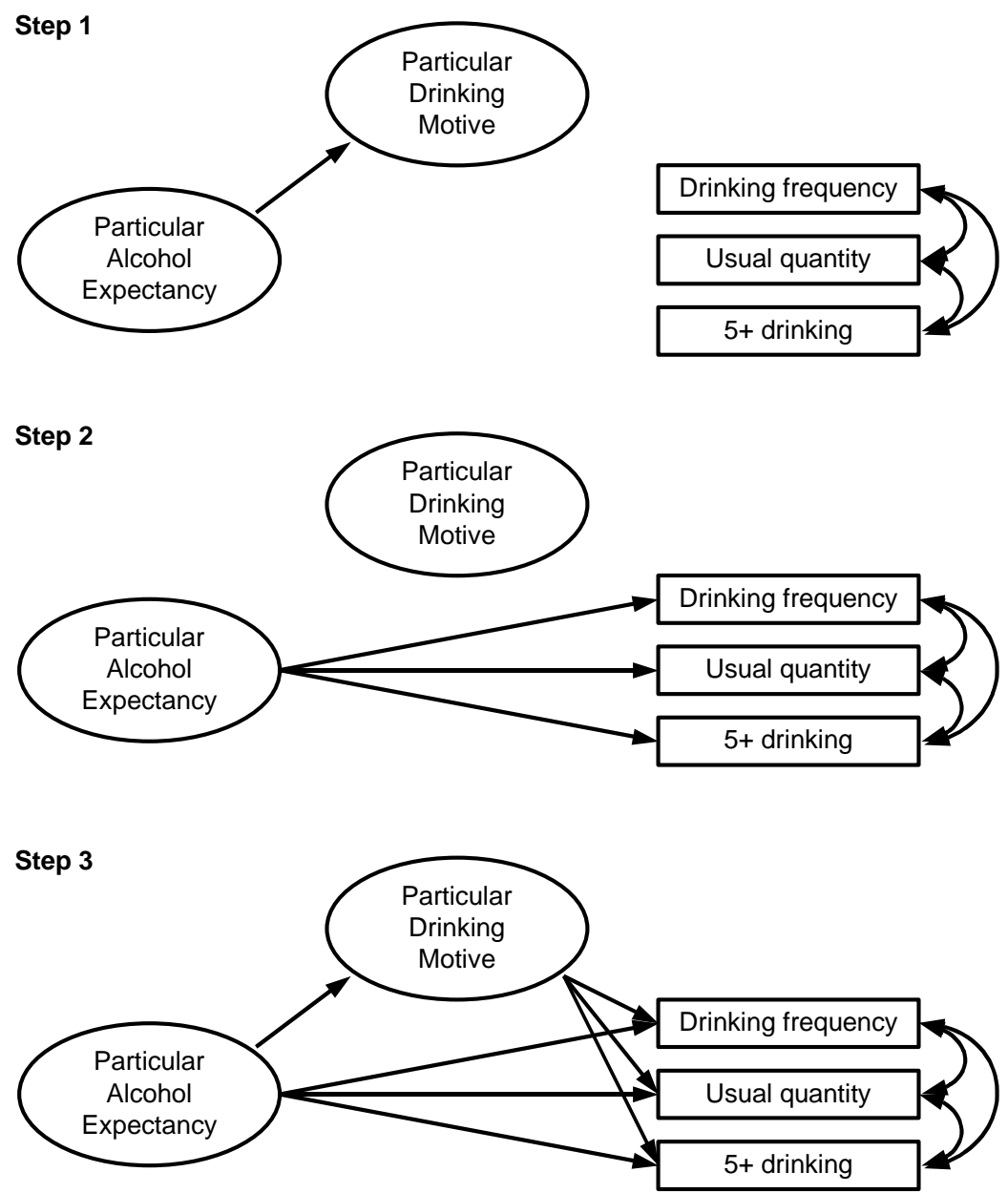

Note. The different alcohol expectancies (tension reduction [original AEQ-A (NSF) scale], tension reduction (revised scale), global positive change, improved cognitive and motor abilities, and changes in social behavior) as well as the different drinking motives (coping, enhancement, and social) were entered as latent variables. The alcohol expectancy summary score, the drinking motive summary score, and the dependent alcohol use measures were entered as observed variables 
Since alcohol expectancies, drinking motives and alcohol use differ according to gender and age (e.g., Kuntsche, Knibbe, Gmel, \& Engels, 2006b; Wiers, Hoogeveen, Sergeant, \& Gunning, 1997), all regression models adjusted for these variables. All models were estimated using the Mplus 3.11 software (Muthén \& Muthén, 2004). This program has the advantage of directly adjusting standard errors and significance levels for the sampling design effect of clusters (school classes). Reported effect sizes are standardized regression coefficients (Betas) and explained variance $\left(R^{2}\right)$. An $R^{2}$ of two percent and higher can be interpreted as substantial effect size (Cohen, 1988). This is equivalent to a Beta value of .14 in a bivariate regression.

\section{Results}

Descriptive results reveal that participants scored highest on tension reduction and on improved ability expectancies, followed by social behavior expectancies and global positive change expectancies (Table 5-1). With regard to drinking motives, participants scored highest on social motives, followed by enhancement and then coping motives. The strongest association was found between social behavior expectancies and social motives $(\beta=.85)$. The association between the original tension reduction expectancy scale and coping motives $(\beta=.43)$ was slightly weaker than that observed in the revised version $(\beta=.56)$. The explained variance of drinking motives varied from 19 to 68 percent. 
Table 5-1: Alcohol expectancies as predictors of drinking motives (standardized Betas, t-values in brackets, and explained variance) and means and standard deviations of the according summary scores

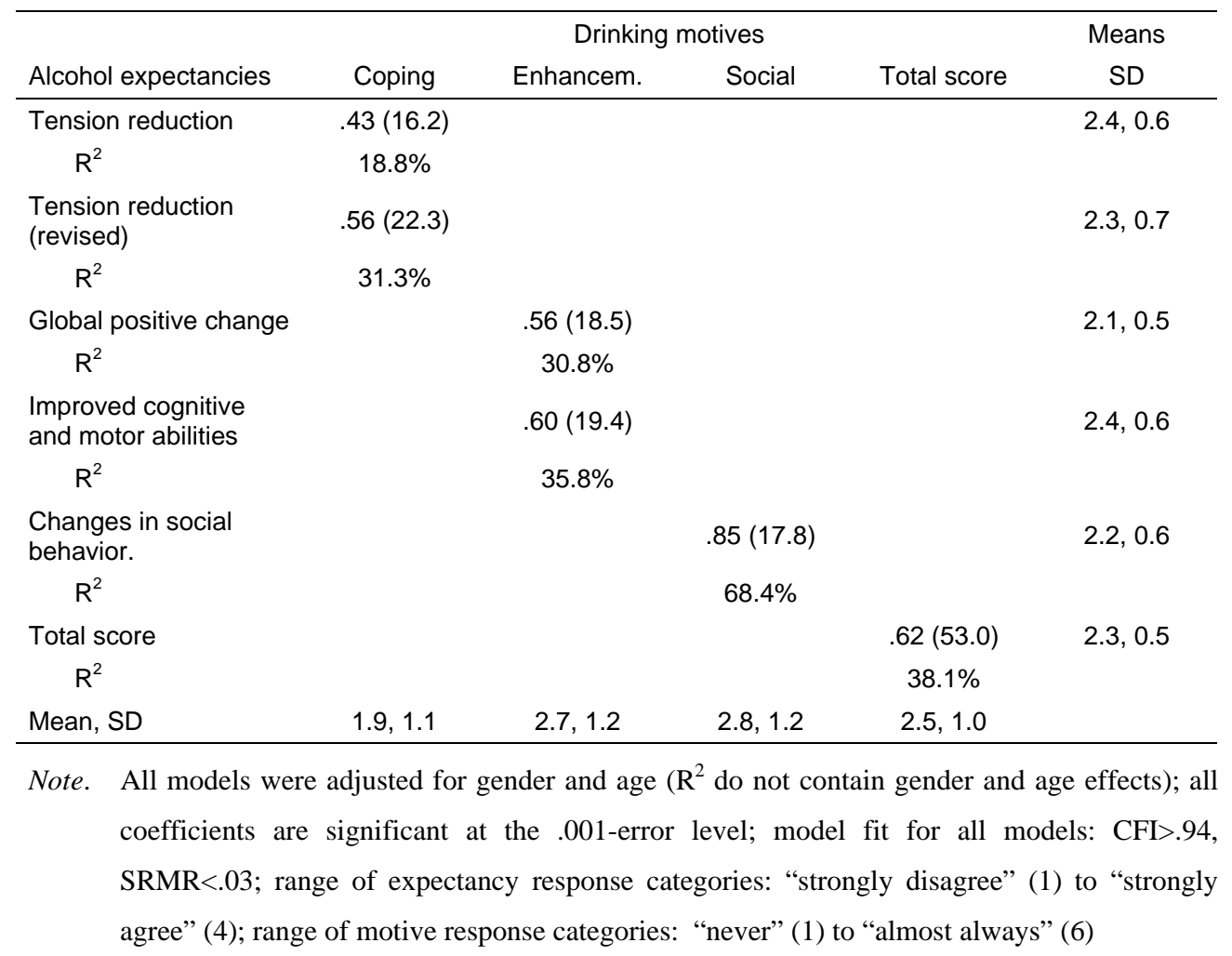

Table 5-2 provides descriptive information on the different alcohol use variables used in the study. On average, the 12- to 18-year old participants had five drinking occasions in the last 30 days, with roughly two drinks consumed on a typical occasion, and more than one heavy drinking occasion in the last 30 days. Table 5-2 also provides the results from the multivariate regression models, which show that, apart from the adjustment for gender and age, a given alcohol expectancy or a given drinking motive were the only predictors of alcohol use. In these models, the 
coping motive coefficients with regard to predicting alcohol use were only slightly higher than those of tension reduction expectancies; the coefficients of social motives with regard to predicting alcohol use were also only slightly higher than those of changes in social behavior expectancies. The explained variance in these models ranged from 3 to 20 percent for expectancies, and from 7 to 33 percent for motives. Concerning enhancement, the coefficients of enhancement motives and the explained variance were roughly twice as high as the coefficients of both positive change expectancies and improved ability expectancies.

In the multiple multivariate models, both a given alcohol expectancy and a given drinking motive were included to predict the three alcohol use measures (Table 53). Across outcomes, the inclusion of tension reduction expectancies (original AEQ-A (NSF) scale) in the multivariate coping motive models led to an increase in explained variance of a mere three percent. A different picture emerges with regard to the revised tension reduction expectancy scale, which matches AOEQ items more closely. The coping motive coefficients remained more or less the same as in the multivariate models, while the expectancy coefficients were reduced to zero and were thus no longer significant. 
Table 5-2: Alcohol expectancies and drinking motives as predictors of alcohol use in multivariate regression models (standardized Betas, $\mathrm{t}$-values in brackets, and explained variance) and means and standard deviations of the three alcohol use measures

\begin{tabular}{|c|c|c|c|}
\hline & Drinking frequency & Usual quantity & $5+$ drinking \\
\hline Means, SD & $5.00,7.53$ & $2.16,1.76$ & $1.29,2.31$ \\
\hline \multicolumn{4}{|l|}{ Tension reduction, coping } \\
\hline Tension reduction expectancies & $.23(9.5)$ & $.32(14.8)$ & $.24(10.1)$ \\
\hline $\mathrm{R}^{2}$ & $5.0 \%$ & $10.0 \%$ & $5.7 \%$ \\
\hline Tension reduction exp. (revised) ${ }^{1}$ & $.16(7.6)$ & $.20(10.5)$ & $.22(10.2)$ \\
\hline $\mathrm{R}^{2}$ & $2.6 \%$ & $3.8 \%$ & $4.7 \%$ \\
\hline Coping motives & $.27(13.7)$ & $.33(22.0)$ & $.34(17.2)$ \\
\hline $\mathrm{R}^{2}$ & $7.3 \%$ & $11.1 \%$ & $11.7 \%$ \\
\hline \multicolumn{4}{|l|}{ Improvement, enhancement } \\
\hline Global positive change expect. & $.21(9.1)$ & $.27(13.0)$ & $.28(11.1)$ \\
\hline $\mathrm{R}^{2}$ & $4.5 \%$ & $7.2 \%$ & $7.5 \%$ \\
\hline $\begin{array}{l}\text { Improved cognitive and motor } \\
\text { ability expectancies }\end{array}$ & $.22(10.6)$ & $.34(15.3)$ & $.28(12.1)$ \\
\hline $\mathrm{R}^{2}$ & $4.9 \%$ & $11.4 \%$ & $7.9 \%$ \\
\hline Enhancement motives & $.37(18.9)$ & $.59(42.1)$ & $.47(25.0)$ \\
\hline $\mathrm{R}^{2}$ & $13.5 \%$ & $33.2 \%$ & $21.5 \%$ \\
\hline \multicolumn{4}{|l|}{ Social } \\
\hline Changes in social behavior exp. & $.31(12.8)$ & $.46(17.0)$ & $.35(14.7)$ \\
\hline $\mathrm{R}^{2}$ & $8.9 \%$ & $20.1 \%$ & $11.4 \%$ \\
\hline Social motives & $.33(18.4)$ & $.54(36.1)$ & $.40(23.4)$ \\
\hline $\mathrm{R}^{2}$ & $10.7 \%$ & $28.0 \%$ & $15.7 \%$ \\
\hline \multicolumn{4}{|l|}{ General } \\
\hline Total expectancy score & $.25(13.6)$ & $.34(25.5)$ & $.29(17.0)$ \\
\hline $\mathrm{R}^{2}$ & $6.0 \%$ & $11.3 \%$ & $8.4 \%$ \\
\hline Total motive score & $.35(19.5)$ & $.52(42.0)$ & $.43^{\star * *}(25.7)$ \\
\hline $\mathrm{R}^{2}$ & $11.9 \%$ & $26.9 \%$ & $18.6 \%$ \\
\hline
\end{tabular}

Note. All models were adjusted for gender and age ( $\mathrm{R}^{2}$ do not contain gender and age effects); all coefficients are significant at the .001-error level; model fit for all motive models: CFI $>.92$, SRMR $<.04$ and for all expectancy models: CFI $>.88$, SRMR $<.04 ;{ }^{1} 3$ tension reduction items of the AEQ-A (NSF) to match AOEQ more closely, see Method section for details 
Table 5-3: Alcohol expectancies and drinking motives as simultaneous predictors of alcohol use in multiple-multivariate regression models (standardized Betas, t-values in brackets, and explained variance)

\begin{tabular}{|c|c|c|c|}
\hline & $\begin{array}{l}\text { Drinking } \\
\text { frequency }\end{array}$ & Usual quantity & $5+$ drinking \\
\hline \multicolumn{4}{|l|}{ Tension reduction - coping } \\
\hline Tension reduction expectancies & $.13^{\star \star \star}(6.0)$ & $.21^{* * *}(9.2)$ & $.11^{* * *}(5.3)$ \\
\hline Coping motives & $.21^{* \star *}(10.9)$ & $.25^{\star \star \star}(13.2)$ & $.30^{\star \star *}(14.4)$ \\
\hline $\mathrm{R}^{2}$ & $8.7 \%$ & $14.7 \%$ & $12.8 \%$ \\
\hline \multicolumn{4}{|l|}{ Tension reduction (revised) - coping } \\
\hline Tension reduction expect. (revised) & $-.03(-1.3)$ & $-.04(-1.9)$ & $.01(0.6)$ \\
\hline Coping motives & $.29^{\star \star \star}(12.5)$ & $.36^{\star * \star}(17.9)$ & $.34^{\star \star *}(14.2)$ \\
\hline $\mathrm{R}^{2}$ & $7.3 \%$ & $11.2 \%$ & $11.7 \%$ \\
\hline \multicolumn{4}{|l|}{ Positive change - enhancement } \\
\hline Global positive change expectancies & $.01(0.5)$ & $-.08^{* * *}(-3.7)$ & $.02(1.0)$ \\
\hline Enhancement motives & $.37^{\star \star \star}(16.0)$ & $.63^{\star \star \star}(31.8)$ & $.46^{\star \star \star}(20.2)$ \\
\hline $\mathrm{R}^{2}$ & $13.5 \%$ & $33.8 \%$ & $21.5 \%$ \\
\hline \multicolumn{4}{|l|}{ Improved abilities - enhancement } \\
\hline $\begin{array}{l}\text { Improved cognitive and motor } \\
\text { ability expectancies }\end{array}$ & $.01(0.3)$ & $-.00(-0.1)$ & $.02(0.6)$ \\
\hline Enhancement motives & $.37^{\star \star \star}(13.5)$ & $.59^{\star \star \star}(28.0)$ & $.46^{\star \star \star}(18.5)$ \\
\hline $\mathrm{R}^{2}$ & $13.5 \%$ & $33.4 \%$ & $21.5 \%$ \\
\hline \multicolumn{4}{|l|}{ Social } \\
\hline Changes in social behavior exp. & $.03(0.7)$ & $-.04(-1.1)$ & $-.03(-0.7)$ \\
\hline Social motives & $.31^{* \star *}(7.2)$ & $.57^{\star \star \star}(15.2)$ & $.42^{* \star *}(11.4)$ \\
\hline $\mathrm{R}^{2}$ & $10.7 \%$ & $28.0 \%$ & $15.6 \%$ \\
\hline \multicolumn{4}{|l|}{ General } \\
\hline Total expectancy score & $.05^{\star}(2.6)$ & $.03(1.6)$ & $.04^{*}(2.2)$ \\
\hline Total motive score & $.32^{\star \star *}(15.9)$ & $.51^{\star \star *}(32.5)$ & $.41^{* * *}(22.4)$ \\
\hline $\mathrm{R}^{2}$ & $12.0 \%$ & $26.9 \%$ & $18.7 \%$ \\
\hline
\end{tabular}

Note. All models were adjusted for gender and age $\left(\mathrm{R}^{2}\right.$ do not contain gender and age effects); model fit for all models: CFI $>.92$, SRMR $<.04 ; * \mathrm{p}<.05, * * * \mathrm{p}<.001$

In all other multiple multivariate models, the coefficients of drinking motives remained more or less the same, while the expectancy coefficients were 
fundamentally reduced and failed to be significant. This result strongly supports the mediation hypothesis. The explained variance of these multiple models was identical to that found in the multivariate motive-only models. One exception concerned positive change expectancies and the usual quantity of alcohol intake, where the expectancy coefficient actually became significantly negative. Another exception concerned the total expectancy score as a predictor of drinking frequency and 5+ drinking. However, the coefficients were significant at the 5\% error level only, and the explained variance of these multiple-multivariate models was only $0.1 \%$ higher than the multivariate motive-only model.

\section{DISCUSSION}

Based on a large national representative sample of adolescents in Switzerland, the aim of the present study was to determine if particular drinking motives mediate the link between particular alcohol expectancies and different alcohol use measures. Descriptive results reveal that the participants scored slightly higher on the expectancy "tension reduction" than on "changes in social behavior" expectancies. This difference was also reported by Aas (1993: $\mathrm{M}_{\text {tension reduction }}=2.6$, $M_{\text {social behavior }}=2.1$ ). For drinking motives, however, the opposite was found. Social motives were more frequently indicated than coping motives; this tallied with the findings of the Cooper study (1994: $\mathbf{M}_{\text {social motives }}=2.5, M_{\text {coping motives }}=1.6$ ). It appears that even if adolescents score high on tension reduction expectancies, they do not necessarily drink frequently to reduce tension or cope with emotional problems. Similarly, despite a relatively low level of "changes in social behavior" expectancies, it appears that adolescents drink relatively often for social motives. Together with the result that adolescents score generally higher on expectancies $(\mathrm{M}=2.3$ on a 1 - to 4-point scale) than on motives ( $\mathrm{M}=2.5$ on a 1 - to 6 -point scale), 
this illustrates the differences between the two concepts (e.g., Baer, 2002; Cox \& Klinger, 1988; Cronin, 1997), i.e. that adolescents do not necessarily drink to achieve a desired effect simply because the corresponding expectancy is endorsed (Cooper, 1994).

Results of the multiple multivariate regression models demonstrate that coping motives were more strongly related to the different alcohol use measures than the original AEQ-A (NSF) scale of tension reduction expectancies. The latter, however, remained significant but accounted only for $0.8 \%$ to $3.6 \%$ more variance than in the multivariate coping motive-only models. It appears that some aspects of tension reduction expectancies as assessed in the AEQ-A (Aas, 1993; Brown, Christiansen, \& Goldman, 1987) go beyond problem coping, such as alcohol making people less shy, less formal, more friendly and able to express their feelings more easily. Furthermore, adolescents who share such beliefs drink more than coping drinkers who do not.

The AEQ-A was, however, repeatedly criticized because its subscales comprise heterogeneous items which measure constructs other than the one of interest, thus raising doubts concerning the discriminant validity of the subscales (Leigh \& Stacy, 1993). This was also reflected in the modest internal consistency measures of the four AEQ-A subscales. The AOEQ (Leigh \& Stacy, 1993) used in the Catanzaro and Laurent study (2004) was developed in part to solve these problems. By collecting items on the AEQ-A (NSF) scale that more closely match those of the AOEQ (Leigh \& Stacy, 1993), perfect mediation was observed, i.e. the previously strong link between tension reduction expectancies and alcohol use $\left(\mathrm{R}^{2}\right.$ between 3 and 5 percent, cf. Cohen, 1988) was reduced to zero, when coping motives were controlled for. This is consistent with the Catanzaro and Laurent (2004) study. 
The results of all other measures of alcohol expectancies, drinking motives, and alcohol use demonstrate that drinking motives function as mediators in the link between alcohol expectancies and alcohol use. There were only two exceptions (total scores of expectancies and motives and drinking frequency and 5+ drinking), where expectancies remained a positive predictor in the multiple multivariate model. However, in both cases, the explained variance increased by only $0.1 \%$ compared with the multivariate motive-only model; significance at the 5\% error level appears to be due to the large sample size $(\mathrm{N}=5616)$. In nearly all other cases, the expectancy coefficient was reduced to zero or close to zero, thus demonstrating the strongest form of mediation (Baron \& Kenny, 1986) and failed to be significant despite the large sample size. For positive change expectancies, enhancement motives and usual quantity of alcohol intake, the drinking motive coefficient was even higher in the multiple multivariate model which included expectancies than the coefficient in the multivariate motive-only model. This was due to the negative value of the expectancy coefficient, which appears to function as a suppressor in the multiple regressions. This means that positive change expectancies actually consolidate the importance of enhancement motives by virtue of suppressing irrelevant variance (Cohen \& Cohen, 1983; Tabachnick \& Fidell, 2001).

Given the consistency of the results across different alcohol expectancies, drinking motives and alcohol measures, the present study provides further evidence to support the Motivational Model of alcohol use (Cox \& Klinger, 1988, 1990), which assumes that drinking motives are the most proximal predictors alcohol use (cf. Carpenter \& Hasin, 1998b; Cooper, 1994), i.e. the gateway through which more distal influences, such as alcohol expectancies, are mediated. Despite the wealth of literature demonstrating the association between alcohol expectancies and drinking (see e.g., Baer, 2002; Ham \& Hope, 2003; Jones, Corbin, \& Fromme, 2001, for reviews), it appears that simply having a particular expectancy does not necessarily 
mean that adolescents automatically decide to drink to achieve the desired effect (Cooper, 1994).

In terms of the identification of excessive or problematic adolescent drinkers who should be targeted by prevention approaches, alcohol expectancies appear to be less important than drinking motives. In other words, drinking motives are particularly relevant for those adolescents who have already started drinking, i.e. who decided to drink, and thus drinking motives are indicative of such a decision. Among adolescents who have yet to decide to drink, alcohol expectancies appear to be particularly important for prevention. Alcohol expectancies are defined as beliefs about the positive or negative behavioral, emotional and cognitive effects of alcohol intake (see Aas, 1993; Baer, 2002, for reviews) and therefore the basis upon which the decision to engage in alcohol use is taken (Cox \& Klinger, 1988). Consequently, alcohol expectancies may help to identify the motives behind adolescent alcohol consumption (see also Catanzaro \& Laurent, 2004; Cooper, Frone, Russell, \& Mudar, 1995; Read, Wood, Kahler, Maddock, \& Palfai, 2003). Overall, alcohol expectancies appear to offer promising potential for primary prevention, e.g., to reduce positive alcohol expectancies that adolescents might have and to reinforce their negative expectancies before engaging in alcohol use for the first time. Drinking motives appear to offer promising potential for secondary prevention, e.g., to reduce enhancement and coping motives which have been shown to be related to problematic alcohol use and alcohol-related problems (see Kuntsche, Knibbe, Gmel, \& Engels, 2005, for a review). Certain authors argue that the identification and collection of information on the specific needs that alcohol serves for particular individuals via drinking motives could lead to the design of more effective preventive strategies (Cooper, 1994; Miller, 1996). Current developments in prevention and early intervention, for example, include the 
interplay between personality and motivational factors which underlie risky alcohol use by adolescents (Stewart, Conrod, Marlatt, Comeau, Thush, \& Krank, 2005).

To our knowledge, this was the first study based on a large national representative sample of adolescents that demonstrates the mediation role of drinking motives in the link between alcohol expectancies and alcohol use across different expectancy and motive dimensions, and for alcohol expectancies and drinking motives in general. Although the present measurement of alcohol expectancies and drinking motives among Swiss $8^{\text {th }}$ to $10^{\text {th }}$ graders was consistent with studies from other cultures and age groups (cf. Aas, 1993; Aas, Klepp, Laberg, \& Aarø, 1995; Cooper, 1994; Kuntsche, Knibbe, Gmel, \& Engels, 2006a), research from other countries is needed to confirm, at a more general level, the mediation of drinking motives in the link between alcohol expectancies and alcohol use. The AEQ-A has been repeatedly criticized and we partly counteracted this by collecting items that more closely match those of the AOEQ tension reduction scale (Leigh \& Stacy, 1993). However, this was not possible for the other expectancy dimensions. Therefore, mediation should be confirmed in future studies by using more recent expectancy scales than the AEQ-A. Using longitudinal designs, it would be particularly important to determine if alcohol expectancies are precursors of drinking motives over time. Owing to the cross-sectional nature of the data, this was not possible in the present study and thus no causal conclusion can be drawn. In future research on early adolescence and even before drinking habits are established (Delgrande Jordan, Kuntsche, \& Sidler, 2005), it would be important to confirm empirically the assumed causal chain of particular antecedents, such as historical, personality, socio-cultural, and environmental factors that lead to alcohol expectancies, which in turn lead to drinking motives, which in turn lead to alcohol use and excessive drinking, and ultimately to alcohol-related problems. 


\section{Chapter 6}

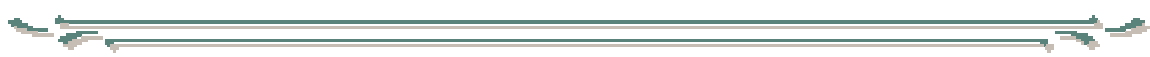

"I drink spirits to get drunk and block out my problems..."

Beverage preference, drinking motives, and alcohol use in adolescence $^{5}$

\footnotetext{
${ }^{5}$ This chapter is based on Kuntsche, E., Knibbe, R., Gmel, G., \& Engels, R. (2006). "I drink spirits to get drunk and block out my problems..." Beverage preference, drinking motives, and alcohol use in adolescence. Alcohol and Alcoholism, 41(5), 566-573.
} 


\section{SUMMARY OF CHAPTER 6}

The aim of this chapter was to investigate among adolescents whether a) drinking motives are related to beverage preference; b) beverage preference is related to alcohol use (drinking levels and risky drinking occasions); c) the association between beverage preference and alcohol use is moderated or mediated by drinking motives. Data from a national representative sample of $5,3798^{\text {th }}$ to $10^{\text {th }}$ graders in Switzerland (mean age 15.1, SD=.95) were analyzed using multiple regression analyses. Beverage preference was based on the proportion of a specific beverage in the total amount of drinks consumed at the last drinking occasion. Drinking motives were assessed by the Drinking Motive Questionnaire Revised (DMQ-R). A significant positive association was found between enhancement motives and a preference for beer and spirits; the association was negative with regard to a preference for wine and alcopops. Conformity motives were positively related to a wine preference but negatively to a beer preference. Only a preference for beer and spirits was significantly associated with alcohol use in models that exclude motives. However, the association between beer preference and adolescent alcohol use was mediated by drinking motives. A preference for alcopops and spirits was moderated by motives: social drinkers who preferred alcopops drank less than those who did not prefer alcopops. Coping drinkers who preferred spirits drank more than those who preferred other alcoholic drinks. Taken together, drinking motives are potential explanatory factors for the association between beverage preference and alcohol use. Prevention approaches should target coping motives, particularly among adolescents who show a preference for spirits. 


\section{INTRODUCTION}

It is well documented in the literature that a preference for particular alcoholic beverages is associated with different drinking patterns. Drinkers of beer and spirits, for example, tend to have a higher alcohol intake and have more alcoholrelated problems than people who mainly drink other beverages (e.g., Gmel \& Maag, 1999; Grønbæk, Jensen, Johansen, Sørensen, \& Becker, 2004; Jensen, Andersen, Sørensen, Becker, Thorsen, \& Grønbæk, 2002; Klein \& Pittman, 1990). Some individuals may prefer spirits because the consumption of spirits raises alcohol concentration in the blood more rapidly than beverages such as beer, wine, or alcopops (Smart \& Walsh, 1995, for a review). Consequently, the drinker will experience the effects of the alcohol more rapidly. Apart from spirits, the consumption of beer was also found to be associated with risky drinking (e.g., binge drinking or heavy episodic drinking) among adolescents and young adults (Clapp \& Shillington, 2001; Kuntsche, 2001b). Beer is rather cheap due to low taxes and advanced brewing technologies, which enable it to be produced in large quantities (World Health Organization (WHO), 1999, 2001). Therefore, it is assumed that beer is the beverage of choice for adolescents who like to get drunk but are on a restricted budget (Edwards, Anderson, Babor, Casswell, Ferrence, Giesbrecht, Godfrey et al., 1994).

In contrast to mainly spirits' or beer drinkers, wine drinkers were described as better educated and relatively free of symptoms or risks of psychophysical illness; they also drink temperately (e.g., Grønbæk, Mortensen, Mygind, Andersen, Becker, Gluud, \& Sørensen, 1999; Klatsky, Armstrong, \& Kipp, 1990). Wine drinkers have a far lower risk of becoming heavy and excessive drinkers than beer or spirits' drinkers have (Grønbæk, Jensen, Johansen, Sørensen, \& Becker, 2004; Jensen, Andersen, Sørensen, Becker, Thorsen, \& Grønbæk, 2002). Furthermore, 
among 13- to 18-year olds from different countries, wine, if consumed exclusively, appears to be the beverage of moderation (Smart \& Walsh, 1995; Kuntsche, 2001b). Wine is considered a social habit (Alvarez \& del Rio, 1994) and usually consumed in normative settings, for example, in the company of others and to accompany meals (Smart, 1996; Smart \& Walsh, 1999).

Alcopops, defined as premixed drinks that are carbonated and contain high levels of sweeteners, coloring and flavoring (e.g., McKeganey, 1998; McKeganey, Forsyth, Barnard, \& Hay, 1996), were introduced in the late 1990s and rapidly penetrated the youth market in most western societies. Youth surveys indicate that alcopops have a positive and attractive image among adolescents (Leeming, Hanley, \& Lyttle, 2002; Hughes, MacKintosh, Hastings, Wheeler, Watson, \& Inglis, 1997) and have become one of the most popular alcoholic beverages among this age group in many European countries (see Wicki, Gmel, Kuntsche, Rehm, \& Grichting, 2006, for a review). Research found that alcopops, like all alcoholic beverages, add to drinking levels and alcohol problems, and seem to be consumed in addition to, rather than as a substitute for conventional alcoholic beverages (Wicki, Gmel, Kuntsche, Rehm, \& Grichting, 2006). Although the evidence is scarce, it appears that alcopops occupy the middle ground between wine which is usually not consumed excessively at single occasions and beer and spirits which are often consumed to get drunk.

However, not much is known about the motivation behind adolescents' preferences for a particular alcoholic beverage and whether the motivation modifies the relation between beverage preference and drinking patterns. Drinking motives are defined as the final decision to consume alcohol, i.e. the gateway through which more distal influences, such as personality factors or alcohol expectancies, are mediated (e.g., Catanzaro \& Laurent, 2004; Kuntsche, Knibbe, Gmel, \& Engels, 2007). The concept of drinking motives further assumes that people drink in order to attain 
certain valued outcomes (Carpenter \& Hasin, 1998a; Cooper, 1994; Cox \& Klinger, 1988).

The present study investigates whether a particular beverage is better suited to achieve valued outcomes, e.g., drinking to celebrate special occasions with friends or to become intoxicated, and how this is related to alcohol use. More precisely, the present study tests whether the association between beverage preference (beer, spirits, wine, and alcopops) and adolescent alcohol use (drinking levels and risky drinking occasions) is mediated or moderated by drinking motives (enhancement, social, conformity, and coping). Mediation implies that drinking motives are the explanatory mechanism underlying the association between the beverage of choice and alcohol use. Hence, a significant association between beverage preference and alcohol use variables is reduced or disappears after the inclusion of motives in the model (cf. Baron \& Kenny, 1986). Moderation would imply that particularly high drinking levels and risky drinking occasions are expected among those who preferred a certain beverage and who score high on a given drinking motive.

To our knowledge, the impact of drinking motives on the association between beverage preference and alcohol use has not yet been addressed directly. There is, however, some research that indirectly suggests such a link. We expect beer and spirits' consumption to be related to higher drinking levels and a high frequency of risky drinking occasions. Additionally, we expect that adolescents who like the effects of alcohol and drink to get drunk (enhancement drinkers) are most likely to choose beer or spirits to achieve the desired effects. Moreover, sensation-seeking, impulsive, and aggressive adolescents were found to drink for enhancement motives (Comeau, Stewart, \& Loba, 2001; Cooper, Frone, Russell, \& Mudar, 1995) and to prefer beer and spirits when they drink (Snortum, Kremer, \& Berger, 1987; Smart \& Walsh, 1995; Smart, 1996). 
Since wine drinkers were found to drink moderately, we expect a wine preference to be negatively related to drinking levels and to the frequency of risky drinking occasions. Since drinking for conformity motives was also found to be related to moderate drinking habits (e.g., Cooper, 1994; Kuntsche, Knibbe, Gmel, \& Engels, 2006a), we expect adolescents who prefer wine to drink for conformity motives (Cooper, 1994).

Due to the positive and attractive image of alcopops among adolescents (Leeming, Hanley, \& Lyttle, 2002; Hughes, MacKintosh, Hastings, Wheeler, Watson, \& Inglis, 1997), we expect that adolescents consume alcopops for social motives, for example, at social gatherings, celebrations, or parties in order to demonstrate that they subscribe to the positive and attractive image this alcoholic beverage has among their peers.

\section{METHODS}

\section{Study design}

Data from Swiss participation in the "European School Survey Project on Alcohol and Drugs" (ESPAD: Hibell, Andersson, Ahlström, Balakireva, Bjarnason, Kokkevi, \& Morgan, 2004), which has been conducted every four years since 1995 in European countries, were used for the present analysis. In 2003, the Swiss Institute for Prevention of Alcohol and Drug Problems (SIPA) and the Addiction Research Institute (ARI) for the first time conducted the survey for Switzerland together with 34 other European countries.

Present data were collected by means of a paper-pencil questionnaire which was administered in class between the end of April and the end of June 2003. To avoid 
systematic dropouts, the exact date of the distribution of the questionnaires was not communicated to the school boards ahead of time. Teachers who administered the questionnaires in the classroom were advised only to respond to adolescents' queries about the procedure and to guarantee the independent completion of the questionnaire without interference from classmates. The time frame for filling out the questionnaires was one school lesson (about 45 minutes). According to the Helsinki Declaration (World Medical Association, 2002) the students could freely choose to participate and confidentiality was ensured at all stages of the study. More information about the ESPAD survey in Switzerland can be found in Gmel, Rehm, Kuntsche, Wicki, and Grichting (2004) or in the according chapter of the international report (Hibell, Andersson, Bjarnason, Ahlström, Balakireva, Kokkevi, \& Morgan, 2004).

\section{Measures}

Beverage preference defined as the proportion of a specific beverage on the total amount of drinks consumed at the last drinking occasion.

The adolescents were asked, "The last time you had an alcoholic drink, did you drink any alcopops? If so, how much?". The possible answers were "I never drink alcopops", "I did not drink alcopops on my last drinking occasion", "Less than 2 regular bottles or cans (<55 cl)", "2-4 regular bottles or cans $(55-110 \mathrm{cl})$ ", "5-8 regular bottles or cans $(137.5-220 \mathrm{cl})$ " and "9 or more regular bottles or cans (>247.5 cl)". Similarly structured questions and answers were used for the quantity of "beer", "wine", "cider", and "spirits" consumed during the previous drinking occasion. All amounts were converted into drinks of $15 \mathrm{~g}$ of pure ethanol, thus reflecting the average drink size of ESPAD measures. Finally, the beveragespecific proportion sum for each beverage was obtained by dividing the amount of 
each single beverage by the total amount of drinks consumed at the last occasion (sum of consumed quantities of alcopops, beer, cider, wine and spirits). Detailed information about these questions can be found in Wicki, Gmel, Kuntsche, Rehm, and Grichting (2006), as well as in Hibell, Andersson, Bjarnason, Ahlström, Balakireva, Kokkevi, and Morgan (2004).

\section{Drinking motives.}

The Drinking Motive Questionnaire Revised (DMQ-R: Cooper, 1994) is a 20-item self-report measure that includes the four conceptually and empirically distinct dimensions of enhancement motives, e.g., drinking because it is fun or to get high; social motives, e.g., drinking to celebrate a special occasion with friends or because it makes social gatherings more fun; conformity motives, e.g., drinking to fit in with a group or because your friends pressure you to drink; and finally coping motives, e.g., drinking to cheer up or to forget your worries. Participants were instructed to consider all the times they have drunk alcohol and to indicate how many of these occasions they have drunk for the particular motive. Each scale consisting of 5 items had to be rated on a relative frequency scale ranging from "Never" (coded as 1) to "Almost always" (coded as 6). The exact wording of all items is given in Cooper (1994) as well as in Kuntsche, Knibbe, Gmel, \& Engels (2006a). Because of high internal consistencies (internal consistencies: $\alpha_{\text {enhancement }}=.85, \alpha_{\text {social }}=.82, \alpha_{\text {conformity }}=.87, \alpha_{\text {coping }}=.88$, note that values above .7 are considered as satisfactory, e.g., Bland \& Altman, 1997; Crichton, 1999; George \& Mallery, 2003), the items of each motive dimension were used to create to summary scales, as originally suggested by Cooper (1994). 
Alcohol use.

Quantity-Frequency index $(Q F)$. For the frequency of alcohol use, the question dealt with the number of drinking occasions in the last 30 days with answer categories "0", “1-2", “3-5", “6-9”, "10-19”, "20-39” and "40 or more”. Midpoints of categories were used and 45 occasions for the highest category (highest category plus half range to mid-point of adjacent category (Wicki, Gmel, Kuntsche, Rehm, \& Grichting, 2006): 40-30=10/2=5). The usual quantity question assessed the total amount of standard drinks of any alcoholic beverage (beer, wine, spirits, and alcopops as examples) consumed on a typical occasion. The answer categories were "less than 1 drink", "1 drink", "2 drinks", "3 drinks", "4 drinks" and "5 or more drinks". Midpoints of categories were used, with 0.5 drinks for the lowest and 5.25 drinks for the highest quantity category (highest category plus half range to mid-point of adjacent category: 5-4.5=0.5/2 $=0.25$ ). The Quantity-Frequency index was obtained by multiplying these two measures.

Risky Single Occasion Drinking (RSOD). The question was "Think back once more over the last 30 days. How many times (if any) have you had five or more drinks in a row?" with the answer categories "none", "1", "2", "3-5", "6-9" and "10 or more times". Midpoints of categories were used and 11.25 occasions for the upper category (highest category plus half range to mid-point of adjacent category: 10$7.5=2.5 / 2=1.25)$.

\section{Sample and missing value imputation}

Random cluster sampling was used, where classes served as the primary sampling unit. An overall response rate of $83.1 \%$ could be achieved. The sample can be considered as representative for all $8^{\text {th }}, 9^{\text {th }}$ and $10^{\text {th }}$ graders in public schools in the German, French, and Italian speaking regions of Switzerland. Since drinking 
motives were exclusively assessed among drinkers, those who did not indicate at least one drinking occasion in the last 12 months $(n=1415,19.7 \%)$ were excluded. Students who failed to answer three or more questions on drinking motives $(n=71$; $1.2 \%$ ) were equally excluded. When a student did not answer one or two items of the drinking motive scales, the missing values were replaced by Markov Chain Monte Carlo (MCMC) estimates (Congdon, 2003; Hox, 2002). The advantage of this imputation method is that it uses the maximum available information for an individual from other items of the same concept (cf. Kuntsche, Knibbe, Gmel, \& Engels, 2006a). The LISREL 8.51 program (Jöreskog \& Sörbom, 2001) was used to impute missing values.

Students who failed to answer questions about alcohol use $(\mathrm{n}=58 ; 1.0 \%)$ were excluded from the analysis. Since the ESPAD questionnaire assessed beverage preference solely on the last drinking occasion, all students who did not indicate drinking on the last drinking occasion were equally excluded $(n=270 ; 4.8 \%)$. However, no differences in terms of $\operatorname{sex}\left(\chi^{2}=3.0, \mathrm{df}=1, \mathrm{p}>.05\right)$ and age $(\mathrm{t}=1.3$; $\mathrm{df}=5705 ; \mathrm{p}>.05)$ were found between the excluded adolescents and the remaining participants. The final sample consists of 5,379 12- to 18-year old students of which $49.6 \%$ were boys; $71.2 \%$ of the total sample came from the Germanspeaking part (22.8\% French and $7.0 \%$ Italian speaking). The total mean age was 15.1 years $(\mathrm{SD}=.95)$.

\section{Statistical Analysis}

The present study tests whether the association between beverage preference (beer, spirits, wine, and alcopops) and adolescents' alcohol use (drinking levels and risky drinking occasions) is mediated or moderated by drinking motives (enhancement, social, conformity, and coping). Figure 6-1 provides an illustration of moderation 
and mediation effects in the link between beverage preference, drinking motives and adolescent alcohol use. First, for mediation, beverage preference was regressed on drinking motives (Step 1 in Figure 6-1). Second, in a first hierarchical multiple regression model, only beverage preferences were included as independent variables (Step 2 in Figure 6-1) to determine Quantity-Frequency and frequency of risky drinking occasions. In the second model, drinking motives were added (Step 3 in Figure 6-1). If a significant association between beverage preference and alcohol use occurs in the first model but was reduced or disappeared after inclusion of motives in the second model, this would provide evidence of mediation (cf. Baron and Kenny, 1986).

To test moderation, interactions between beverage preference and drinking motives were included in the third model of the hierarchical regression, and a backward stepwise selection strategy on all possible interactions was applied to identify significant interactions. The interaction terms were obtained by multiplying each drinking motive with each beverage preference as standard procedure for including interactions in multiple regressions (Jaccard, Turrisi, \& Wan, 1990). If a significant interaction occurs in the third model this provide evidence of moderation (cf. Baron \& Kenny, 1986).

All regression models were adjusted for sex and age. Since the participating students were selected by means of cluster sampling, all regression analyses were adjusted for design effects of clusters (school classes) by using the Huber-White sandwich estimator for standard errors in the statistical software package STATA 7.0 (StataCorp., 2001). 
Figure 6-1: Illustration of moderation and mediation effects in the link between beverage preference, drinking motives and adolescent alcohol use

\section{Mediation}

1. step: Drinking motives

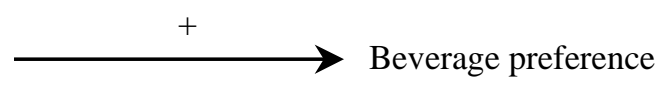

2. step: Beverage preference

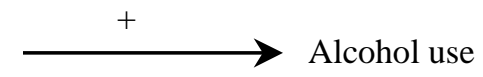

3. step: Drinking motives

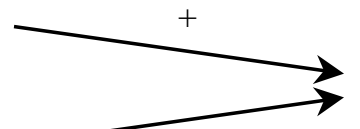

Alcohol use

Beverage preference

n.S.

Moderation

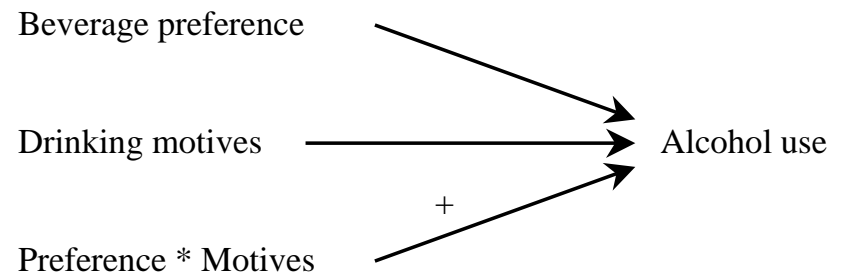

Note. + significant effect expected, n.s. no significant effect expected 


\section{RESULTS}

\section{Beverage preference and drinking motives}

About two thirds of boys and one third of girls drank at least one beer at the last drinking occasion; about one third of boys and one fourth of girls had at least one glass of wine; more than one third of boys and one third of girls had at least one glass of spirits (Table 6-1). Nearly one third of boys and more than half of the girls drank more alcopops on the last drinking occasion than any other alcoholic beverage.

Table 6-1: Share of adolescents with a given proportion of a particular beverage at last drinking occasion

\begin{tabular}{lcccc}
\hline & Beer & Wine & Alcopops & Spirits \\
Share among boys & & & & $57.6 \%$ \\
Zero & $37.3 \%$ & $68.7 \%$ & $39.0 \%$ & $33.1 \%$ \\
Half and less & $28.0 \%$ & $23.7 \%$ & $30.5 \%$ & $9.3 \%$ \\
More than half & $34.7 \%$ & $7.6 \%$ & $30.4 \%$ & $66.0 \%$ \\
Share among girls & & & & $23.7 \%$ \\
Zero & $65.5 \%$ & $73.4 \%$ & $20.0 \%$ & $10.3 \%$ \\
Half and less & $18.6 \%$ & $17.7 \%$ & $53.3 \%$ & \\
More than half & $15.9 \%$ & $8.9 \%$ & & \\
\hline
\end{tabular}

Note. For presentation purposes, proportions were recoded in three categories

Multiple regression analyses revealed that enhancement motives were positively related to the consumption of beer and spirits but negatively to the consumption of wine and alcopops (Table 6-2). For example, as regards enhancement motives and beer preferences, the coefficient of 0.026 can be interpreted to mean that for each increase of one point on the 6-point enhancement scale, the share of beer in 
adolescents' total alcohol consumption at the last drinking occasion increased on average by $2.6 \%$. Social motives were positively related to the consumption of alcopops and negatively to wine consumption. Conformity motives were positively related to wine consumption and negatively to beer consumption.

Table 6-2: Drinking motives as predictors in multiple regression analyses (unstandardized regression coefficients and standard errors and t-values in brackets)

\begin{tabular}{|c|c|c|c|c|}
\hline & Beer & Wine & Alcopops & Spirits \\
\hline Enhancement & $\begin{array}{c}.026^{* * *} \\
(.007,3.55)\end{array}$ & $\begin{array}{c}-.015^{\star \star *} \\
(.004,-3.32)\end{array}$ & $\begin{array}{c}-.025^{\star \star *} \\
(.007,-3.40)\end{array}$ & $\begin{array}{c}.014^{\star * *} \\
(.005,2.99)\end{array}$ \\
\hline Social & $\begin{array}{c}-.005 \\
(.008,-.65)\end{array}$ & $\begin{array}{c}-.022^{* * *} \\
(.005,-4.59)\end{array}$ & $\begin{array}{c}.034^{\star \star \star} \\
(.008,4.47)\end{array}$ & $\begin{array}{c}-.004 \\
(.005,-.88)\end{array}$ \\
\hline Conformity & $\begin{array}{c}-.019^{*} \\
(.008,-2.53)\end{array}$ & $\begin{array}{c}.015^{*} \\
(.006,2.55)\end{array}$ & $\begin{array}{c}-.003 \\
(.008,-.45)\end{array}$ & $\begin{array}{c}.000 \\
(.005, .02)\end{array}$ \\
\hline Coping & $\begin{array}{c}.003 \\
(.005, .55)\end{array}$ & $\begin{array}{c}-.005 \\
(.003,-1.74)\end{array}$ & $\begin{array}{c}.010 \\
(.005,1.87)\end{array}$ & $\begin{array}{c}-.005 \\
(.004,-1.45)\end{array}$ \\
\hline $\mathrm{R}^{2}$ & $7.4 \%$ & $3.6 \%$ & $7.7 \%$ & $5.6 \%$ \\
\hline
\end{tabular}

Note. All regression models were adjusted for sex, age, and the total amount of drinks consumed at the last occasion; * $\mathrm{p}<.05, * * \mathrm{p}<.01, * * * \mathrm{p}<.001$

\section{Beverage preference and alcohol use}

The preference for beer or spirits was related to high quantity-frequency drinking and to a high frequency of RSOD (Table 6-3). No associations emerged between a preference for wine and alcopops and adolescent alcohol use. However, additional analyses reveal that adolescents who drank more wine than any other beverage had significantly lower drinking levels in terms of QF (mean difference $=11.1$, standard error $=1.2, \mathrm{t}=9.2, \mathrm{p}<.001$ ) and RSOD (mean difference $=.81$, standard error $=.10$, 
$\mathrm{t}=8.2, \mathrm{p}<.001)$. The same was true for alcopops ( $\mathrm{QF}$ mean difference $=10.8$, standard error=1.0, $\mathrm{t}=10.7, \mathrm{p}<.001 ;$ RSOD mean difference $=.78$, standard error=.07, $\mathrm{t}=11.7, \mathrm{p}<.001$ ). The opposite, however, was not the case because those who had the highest drinking levels preferred beer and spirits but also drank wine and alcopops, albeit to a lesser extent.

Table 6-3: Drinking motives, beverage preference, and their interactions as predictors (unstandardized regression coefficients and standard errors and t-values in brackets) of adolescent alcohol use (quantity-frequency and risky single occasion drinking)

\begin{tabular}{|c|c|c|}
\hline & QF & RSOD \\
\hline \multicolumn{3}{|l|}{ 1st model } \\
\hline \multicolumn{3}{|l|}{ Beverages only } \\
\hline Beer & $10.76^{\star * *}(2.61,4.13)$ & $.853^{\star \star *}(.199,4.29)$ \\
\hline Wine & $-1.53(2.71,-0.57)$ & $.218(.181,1.21)$ \\
\hline Alcopops & $1.75(2.26,0.77)$ & $-.008(.207,-0.04)$ \\
\hline Spirits & $17.52^{\star \star \star}(2.97,5.89)$ & $1.647^{\star \star *}(.213,7.72)$ \\
\hline $\mathrm{R}^{2}$ & $4.9 \%$ & $5.4 \%$ \\
\hline \multicolumn{3}{|l|}{ 2nd model } \\
\hline \multicolumn{3}{|l|}{ Beverages } \\
\hline Beer & $4.41(2.41,1.83)$ & $.367^{\star}(.174,2.11)$ \\
\hline Wine & $1.95(2.57,0.76)$ & $.269(.188,1.43)$ \\
\hline Alcopops & $-1.69(2.15,-0.79)$ & $-.037(.163,-0.23)$ \\
\hline Spirits & $7.74^{\star \star}(2.77,2.79)$ & $.889^{\star \star \star}(.191,4.65)$ \\
\hline \multicolumn{3}{|l|}{ Drinking motives } \\
\hline Enhancement & $5.82^{* * *}(0.76,7.62)$ & $.497^{\star * *}(.048,10.45)$ \\
\hline Social & $3.74^{\star * *}(0.76,4.89)$ & $.181^{* * *}(.046,3.96)$ \\
\hline Conformity & $-1.07^{\star *}(1.14,-2.70)$ & $-.163^{* *}(.062,-2.61)$ \\
\hline Coping & $3.25^{\star * \star}(0.67,4.85)$ & $.336^{* * *}(.045,7.43)$ \\
\hline $\mathrm{R}^{2}$ & $16.3 \%$ & $22.5 \%$ \\
\hline
\end{tabular}


Table 6-3 continued

\begin{tabular}{|c|c|c|}
\hline & QF & RSOD \\
\hline \multicolumn{3}{|l|}{ 3rd model } \\
\hline \multicolumn{3}{|l|}{ Beverages } \\
\hline Beer & $3.58(2.45,1.47)$ & $.315(.175,1.80)$ \\
\hline Wine & $2.11(2.62,0.80)$ & $.273(.191,1.44)$ \\
\hline Alcopops & $-3.26(2.30,-1.42)$ & $-.142(.171,-0.83)$ \\
\hline Spirits & $7.42^{*}(2.92,2.54)$ & $.882^{\star * *}(.197,4.48)$ \\
\hline \multicolumn{3}{|l|}{ Drinking motives } \\
\hline Enhancement & $5.69^{\star \star \star}(0.76,7.46)$ & $.488^{* \star *}(.048,10.25)$ \\
\hline Social & $3.78^{* * *}(0.76,4.98)$ & $.185^{\star * *}(.045,4.08)$ \\
\hline Conformity & $-3.15^{\star \star}(1.12,-2.80)$ & $-.169^{* *}(.062,-2.73)$ \\
\hline Coping & $3.21^{* * *}(0.66,4.86)$ & $.331^{* * *}(.045,7.35)$ \\
\hline \multicolumn{3}{|l|}{ Interactions } \\
\hline Social ${ }^{\star}$ Alcopops & $-2.15^{\star \star \star}(0.55,-3.88)$ & $-.144^{\star \star *}(.032,-4.51)$ \\
\hline CopingSpirits & $1.49^{*}(0.68,2.20)$ & $.143^{*}(.041,3.50)$ \\
\hline$R^{2}$ & $16.9 \%$ & $23.3 \%$ \\
\hline
\end{tabular}

Note. All models were adjusted for sex and age; $* \mathrm{p}<.05, * * \mathrm{p}<.01, * * * \mathrm{p}<.001$

\section{Moderation}

In addition to the main effects of beverage preference and drinking motives, their interactions were included in the third model. Two interactions emerged from the backward selection method in this model. To reach a better understanding of these interactions, the relation between the proportion of a particular beverage and the frequency of having five drinks or more at a single occasion for a particular drinking motive was plotted on a graph. This was achieved by using the results of the third model and the lowest and highest category of the particular beverage preference and drinking motive.

Figure 6-2 shows a slight (and non-significant) decrease in the frequency of RSOD, with an increasing percentage of alcopops in the total amount consumed at the last 
drinking occasion. The decrease, however, was steeper among those who indicated drinking almost always for social motives than among those who indicated that they never drank for social motives. The increase in the frequency of RSOD with a higher percentage of spirits in the total amount consumed at the last drinking occasion was steeper among those who indicated almost always drinking for coping or enhancement motives than among those who indicated that they never drank for coping or enhancement motives.

Figure 6-2: Illustration of the interaction between beverage preference and drinking motives in predicting the frequency of risky single occasion drinking

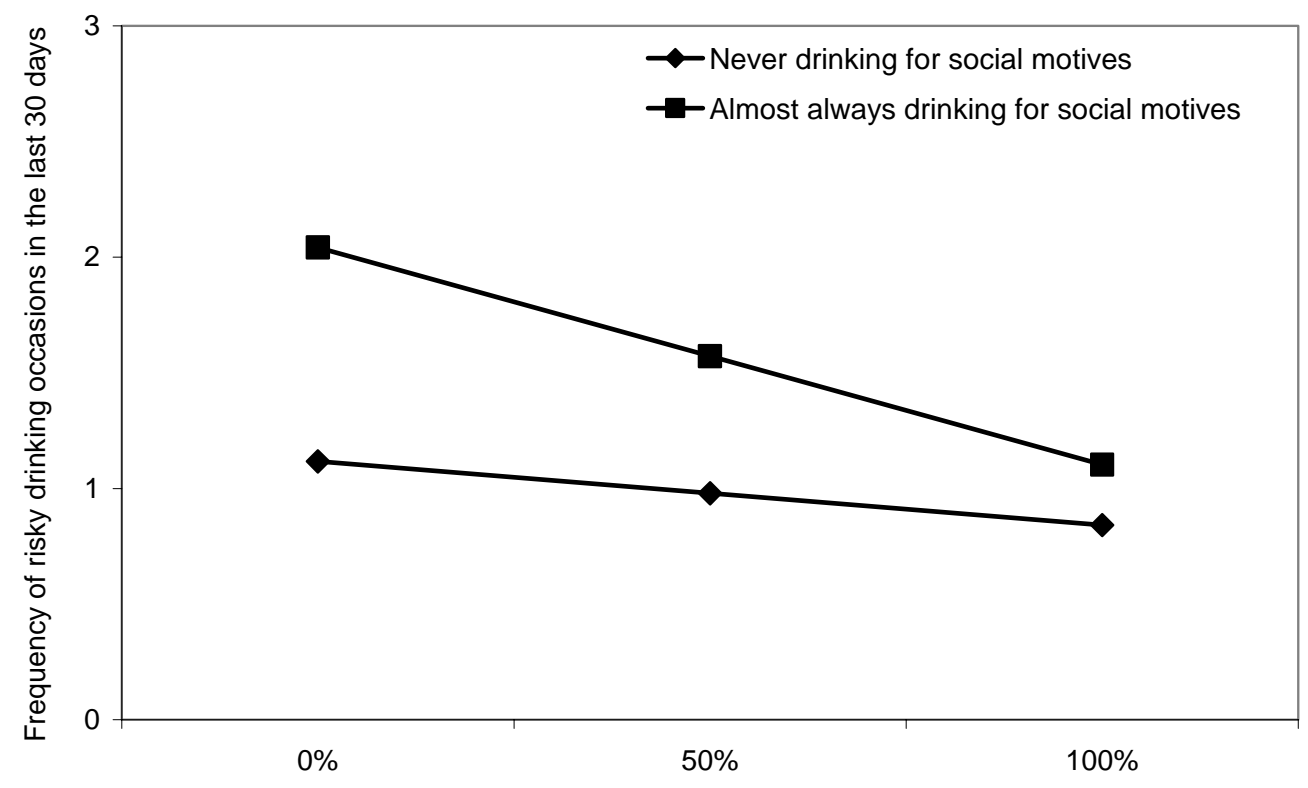

Proportion of alcopops consumption on the total amount consumed at the last drinking occasion 
Figure 6-2 continued

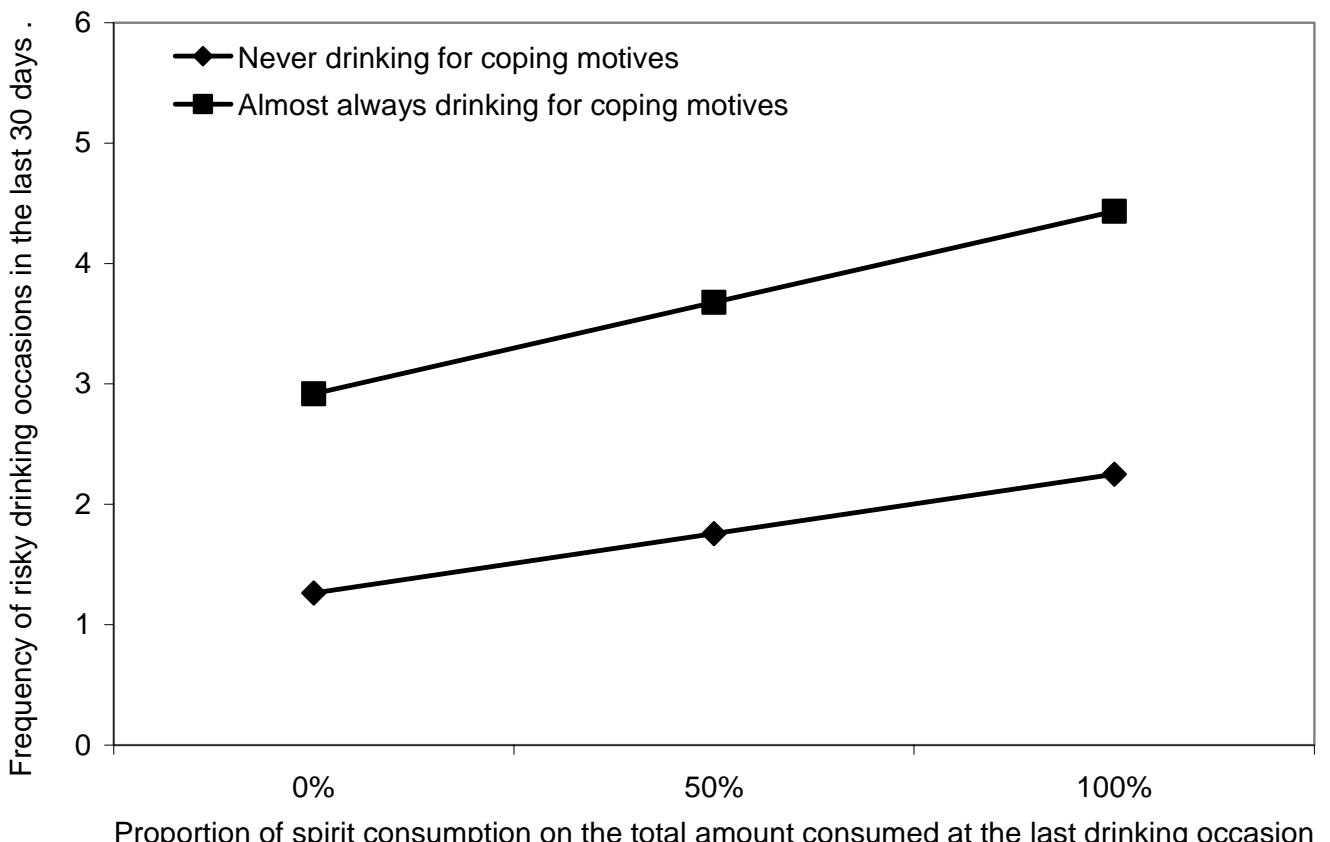

\section{Mediation}

The second model reveals that all drinking motives were significantly associated with adolescent alcohol use regardless of beverage preference (Table 6-2). However, compared with the inclusion of beverage preference only, both the coefficients of a beer and spirits' preference were reduced and only a spirits' preference remained significant for both quantity-frequency and RSOD, when drinking motives were added in the second model. Moreover, the inclusion of drinking motives considerably increased the explained variance from about $5 \%$ in the first model to about $20 \%$ in the second. 


\section{DISCUSSION}

Apart from associations between beverage preference and alcohol use, the present study investigated the motives behind adolescents' preference for a particular beverage, i.e. whether a particular beverage better achieves valued outcomes.

It appears that certain adolescents, particularly those who preferred beer and spirits but not wine and alcopops, like to have fun, to feel the effects of alcohol, and to get drunk. It might be the case that these adolescents consider spirits as the most effective way and beer as the cheapest way to achieve the desired effects (Edwards, Anderson, Babor, Casswell, Ferrence, Giesbrecht, Godfrey et al., 1994; Smart \& Walsh, 1995; World Health Organization (WHO), 1999, 2001). Adolescents who prefer wine tend not to drink excessively. If they drink, they seem to do so in order to conform to the drinking group norm, i.e. not to feel left out and so that others will not make fun of them for abstaining. This might also be related to the rather normative use of wine in the adult drinking culture (Smart, 1996; Smart \& Walsh, 1999) and because it is a social custom (Alvarez \& del Rio, 1994). Furthermore, adolescents consume alcopops especially with peers at social gatherings, celebrations or parties, apparently due to the positive and attractive image of this alcoholic beverage (Leeming, Hanley, \& Lyttle, 2002; Hughes, MacKintosh, Hastings, Wheeler, Watson, \& Inglis, 1997). Their popularity (Boreham \& McManus, 2003; Roberts, Blakey, \& Tudor-Smith, 1999) mirrors the popularity of social motives as the most prevalent drinking motive among adolescents (see Kuntsche, Knibbe, Gmel, \& Engels, 2005, 2006a).

The results also confirm that both beer and spirit consumption is related to high drinking levels and an increased frequency of risky drinking occasions (e.g., Clapp \& Shillington, 2001; Grønbæk, Jensen, Johansen, Sørensen, \& Becker, 2004; Jensen, Andersen, Sørensen, Becker, Thorsen, \& Grønbæk, 2002; Klein \& Pittman, 
1990; Kuntsche, 2001b), but only in the first regression model, which excludes drinking motives. When the latter were included in the second model, the effects of a preference for beer and spirits were markedly reduced, and in the third model the effects of a beer preference became non-significant for both quantity-frequency and RSOD. Thus, the results revealed that the link between beer preference and adolescent alcohol use was mediated by drinking motives. Beer preference, therefore, appears to be only indirectly associated with high drinking levels and an increased frequency of risky drinking occasions. However, enhancement drinkers prefer beer (and spirits) to achieve the desired effect of having fun, feeling the effects of alcohol, and to get drunk.

Furthermore, two moderating effects emerged in the second regression model. First, adolescents who reported drinking for social motives have higher drinking levels and a higher frequency of risky drinking occasions than those who scored low on social motives. This difference, however, was less pronounced among those who had a strong preference for alcopops. It appears that there are two groups of socially motivated drinkers. First, there are adolescents who like drinking alcopops at social gatherings and parties, probably due to the positive and attractive image of this alcoholic beverage (Leeming, Hanley, \& Lyttle, 2002; Hughes, MacKintosh, Hastings, Wheeler, Watson, \& Inglis, 1997). These adolescents, however, tend to drink moderately, probably because of the higher price of alcopops. Second, adolescents who like to have fun and to get drunk tend also to drink at social gatherings and parties (Kuntsche, Knibbe, Gmel, \& Engels, 2005, 2006a). Additional analyses reveal that adolescents who score high on social motives but do not have a preference for alcopops score far higher on enhancement motives (median split; $\mathrm{M}=3.41$ ) than those who score high on social motives but prefer alcopops $(\mathrm{M}=2.15 ; \mathrm{t}=39.3 ; \mathrm{p}<.001)$. Thus, the results of the present study do not add to concerns that alcopops encourage adolescents to drink heavily (e.g., 
Glenewinkel, Iffland, \& Grellner, 1998; Romanus, 2000) due to the ethanolmasking effects of sweeteners (Confederatio Helvetica, 2003; McKeganey, 1998), but rather encourage socially motivated adolescents who prefer alcopops to drink moderately. This might be due to the higher price of alcopops compared to beer, which contains the same amount of pure ethanol (Confederatio Helvetica, 2003).

The second moderation effect concerns the result that drinking to cope with problems was related to high drinking levels and a high frequency of risky drinking occasions (e.g., Cooper, Frone, Russell, \& Mudar, 1995; Kuntsche, Knibbe, Gmel, \& Engels, 2005). However, those coping drinkers who had a strong preference for spirits had even higher drinking levels and a higher frequency of risky drinking occasions than those with a low preference for spirits. There might be adolescents who consider drinking spirits as a more effective way to forget about their problems and worries than the consumption of other alcoholic beverages. This is particularly worrisome since coping drinkers were found to be at risk of adverse long-term consequences, because the problems that produce negative affects have never been adequately addressed (Cooper, Frone, Russell, \& Mudar, 1995; Kassel, Jackson, \& Unrod, 2000).

\section{Limitations and future research directions}

The results might be biased due to the different legal drinking ages in this study. In fact, Switzerland has no legal drinking age but only legal restrictions for selling alcohol to minors (16 years for beer and wine and 18 years for alcopops and spirits), this means that consumption is legal at all ages. Results were similar for types of beverages, although these varied according to the different restrictions on purchasing ages. This makes legal ages for alcohol purchases a less likely explanation for our findings. In addition, despite the legal purchasing age of 18 , 
about two thirds of adolescents consumed at least one bottle of alcopops at the last drinking occasion. Thus, it would appear that the under-18s who were surveyed in the present study (99.7\%) have no problems buying alcopops or obtaining them from adults.

Another shortcoming might be that the study was based exclusively on adolescent self-reports. However, self-reports of adolescent alcohol consumption and other drug use were found to be highly reliable and valid particularly in school surveys, in which anonymity and confidentiality were assured (see Brener, Billy, \& Grady, 2003, for a review), as is the case in the present study. Concerning the measurement of beer, wine, alcopops, and spirits' consumption in the ESPAD core questionnaire, only the amount of beer, wine, alcopops, and spirits consumed on the last occasion was assessed, but not the frequency and usual volume of beer, wine, alcopops and spirit consumption. Future research has to confirm if the present results can also be found among adolescents who generally prefer a specific beverage. Another limitation concerns the cross-sectional design of the study, in which it is impossible to determine if beverage preference forms a particular motive structure or if adolescents with a particular motive structure increasingly tend towards the consistent consumption of a particular beverage to obtain a specific valued outcome. The analysis of such questions requires longitudinal data and remains a task for future research.

\section{Conclusions}

Based on the results of our study, it appears that there are different groups of adolescents who drink particular beverages to achieve valued outcomes. First, adolescents who like to have fun and to get drunk tend to drink beer or spirits to become intoxicated. Some of these adolescents might also use parties and 
celebrations to have fun and to get drunk, while other adolescents who like drinking alcopops at these parties drink rather moderately. Adolescent wine drinkers like to conform and tend to drink moderately.

Particularly those adolescents who prefer spirits and drink to forget problems and worries tend to drink excessively. These adolescents should be targeted by programs that aim to enhance multiple competences through life skills training (e.g., Botvin, 2000, for a review). This type of training focuses for example on enhancing self-esteem and adopting coping strategies for managing stress and anxiety. In addition, it is necessary to restrict access to spirits. For example, the legal age limit of 18 years to sell distilled alcoholic beverages should be better controlled and reinforced. It is also important to sensitize parents to restrict access of alcoholic beverages at home, particularly spirits. 


\section{Chapter 7}

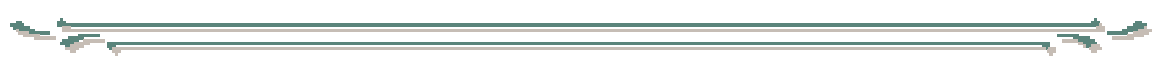

Bullying and fighting among adolescents Do drinking motives and alcohol use matter? ${ }^{6}$

${ }^{6}$ This chapter is based on Kuntsche, E., Knibbe, R., Engels, R., \& Gmel, G. (2007).

Bullying and fighting among adolescents - Do drinking motives and alcohol use matter? Addictive Behaviors, 32(12), 3131-3135. 


\section{SUMMARY OF CHAPTER 7}

The purpose was to investigate the direct and indirect links (through alcohol use) between drinking motives and violent behaviors (i.e. bullying and fighting) among adolescents. As part of the international ESPAD study, a national representative sample of $5,4198^{\text {th }}$ to $10^{\text {th }}$ graders in Switzerland (mean age $15.0, \mathrm{SD}=.86$ ) was analyzed by means of structural equation modeling. The results show that enhancement motives were only indirectly related (through alcohol use) to violent behaviors, whereas coping motives were both directly and indirectly related, particularly among girls. No consistent relation was found for social motives. Despite the negative indirect link (through alcohol use), conformity motives were the strongest predictor of bullying and fighting among boys because of the clear direct link, and even stronger than alcohol use itself. To conclude, drinking motives probably have a role to play in other problem behaviors besides excessive drinking, and may be useful for the early identification and intervention of students who are likely to experience a variety of problems. 


\section{INTRODUCTION}

It is common knowledge that alcohol use and violence in adolescence is interrelated (see e.g., Milgram, 1993; White, 1997, for reviews). Longitudinal evidence, for example, demonstrated that alcohol use in early adolescence led to subsequent violent behavior (Blitstein, Murray, Lytle, Birnbaum, \& Perry, 2005; Kandel, Simcha-Fagan, \& Davies, 1986), that violent behavior in early adolescence led to alcohol use in later life (White, Brick, \& Hansell, 1993; Windle, 1990), and that both were true (Huang, White, Kosterman, Catalano, \& Hawkins, 2001; Newcomb \& McGee, 1989). Although the causal relation is still unclear, there is evidence that the link between alcohol use and violence is more pronounced among a specific group of drinking adolescents. Kuntsche and Gmel (2004), for example, found that socially integrated but not socially isolated risky drinking adolescents were likely to bully and fight. In another study, drinking for social and coping motives was found to be associated among adolescents with "beating someone up" and other aggressive behaviors (Windle \& Windle, 1996). The authors conclude that drinking motives, which typically have been viewed as alcohol-specific, have also a predictive value for other domains of adolescent functioning such as violent behaviors. Carey and Correia (1997) argue that drinking motives play a role in predicting problems other than excessive drinking and may be useful for early identification and intervention of students who are likely to experience a variety of problems.

Since drinking motives in adolescence are closely associated with alcohol use (e.g., Kuntsche, Knibbe, Gmel, \& Engels, 2005; Kuntsche, Knibbe, Gmel, \& Engels, 2006a) and alcohol use is closely associated with violent behaviors (see e.g., Milgram, 1993; White, 1997, for reviews), any investigation of the links between drinking motives and bullying/fighting should look at not only the direct links 
between the two areas but also the indirect links via alcohol use levels. However, current research on the link between drinking motives and violent behaviors (e.g., Carey \& Correia, 1997; Cooper, 1994; Cooper, Frone, Russell, \& Mudar, 1995; Kassel, Jackson, \& Unrod, 2000; Kuntsche, Knibbe, Gmel, \& Engels, 2006a; Simons, Correia, \& Carey, 2000; Windle \& Windle, 1996) has suffered from several limitations: (1) violent behaviors were often grouped together in one indicator variable with other problem behaviors in adolescence such as truancy or academic failure; (2) the assessment of violent behaviors was often exclusively alcohol-attributed (e.g., how often have you been involved in a fight because of your drinking?), which might create associations because of individuals who admit consumption and attribute consequences to their drinking (Gmel, Rehm, Room \& Greenfield, 2000; Rehm \& Gmel, 1999); and (3) alcohol use levels were often not taken into account when studying the link between motives and aggressive behaviors, making it impossible to determine whether particular motives increase alcohol consumption and are thus indirectly associated with violence among adolescents, or whether a particular motive itself directly explains violent behaviors. The present study aims to overcome these weaknesses by investigating direct and indirect links (via alcohol use) between drinking motives and bullying/fighting that were not subject to an alcohol-attributed assessment.

Literature on drinking motives and alcohol-related consequences show that in models in which enhancement and coping motives, alcohol use levels, and alcoholrelated consequences were included simultaneously, only coping motives remained directly associated with alcohol-related consequences (Carey \& Correia, 1997; Cooper, Frone, Russell, \& Mudar, 1995; Kassel, Jackson, \& Unrod, 2000). Thus, it appears that enhancement motives are only indirectly associated with alcoholrelated violence and other consequences (i.e. mediated by alcohol consumption) whereas coping motives are both directly and indirectly associated. People who 
drink to cope with their problems are likely to have problem-coping deficits generally, regardless of their use of alcohol to cope with problems (Cooper, Frone, Russell, \& Mudar, 1995; Kassel, Jackson, \& Unrod, 2000). Consequently, they might experience problems beyond those related to their consumption of alcohol.

Studies found that adolescents who are socially integrated or drink socially are likely to bully and fight (Kuntsche \& Gmel, 2004; Rossow, Pape, \& Wichstrøm, 1999). This might suggest that adolescents who drink for social or conformity motives (e.g., to fit in a group they like) may have a tendency to act violently. Since these were not found to be related to high alcohol use levels (e.g., Cooper, 1994; Kuntsche, Knibbe, Gmel, \& Engels, 2006a), they are expected to be directly rather than indirectly related to bullying and fighting.

A graphical representation of the final model to be tested in the present study is provided in Figure 7-1. We expect (1) an indirect relation (through alcohol use) between enhancement motives and violent behaviors (full path) but not a direct one (dotted path); (2) a direct relation between social and conformity motives respectively, and violent behaviors (full path) but not an indirect one (dotted path); and (3) a direct and indirect relation between coping motives and violent behaviors. From a prevention perspective it is important to know whether drinking motives have an effect on violent behaviors independent of alcohol consumption levels. If there is only an indirect effect of motives on consequences, one might argue that it is important to prevent alcohol use while ignoring the underlying motives, because the link between motives would not exist if there was no alcohol consumption. On the other hand, if particular motives are also directly associated, a more efficient way to prevent violent behaviors would be to target these motives directly. 
Figure 7-1: Conceptual model

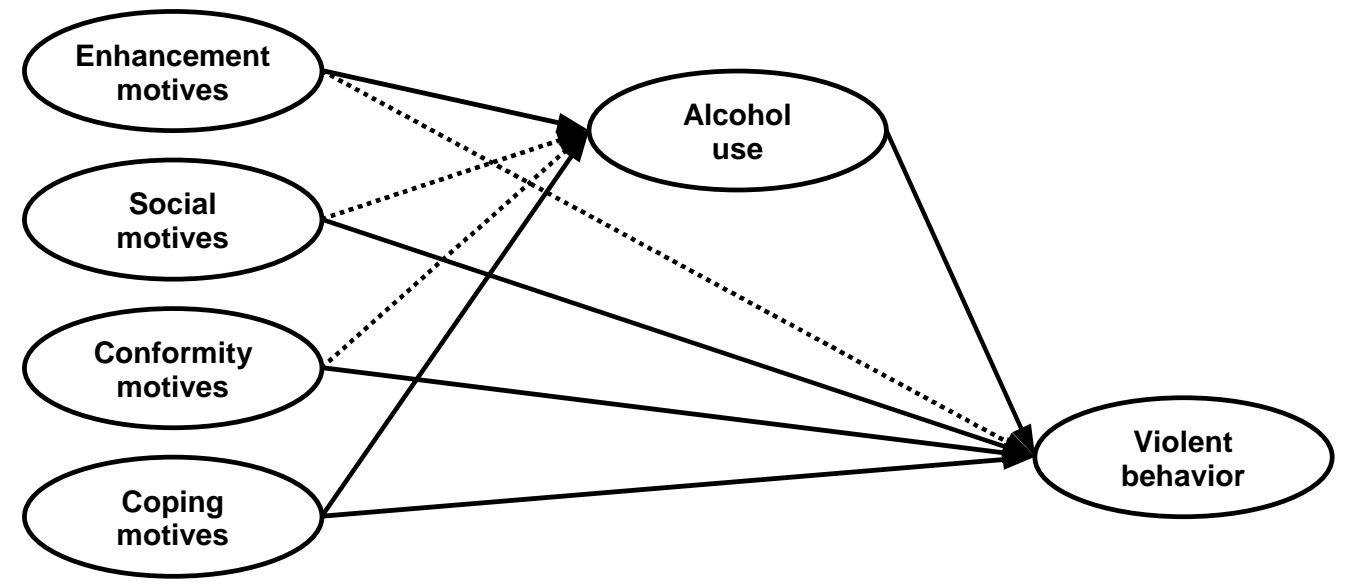

\section{MethodS}

\section{Study design}

The study uses data from the 2003 Swiss participation in the "European School Survey Project on Alcohol and Drugs" (Hibell, Andersson, Bjarnason, Ahlström, Balakireva, Kokkevi, \& Morgan, 2004), which has been conducted every four years since 1995 in European countries.

Between the end of April and the end of June 2003, paper-pencil questionnaires were administered in school classes. Classes were sampled randomly stratified by cantons and proportionate to size of cantons. To avoid systematic dropouts, the distribution date of the questionnaires was not communicated to the school boards ahead of time. The time frame for filling out the questionnaires was one school lesson (about 45 minutes). According to the Helsinki Declaration (World Medical 
Association (WMA), 2002), the students could freely choose to participate and confidentiality was ensured at all stages of the study (for further information see Hibell, Andersson, Bjarnason, Ahlström, Balakireva, Kokkevi, \& Morgan, 2004; Gmel, Rehm, Kuntsche, Wicki, \& Grichting, 2004).

\section{Measures}

\section{Drinking Motives}

The Drinking Motive Questionnaire Revised (Cooper, 1994) is a 20-item selfreport measure which comprises the four conceptually and empirically distinct dimensions of enhancement motives, e.g., drinking because it is fun or to get high; social motives, e.g., drinking to celebrate a special occasion with friends or because it makes social gatherings more fun; conformity motives, e.g., drinking to fit in with a group or because your friends pressure you to drink; and finally coping motives, e.g., drinking to cheer up or to forget your worries (for further information see Cooper, 1994; Kuntsche, Knibbe, Gmel, \& Engels, 2006a). Participants were instructed to consider all the times they have drunk alcohol and to indicate how many of these occasions they have drunk for each motive. Each scale consisting of 5 items (internal consistencies: $\alpha_{\text {enhancement }}=.85, \quad \alpha_{\text {social }}=.82, \quad \alpha_{\text {conformity }}=.87$, $\alpha_{\text {coping }}=.88$ ) had to be rated on a relative frequency scale ranging from "Never" (coded as 1) to "Almost always" (coded as 6).

\section{Alcohol use}

For the usual frequency of alcohol use, the questions asked the number of drinking occasions in the last 12 month with answer categories "0", "1-2", "3-5", "6-9", "10-19", "20-39" and "40 or more". Midpoints of categories were used and 45 
occasions for the upper category (40 times plus half range to mid-point of adjacent category).

Usual quantity of alcohol use assessed the total amount of standard drinks of any alcoholic beverage (beer, wine, spirits, and alcopops as examples) consumed at a typical occasion. The answer ranged from "less than 1 drink" to "5 or more drinks". Midpoints of categories were used and 0.5 drinks for the lower and 5.5 drinks for the upper category ( 5 times plus half range to mid-point of adjacent category).

$5+$ drinking. The question was "Think back once more over the last 30 days. How many times (if any) have you had five or more drinks in a row?" with the answer categories "None", "1", "2", "3-5", "6-9" and "10 or more times". Midpoints of categories were used and 11.25 occasions for the upper category (10 times plus half range to mid-point of adjacent category).

\section{Violence}

According to the Olweus definition (Olweus, 1993), the two bullying questions in the ESPAD deviance module (Hibell, Andersson, Bjarnason, Ahlström, Balakireva, Kokkevi, \& Morgan, 2004) emphasize the victim-aggressor power imbalance: "During the last 12 months, how often have you (1) participated in a group teasing an individual and (2) participated in a group bruising an individual?”. Fighting among adolescents was also assessed by two questions: "During the last 12 months, how often have you (1) participated in a group starting a fight with another group and (2) started a fight with another individual?". For all questions answer categories were "0", "1-2", “3-5", "6-9”, “10-19”, “20-39” or "40 or more”. As for the drinking frequency, midpoints of categories were used, and 45 occasions were used for the highest category. Violent behaviors are not common among 
adolescents in Switzerland (e.g., Kuntsche, 2004a; Kuntsche \& Klingemann, 2004). To counteract any resulting skewness, the violence items were logarithmized. One occasion was added before taking the logarithms (e.g., teasing $=\ln ($ teasing +1$))$, because the $\log$ of zero is not defined. After adding one occasion, the minimum useful value of the logarithmic transform reverts to zero (Lee, 1993).

\section{Sample and missing value imputation}

Based on a list of all classes of public schools in Switzerland, classes were randomly sampled. An overall response rate of $83.1 \%$ could be achieved. The sample can be considered as representative for all $8^{\text {th }}, 9^{\text {th }}$ and $10^{\text {th }}$ graders in schools in the German, French, and Italian speaking regions in Switzerland. The sample contains 6,993 adolescents born between 1986 and 1989. Since drinking motives were exclusively assessed among drinkers, those who did not indicate at least one drinking occasion in the last 12 months $(n=1393,19.9 \%)$ were excluded. The students who did not answer questions on the other alcohol use measures $(n=2$; $0.0 \%)$ or three or more questions on drinking motives $(n=47 ; 0.8 \%)$ or three or four questions about violence $(\mathrm{n}=137 ; 2.4 \%)$ were equally excluded.

When a student did not answer one or two items in the drinking motive scales $(n=390 ; 7.2 \%)$ or one or two questions about violence $(n=266 ; 4.9 \%)$, the missing values were replaced by Markov Chain Monte Carlo (MCMC) estimates (Congdon, 2003; Hox, 2002). Starting with the prior distribution of observed values, random draws of missing values were taken, conditional on the item and individual parameters of the observed values. The individual missing value is imputed by randomly selecting a value from this conditional distribution for the given individual and his or her observed item response pattern. The advantage of 
such an imputation method is that it uses the maximum available information on each individual (cf. Kuntsche, Knibbe, Gmel, \& Engels, 2006a). The LISREL 8.51 program (Jöreskog \& Sörbom, 2001) was used to impute missing values. The final sample consists of 5,419 13- to 16-year old students of which $48.8 \%$ were boys. The total mean age was 15.0 years $(\mathrm{SD}=0.86)$.

\section{Statistical Analysis}

The means of drinking motive scores, alcohol use indicators, and forms of violence will be presented separately for each sex. Since the participating students were selected by means of cluster sampling, sex difference tests were adjusted for the design effects of clusters (school classes) by using the adjusted Wald test in the statistical software package STATA 7.0 (StataCorp, 2001). A correlation matrix of all variables used in the study is provided in the Appendix.

In the first structural equation model, drinking motives were used as determinants of alcohol use. In the second model, bullying and fighting were regressed on the different drinking motives. Finally, in the third model, alcohol use was added, and direct and indirect associations between drinking motives and violent behavior could be derived. Direct associations were assessed by the coefficients of the paths between drinking motives and violent behaviors (i.e. bullying and fighting). Indirect associations, i.e. the product of the coefficient of the paths between drinking motives and alcohol use, and alcohol use and violent behaviors, are directly provided by the linear structural equation model software Mplus 3.13 (Muthén \& Muthén, 2004). Standard errors of indirect effects were obtained by means of the delta method (Muthén \& Muthén, 2004).

Adjusted for age effects, all regression models were estimated for boys and girls and for bullying and fighting separately. Drinking motives (5 observed items in 
each dimension), alcohol use ( 3 observed items), bullying ( 2 observed items), and fighting ( 2 observed items) were used as latent variables. The models were estimated using the Mplus 3.13 software (Muthén \& Muthén, 2004). This program has the advantage of directly adjusting standard errors and significance levels to the sampling design effect of clusters (school classes).

To check the accuracy of the coefficients, bootstrapping was used (Otten, Van den Eijnden, \& Engels, in press). Bootstrapping generates a sampling distribution of direct and indirect effects by resampling (MacKinnon, Lockwood, \& Williams, 2004; Preacher \& Hayes, 2004). From the original sample, 5,000 subsamples were randomly selected (with a replacement). These form the basis of the analysis. Unfortunately, in Mplus, bootstrapping cannot be conducted when using standard errors that are adjusted to the cluster sampling design. Given that the present analysis focused exclusively on the accuracy of the coefficients and not on the accuracy of the standard errors, we re-estimated the final models by using bootstrapping and by ignoring the cluster sampling design.

\section{RESULTS}

Descriptive results reveal that both boys and girls scored highest on social motives, followed closely by enhancement and coping motives (Table 7-1). Boys scored higher on social, enhancement, and conformity motives but lower on coping motives than girls. Boys had higher alcohol use levels and displayed violent behavior more frequently than girls. 
Table 7-1: Means (standard errors in brackets) of drinking motives and alcohol use and violence variables according to sex and F-values of the adjusted Wald test

\begin{tabular}{|c|c|c|c|}
\hline & $\begin{array}{c}\text { Boys } \\
(\mathrm{n}=2645)\end{array}$ & $\begin{array}{c}\text { Girls } \\
(\mathrm{n}=2774)\end{array}$ & $F_{(1,407)}$ \\
\hline \multicolumn{4}{|l|}{ Drinking motives ${ }^{1}$} \\
\hline Enhancement & $2.9(.03)$ & $2.6(.03)$ & 50.9 \\
\hline Social & $3.0(.03)$ & $2.7(.03)$ & 86.3 \\
\hline Conformity & $1.4(.02)$ & $1.3(.01)$ & 36.7 \\
\hline Coping & $1.9(.02)$ & $2.0(.03)$ & $9.0^{\star *}$ \\
\hline \multicolumn{4}{|l|}{ Alcohol use } \\
\hline Usual frequency ${ }^{2}$ & $15.5(.38)$ & $11.4(.30)$ & 92.7 \\
\hline Usual quantity ${ }^{3}$ & $2.4(.05)$ & $1.9(.04)$ & 66.1 \\
\hline $5+$ drinking $^{4}$ & $1.6(.06)$ & $1.0(.05)$ & 82.7 \\
\hline \multicolumn{4}{|l|}{ Bullying ${ }^{2}$} \\
\hline Teasing & $5.0(.26)$ & $2.4(.16)$ & 89.4 \\
\hline Bruising & $1.4(.14)$ & $0.3(.04)$ & 60.8 \\
\hline \multicolumn{4}{|l|}{ Fighting $^{2}$} \\
\hline Group fights & $1.5(.14)$ & $0.3(.04)$ & 64.5 \\
\hline Individual fights & $2.0(.15)$ & $0.5(.06)$ & 87.4 \\
\hline
\end{tabular}

Note: ${ }^{1}$ Summary scores ranging from 1 "never" to 6 "almost always"; ${ }^{2}$ frequency in the last 12 months; ${ }^{3}$ number of drinks per occasion; ${ }^{4}$ frequency of occasions in the last 30 days; all sex differences are significant at $\mathrm{p}<.001$ except $* * \mathrm{p}<.01$

The first model reveals that enhancement and coping motives among both boys and girls were positively associated with alcohol use, while conformity motives were negatively associated (Table 7-2). Additionally, social motives were positively related to alcohol use. However, the coefficient is only statistically significant for boys. Across both sexes, nearly half of the variance in alcohol use can be explained by drinking motives. 
Table 7-2: Alcohol use regressed on drinking motives (Model 1, unstandardized regression coefficients, standard errors and t-values in brackets, and explained variance)

\begin{tabular}{lcc}
\hline & \multicolumn{2}{c}{ Alcohol use } \\
& Boys & Girls \\
\hline 1. Motives - alcohol use & & \\
Enhancement & $3.88^{* * *}(.71,5.4)$ & $3.82^{* * *}(.75,5.1)$ \\
Social & $1.78^{* *}(.63,2.8)$ & $1.23(.70,1.7)$ \\
Conformity & $-4.10^{* * *}(.62,-6.6)$ & $-3.23^{* * *}(.67,-4.8)$ \\
Coping & $1.39^{* * *}(.38,3.7)$ & $0.94^{* * *}(.27,3.5)$ \\
$\mathrm{R}^{2}$ & $45.4 \%$ & $49.8 \%$ \\
\hline
\end{tabular}

Note: All models are adjusted for age; explained variance $\left(\mathrm{R}^{2}\right)$ do not contain age effects; $\mathrm{CFI}=.91$, $\mathrm{TLI}=.90, \mathrm{RMSEA}=.06, \mathrm{SRMR}=.07 * * \mathrm{p}<.01, * * * \mathrm{p}<.001$

In the second model which excludes alcohol use, enhancement and conformity motives were associated with bullying among boys, while social and coping motives were associated with bullying among girls (Table 7-3). With regard to fighting, there was a strong association with conformity and coping motives among boys, while for girls the association was strongest with coping motives. 
Table 7-3: Violent behaviors regressed on drinking motives (2nd model) and on drinking motives and alcohol use (Model 3 including direct and indirect effects; unstandardized regression coefficients, standard errors and tvalues in brackets, and explained variance)

\begin{tabular}{|c|c|c|c|c|}
\hline & \multicolumn{2}{|c|}{ Bullying } & \multicolumn{2}{|c|}{ Fighting } \\
\hline & Boys & Girls & Boys & Girls \\
\hline \multicolumn{5}{|c|}{ 2. Motives - violence } \\
\hline Enhancement & $.179^{\star *}(.063,2.8)$ & $-.053(.050,-1.1)$ & $.023(.042,0.6)$ & $.041(.029,1.4)$ \\
\hline Social & $-.003(.056,-0.1)$ & $.113^{*}(.052,2.2)$ & $.067(.040,1.7)$ & $-.022(029,-0.8)$ \\
\hline Conformity & $.228^{\star * *}(.068,3.4)$ & $.093(.055,1.7)$ & $.106^{*}(.048,2.2)$ & $.025(.031,0.8)$ \\
\hline Coping & $.028(.036,0.8)$ & $.077^{\star \star \star}(.019,4.1)$ & $.072^{\star \star}(.024,2.9)$ & $.063^{\star \star *}(.012,5.4)$ \\
\hline $\mathrm{R}^{2}$ & $12.3 \%$ & $11.5 \%$ & $10.5 \%$ & $8.7 \%$ \\
\hline \multicolumn{5}{|c|}{ 3. Multiple model } \\
\hline \multicolumn{5}{|l|}{ Direct effects } \\
\hline Enhancement & $.098(.063,1.5)$ & $-.096(.050,-1.9)$ & $-.041(.042,-1.0)$ & $.002(.028,0.1)$ \\
\hline Social & $-.050(.057,-0.9)$ & $.090(.053,1.7)$ & $.036(.041,0.9)$ & $-.035(.029,-1.2)$ \\
\hline Conformity & $.326^{\star * *}(.069,4.7)$ & $.142^{*}(.059,2.4)$ & $.180^{\star * *}(.049,3.7)$ & $.060(.033,1.8)$ \\
\hline Coping & $-.009(.036,-0.3)$ & $.063^{\star \star}(.019,2.8)$ & $.049^{\star}(.024,2.0)$ & $.054^{* * *}(.012,4.4)$ \\
\hline Alcohol use & $.023^{* * *}(.004,5.9)$ & $.014^{\star * *}(.003,4.2)$ & $.017^{\star \star \star}(.003,6.5)$ & $.010^{\star * *}(.002,5.7)$ \\
\hline \multicolumn{5}{|c|}{$\begin{array}{l}\text { Indirect effects } \\
\text { through alcohol use }\end{array}$} \\
\hline Enhancement & $.090^{* * *}(.022,4.2)$ & $.052^{* * *}(.017,3.1)$ & $.068^{* * *}(.017,4.0)$ & $.040^{* * *}(.010,3.9)$ \\
\hline Social & $.040^{*}(.016,2.4)$ & $.017(.010,1.7)$ & $.030^{\star *}(.012,2.6)$ & $.013(.008,1.6)$ \\
\hline Conformity & $-.094^{* * *}(.022,4.3)$ & $-.045^{\star \star *}(.013,-3.4)$ & $-.071^{* * *}(.015,-4.8)$ & $-.034^{* * *}(.009,-3.6)$ \\
\hline Coping & $.032^{* *}(.010,3.1)$ & $.013^{* \star}(.005,2.7)$ & $.024^{* * *}(.007,3.3)$ & $.010^{* *}(.003,2.8)$ \\
\hline $\mathrm{R}^{2}$ & $16.5 \%$ & $14.9 \%$ & $15.4 \%$ & $13.1 \%$ \\
\hline
\end{tabular}

Note: All models are adjusted for age; explained variance $\left(\mathrm{R}^{2}\right)$ do not contain age effects; $\mathrm{CFI}=.91$ $.92, \mathrm{TLI}=.90, \mathrm{RMSEA}=.05-.06, \mathrm{SRMR}=.07$ for all models; $* \mathrm{p}<.05, * * \mathrm{p}<.01, * * * \mathrm{p}<.001$

In the third model, direct and indirect paths from drinking motives to violent behaviors were included. Compared with the motive-only model, the direct positive effect of conformity motives on violent behavior increased due to the negative indirect effect. The positive effect of enhancement motives on bullying among 
boys and the positive effect of coping motives on violent behaviors (except bullying among boys) was seen to be partly direct and partly indirect. The explained variance ranges from 13 to 17 percent. Results obtained by bootstrapping were very similar to those obtained in the final model which includes the cluster sampling design effect? ${ }^{?}$.

Since we found both a positive direct and a negative indirect effect of conformity motives on violent behaviors, we conducted an additional analysis to obtain a more detailed insight into the relation between conformity motives, alcohol use and violent behaviors. Results in Table 7-4 reveal that for both sexes and for both forms of violence, conformity drinkers who were violent (according to median splits) had alcohol use levels that were significantly higher than those of nonviolent conformity drinkers.

Table 7-4: Means (standard errors in brackets) of alcohol use (summary score of ztransformed variables) according to bullying and fighting (median split) among conformity drinkers and F-values of the adjusted Wald test

\begin{tabular}{|c|c|c|c|c|}
\hline & \multicolumn{2}{|c|}{ Boys } & \multicolumn{2}{|c|}{ Girls } \\
\hline & Non-violent & Violent & Non-violent & Violent \\
\hline Bulllying (n) & (726) & (453) & $(772)$ & $(259)$ \\
\hline Mean (SD) & $0.26(0.10)$ & $1.00(0.15)$ & $-0.61(0.08)$ & $0.22(0.18)$ \\
\hline F-value & \multicolumn{2}{|c|}{17.1} & \multicolumn{2}{|c|}{20.2} \\
\hline Fighting (n) & $(651)$ & (528) & (785) & $(246)$ \\
\hline Mean (SD) & $0.07(0.10)$ & $1.13(0.14)$ & $-0.57(0.08)$ & $0.14(0.17)$ \\
\hline F-value & \multicolumn{2}{|c|}{36.0} & \multicolumn{2}{|c|}{15.8} \\
\hline
\end{tabular}

Note. All F-values are significant at $\mathrm{p}<.001$

${ }^{7}$ Therefore, we do not present the results. They can, however, be obtained from the authors on request. 


\section{DisCUSSION}

The aim of the present study was to investigate to what extent different drinking motives are directly and indirectly (through alcohol use) associated with bullying and fighting among adolescents. The results show that enhancement motives were directly and indirectly related to bullying among boys. However, only the indirect link through alcohol use was statistically significant. This result appears to be consistent with research on alcohol-related consequences, demonstrating that enhancement motives are mainly linked with alcohol-attributed violence and other consequences due to their strong association with alcohol use levels (Carey \& Correia, 1997; Cooper, Frone, Russell, \& Mudar, 1995; Kassel, Jackson, \& Unrod, 2000).

Similarly consistent are the results on coping motives. The link between coping motives and bullying among girls and fighting among both sexes was partly direct and partly indirect in the model in which alcohol use was taken into account. Both the direct and the indirect paths remained statistically significant. This is in line with previous research which demonstrated that coping motives were directly related to alcohol-attributed violence and other consequences, and indirectly through alcohol use (Carey \& Correia, 1997; Cooper, Frone, Russell, \& Mudar, 1995; Kassel, Jackson, \& Unrod, 2000). Scholars argue that people who have problem-coping deficits experience problems regardless of their alcohol use (Cooper, Frone, Russell, \& Mudar, 1995; Kassel, Jackson, \& Unrod, 2000).

In contrast to what was expected (Kuntsche \& Gmel, 2004; Rossow, Pape, \& Wichstrøm, 1999; Windle \& Windle, 1996), social motives were generally neither directly nor indirectly related to violent behaviors in the multiple regression models. Social motives were found to be the most commonly indicated drinking motives and were associated with moderate alcohol consumption (see Kuntsche, 
Knibbe, Gmel, \& Engels, 2005). Thus, it appears that social motives are indicated by a majority of adolescents who normally do not drink excessively or act violently.

However, drinking to avoid social rejection (conformity motives) was found to be strongly associated with bullying and fighting, particularly among boys. When alcohol use was added in the third model, the coefficients of the direct path in fact increased due to the negative association between conformity motives and alcohol use. Consequently, there was also a negative indirect link between conformity motives and violence. However, the negative indirect link did not compensate for the strong direct link. As a consequence, conformity motives are the strongest predictor of bullying and fighting among boys, even stronger than alcohol use itself. Since items on conformity motives such as "I drink so that I will not feel left out of the group" were subsumed under social motives in the Windle and Windle (1996) study, this might explain the reported link between social motives and violence in their study.

In the context of violent behaviors it appears to be particularly important to fit into a peer group or at least not to be rejected by peers. Since the link between alcohol use and violence was found to be particularly strong among adolescents who frequently drink together (e.g., Kuntsche \& Gmel, 2004; Rossow, Pape, \& Wichstrøm, 1999), alcohol use might be perceived as the group norm among violent adolescents. Thus, drinking to fit into the group and not to be rejected by peers (i.e. conformity motives) appears to be particularly important among adolescents who act violently, even among those who do not drink excessively.

Additional analyses revealed that among adolescents who indicated conformity motives the majority was not violent and also had a low level of alcohol use, whereas those few adolescents who were violent had high alcohol consumption. It 
appears that the negative relation between conformity motives and drinking is due to the majority of non-violent adolescents, whereas the direct positive relation between conformity motives and violent behaviors is due to those adolescents who have both a high level of conformity motives and alcohol use.

Previous research demonstrated that the association between alcohol use and violence is different in groups of drinking adolescents depending on the extent of their social integration (Kuntsche \& Gmel, 2004; Rossow, Pape, \& Wichstrøm, 1999). The present study adds that apart from the indirect link through alcohol use, the direct link of coping and conformity motives is important. Interestingly, a direct association with violent behaviors was only found for motives that are related to the expectation that negative affect will be reduced by drinking either internally (coping motives, e.g., to alleviate worries) or externally (conformity motives, e.g., not to feel left out). No direct association was found for motives that are related to the expectation that positive affect will be increased by drinking either internally (enhancement) or externally (social motives). It might be the case that violent behaviors and heavy drinking often occur in the context of a wider range of problem behaviors (e.g., Jessor \& Jessor, 1977) and that adolescents tend to drink to reduce the negative consequences of their multiple problems. For example, Windle and Windle (1996) conclude from their study that drinking motives, which typically have been viewed as alcohol-specific, also have a predictive value for other domains of adolescent functioning. Unfortunately, owing to the crosssectional nature of the data, it was not possible to investigate causal relationships between drinking motives, alcohol use, and violent behaviors. Another shortcoming might be that the study was based exclusively on adolescent selfreports. However, self-reports of adolescent alcohol consumption and violent behaviors were found to be highly reliable and valid particularly in school surveys, 
in which anonymity and confidentiality were assured (see Brener, Billy, \& Grady, 2003), as is the case in the present study.

The present study also provides important information for prevention. Based on the results, it appears that any efforts to prevent violent behaviors among adolescents should not only attempt to prevent excessive drinking but should also take into account adolescents' motivation to engage in drinking. Drinking motives were not only found to be powerful predictors of alcohol use (e.g., Cox \& Klinger, 1988; Kuntsche, Knibbe, Gmel, \& Engels, 2006a), since they explained nearly 50 percent of the variance of alcohol use among adolescents but they are also powerful predictors of violent behaviors. For example, the effect of conformity motives on bullying $\left(\mathrm{B}_{\text {total }}=\mathrm{B}_{\text {direct }}+\mathrm{B}_{\text {indirect }} ; .230=.326-.094\right)$ among boys was 10 times higher than the one of alcohol use $(\mathrm{B}=.023)$. Given that adolescents who were violent and scored high on conformity motives had a high level of alcohol use (cf. Table 7-4), it would be beneficial to introduce prevention programs targeted specifically at this group.

\section{Conclusions}

Drinking motives are likely to play a role in other problem behaviors besides excessive drinking, and may be useful in early identification and intervention for students who are likely to experience a variety of problems (Carey \& Correia, 1997). Prevention approaches that take into account the different motives for adolescent drinking are likely to be particularly effective because they might target not only the function alcohol serves for young people but also other problem behaviors such as bullying and fighting. Based on the results of the present study, coping and conformity motives are particularly important for the prevention of violent behaviors in adolescence. 


\section{Chapter 8}

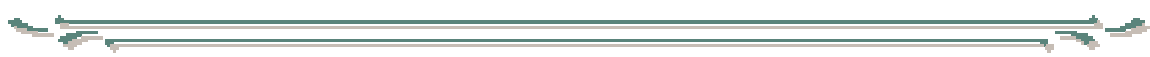

Being drunk to have fun or to forget problems?

Identifying enhancement and coping drinkers

among risky drinking adolescents ${ }^{8}$

\footnotetext{
${ }^{8}$ This chapter is based on Kuntsche, E., Knibbe, R., Engels, R., \& Gmel, G. (submitted for publication). Identifying enhancement and coping drinkers among risky drinking adolescents.
} 


\section{SUMMARY OF CHAPTER 8}

The aim of this chapter was to identify and classify risky single occasion drinking (RSOD) adolescents according to their motivation to engage in drinking. An easyto-use coding procedure was developed as a tool for practitioners. It was validated by means of cluster analyses and structural equation modeling based on two randomly selected sub-samples of a national representative sample of 2,449 12- to 18-year old RSOD students in Switzerland. Results revealed that the coding procedure classified RSOD adolescents as either "enhancement drinkers" or "coping drinkers". The high concordance (Sample A: $\kappa=.88$, Sample B: $\kappa=.90$ ) with the results of the final cluster analysis demonstrated convergent validity. The fact that enhancement drinkers in both sub-samples were found to go out more frequently in the evenings and to have more satisfactory social relationships, a higher proportion of drinking peers, and a lower likelihood to drink at home than coping drinkers demonstrated the concurrent validity of the classification. To conclude, the aforementioned coding procedure appears to be a valid, reliable, and easy-to-use diagnostic tool to help adapt prevention activities more closely to the motivations behind adolescent risky drinking. 


\section{INTRODUCTION}

In adolescence, moderate alcohol use can lead to positive consequences, such as a better social integration, a higher likelihood to be involved in intimate relationships, and higher levels of well-being (e.g., Engels \& Knibbe, 2000; Engels, Knibbe, \& Drop, 1999). However, risky single occasion drinking (RSOD, i.e. having 5 drinks or more at a single occasion, otherwise labeled binge drinking or heavy episodic drinking, see Gmel, Rehm, \& Kuntsche, 2003, for an overview) has been shown to be associated with a variety of adverse consequences, such as low life satisfaction, depressive mood, poor academic performance, accidents and injuries, bullying and fights, and unprotected sexual intercourse, (e.g., Castilla, Barrio, Belza, \& de la Fuente, 1999; Kuntsche \& Gmel, 2004; Windle, 2003; Gmel, Rehm, \& Kuntsche, 2003). Consequently, RSOD adolescents are a target of prevention programs, hence our decision to focus on this group. However, the question remains on how to target prevention programs effectively to RSOD adolescents.

Experts in prevention generally argue that to be effective prevention programs should take into account the different needs and problems of individuals (Hawks, Scott, McBride, Jones, \& Stockwell, 2002; Conrod, Stewart, Comeau, \& Maclean, 2006). There is very little evidence that universally applied prevention programs are effective (Masterman \& Kelly, 2003; Turrisi, Padilla, \& Wiersma, 2000). For example, prevention programs in adolescence are particularly effective if they are designed for and targeted at homogenous risk groups of adolescents who share a constellation of particular needs and problems. RSOD adolescents, however, are not a homogeneous group. For example, Kuntsche and Gmel (2004) found two groups of RSOD adolescents: (a) those who were socially inhibited, depressive, and often victims of bullying (solitary RSOD), and (b) those who were socially 
accepted but prone to violence (social RSOD). The authors argued that prevention programs which aim to enhance multiple competences through life skills training (e.g., Botvin, 2000, for a review) might be more appropriate for solitary RSOD adolescents, whereas prevention programs focusing on social influences (e.g., Botvin, 2000) might be better suited to social RSOD adolescents (Kuntsche \& Gmel, 2004).

The different needs and problems of RSOD adolescents find expression in their motivation to drink (Cooper, Frone, Russell, \& Mudar, 1995). To encourage people to drink less, we must first understand their specific motivation for drinking (Cox \& Klinger, 2004). Carey and Correia (1997) concluded from their work that drinking motives may be useful in early identification and intervention with regard to students who drink excessively and who are likely to experience a variety of problems. For example, new developments in prevention focus on the interplay between personality factors and drinking motives in order to reduce excessive drinking and alcohol-related problems among young people (e.g., Conrod, Stewart, Comeau, \& Maclean, 2006; Stewart, Conrod, Marlatt, Comeau, Thush, \& Krank, 2005).

A first step to a successful motive-specific intervention is to identify (i.e. to classify in statistical terms) homogenous groups among RSOD adolescents. A common statistical tool to classify individuals is the cluster analysis (e.g., Everitt, Landau, \& Leese, 2001). To identify at-risk juvenile drinkers, Stewart and Powers (2002), for example, used cluster analyses to classify adolescents according to eight homogenous groups based on their alcohol consumption and consequences, drinking motives, and social drinking context. However, sufficiently large samples are required to run a cluster analysis. Practitioners in the field of prevention often do not have access to such large samples, given that they tend to deal with single cases, i.e. adolescents who attend counseling on an individual basis. In addition, 
practitioners may not necessarily have the statistical skills to perform such a complex analysis, which contributes further to the unsuitability of cluster analyses for practical diagnostic purposes. To identify the needs and problems of RSOD adolescents and to classify them according to a particular group for which a specific prevention program fits their needs and problems best, clinical psychologists, physicians, prevention specialists, teachers, school administrators and social workers need an easy-to-use tool which they can administer without any statistical computer programs or statistical expertise. The present study aims to develop and validate an easy-to-use coding procedure to identify RSOD adolescents either as enhancement or as coping drinkers.

The concept of drinking motives assumes that people drink in order to attain certain valued outcomes and that drinking behavior is motivated by different needs and serves different functions (Cooper, 1994; Cox \& Klinger, 1988, 1990). It is thought that individuals drink to obtain positive outcomes or to avoid negative consequences. In addition, they may be motivated by internal rewards such as enhancement of a desired emotional state, or by external rewards such as social approval or acceptance (Cox \& Klinger, 1988, 1990). Based on these considerations, Cooper (1994) developed the Drinking Motive Questionnaire Revised (DMQ-R) that reliably measures (see also MacLean \& Lecci, 2000; Kuntsche, Knibbe, Gmel, \& Engels, 2006a) the four drinking motive categories: enhancement (internal, positive: e.g., to have fun and to get drunk); coping (internal, negative: e.g., to cheer oneself up when in a bad mood and to forget problems); social (external, positive: to be sociable and to celebrate special occasions with friends); and conformity (external, negative). At present, the DMQ$\mathrm{R}$ is the most often applied multidimensional instrument to assess drinking motives among adolescents (see Kuntsche, Knibbe, Gmel, \& Engels, 2005, for a review). It will also be used in the present study. 
Research has demonstrated that two of the four motive dimensions, i.e. enhancement and coping, were strongly associated with RSOD among adolescents (see Kuntsche, Knibbe, Gmel, \& Engels, 2005, for a review). These will therefore be the focus of the present study. Adolescents who drink for internal motives have been shown to drink consistently across different drinking situations, resulting in excessive drinking overall (Cooper, 1994). Although both motive groups drink heavily, the personality of coping and enhancement drinkers was found to differ considerably: enhancement drinking (e.g., drinking to have fun and to get drunk) was found to be associated with extraversion, sensation-seeking and aggression, while drinking to cope was associated with neuroticism, anxiety, and depression (e.g., Comeau, Stewart, \& Loba, 2001; Cooper, Frone, Russell, \& Mudar, 1995; Cooper, Agocha, \& Sheldon, 2000; Loukas, Krull, Chassin, \& Carle, 2000; Stewart \& Devine, 2000; Stewart, Loughlin, \& Rhyno, 2001; Theakston, Stewart, Dawson, Knowlden-Loewen, \& Lehman, 2002).

Moreover, boys and older adolescents score higher on enhancement but lower on coping motives than girls and younger adolescents (Cooper, 1994). Drinking for enhancement motives was found to be associated with drinking with friends and going out in the evening (e.g., to parties and bars), while coping motives were associated with drinking at home (Cooper, 1994). In addition, drinking for coping motives but not for enhancement was found to be related to poor academic performance (Kuntsche, Knibbe, Gmel, \& Engels, 2006a). It also affects social relationships negatively (Bradley, Carman, \& Petree, 1992; Karwacki \& Bradley, 1996). These variables (gender, age, going out, academic performance, relationship with parents and peers) will be used as one criterion to validate the suggested coding procedure. To summarize, it is clear from the literature that enhancement and coping drinkers form two distinct groups (Stewart, Hall, Wilkie, \& Birch, 
2002; Cooper, Frone, Russell, \& Mudar, 1995; Ooteman, Koeter, Verheul, Schippers, \& Van den Brink, 2006).

One may wonder why a special coding procedure is needed. Why not simply classify those who feature at the higher end of the enhancement scale as enhancement drinkers and those at the higher end of the coping scale as coping drinkers? Reliable and valid motive questionnaires consist of multiple-item instruments. The DMQ-R, for example, consists of 20 items with 6 point-Likert scales, where five items characterize each one of the four dimensions. Filling out such a questionnaire often does not result in an answer pattern with exclusive scores on one dimension. Adolescents drink for different motives, and thus "enhancement drinkers" and "coping drinkers" are characterized more by the relative positions of scores across scales than by only a single score on one dimension. Thus, people who often drink to cope with problems ("coping drinkers") have relatively higher values on the coping dimensions than those who do so less frequently.

Unfortunately, not even the comparison of scores on different dimensions for each individual is sufficient. Adolescents are generally more likely to report drinking to increase positive feelings rather than to curb negative feelings. Thus, even coping drinkers may score much higher on the enhancement scale. What makes them coping drinkers is that they have higher coping values than others. Consequently, in various studies, adolescents scored higher on enhancement motives than on coping motives (Cooper, 1994; Kuntsche, Knibbe, Gmel, \& Engels, 2005, 2006a). Conducting a coding procedure based on the absolute original drinking motive scores would therefore classify almost all on the positive valence axis (i.e. enhancement and social) and thus overlook those who often drink to curb negative feelings (conformity and coping), as the latter also tend to highlight the positive aspects of drinking. Therefore, analytical strategies have to be based on drinking 
motive dimension scores that take account of the imbalance between positive and negative motive dimensions (Stewart, Hall, Wilkie, \& Birch, 2002). A standard procedure for this is mean adjustment, based on the population norm. This means that the coping and enhancement scales have the same mean (i.e. zero). Furthermore, deviation (positive or negative) from this mean predicts whether someone, relative to the norm, tends towards enhancement or coping.

Another aspect which is not related to the coding of individuals but to statistical techniques such as cluster analysis is linked to the Likert-scale type of questions. Those drinking more frequently generally have higher scores on all items than those drinking less frequently and there is a greater likelihood that those who drink more frequently are also heavy drinkers. Consequently, apart from associations with specific drinking motives, RSOD was found to be related to the total drinking motivation score of adolescents (e.g., Montgomery, Benedicto, \& Haemmerlie, 1993; Plant, Bagnall, \& Foster, 1990; Stewart \& Power, 2002). This is not a problem for within-individual comparisons of scores across dimensions. Cluster analyses, however, also take the between-individual variation into account and are thus likely to result in clusters comparing frequent versus less frequent drinkers, and not drinkers with different motivation patterns. To be clear, the adjustment for total motive scores is only needed in cluster analysis techniques and is not relevant for the proposed coding procedure. The present study, however, uses cluster analyses to validate the coding procedure. It also advocates a simple coding procedure - given the complex arithmetic needed to conduct valid cluster analyses on drinking motives - which would in most cases exceed the statistical and mathematical knowledge of most practitioners.

The principal aim of the study is to develop a coding procedure to identify enhancement and coping drinkers among RSOD adolescents. A step-by-step description of the procedure aims to facilitate its practical use. The second aim is to 
show that such a coding procedure results in a classification into homogeneous groups that (a) is comparable to those of sophisticated cluster analyses, and (b) has high reliability and validity.

\section{METHODS}

\section{Study design}

Data from the Swiss participation in the "European School Survey Project on Alcohol and Drugs" (ESPAD: Hibell, Andersson, Bjarnason, Ahlström, Balakireva, Kokkevi, \& Morgan, 2004), which has been conducted every four years since 1995 in European countries, were used for the present analysis. In 2003, Switzerland conducted the survey together with 34 other European countries.

The present data were collected by means of a paper-pencil questionnaire which was sent to schools to be administered to each pupil in the sampled classes between the end of April and the end of June 2003. Authorization to conduct the study was obtained from all 24 cantons (local Swiss governments) participating in the study. The school boards were informed about the study ahead of time and could refuse participation at any time. Teachers who administered the questionnaires in the classroom were advised only to respond to adolescents' queries about the procedure and to guarantee the independent completion of the questionnaire without interference from classmates. The time frame for filling out the questionnaires was one school lesson (about 45 minutes). The survey was completely anonymous. Unmarked envelopes were provided to be sealed after the completion of the questionnaire. According to APA Ethical Principles (American Psychological Association, 2002), the students could freely choose to participate 
and confidentiality was ensured at all stages of the study. More information about the ESPAD survey can be found online at www.espad.org.

\section{Measures}

An interdisciplinary research group from the participating countries developed the ESPAD questionnaire (Hibell, Andersson, Bjarnason, Ahlström, Balakireva, Kokkevi, \& Morgan, 2004) including substance use and different variables of adolescent functioning. Countries were free to include additional questions in the ESPAD core questionnaire. In Switzerland, the Drinking Motive Questionnaire (DMQ-R, Cooper, 1994) was included. The resulting questionnaire was translated under the supervision of SIPA into the three languages most frequently spoken in Switzerland: German, French, and Italian.

\section{Dinking Motives}

The Drinking Motive Questionnaire Revised (DMQ-R, Cooper, 1994) is a 20-item self-report measure of the relative frequency of drinking for four conceptually and empirically distinct motive dimensions (i.e. enhancement, social, conformity, and coping motives). Participants were instructed to consider all the times they have drunk alcohol and to indicate on how many of these occasions they have drunk for the given motive. Each five-item scale had to be rated on a relative frequency scale, ranging from never (coded as 1) to almost always (coded as 6). The internal consistencies of the scales are $\alpha_{\text {enhancement }}=.85, \alpha_{\text {social }}=.82, \alpha_{\text {conformity }}=.87$, and $\alpha_{\text {coping }}=.88$. Detailed information on the measurement properties of the DMQ-R among adolescents in Switzerland can be found in Kuntsche, Knibbe, Gmel, and Engels (2006a). 
Domains of adolescent functioning.

Risky single occasion drinking (RSOD). The question was "Think back once more over the last 30 days. How many times (if any) have you had five or more drinks in a row?" with the answer categories "None", "1", “2”, “3-5", "6-9" and "10 or more times". Midpoints of categories were used and 11.25 occasions for the upper category (10 times plus half range to mid-point of adjacent category, Wicki, Gmel, Kuntsche, Rehm, \& Grichting, 2006).

Poor academic performance. The students were asked "Which of the following best describes your average grade at the end of the last school term?". The answers were coded 1 for the best possible grade to 6 for the worst, thereby enabling an assessment of poor academic performance.

Going out in the evening. The question was "How often (if at all) do you do each of the following? Go out in the evening (to a disco, cafe, party etc)". Answer categories were "never", "a few times a year", "once or twice a month", "at least once a week ", and "almost every day". Answer categories were coded as annual frequency, ranging from "never (0)" to "almost every day (365)".

Unsatisfactory relationships. The students were asked three questions "How satisfied are you usually with your relationship to your mother / father / friends?" Answer categories varied from "very satisfied" (coded as 1) to "not at all satisfied" (coded as 5). The inverse coding measures unsatisfactory relationships. To indicate an unsatisfactory relationship with their parents, the questions pertaining to their mother and to their father respectively were added together and divided by two.

Drinking at home. The students were asked "Think of the last day on which you drank alcohol. Where were you when you drank?" Subsequently, the students could indicate whether this was at home (coded as 1) or not (coded as 0$)$. 
Proportion of drinking peers. The question was "How many of your friends would you estimate get drunk at least once a week?" with the answer categories "none", "a few", "some", "most", and "all". Answer categories were coded as proportions that varied from 0 (none) to 1 (all).

\section{Sample}

Based on a list of all public school classes from $8^{\text {th }}$ to $10^{\text {th }}$ grade in Switzerland, random cluster sampling was used in which the classes served as the primary sampling unit. From the original sample of 473 classes, 65 (13.7\%) classes did not send back their questionnaires in the required time limit of three months (i.e. 86.3\% response rate at class level). Only $4.1 \%$ of the students in the participating classes did not take part in the survey because of illness-related absence or truancy, or because they refused (i.e. 95.9\% response rate at individual level). This resulted in an overall response rate of $83.1 \%$. The final sample of 7,193 adolescents can be considered as representative for all $8^{\text {th }}, 9^{\text {th }}$ and $10^{\text {th }}$ graders in public schools in the three linguistic regions (German, French, and Italian) of Switzerland. Since drinking motives were exclusively assessed among drinkers, those who did not indicate at least one drinking occasion in the last 12 months $(n=1415,19.7 \%)$ were excluded. All students who answered less than 18 out of 20 questions on drinking motives $(\mathrm{n}=71 ; 1.2 \%)$ and those who answered less than six out of eight questions on adolescent functioning $(n=133 ; 2.3 \%)$ were excluded from the analysis. Since the aim of the study was to identify homogenous groups among excessively drinking adolescents, those who did not report at least one risky drinking occasion in the last 30 days $(n=3125,56.1 \%)$ were excluded. The analyzed data consist of 2,44912 - to 18 -year old risky drinking students $\left(12.5 \% 8^{\text {th }}\right.$ graders, $50.3 \% 9^{\text {th }}$ graders, and $37.1 \% 10^{\text {th }}$ graders) of which $57.2 \%$ were boys and $72.1 \%$ came from 
the German-speaking part (22.3\% French-speaking and 5.6\% Italian-speaking). The mean age of the total sample was 15.2 years $(\mathrm{SD}=.93)$.

\section{Missing value imputation}

When a student did not answer one or two questions on drinking motives or one or two questions on adolescent functioning (i.e. poor academic performance, going out in the evening, unsatisfactory relationships, drinking context), the missing values were replaced by means of Markov Chain Monte Carlo (MCMC) estimates (Congdon, 2003; Hox, 2002). In MCMC, individual missing values are imputed by randomly selecting values from a conditional distribution for the given individual and his or her observed item response pattern. The advantage of such an imputation method is that information on the observed values for an individual is taken into account, i.e. imputation is conditional on individuals that have the same response pattern on all but the missing items. Thus, a maximum of information for an individual from other items of the drinking motive questionnaire was used. The program LISREL 8.51 (Jöreskog \& Sörbom, 2001) was applied for missing value imputations.

\section{Statistical Analysis}

\section{Reliability of the classifications}

Two randomly selected sub-samples of approximately the same size (split-half) were created and all procedures and analyses were conducted for these two subsamples separately. Both sub-samples were similar in terms of sex and age (Sample A: $58.6 \%$ boys; mean age $15.2, \mathrm{SD}=.93$; Sample B: $55.9 \%$ boys; mean age 15.2 , 
$\mathrm{SD}=.92$ ). To assess reliability, the results obtained in these two replications were compared.

\section{The coding procedure}

To account for the general tendency of adolescents to indicate enhancement motives more frequently than coping motives (e.g., Cooper, 1994; Kuntsche, Knibbe, Gmel, \& Engels, 2005; Stewart, Hall, Wilkie, \& Birch, 2002), the population mean of enhancement motives among RSOD adolescents was subtracted from the individual enhancement summary score and the result was divided by the standard deviation of enhancement motives among all RSOD adolescents in the sample. The same procedure was applied to coping motives. After this norm adjustment, enhancement drinkers and coping drinkers were defined based on their higher score on one of the two dimensions. An easy step-bystep description of the coding procedure is given in the Appendix.

\section{Testing convergent validity}

Two tests of convergent validity were used. First, the means of the original enhancement and coping motive scales were compared between the two groups resulting from the coding procedure. To be correctly classified adolescents in the one group should score higher on enhancement and lower on coping motives (i.e. "enhancement drinkers") than in the other group (i.e. "coping drinkers"). Enhancement drinkers are further expected to show a high level of social motives because both motives are assumed to increase the positive affect. Coping drinkers, on the other hand, are expected to score highly in relation to conformity motives because both motives are assumed to decrease the negative affect (Cox \& Klinger, 1988, 1990; Cooper, 1994). Empirically, social motives were found to be most 
closely related to enhancement motives, while conformity motives were found to be most closely related to coping motives (e.g., Cooper, 1994; Kuntsche, Knibbe, Gmel, \& Engels, 2006a). Should the group which scores higher on enhancement motives and lower on coping motives also scores higher on social motives and lower on conformity motives than the second group, this provides further evidence that the classification is correct. Since the participating students were selected by means of cluster sampling (based on school classes), the differences in enhancement, social, conformity, and coping motives between the two groups were tested by means of the adjusted Wald test, in which standard errors had been adjusted for the cluster sampling design effect using the statistical software package STATA 9.1. (StataCorp, 2005).

Second, three two-group $k$-means cluster analyses were performed. The $k$-means algorithm starts with a pre-determined number of clusters and objects per cluster. It then displaces objects between clusters iteratively so that within clusters distances to the center are minimized and distances between centers are maximized (Everitt, Landau, \& Leese, 2001). To maximize the efficiency of the analytical procedure, a randomly selected sub-sample was used to determine cluster centers. Subsequently, the entire sample was classified according to the centers estimated from the subsample. This procedure accounts for the problem of local minima in the hillclimbing algorithm and therefore enhances the reliability of the group classification (Everitt, Landau, \& Leese, 2001; SPSS Inc., 2005). The first cluster analysis was based on the original enhancement and coping motives scores. The second one was based on the population norm-adjusted scores (i.e. the same scores on which the coding procedure was based). The third one was based on population normadjusted scores from which the individual total motivation (i.e. the summary score of all enhancement and coping items) was subtracted. All cluster analyses were performed using the SPSS 14.0 statistical package (SPSS Inc., 2005). 
To support the convergent validity, group membership resulting from the coding procedure was cross-matched with the group membership resulting from each of the three $k$-means cluster analyses. High convergent validity is evidenced by a high concordance of enhancement drinkers (and of coping drinkers respectively) classified by the coding procedure with those enhancement (coping) drinkers classified by a given cluster analysis. Convergent validity was tested by means of the $\kappa$-coefficient (Cohen, 1960). $\kappa$-values between .40 and .75 represent fair to good concordance beyond chance and values above .75 express excellent concordance (Fleiss, Levin, \& Paik, 2003) and high convergent validity.

\section{Testing concurrent validity}

To test concurrent validity, a multivariate regression analysis was performed. Group membership was taken as an independent variable; dependent variables were derived from socio-demographic factors and from various domains of adolescent functioning. The multivariate regression analyses were performed using the structural equation modeling software Mplus 4.2 (Muthén \& Muthén, 2004). This program has the advantage of directly adjusting the analysis for the cluster sampling effect. A second advantage of the program is that it can combine continuous outcomes (e.g., proportion of drinking peers) and dichotomous outcomes (e.g., gender and drinking at home) in one multivariate model. A third advantage is that Mplus 4.2 accounts for the skewness of dependent variables by using maximum likelihood parameter estimates with standard errors that are robust to non-normality (Muthén \& Muthén, 2004). 


\section{RESULTS}

Results from the coding procedure to classify RSOD adolescents in two groups based on their adjusted enhancement and coping motive scores revealed that participants in Group 1 had a significantly $(\mathrm{p}<.001)$ higher level of enhancement motives and a lower level of coping motives than those in Group 2 (Table 8-1). In addition, participants in Group 1 had a significantly $(\mathrm{p}<.001)$ higher level of social motives and a lower level of conformity motives than those in Group 2. This was the case in both replications. Therefore, Group 1 which emerged from the coding procedure can be labeled "enhancement drinkers" and Group 2 "coping drinkers".

The first two-group k-means cluster analysis was based on the original enhancement and coping scores. Again, two groups emerged which had significantly different scores on enhancement, social, conformity, and coping motives. However, in both randomly selected sub-samples, participants in the first group scored higher on all different drinking motive dimensions than those in the second group. This cluster analysis distinguished mainly between high versus low motivated adolescents, but not between adolescents who had a particular motivation for their drinking. In addition, there was a low concordance with the results obtained by the coding procedure. The second cluster analysis was based on the population norm-adjusted enhancement and coping scores. Although these scores were the same as those used for the coding procedure, the second cluster analysis produced the same results by and large as the first cluster analysis. Participants in the first group scored higher on all different drinking motive dimensions than those in the second group and the concordance with the results obtained by the coding procedure was low. 
Table 8-1: Means and standard deviations (in brackets) of drinking motives among RSOD adolescents grouped by the coding procedure and by three different cluster analyses

\begin{tabular}{|c|c|c|c|}
\hline & \multicolumn{3}{|c|}{ Sample A ( $n=1221)$} \\
\hline & Group 1 & Group 2 & $F_{(1,402)}$ \\
\hline \multicolumn{4}{|c|}{ Coding procedure } \\
\hline Group size (\%) & $604(49.5)$ & $617(50.5)$ & \\
\hline Enhancement & $4.00(0.04)$ & $2.83(0.05)$ & 389.5 \\
\hline Social & $3.72(0.04)$ & $3.12(0.05)$ & 96.6 \\
\hline Conformity & $1.26(0.02)$ & $1.57(0.04)$ & 53.7 \\
\hline Coping & $1.81(0.03)$ & $2.75(0.06)$ & 224.2 \\
\hline \multicolumn{4}{|c|}{ CA based on raw scores } \\
\hline Group size (\%) & $714(58.5)$ & $507(41.5)$ & \\
\hline Enhancement & $4.39(0.04)$ & $2.71(0.0)$ & 1212.6 \\
\hline Social & $4.08(0.04)$ & $2.94(0.04)$ & 462.6 \\
\hline Conformity & $1.65(0.05)$ & $1.25(0.02)$ & 65.1 \\
\hline Coping & $3.13(0.06)$ & $1.67(0.03)$ & 518.2 \\
\hline Concordance $^{1}$ & & $.08(.03,2.9)$ & \\
\hline \multicolumn{4}{|c|}{ CA adj. for the population norm } \\
\hline Group size (\%) & $738(60.4)$ & $483(39.6)$ & \\
\hline Enhancement & $4.38(0.04)$ & $2.78(0.04)$ & 1000.3 \\
\hline Social & $4.07(0.04)$ & $2.99(0.04)$ & 394.1 \\
\hline Conformity & $1.66(0.05)$ & $1.26(0.02)$ & 65.7 \\
\hline Coping & $3.23(0.06)$ & $1.67(0.02)$ & 630.4 \\
\hline Concordance $^{1}$ & & $.03(.03,1.2)$ & \\
\hline \multicolumn{4}{|l|}{$C A^{2}$} \\
\hline Group size (\%) & 529 (43.3) & $692(56.7)$ & \\
\hline Enhancement & $4.12(0.04)$ & $2.88(0.05)$ & 466.9 \\
\hline Social & $3.78(0.04)$ & $3.14(0.05)$ & 111.4 \\
\hline Conformity & $1.26(0.02)$ & $1.54(0.03)$ & 49.1 \\
\hline Coping & $1.79(0.03)$ & $2.67(0.05)$ & 214.5 \\
\hline Concordance $^{1}$ & & $.88(.01,30.9)$ & \\
\hline
\end{tabular}


Table 8-1 continued

\begin{tabular}{|c|c|c|c|}
\hline & \multicolumn{3}{|c|}{ Sample B $(n=1228)$} \\
\hline & Group 1 & Group 2 & $F_{(1,402)}$ \\
\hline \multicolumn{4}{|c|}{ Coding procedure } \\
\hline Group size (\%) & $603(49.1)$ & $625(50.9)$ & \\
\hline Enhancement & $3.87(0.04)$ & $2.92(0.05)$ & 242.9 \\
\hline Social & $3.60(0.04)$ & $3.14(0.05)$ & 58.6 \\
\hline Conformity & $1.26(0.02)$ & $1.55(0.04)$ & 43.5 \\
\hline Coping & $1.79(0.03)$ & $2.84(0.05)$ & 295.2 \\
\hline \multicolumn{4}{|c|}{ CA based on raw scores } \\
\hline Group size (\%) & $819(66.7)$ & $409(33.3)$ & \\
\hline Enhancement & $4.37(0.05)$ & $2.91(0.04)$ & 606.1 \\
\hline Social & $4.10(0.05)$ & $3.00(0.04)$ & 328.1 \\
\hline Conformity & $1.78(0.06)$ & $1.22(0.02)$ & 99.9 \\
\hline Coping & $3.62(0.05)$ & $1.68(0.02)$ & 1088.1 \\
\hline Concordance $^{1}$ & & $.12(.03,4.6)$ & \\
\hline \multicolumn{4}{|c|}{ CA adj. for the population norm } \\
\hline Group size (\%) & $866(70.5)$ & $362(29.5)$ & \\
\hline Enhancement & $4.46(0.05)$ & $2.95(0.04)$ & 651.5 \\
\hline Social & $4.14(0.05)$ & $3.04(0.04)$ & 322.4 \\
\hline Conformity & $1.81(0.06)$ & $1.24(0.02)$ & 85.7 \\
\hline Coping & $3.73(0.06)$ & $1.74(0.02)$ & 1032.0 \\
\hline Concordance $^{1}$ & & $.13(.03,5.1)$ & \\
\hline \multicolumn{4}{|l|}{$\mathrm{CA}^{2}$} \\
\hline Group size (\%) & $665(54.2)$ & $563(45.8)$ & \\
\hline Enhancement & $3.83(0.04)$ & $2.89(0.05)$ & 228.5 \\
\hline Social & $3.57(0.04)$ & $3.13(0.05)$ & 52.9 \\
\hline Conformity & $1.26(0.02)$ & $1.58(0.04)$ & 45.4 \\
\hline Coping & $1.83(0.03)$ & $2.91(0.06)$ & 274.6 \\
\hline Concordance $^{1}$ & & $.90(.01,31.7)$ & \\
\hline
\end{tabular}

Note: CA: Cluster analysis; ${ }^{1}$ concordance with the results obtained by the coding procedure assessed by $\kappa$-values (asymptotical standard errors and approximate t-values in brackets); ${ }^{2}$ adjusted for the population norm and the individual total motivation; all F-values are significant at the .001-error level. 
The third cluster analysis was based on enhancement and coping scores which were adjusted for the population norm and the individual total motivation of enhancement and coping. The results revealed that in both randomly selected subsamples participants in group one had a significantly higher level $(\mathrm{p}<.001)$ of enhancement and social motives and a significantly lower level $(\mathrm{p}<.001)$ of coping and conformity motives than those in group two (Table 8-1). Moreover, there was a high concordance with the results obtained from the coding procedure ( $\kappa$-values of .88 and .90).

To test the concurrent validity, a multivariate regression analysis was conducted, with group membership as an independent variable (Table 8-2). Results reveal that enhancement drinkers had on average 2.9 risky drinking occasions in the last 30 days (3.2 in Sample B); coping drinkers had 0.1 fewer occasions (0.5 in Sample B). Coping drinkers were found to be significantly less often male and to be younger than enhancement drinkers (significant only in Sample A). Enhancement drinkers indicated that on average they had been out on 79 evenings in the last year (89 evenings in Sample B) compared to 72 evenings among coping drinkers (70 evenings in Sample B). The differences were significant in Sample B. In both replications, coping drinkers were significantly less satisfied with their relationships with parents and friends. Coping drinkers were found to be more likely to drink at home and to have a lower proportion of drinking peers. Taken together, the results obtained in Sample A are consistent with those obtained in Sample B. Although not always statistically significant, the direction of effects (positive or negative) was the same in the two randomly selected sub-samples. This was the case for all dependent variables. 
Table 8-2: Results of multivariate regression analyses with group membership of the coding procedure (enhancement drinkers $=0$ and coping drinkers $=1$ ) as an independent variable and domains of adolescent functioning as dependent variables

\begin{tabular}{|c|c|c|c|c|}
\hline & \multicolumn{2}{|c|}{ Sample A (n=1221) } & \multicolumn{2}{|c|}{ Sample B (n=1228) } \\
\hline & Intercept & B (SE) & Intercept & $\mathrm{B}(\mathrm{SE})$ \\
\hline RSOD frequency & 2.92 & $-0.13(0.15)$ & 3.24 & $-0.49^{* *}(0.17)$ \\
\hline \multicolumn{5}{|l|}{ Demographics } \\
\hline Sex & -1 & $-0.33^{\star * *}(0.08)$ & $-{ }^{1}$ & $-0.25^{\star * *}(0.07)$ \\
\hline Age & 15.33 & $-0.24^{\star \star *}(0.06)$ & 15.22 & $-0.08(0.06)$ \\
\hline \multicolumn{5}{|l|}{ School / leisure time } \\
\hline Poor academic performance & 2.50 & $0.09(0.05)$ & 2.52 & $0.08(0.05)$ \\
\hline Outgoing in the evening & 78.54 & $-6.35(5.18)$ & 89.05 & $-19.05^{\star * *}(5.32)$ \\
\hline \multicolumn{5}{|l|}{ Unsatisfactory relationship } \\
\hline with parents & 1.81 & $0.15^{\star \star}(0.05)$ & 1.77 & $0.15^{\star \star}(0.05)$ \\
\hline with friends & 1.35 & $0.10^{\star *}(0.04)$ & 1.30 & $0.16^{\star * *}(0.04)$ \\
\hline \multicolumn{5}{|l|}{ Drinking context } \\
\hline Drinking at home & -1 & $0.42^{\star \star *}(0.10)$ & -1 & $0.24^{* *}(0.10)$ \\
\hline Proportion of drinking peers & 0.39 & $-0.02(0.01)$ & 0.41 & $-0.04^{* *}(0.02)$ \\
\hline
\end{tabular}

\section{DISCUSSION}

The present study aimed to develop and validate an analytical approach to identify and classify adolescents according to their motivation to engage in drinking. The two groups that emerged from the coding procedure can be reasonably labeled "enhancement drinkers" and "coping drinkers". Consistent with research on drinking motives scales (e.g., Cooper, 1994; Kuntsche, Knibbe, Gmel, \& Engels, 2006a), enhancement drinkers scored not only higher on enhancement motives and lower on coping motives but also higher on social motives and lower on 
conformity motives than coping drinkers. This was the case in both randomly selected sub-samples and demonstrates the reliability of the coding procedure classification.

The results obtained by the third k-means cluster analysis confirmed the results obtained by the coding procedure. Although the statistical procedure and the adjustment of the motive scores were different, in both randomly selected subsamples the two approaches resulted in a highly congruent classification of enhancement and coping drinkers. By cross-matching membership generated by the two approaches, $93.9 \%$ of the participants in Sample A and 95.0\% in Sample B were correctly classified as enhancement and coping drinkers. Together with the highly significant $\kappa$-value of .88 in Sample A and .90 in Sample B (note that values above .75 represent excellent concordance, Fleiss, Levin, \& Paik, 2003), this result demonstrates the high convergent validity of the coding procedure to classify RSOD adolescents according to their motivation to engage in drinking. This was not the case for the cluster analysis which was based on the original enhancement and coping scores, or on scores which were adjusted exclusively for the population norm. In these two cluster analyses, adolescents were classified as more or less highly motivated but no differences in the particular drinking motive dimensions emerged. These results demonstrate the need to adjust the enhancement and coping dimensions not only by the population norm but also by the individual score in the cluster analysis to be able to classify RSOD adolescents into groups of enhancement and coping drinkers, whereas for the coding procedure only population norms are needed.

To test the concurrent validity, a multivariate regression analysis was conducted. Present results were consistent with research on drinking motives scales. Enhancement drinkers were found to have a higher proportion of boys and to be older than coping drinkers (cf. Cooper, 1994; Kuntsche, Knibbe, Gmel, \& Engels, 
2006a). Enhancement drinkers were also found to go out more frequently in the evenings and to have a higher proportion of drinking peers and a lower likelihood to drink at home than coping drinkers (cf. Cooper, 1994). In addition, coping drinkers were found to have a higher level of poor academic performance (cf. Kuntsche, Knibbe, Gmel, \& Engels, 2006a) and unsatisfactory relationships with their parents and friends (cf. Bradley, Carman, \& Petree, 1992; Karwacki \& Bradley, 1996) than enhancement drinkers. These results were similar in both replications and again demonstrate the reliability of the classifications resulting from the coding procedure.

A major advantage of the coding procedure is that any given adolescent who attends counseling or treatment, or adolescents in any given school or community can be identified as either enhancement or coping drinkers. Another advantage of this coding approach is the fact that no complex statistical procedure (such as cluster analysis) is needed. Moreover, the step-by-step description in the Appendix provides clinical psychologists, physicians, prevention specialists, teachers, school administrators and social workers with an easy-to-use diagnostic tool. The population norms of enhancement and coping motives given in the Appendix came from a national representative sample of nearly 2,500 RSOD adolescents in Switzerland. Although drinking motives have been shown to be relatively stable across cultures (e.g., Kuntsche, Knibbe, Gmel, \& Engels, 2005, 2006a), studies in other cultures with other age groups have to use their own population norms of enhancement and coping motives among RSOD adolescents in other countries. Although the present study demonstrated the reliability of the coding procedure by means of randomly selected sub-samples, longitudinal designs are needed to measure its test-retest reliability and the predictive validity.

Concerning prevention, it has been argued that effective programs should be targeted at homogenous groups of adolescents who share a particular constellation 
of needs and problems rather than single programs that are universally applied to all adolescents (Hawks, Scott, McBride, Jones, \& Stockwell, 2002; Masterman \& Kelly, 2003; Turrisi, Padilla, \& Wiersma, 2000). In the present study, two risk groups, i.e. enhancement and coping drinkers, were identified among RSOD adolescents. These two groups not only differed in their motivation to engage in drinking but also in various other aspects such as demographics, school and leisure time variables, social relationships, and drinking contexts. It appears that among risky single occasion drinkers there is one group of enhancement drinkers who drink to better enjoy parties, to have fun, and to get drunk; this comprises more boys and older adolescents and have better social relationships, more drinking peers, and go out more frequently in the evenings. The second group of coping drinkers who drink not to be rejected by others and to alleviate problems and worries consists of more girls and younger adolescents; the members of this group are also less satisfied with their social relationships, and often stay in and drink at home.

Due to these differences, it appears promising to target enhancement and coping drinkers with specific prevention programs that take into account their specific needs and problems. Cooper, Frone, Russell, and Mudar (1995), for example, suggested that interventions aimed at reducing levels of stress and providing alternative ways of coping with stress may be maximally beneficial for individuals who rely on alcohol as a way of coping with negative emotions. Accordingly, enhancing multiple competences through life skills training (e.g., Botvin, 2000, for a review) appears to be a very promising approach for coping drinkers. This type of training focuses on enhancing self-esteem and adopting coping strategies for managing stress and anxiety.

In contrast, providing alternative sources of stimulation (see e.g., Correia, 2004, and Komro \& Toomey, 2002, for reviews), or cognitive restructuring techniques 
aimed at altering expectancies of the enhancing effects of alcohol might be more appropriate for individuals who drink primarily to enhance emotional experiences (Cooper, Frone, Russell, \& Mudar, 1995). In addition, for enhancement drinkers who were found to go out frequently in the evenings (see also Cooper, 1994), it appears promising to promote safer drinking environments (e.g., Homel, Carvolth, Hauritz, McIlwain, \& Teague, 2004; World Health Organization (WHO), 2005). Since their heavy drinking appears to occur often in social situations such as at parties, celebrations, or social gatherings, intervention approaches focusing on social influences (e.g., Botvin, 2000, for a review) are more promising for enhancement drinkers. Components of such programs, like normative education or resistance skills training, are designed to impede the modeling of alcohol use and to reinforce resistance to offers of alcohol by peers and advertising in the media.

Carey and Correia (1997) argue that drinking motives play a role in predicting excessive drinking and other problem behaviors and may be useful in early identification and intervention. The present study provides a coding procedure to identify two risk groups among RSOD adolescents that differed in various aspects and should be targeted by different prevention approaches. The results suggests that the DMQ-R, a validated instrument for the assessment of drinking motives for research purposes (Cooper, 1994; Kuntsche, Knibbe, Gmel, \& Engels, 2006a; MacLean \& Lecci, 2000), could also be used as a diagnostic tool in relation to intervention and prevention. Drinking motives are not only defined as the most proximal factors of alcohol use but also tend to reflect distal factors such as culture, personality, or expectancies (see Cox \& Klinger, 1990; and Kuntsche, Knibbe, Gmel, \& Engels, 2006b). For example, Windle and Windle (1996) concluded from their study that drinking motives, which typically have been viewed as alcoholspecific in terms of their relevance for dysfunctional or problematic behavior, also have a predictive value for other domains of adolescent functioning. Prevention 
programs that are based on homogenous groups of adolescents who drink for a particular constellation of motives might therefore effectively target not only risky drinking among adolescents but also a variety of other problems such as social rejection or violent behaviors. 


\section{APPENDIX}

With the following questionnaire and coding procedure it is possible to identify an adolescent who drinks heavily as either an "enhancement drinker" or a "coping drinker".

1. The adolescent has to fill out the following 11 questions:

Thinking of all the times you drank in the past year, how often ...

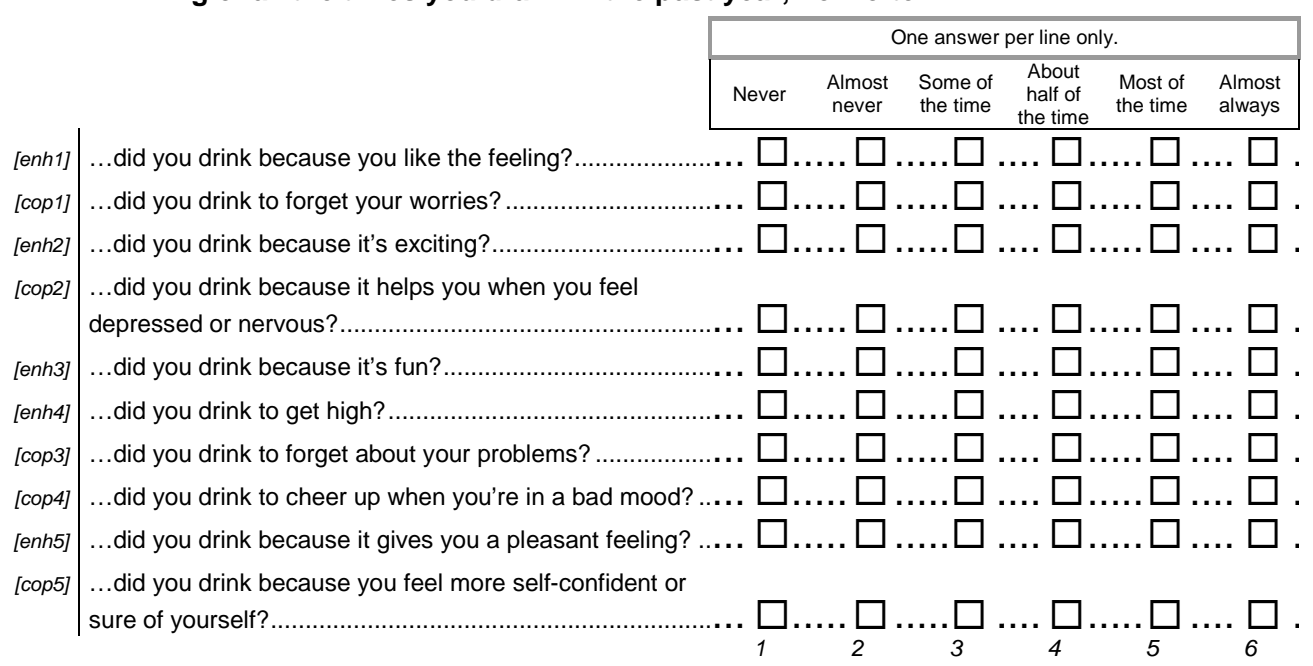

Think now back over the LAST 30 DAYS. How many times (if any) have you had...

[alc] ...five or more drinks in a row? (A "drink" is a glass of

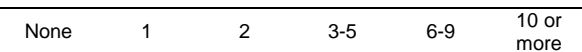

wine (approx. $15 \mathrm{cl}$ ), a bottle or can of beer (approx. 50

$\mathrm{cl})$, a shot glass of spirits (approx. $5 \mathrm{cl}$ ) or a mixed drink.) .... $\square . \ldots . . \square \ldots . . \square \ldots . . \square \ldots . . \square \ldots . \square$. 
2. Make sure that the adolescent had at least one heavy drinking occasion in the last 30 days ("alc" not equal "None").

3. Add all values (indicated on the bottom of the scale) for the five enhancement items (enh1 to enh5) and divide the resulting summary score by five to obtain the enhancement summery score (ess). Add all values of the five coping items (cop1 to cop5) and divide the resulting summary score by five to obtain the coping summery score (css).

4. Subtract 3.40 (the national enhancement norm for heavily drinking adolescents) from the obtained enhancement summary score (ess) and divide the resulting value by 1.16 (the national norm for the standard deviation) to obtain the standardized enhancement summary score (sess). Subtract 2.31 (the national coping norm for heavily drinking adolescents) from the obtained coping summary score (css) and divide the resulting value by 1.19 (the norm for the standard deviation) to obtain the standardized coping summary score (scss).

5. If the value of the standardized enhancement summary score (sess) is greater than the value of the standardized coping summary score (scss), the adolescent is classified as an "enhancement drinker". If the sess-value is lower than the scssvalue, the adolescent is classified as a "coping drinker". 


\section{Chapter 9}

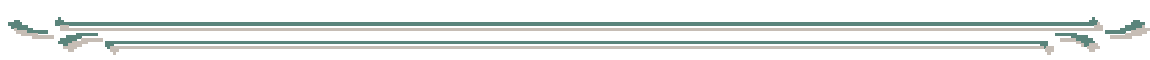

General discussion 


\section{Main outcomes of the present work}

The key findings that emerged from Chapters 2 to 8 are briefly summarized in Table 9-1.

In the following paragraphs, the main outcomes of Chapters 2 to 8 are integrated into a broader perspective. In the first part of the discussion, issues related to the measurement of drinking motives and theoretical considerations are discussed. This primarily concerns the four-dimensional factor structure, the categorization of drinkers according to motives, and the links between expectancies, motives, and implicit cognitions. The explanatory value of drinking motives is discussed in the second part. This primarily concerns alcohol-related outcomes such as risky drinking and alcohol-related problems and adolescent problem behaviors which go beyond excessive drinking, like bullying and fighting. In the third part, a developmental perspective was used to discuss the limitations of the present work and the direction of future research. In the final part, prevention recommendations are given, primarily specific approaches for enhancement and coping drinkers using the personality-motive link for prevention, as well as ideas on the development of motive-tailored feedback interventions. 
Table 9-1: Overview of the key findings of Chapters 2 to 8

Chapter, Findings

2. Different items and instruments were used to assess drinking motives, mostly in very specific populations.

The most frequently indicated social motives were not linked to heavy drinking and related problems. Enhancement motives were associated with heavy drinking. Coping motives were associated with both heavy drinking and drinking problems as well as with other forms of problem behavior, such as low academic achievement and delinquency. The greater the general drinking motivation the higher the alcohol use.

3. In early adolescence, only one general drinking motive factor was found, whereas in late adolescence the associations between drinking motives and consumption or consequences are more specific and vary for boys and girls.

Two groups of young people with a particular personality and motive structure were found:

(a) Those who drink for enhancement motives were found to be extraverted, impulsive, and aggressive.

(b) Those who drink for coping motives were found to be neurotic and to have a low level of agreeableness as well as a negative self-image.

4. The four-dimensional factor structure has been confirmed in a nationally representative Swiss sample, for boys and girls, for different age groups, and for different linguistic regions. Mirroring the international literature, enhancement motives and coping motives were positively associated with alcohol use and risky drinking. Coping motives were positively related to different problems such as poor school performance and violent behavior.

5. The link between expectancy and alcohol use was mediated by drinking motives. This was the case for different expectancy and motive dimensions as well as for the general drinking motivation and general drinking expectancy.

6. Adolescents who preferred beer and spirits over wine and alcopops were likely to indicate enhancement motives and to become involved in risky drinking (bivariate models).

The link between beer preference and alcohol use did not remain significant when enhancement motives were taken into account, demonstrating the mediation of beer preferences through motives. The link between social motives and alcohol use was closer among adolescents who did not prefer alcopops. Coping motives were related to risky drinking. This link was particularly strong among adolescents who preferred spirits, demonstrating that this type of alcohol may be the drink of choice for adolescents coping with problems.

7. Enhancement motives were only indirectly (through alcohol use) related to bullying and fighting. Coping motives were both directly and indirectly related. In contrast to enhancement motives, coping drinkers experienced problems regardless of their alcohol use.

Conformity motives were strongly and directly related to bullying and fighting. In the context of violent behaviors it appears to be particularly important to drink in order to fit into a peer group and not to be rejected by peers.

8. Risky drinking adolescents are classified in two categories of enhancement and coping drinkers. Enhancement drinkers were found to go out more frequently in the evenings and to have more satisfactory social relationships, a higher proportion of drinking peers and a lower likelihood of drinking at home than coping drinkers. Enhancement and coping drinkers should be targeted with specific prevention approaches, which take into account their specific motives, needs, and problems. 


\section{Measurement and theoretical considerations}

\section{Measuring motives and categorizing drinkers according to motives}

The literature review in Chapter 2 revealed that different approaches were used to assess drinking motives: qualitative interviews and quantitative studies using single items or different multidimensional scales. Even among studies that used multidimensional classifications a high degree of heterogeneity was found: 54 studies used 25 different instruments, in which 10 to 40 items were grouped into 2 to 10 dimensions. Importantly, across studies dimensions with similar names (e.g., social motives) consisted of qualitatively different items and the same items had been allocated to different motive dimensions. The most commonly used instrument was the Drinking Motives Questionnaire Revised (DMQ-R, Cooper, 1994). This questionnaire was based on the theoretical considerations of the Motivational Model of Alcohol Use (Cox \& Klinger, 1988), i.e. that drinking motives can be classified according to the valence (positive or negative) and source (internal or external) of what individuals expect to achieve by drinking. By crossing these two dimensions, four distinct drinking motive dimensions can be distinguished: enhancement (positive-internal), social (positive-external), conformity (negative-external), and coping (negative-internal). The literature review in Chapter 2 also revealed that the DMQ-R was exclusively used in North American studies.

In Chapter 4, the Drinking Motive Questionnaire Revised (DMQ-R, Cooper, 1994) was replicated and validated for the first time outside the North American context, namely in a nationally representative sample of adolescents in Switzerland. The data reported in this chapter (as well as in Chapters 5 to 8) came from a sample of more than five thousand alcohol-using $8^{\text {th }}$ to $10^{\text {th }}$ graders who participated in the 2003 European School Survey Project on Alcohol and Drugs (ESPAD). Results 
demonstrated that the four-dimensional factor structure could be confirmed for the total sample as well as separately for boys and girls, different age groups (12- to 14-year olds and 15- to 18-year olds), and different linguistic regions (German-, French-, and Italian-speaking parts of Switzerland). Additionally, the results were highly consistent with those obtained in a sample of adolescents in the US more than 10 years ago (Cooper, 1994). To conclude, it has been shown that the DMQ-R is a valid and reliable instrument to assess adolescent drinking motives not only in North America but also in Switzerland. Given the multicultural character of Switzerland, this suggests that the DMQ-R is also valid in other drinking cultures in Europe.

Apart from the usefulness of the DMQ-R as a validated instrument for the assessment of drinking motives for research purposes (cf. Chapters 2 and 4), also its usefulness as a diagnostic tool in relation to intervention and prevention has been demonstrated. In Chapter 8, two risk groups, i.e. enhancement and coping drinkers, were identified among risky single occasion drinking adolescents (i.e. those who drink 5 or more drinks on a single occasion at least monthly). These two groups differed in their motivations to engage in drinking and also in various other aspects such as demographics, school and leisure time variables, social relationships, and drinking context. Thus, the results demonstrated that risky single occasion drinking (RSOD) adolescents are not a homogeneous group, and that RSOD served different needs and purposes for adolescents. To our knowledge, this study was the first to empirically show that RSOD adolescents are not only heterogeneous in terms of social and psychological factors (Kuntsche \& Gmel, 2004) but that they differ also in terms of the motivation to engage in drinking. Given these differences, it appears promising to target enhancement and coping drinkers with specific prevention programs that take into account their specific 
needs and problems (for further information, see the "Recommendations for prevention" section below).

\section{Expectancies, motives, and implicit cognitions}

The Motivational Model of Alcohol Use assumes that each person (consciously or unconsciously) makes a decision about whether he or she will consume alcohol (Cox \& Klinger, 1988, 1990). According to the model, the decision to drink is embedded in personality characteristics (e.g., extraversion, sensation-seeking), socio-cultural factors (e.g., drinking styles), environmental factors (e.g., alcohol availability), situational factors (e.g., reinforcement from recent drinking), alcohol expectancies, and lastly drinking motives. Thus, drinking motives are assumed to be the final path towards alcohol use, i.e. the gateway through which more distal influences, such as alcohol expectancies, are mediated.

Numerous studies demonstrated that both alcohol expectancies and drinking motives are related to alcohol use (for reviews, see Chapter 2 and Baer, 2002; Ham \& Hope, 2003; Jones, Corbin, \& Fromme, 2001). However, few studies empirically addressed both the associations between the two concepts and their links to alcohol use (Catanzaro \& Laurent, 2004; Cooper, Frone, Russell, \& Mudar, 1995; Cronin, 1997; Nagoshi, Nakata, Sasano, \& Wood, 1994; Read, Wood, Kahler, Maddock, \& Palfai, 2003). In Chapter 5, it was empirically tested whether the link between alcohol expectancies and alcohol use is actually mediated by drinking motives. Although all expectancy and all motive dimensions were closely related to a range of alcohol use measures, the expectancy link in multiple models (in which both expectancies and motives were taken into account to explain alcohol use) was reduced to zero, yet the motive link remained basically the same. This demonstrated the strongest form of mediation (Baron \& Kenny, 1986). Moreover, 
the mediation of drinking motives in the link between alcohol expectancies and alcohol use could be confirmed for different expectancy and motive dimensions as well as for the general motivation (measured by a summary score of the different drinking motive dimensions) and general expectancy (measured by a summary score of the different alcohol expectancy dimensions). These results demonstrated that even if an adolescent expects a desired effect to occur when drinking alcohol he or she will not necessarily drink to achieve the expected effect (Cooper, 1994). To actually engage in drinking, the realization of the expected effect in terms of a decision to drink depends on whether there is actually a motivation to drink to obtain the desired effect.

The assessment of drinking motives and alcohol expectancies via questionnaires covers only one aspect of alcohol-related cognitions. They shed light on what can be called the "visible side of the moon". Although some authors have argued that engaging in drinking can be considered as rational, goal-directed action (see Maggs, 1997, for an overview) and that the personal motivation to engage in drinking can be consciously reflected at any given moment or situation in which a goal-related cue is encountered (see Chapter 1), the Motivational Model stresses that decisions about drinking can also be taken automatically and unconsciously (Cox \& Klinger, 1988). The latter, which can be referred to as the "dark side of the moon", comprise aspects of behavior which are not consciously present on a permanent basis or directly accessible by the consumers' introspection. Unintrusive methods such as behavioral measures (e.g., reaction times on pictures displayed on a computer screen or on word associations) are more appropriate to assess processes which go beyond what people are willing or even able to tell, e.g., in questionnaires (Sher, 2006).

Recently, authors have suggested that social behavior is determined by the joint operation of two systems, each of which qualitatively represent and transform 
social information in different ways (e.g., Smith \& DeCoster, 2000; Strack \& Deutsch, 2004): These are the reflective system which contains explicit processes that are deliberate, slow and require awareness, and the impulsive system which contains implicit processes that are spontaneous, fast, and mostly outside of conscious awareness. This Dual-Process Model has also been used to explain addictive behaviors (Deutsch \& Strack, 2006; Wiers, Bartholow, van den Wildenberg, Thush, Engels, Sher, Grenard, Ames, \& Stacy, 2007). It states that alcohol use results from the operation of two semi-independent systems: a reflective system with explicit alcohol-related cognitions such as alcohol expectancies and drinking motives, and a fast associative impulsive system of implicit alcohol-related cognitions which includes, for example, automatic appraisal of alcohol-related stimuli. Implicit cognitions are supposed to better reflect neurobiological processes than explicit cognitions (Wiers, Houben, Smulders, Conrod, \& Jones, 2006). Moreover, clinical studies (e.g., Berridge, 2001) suggested that incentives (possibly reflected by implicit cognitions) and cognitive expectations are located in different areas in the brain.

According to the assumption of the Dual-Process Model, explicit cognitions such as alcohol expectancies were found to be only moderately related (Stacy, 1997) or even unrelated (Thush \& Wiers, 2007) to implicit cognitions, but both explicit and implicit cognitions predicted alcohol use independently from each other (e.g., Stacy, 1997; Thush \& Wiers, 2007; Wiers, van Woerden, Smulders, \& de Jong, 2002). Sometimes, both systems can even provide contradictory information resulting in a seemingly irrational behavior such as smoking, harmful drinking patterns or panic attacks in objectively harmless situations (Deutsch \& Strack, 2006). For example, most smokers know that smoking causes cancer but they continue to smoke; most heavy drinkers know that heavy drinking is bad for their health but they still drink large quantities (e.g., each time they are in a bar with 
friends); people normally know that mice are not dangerous but some still scream and jump on chairs each time they see one.

Research found that college students who associated alcohol-related words (e.g., whisky, beer) faster with negative words (e.g., bad, unpleasant, stupid) in an Implicit Association Test scored high on positive alcohol expectancies (e.g., drinking alcohol makes me feel energetic) assessed with a questionnaire (e.g., Wiers, van Woerden, Smulders, \& de Jong, 2002; Wiers, van de Luitgaarden, van den Wildenberg, \& Smulders, 2005). However, among 11- to 16-year olds, the opposite appears to hold - implicit positive associations (i.e. reaction times between positive words such as happy, nice, cozy and alcohol-related words) and explicit negative expectancies (e.g., drinking alcohol makes me feel sad) predicted alcohol use both cross-sectionally and one year later (Thush \& Wiers, 2007). Based on these studies, implicit associations measured in experiments and self-reported expectancies cover different aspects of alcohol-related cognitions.

Existing studies comparing implicit and explicit cognitions have focused on expectancies as explicit cognitions. Given that expectancies and motives are strongly interrelated (see Chapter 5), it is plausible that there are also implicit alcohol-related cognitions behind self-reported drinking motives. These implicit cognitions may provide supplementary information on the issue of why young people drink. An investigation of the implicit alcohol-related cognitions in relation to drinking motives was beyond the scope of this thesis. Although research on implicit alcohol-related cognitions may provide some new insights, it should be kept in mind that such research does not come without its limitations. For example, complex laboratory designs prevent large sample sizes and are susceptible to selection effects. This may limit the possibilities of drawing any conclusions for the general population, and makes it difficult to integrate in large-scale prevention programs. 


\section{The explanatory value of drinking motives}

Drinking motives and alcohol-related outcomes in adolescence

The literature review in Chapter 2 shows that most adolescents drink for social motives, and that social motives were generally not related to heavy drinking and alcohol-related problems (one exception was social drinkers who did not prefer alcopops, see Chapter 6 for more information). In contrast, enhancement and coping motives were associated with risky drinking. Drinking to cope was also found to be associated with alcohol-related problems and those that go beyond alcohol use (see also Chapter 4). The literature review in Chapter 2 also revealed that the fourth drinking motive dimension according to the valence* source classification containing motives to avoid social rejection (labeled as conformity motives) were neglected in most studies to date, although this set of motives was shown to form an independent dimension among adolescents and young adults (MacLean \& Lecci, 2000; Cooper, 1994) and was related to low levels of alcohol use.

These results, which were mainly taken from North American studies, were also found among adolescents in Switzerland. The results in Chapter 4 confirmed that enhancement and coping motives are positively related to different alcohol use measures (i.e. drinking frequency in the last 30 days, usual quantity consumed at a typical occasion, and 5+ drinking) and that conformity motives are negatively related. The results also showed that enhancement and coping but not social or conformity motives were positively related to alcohol-attributed problems.

Taken together, Chapters 2 and 4 provide evidence of how the different drinking motive dimensions are related to different alcohol use patterns. Until now not much was known about drinking motives and adolescents' preferences for a particular alcoholic beverage and whether motives modify the association between beverage 
preference and drinking patterns. The results in Chapter 6 showed that the link between beer preference and risky drinking was no longer significant when enhancement motives were taken into account. This means that beer preference in itself might not lead to risky drinking but that those who like to have fun and to get drunk prefer beer to obtain the desired effect. Beer is rather cheap due to low taxes and advanced brewing technologies (World Health Organization (WHO), 1999, 2001). Therefore, beer might be the beverage of choice for adolescents who like to get drunk but are on a restricted budget (Edwards, Anderson, Babor, Casswell, Ferrence, Giesbrecht, Godfrey et al., 1994).

The results in Chapter 6 also showed that alcopops are very popular among adolescents and most of them drink for social motives (see also Chapters 2 and 4). Those who drink for social motives and prefer alcopops drink even more moderately than those with social motives preferring the other types of beverages, perhaps due to the higher taxes on alcopops and the higher price of these beverages. No link between coping motives and beverage preference was found. However, adolescents who scored high on coping motives and who preferred spirits were found to have a particularly high frequency of risky drinking. Since the consumption of spirits raises alcohol concentration in the blood more rapidly than other beverages (Smart \& Walsh, 1995, for a review), they might be considered by coping drinkers to be particularly efficient in (temporarily) banishing problems or allowing them to forget their worries.

Drinking motives and adolescent problem behaviors which go beyond excessive drinking

The results presented in Chapters 2 and 4 demonstrated that coping motives were associated both with problems which were directly alcohol-related (e.g., involved 
in a fight because of alcohol consumption) and with forms of adolescent problem behavior that cannot be attributed to alcohol use (e.g., low academic achievement and delinquency in general). However, in most of these studies, different problems were combined in one indicator variable and the assessment of problem behaviors was exclusively alcohol-attributed.

The study in Chapter 7 investigated direct and indirect links (through alcohol use) between drinking motives and different violent behaviors (i.e. bullying and fighting which were measured as non-alcohol attributed). The results showed that coping motives were both directly and indirectly associated with violence, particularly among girls. These findings support the view that deficits in coping, namely coping through alcohol consumption, is an expression of an underlying multiple problem behavior syndrome (e.g., Brener \& Collins, 1998: Jessor \& Jessor, 1977; Osgood, Johnston, O'Malley, \& Bachman, 1988) in which risky drinking clusters with violence, delinquency, unprotected sexual intercourse etc. Enhancement motives were indirectly (through alcohol use) associated with violent behaviors but not directly. This result is in accordance with the one reported in Chapter 4, namely that enhancement motives are related to alcohol-attributed problems, but not when problems are assessed as non-alcohol related. It appears that adolescents who mainly drink to have fun and to get drunk experience problems such as being involved in violent acts because of their risky drinking, but they are not prone to problems which are not linked to risky drinking and its related consequences (see also Chapter 8).

The results presented in Chapter 7 further revealed that conformity motives were the strongest predictor of bullying and fighting, even stronger than alcohol use itself. At first glance, it appears strange that adolescents who score high on conformity motives have low drinking levels but high levels of violence despite the strong link between alcohol use and violence. However, additional analyses 
revealed that there are two subgroups of conformity drinkers: those who were not violent also had a low level of alcohol use in terms of frequency, usual quantity, and risky drinking, whereas those who were violent had high levels of alcohol consumption. According to the literature, violence often occurs together with risky drinking in particular peer groups (e.g., Kuntsche \& Gmel, 2004; Rossow, Pape, \& Wichstrom, 1999). Thus, alcohol use might be perceived as a group norm among violent adolescents. By drinking to conform to the perceived drinking level of violent peers, even those adolescents who do not normally drink might do so in order to avoid becoming a victim of violent acts when in the company of violent peers.

\section{Limitations and further research directions: A developmental perspective of drinking motives}

Beyond the results of the present work and the current state of knowledge in the literature, there are several issues which should be addressed in future drinking motive research. This concerns the development of drinking motives and the resulting consequences. For example, Cox and Klinger $(1988 ; 1990)$ argue in their Motivational Model of Alcohol Use that historical (genetic, personality, sociocultural, and environmental characteristics), current (e.g., quality of life), and situational (e.g., alcohol availability, drinking peers) factors are the basis for individual alcohol expectancies, which in turn are precursors for drinking motives and, ultimately, alcohol use. Although there is empirical evidence to support each part of the model (cf. Cox \& Klinger, 1988 and Chapters 1 and 5), no study, to our knowledge, has ever investigated the assumed causal chain (from historical, current, and situational factors to different alcohol expectancies, different drinking motives, drinking patterns, and eventually alcohol-related and other problems in 
life) in the same individuals over time. To confirm such a causal chain would not only back up the theoretical model but would also make a major contribution to the understanding of alcohol use, risky drinking and related problems in adolescence and beyond. For example, the results presented in Chapter 5 clearly demonstrated that drinking motives function as mediator in the link between alcohol expectancies and alcohol use. However, both this study and earlier studies which investigated this type of mediation were exclusively based on cross-sectional data. Using longitudinal data in cross-lagged regression models, it would be possible to investigate the causal chain of alcohol expectancies, drinking motives, and alcohol use over time. Such a study could provide a stronger demonstration of mediation.

Moreover, a longitudinal study conducted from late childhood to early adulthood could answer a variety of further research questions. The literature review in Chapter 3, for example, concluded that a developmental trend existed - from a general drinking motivation (e.g., one single factor) in late childhood and early adolescence towards more specific drinking motive patterns (e.g., four distinct drinking motive categories, see Chapter 4) in subsequent years. Evidence presented in Chapter 3 also points to the differences in the development of enhancement, social, conformity, and coping motives among boys and girls during adolescence and early adulthood. Previous research demonstrated that drinking patterns such as risky single occasion drinking also develop differently among boys and girls in the same time period (Jackson, Sher, Cooper, \& Wood, 2002; Kuntsche, Gmel, Wicki, Rehm, \& Grichting, 2006). However, no longitudinal study to date has investigated to what degree the development of gender differences in drinking motives are responsible for the development of gender differences in alcohol use patterns during adolescence and early adulthood. Such a study would not only contribute to clarifying the role of drinking motives in the development of gender-specific 
drinking patterns but might also be important in any work aiming to clarify to what degree gender-specific prevention is necessary in adolescence.

The literature review in Chapter 3 also provides evidence that drinking motives are situation-specific, i.e. adolescents drink for different motives according to the characteristic of the drinking situation (e.g., Cooper, 1994; Kairouz, Gliksman, Demers, \& Adlaf, 2002). In contrast, Chapter 3 revealed that drinking motives were strongly linked with personality factors which were shown to be invariant across situations and even across the life span (e.g., Gotham, Sher, \& Wood, 1997; McCrae, Costa, Terracciano, Parker, Mills, De Fruyt, \& Mervielde, 2002). Furthermore, as mentioned above, drinking motives such as coping are supposed to be an indicator of an underlying multiple problem behavior syndrome (e.g., Brener \& Collins, 1998; Jessor \& Jessor, 1977; Osgood, Johnston, O'Malley, \& Bachman, 1988) which is also likely to be stable across situation and even across the life span (e.g., Moffitt, 1993). Taken together, it remains to be seen to what degree or under which circumstances individual motives depend on the characteristics of the drinking situation and not on the (personality) characteristics of the drinker and vice versa. Moreover, the contribution of both situation and personality might change during adolescence. For example, in early adolescence when drinking habits are not yet established drinking motives and drinking levels might depend more strongly on the characteristics of the situation than on individual characteristics, whereas in late adolescence the opposite might be the case.

Bearing in mind the time frame, the development of drinking motives and their association with alcohol use over time, different gender trajectories, and differences in drinking situations and personality might help to further understand the disparities in the few longitudinal studies which investigated the prediction of drinking motives on subsequent alcohol use (see Chapter 3). One study found that 13- to 16-year old adolescents who scored high on enhancement motives had high 
levels of risky drinking five to six years later (Bradizza, Reifman, \& Barnes, 1999), whereas among college students (Read, Wood, Kahler, Maddock, \& Palfai, 2003) and 18- to 65-year olds (Carpenter \& Hasin, 1998b) this was not the case for shorter time lags. One study found a link between coping motives and alcoholrelated problems among 18- to 65-year olds one year later (Carpenter \& Hasin, 1998b), whereas another study among college students did not (Read, Wood, Kahler, Maddock, \& Palfai, 2003). Two relatively new studies which were published after the literature review in Chapters 2 and 3 had been conducted demonstrated that enhancement motives were positively related and conformity motives negatively related to drinking quantity among college students in threeweek follow-ups (Mohr, Armeli, Tennen, Temple, Todd, Clark, \& Carney, 2005) and among adolescents in four-month follow-ups (Mushquash, Stewart, Comeau, $\&$ Conrod, 2006).

\section{Recommendations for prevention}

\section{Interventions for enhancement and coping drinkers}

As shown in Chapters 2 and 4, enhancement and coping motives were positively related to risky drinking in adolescence. Thus, it appears that even if adolescents were similar in terms of their drinking patterns, their motivation to engage in drinking might still be completely different. Neighbors, Larimer, and Lewis (2004) concluded from their study that "knowing why college students drink should not only inform the types of interventions we develop, but also enable us to identify the best (and worst) candidates for particular types of interventions" (p. 435). Therefore, a procedure was developed in Chapter 8 to distinguish among drinkers with similar drinking patterns (i.e. risky drinkers) two groups which differed in terms of drinking motives. Two distinct groups were identified which could 
reasonably be labeled as enhancement and coping drinkers. These two groups not only differed in their motivation to engage in drinking but also in various other aspects such as demographics, school and leisure time variables, social relationships, and drinking context.

Because enhancement and coping drinkers have different motives and drink in different environments it might be promising to target them differently with specific prevention programs that take into account their specific needs and problems (e.g., Hawks, Scott, McBride, Jones, \& Stockwell, 2002; Masterman \& Kelly, 2003; Turrisi, Padilla, \& Wiersma, 2000). The developed coding procedure can be used by clinical psychologists, medical doctors, prevention specialists, school administrators, social workers etc. as diagnostic tool to identify heavily drinking adolescents either as enhancement or as coping drinkers to which prevention attempts can be applied differently according to their drinking motivation and associated needs and problems. For example, providing alternative and less risky sources of excitement (see e.g., Correia, 2004; Komro \& Toomey, 2002, for reviews), or cognitive restructuring techniques aimed at altering expectancies of the enhancing effects of alcohol might be more appropriate for individuals who drink primarily to enhance emotional experiences (Cooper, Frone, Russell, \& Mudar, 1995). In contrast, interventions aimed at reducing levels of stress and providing alternative ways of coping with stress through life skills training may be more beneficial among individuals who rely on alcohol as a way of coping with negative emotions (Cooper, Frone, Russell, \& Mudar, 1995; Botvin, 2000). Similarly, since coping drinkers were likely to drink at home (see also Cooper, 1994) prevention programs which aim at restricting unsupervised drinking of adolescents (Kypri, Dean, Kirby, Harris, \& Kake, 2005; McBride, Farringdon, Midford, Meuleners, \& Phillips, 2003) might be additionally effective for coping drinkers. 
Apart from these prevention strategies, the present work provided information that also policy measures might be effective to reduce alcohol use among enhancement and coping drinkers. In Chapter 8, enhancement drinkers were found to have drinking peers and to go out frequently in the evenings and they are likely to drink in bars (see also Cooper, 1994). In this case, it appears important to reduce underage sales of alcohol in public drinking places, for example by increasing enforcement and/or through server training programs (Grube, 1997; World Health Organization (WHO), 2005). The results presented in Chapter 6 showed that adolescents who frequently drink for coping motives had particularly high levels of risky drinking if they preferred spirits. However, adolescents are not allowed to buy spirits since the legal purchase age of these beverages is 18 years in Switzerland (and in most other European countries). Consequently, it appears important to reduce the sale of alcohol to minors by strictly enforcing age-ofpurchase legislation through test purchasing and penalties that include revoking sales licenses (Grube, 1997; World Health Organization (WHO), 2005).

\section{Using the personality-motive link}

The literature review in Chapter 3 revealed that there is a particular personalitymotive structure among enhancement and coping drinkers: Those who mainly drink for enhancement motives were found to be extraverted, impulsive, and aggressive. They tend to be sensation seekers, to have low inhibitory control, low levels of responsibility and low achievement motivation. Apparently, these adolescents like and actively seek sensations, such as feeling drunk, due to their extraverted, risk-seeking personality. In contrast, those who mainly drink for coping motives were found to be neurotic and to have a low level of agreeableness and a negative self-perception. These young people tend to accumulate personal 
problems due to their oversensitive, anxiety-fearing personality and they tend to use alcohol as a means to cope with problems.

Recently, an approach to prevent early and risky drinking among adolescents has been developed that was based on the assumption that by intervening at the level of personality, it is possible to change or to help manage adolescents' maladaptive drinking motives (e.g., coping, enhancement) and finally to reduce excessive drinking and alcohol-related problems (Conrod, Pihl, Cote, Fontaine, \& Dongier, 2000; Conrod, Stewart, Comeau, \& Maclean, 2006; Stewart, Conrod, Marlatt, Comeau, Thush, \& Krank, 2005). Participants in a personality-targeted intervention were selected based on their drinking status and their scores on different personality measures such as sensation-seeking or anxiety sensitivity and were randomly assigned to a treatment and a control group (Conrod, Stewart, Comeau, \& Maclean, 2006). Based on motivational interviewing and cognitive-behavioral therapy, the treatments consisted of educational approaches and cognitive and behavioral coping skills training specific to each personality type. Results from this randomized control trial revealed lower levels of drinking quantity, risky drinking, and alcohol-related problems at 4-month follow-up in the intervention group compared to the control group. However, drinking motives were not directly included in the intervention which lead the authors to conclude that "future research might also include potential mediators of treatment impact such as changes in drinking motives" (Stewart, Conrod, Marlatt, Comeau, Thush, \& Krank, 2005, p. 560). Thus, it remains to be demonstrated whether such an intervention actually changes drinking motives which might be responsible for a variety of alcohol-related outcomes. 
Motive-tailored feedback

Randomized control trials revealed that providing feedback on the participants drinking patterns and their estimation how much their peers drink and giving information of the actual drinking levels in the participant's sex and age group was related to a reduction of alcohol use in follow-ups (Agostinelli, Floyd, Grube, Woodall, \& Miller, 2004; Kypri, Gallagher, \& Cashell-Smith, 2004; Walters, Bennett, \& Noto, 2000; Neighbors, Larimer, \& Lewis, 2004). Other studies even compared personalized feedback with more comprehensive brief motivational interventions and found that personalized feedback had the same or an even higher impact on adolescent alcohol use (Collins, Carey, \& Sliwinski, 2002; Murphy, Correia, Colby, \& Vuchinich, 2005; Walters, Bennett, \& Noto, 2000; White, Morgan, Pugh, Celinska, Labouvie, \& Pandina, 2006). These studies also demonstrated that personalized feedback can be easily delivered by postal mail (e.g., Collins, Carey, \& Sliwinski, 2002; Walters, Bennett, \& Noto, 2000) or electronically (Kypri, Gallagher, \& Cashell-Smith, 2004; Neighbors, Larimer, \& Lewis, 2004). Taken together, personalized feedback was shown to be an easy and cost-effective solution for large-scale prevention (Walters, Bennett, \& Noto, 2000). It appears that personalized feedback is an effective way to increase problem recognition and to decrease alcohol consumption among adolescents.

One study included social drinking motives and found that personalized feedback was somewhat more effective among participants who drank frequently for social motives than those who did not drink not for social motives (Neighbors, Larimer, \& Lewis, 2004). Unfortunately, in their study, Neighbors, Larimer, and Lewis (2004) did not include enhancement, conformity, and coping motives nor did they give feedback on the social motives they did include in their study. Therefore, it remains to be demonstrated to what extent the inclusion of information about motives enhances the effect of personalized feedback. 
Apart from including drinking motives in personalized feedback interventions, drinking motives could be directly used to provide feedback on the personal drinking motivation. As mentioned in the introductory chapter, effective goal pursuit (e.g., "finding a drink") can be described as a latent process in which individuals are sensitized to the alcohol-related cues and to be ready to act without consciously thinking exclusively on drinking. In fact, a person does not have to be aware of either having made a decision to have a drink in a given situation or the factors affecting this decision. In most cases, decisions about drinking are unconscious and automatized. However, this does not mean that the decision or its underlying motivational process could not be consciously reflected upon when individuals encounter cues which push them to reflect their way and reasons for consumption. Confronting people with personalized information on their motivation to engage in drinking might trigger such a process in which individuals reflect on their various (otherwise unconscious) decisions to drink.

Similar to the alcohol use feedback interventions described above, feedback on the individuals' drinking motives and their estimation of what motivates their peers drink and providing information about the link between the different motives, risky drinking, and alcohol-related problems could be used as intervention approach. For example, adolescents could answer the DMQ-R and different alcohol use questions on the computer. They could also estimate their peers drinking motives and alcohol use. Subsequently, a computer program would calculate the deviations of these personal answers from the age- and gender-specific means. The program could also identify participants as enhancement or coping drinkers according to the coding procedure developed in Chapter 8. Subsequently, information could be provided about the specific function alcohol serves for them and about the personal risks associated with such a drinking motivation and drinking style. Moreover, alternative ways to obtain the desired effect without alcohol use can be suggested. 
Future research using randomized controlled trials is needed to demonstrate the effectiveness of this type of motive-tailored feedback intervention. 


\section{REFERENCES}

Aas, H. N. (1993). Adaptation of the Alcohol Expectancy Questionnaire (AEQ-A): A short version for use among 13-year-olds in Norway. Scandinavian Journal of Psychology, 34(2), 107-118.

Aas, H. N., Klepp, K.-I., Laberg, J. C., \& Aarø, L. E. (1995). Predicting adolescents' intentions to drink alcohol: outcome expectancies and self-efficacy. Journal of Studies on Alcohol, 56(3), 293-299.

Aas, H. N., Leigh, B. C., Anderssen, N., \& Jakobsen, R. (1998). Two-year longitudinal study of alcohol expectancies and drinking among Norwegian adolescents. Addiction, 93(3), 373-384.

Abbey, A., Smith, M. J., \& Scott, R. O. (1993). The relationship between reasons for drinking alcohol and alcohol consumption: an interactional approach. Addictive Behaviors, 18(6), 659-670.

Agostinelli, G., Floyd, T. E., Grube, J. W., Woodall, G., \& Miller, J. H. (2004). Alcohol problem recognition as a function of own and others' perceived drinking. Addictive Behaviors, 29(1), 143-157.

Ajzen, I. (1985). From intentions to actions: A theory of planned behavior. In J. Kuhl \& J. Beckman (Eds.), Action-control: From cognition to behavior (pp. 11-39). Heidelberg: Springer.

Ajzen, I. (1988). Attitudes, Personality and Behavior. Milton Keynes, CA: Open University Press.

Ajzen, I. (1991). The theory of planned behavior. Organizational Behavior and Human Decision Processes, 50, 179-211.

Ajzen, I. \& Fishbein, M. (1980). Understanding attitudes and predicting social behavior. Englewood-Cliffs, NJ: Prentice-Hall.

Akers, R. L. (1977). Deviant behavior: A social learning approach ( $2^{\text {nd }}$ ed.). Belmont, CA: Wadsworth Press. 
Alvarez, F. J. \& del Rio, M. C. (1994). Gender differences in patterns of alcohol consumption in Spain. Alcoholism, Clinical and Experimental Research, 18(6), 1342-1347.

American Psychological Association. (2002). Ethical Principles of Psychologists and Code of Conduct 2002. Washington, DC: Author.

Annis, H. M. (1984). Inventory of Drinking Situations, Short Form. Toronto, Ontario: Addiction Research Foundation.

Babor, T. F., Caetano, R., Casswell, S., Edwards, G., Giesbrecht, N., Graham, K., Grube, J. W., Gruenewald, P. J., Hill, L., Holder, H. D., Homel, R., Österberg, E., Rehm, J., Room, R., \& Rossow, I. (2003). Alcohol: No Ordinary Commodity. Research and Public Policy. Oxford: Oxford Medical Publication, Oxford University Press.

Baer, J. S. (1994). Effects of college residence on perceived norms for alcohol consumption: An examination of the first year in college. Addictive Behaviors, $8(1), 43-50$.

Baer, J. S. (2002). Student factors: understanding individual variation in college drinking. Journal of Studies on Alcohol, 14(Suppl.), 40-53.

Bailly, R. C. (1987). The influence of gender on purposes and outcomes of alcohol use. Unpublished master's thesis, University of Wyoming, Laramie.

Bailly, R. C., Carman, R. S., \& Forslund, M. A. (1991). Gender differences in drinking motivations and outcomes. Journal of Psychology, 125(6), 649-656.

Bandura, A. (1977). Social Learning Theory. Englewood Cliffs, NJ: Prentice Hall.

Bandura, A. (1982). Self efficacy mechanism in human agency. American Psychologist 37, 122-147.

Barnes, G. M. (1981). Drinking among adolescents: a subcultural phenomenon or a model of adult behaviors. Adolescence, 16(61), 211-229.

Baron, R. M. \& Kenny, D. A. (1986). The moderator-mediator variable distinction in social psychological research: Conceptual, strategic, and statistical considerations. Journal of Personality and Social Psychology, 51(6), 1173-1182. 
Basen-Engquist, K., Edmundson, E. W., \& Parcel, G. S. (1996). Structure of health risk behavior among high school students. Journal of Consulting and Clinical Psychology, 64(4), 764-775.

Bechara, A., Damasio, H., Tranel, D., \& Damasio, A. R. (1997). Deciding advantageously before knowing the advantageous strategy. Science, 275(5304), 1293-1295.

Beck, K. H., Thombs, D. L., Mahoney, C. A., \& Fingar, K. M. (1995). Social context and sensation seeking: gender differences in college student drinking motivations. International Journal of the Addictions, 30(9), 1101-1115.

Bentler, P. M. \& Bonett, D. G. (1980). Significance tests and goodness of fit in the analysis of covariance structures. Psychological Bulletin, 88, 588-606.

Berridge, K. C. (2001). Reward learning: Reinforcement, incentives and expectations. Psychology of Learning and Motivation, 40, 223-278.

Billingham, R. E., Parrillo, A. V., \& Gross, W. C. (1993). Reasons given by college students for drinking: a discriminant analysis investigation. International Journal of the Addictions, 28(8), 793-802.

Bland, J. M. \& Altman, D. G. (1997). Cronbach's alpha. British Medical Journal, 314(7080), 572.

Blitstein, J. L., Murray, D. M., Lytle, L. A., Birnbaum, A. S., \& Perry, C. L. (2005). Predictors of violent behavior in an early adolescent cohort: similarities and differences across genders. Health Education and Behavior, 32(2), 175-194.

Bock, M. \& Klinger, E. (1986). Interaction of emotion and cognition in word recall. Psychological Research, 48, 99-106.

Boreham, J. \& McManus, S. (2003). Smoking, Drinking and Drug Use Among Young People in England in 2002. London: The Stationery Office.

Botvin, G. J. (2000). Preventing drug abuse in schools: Social and competence enhancement approaches targeting individual-level etiologic factors. Addictive Behaviors, 25(6), 887-897. 
Boys, A., Marsden, J., \& Strang, J. (2001). Understanding reasons for drug use amongst young people: a functional perspective. Health Education Research, 16(4), 457469.

Bradizza, C. M., Reifman, A., \& Barnes, G. M. (1999). Social and coping reasons for drinking: Predicting alcohol misuse in adolescents. Journal of Studies on Alcohol, 60(4), 491-499.

Bradley, J. R., Carman, R. S., \& Petree, A. (1991). Expectations, alienation, and drinking motives among college men and women. Journal of Drug and Alcohol Education, 21(1), 27-33.

Bradley, J. R., Carman, R. S., \& Petree, A. (1992). Personal and social drinking motives, family drinking history, and problems associated with drinking in two university samples. Journal of Drug Education, 22(3), 195-202.

Brener, N. D., Billy, J. O., \& Grady, W. R. (2003). Assessment of factors affecting the validity of self-reported health-risk behavior among adolescents: evidence from the scientific literature. Journal of Adolescent Health, 33(6), 436-457.

Brener, N. D. \& Collins, J. L. (1998). Co-occurrence of health-risk behaviors among adolescents in the United States. Journal of Adolescent Health, 22(3), 209-213.

Brown, J. \& Finn, P. (1982). Drinking to get drunk: Findings of a survey of junior and senior high school students. Journal of Alcohol and Drug Education, 27(3), 13-25.

Brown, S. A., Christiansen, B. A., \& Goldman, M. S. (1987). The Alcohol Expectancy Questionnaire: an instrument for the assessment of adolescent and adult alcohol expectancies. Journal of Study on Alcohol, 48(5), 483-491.

Browne, M. W. \& Cudeck, R. (1993). Alternative ways of assessing model fit. In K. Bollen \& J. S. Long (Eds.), Testing Structural Models. Newbury Park, CA: Sage.

Cahalan, D., Cisin, I. H., \& Crossley, H. M. (1969). American Drinking Practices: A National Study of Drinking Behavior and Attitudes. Brunswick, NJ: Rutgers Center for Alcohol Studies. 
Cambridge University. (2001). Cambridge International Dictionary of English. Cambridge: Cambridge University Press.

Carey, K. B. (1993). Situational determinants of heavy drinking among college students. Journal of Counseling Psychology, 40(2), 217-220.

Carey, K. B. (1995). Heavy drinking contexts and indices of problem drinking among college students. Journal of Studies on Alcohol, 56(3), 287-292.

Carey, K. B. \& Correia, C. J. (1997). Drinking motives predict alcohol-related problems in college students. Journal of Studies on Alcohol, 58(1), 100-105.

Carman, R. S., Fitzgerald, B. J., \& Holmgren, C. (1983). Alienation and drinking motivations among adolescent females. Journal of Personality and Social Psychology, 44(5), 1021-1024.

Carpenter, K. M. \& Hasin, D. S. (1998a). A prospective evaluation of the relationship between reasons for drinking and DSM-IV alcohol-use disorders. Addictive Behaviors, 23(1), 41-46.

Carpenter, K. M. \& Hasin, D. S. (1998b). Reasons for drinking alcohol: Relationships with DSM-IV alcohol diagnoses and alcohol consumption in a Community Sample. Psychology of Addictive Behaviors, 12(3), 168-184.

Carpenter, K. M. \& Hasin, D. S. (1999). Drinking to cope with negative affect and DSMIV alcohol use disorders: a test of three alternative explanations. Journal of Studies on Alcohol, 60(5), 694-704.

Carrigan, G., Samoluk, S. B., \& Stewart, S. H. (1998). Examination of the short form of the Inventory of Drinking Situations (IDS-42) in a young adult university student sample. Behavior Research and Therapy, 36(7-8), 789-807.

Carver, C. S. \& Scheier, M. F. (1998). On the self-regulation of behavior. Cambridge, UK: Cambridge University Press.

Castilla, J., Barrio, G., Belza, M. J., \& de la Fuente, L. (1999). Drug and alcohol consumption and sexual risk behaviour among young adults: results from a national survey. Drug and Alcohol Dependence, 56(1), 47-53. 
Catanzaro, S. J. \& Laurent, J. (2004). Perceived family support, negative mood regulation expectancies, coping, and adolescent alcohol use: evidence of mediation and moderation effects. Addictive Behaviors, 29(9), 1779-1797.

Christiansen, B. A., Goldman, M. S., \& Inn, A. (1982). Development of alcohol-related expectancies in adolescents: separating pharmacological from social-learning influences. Journal of Consulting and Clinical Psychology, 50(3), 336-344.

Clapp, J. D. \& Shillington, A. M. (2001). Environmental predictors of heavy episodic drinking. American Journal of Drug Abuse, 27(2), 301-313.

Cohen, J. (1960). A coefficient of agreement for nominal scales. Educational and Psychological Measurement, 20, 37-46.

Cohen, J. (1988). Statistical Power Analysis for the Behavioral Sciences. Hillsdale, NY: Erlbaum.

Cohen, J. \& Cohen, P. (1983). Applied Multiple Regression/Correlation Analysis for the Behavioral Sciences. Hillsdale, NJ: Erlbaum.

Colder, C. R. (2001). Life stress, physiological and subjective indexes of negative emotionality, and coping reasons for drinking: is there evidence for a selfmedication model of alcohol use? Psychology of Addictive Behaviors, 15(3), 237245 .

Colder, C. R. \& O'Connor, R. (2002). Attention biases and disinhibited behavior as predictors of alcohol use and enhancement reasons for drinking. Psychology of Addictive Behaviors, 16(4), 325-332.

Collins, S. E., Carey, K. B., \& Sliwinski, M. J. (2002). Mailed personalized normative feedback as a brief intervention for at-risk college drinkers. Journal of Studies on Alcohol 63(5), 559-567.

Comeau, N., Stewart, S. H., \& Loba, P. (2001). The relations of trait anxiety, anxiety sensitivity, and sensation seeking to adolescents' motivations for alcohol, cigarette, and marijuana use. Addictive Behaviors, 26(6), 803-825. 
Confederatio Helvetica. (2003). Botschaft betreffend die Einführung einer Sondersteuer auf $\begin{array}{lll}\text { Alcopops. } & \text { Retrieved } & \text { f7.03.2006, }\end{array}$ http://www.admin.ch/ch/d/ff/2003/index0_10.html

Congdon, P. (2003). Applied Bayesian Modelling. Chichester, UK: John Wiley \& Sons, Ltd.

Connors, G. J., O'Farrell, T. J., \& Cutter, H. S. (1990). Using a drinking motivation scale to predict degrees of problematic drinking. Drug and Alcohol Dependence, 26(2), 175-181.

Conrod, P. J., H., S. S., Pihl, R. O., Cote, S., Fontaine, V., \& Dongier, M. (2000). Efficacy of brief coping skills interventions that match different personality profiles of female substance abusers. Psychology of Addictive Behaviors 14(3), 231-242.

Conrod, P. J., Stewart, S. H., Comeau, N., \& Maclean, A. M. (2006). Efficacy of cognitive behavioral interventions targeting personality risk factors for youth alcohol misuse. Journal of Clinical Child and Adolescent Psychology, 35(4), 550-563.

Cook, M., Young, A., Taylor, D., \& Bedford, A. P. (1998). Personality correlates of alcohol consumption. Personality and Individual Differences, 24(5), 641-647.

Cooper, M. L. (1994). Motivations for alcohol use among adolescents: Development and validation of a four-factor-model. Psychological Assessment, 6(2), 117-128.

Cooper, M. L., Agocha, V. B., \& Sheldon, M. S. (2000). A motivational perspective on risky behaviors: the role of personality and affect regulatory processes. Journal of Personality, 68(6), 1058-1088.

Cooper, M. L., Frone, M. R., Russell, M., \& Mudar, P. (1995). Drinking to regulate positive and negative emotions: a motivational model of alcohol use. Journal of Personality and Social Psychology, 69(5), 990-1005.

Cooper, M. L., Russell, M., Skinner, J. B., \& Windle, M. (1992). Development and validation of a three-dimensional measure of drinking motives. Psychological Assessment, 4, 123-132. 
Correia, C. J. (2004). Behavioral economics: Basic concepts and clinical applications. In W. M. Cox \& E. Klinger (Eds.), Handbook of Motivational Counseling (pp. 4964). Chichester: John Wiley \& Sons.

Corsini, R. J. (2002). The Dictionary of Psychology. New York, London: BrunnerRoutledge.

Costa, P., Jr. \& McCrae, R. R. (1992). Revised NEO personality inventory (NEO-PI-R) and NEO five-factor inventory (NEO-FFI): Professional manual. Odessa, FL: Psychological Assessment Resources.

Cox, W. M. \& Klinger, E. (1988). A Motivational Model of Alcohol Use. Journal of Abnormal Psychology, 97(2), 168-180.

Cox, W. M. \& Klinger, E. (1990). Incentive motivation, affective change, and alcohol use: A model. In W. M. Cox (Ed.), Why people drink. Parameters of alcohol as a reinforcer (pp. 291-314). New York / Oxford: Gardner Press.

Cox, W. M. \& Klinger, E. (2002). Motivational structure. Relationships with substance use and processes of change. Addictive Behaviors, 27(6), 925-940.

Cox, W. M. \& Klinger, E. (2004). A motivational model of alcohol use: determinants of use and change. In W. M. Cox \& E. Klinger (Eds.), Handbook of Motivational Counseling: Concepts, Approaches, and Assessment (pp. 121-138). Chichester: John Wiley \& Sons, Ltd.

Crichton, N. (1999). Information point: coefficient alpha. Journal of Clinical Nursing, 8, 283.

Cronin, C. (1997). Reasons for drinking versus outcome expectancies in the prediction of college student drinking. Substance Use and Misuse, 32(10), 1287-1311.

Damasio, A. R. (1994). Descartes' error: Emotion, reason, and the human brain. New York: Avon.

De Micheli, D. \& Formigoni, M. L. (2002). Are reasons for the first use of drugs and family circumstances predictors of future use patterns? Addictive Behaviors, 27(1), 87-100. 
Delgrande Jordan, M., Kuntsche, E., \& Sidler, J. (2005). Arbeitsüberforderung und -unzufriedenheit von Lehrpersonen in der Schweiz - Zusammenhänge mit Depressivität und somatischen Beschwerden. Schweizerische Zeitschrift für Bildungsforschung, 27(1), 123-139.

Deutsch, R. \& Strack, F. (2006). Reflective and Impulsive Determinantsof Addictive Behavior. In R. W. Wiers \& A. W. Stacy (Eds.), Handbook of Implicit Cognition and Addiction (pp. 45-58). Thousand Oaks: Sage.

Edwards, G., Anderson, P., Babor, T. F., Casswell, S., Ferrence, R. G., Giesbrecht, N., Godfrey, C., Holder, H. D., Lemmens, P. H., Mäkelä, K., Midanik, L. T., Norström, T., Österberg, E., Romelsjö, A., Room, R., Simpura, J., \& Skog, O.-J. (1994). Alcohol Policy and the Public Good. New York, NY: Oxford University Press.

Edwards, G., Hensman, C., \& Peto, J. (1973). A comparison of female and male motivation for drinking. International Journal of the Addictions, 8(4), 577-587.

Engels, R., Knibbe, R., De Vries, H., Drop, M. J., \& Van Breukelen, G. J. (1999). Influences of parental and best friends' smoking and drinking on adolescent use: a longitudinal study. Journal of Applied Social Psychology, 29, 338-362.

Engels, R. C. M. E. \& Knibbe, R. A. (2000). Young people's alcohol consumption from a European perspective: risks and benefits. European Journal of Clinical Nutrition, 54(Suppl 1), S52-S55.

Engels, R. C. M. E., Knibbe, R. A., \& Drop, M. J. (1999). Visiting public drinking places: an explorative study into the functions of pub-going for late adolescents. Substance Use and Misuse, 34(9), 1261-1280.

Everitt, B. S., Landau, S., \& Leese, M. (2001). Cluster Analysis. New York: Oxford University Press.

Fahrenkrug, H. \& Gmel, G. (1998). Drinking alcohol with your meals in Switzerland: is it beneficial to your health? Alcologia, 10(3), 118-125. 
Farber, P. D., Khavari, K. A., \& Douglass, F. M., 4th. (1980). A factor analytic study of reasons for drinking: empirical validation of positive and negative reinforcement dimensions. Journal of Consulting and Clinical Psychology, 48(6), 780-781.

Feather, N. T. (1982). Expectations and actions: Expectancy-value models in psychology. Hillsdale, NJ: Erlbaum.

Feldman, L., Harvey, B., Holowaty, P., \& Shortt, L. (1999). Alcohol use beliefs and behaviors among high school students. Journal of Adolescent Health, 24(1), 4858.

Fergusson, D. M., Swain-Campbell, N. R., \& Horwood, L. J. (2002). Deviant peer affiliations, crime and substance use: a fixed effects regression analysis. Journal of Abnormal Child Psychology, 30(4), 419-430.

Fishbein, M. \& Ajzen, I. (1975). Belief, attitude, intention, and behavior: An introduction to theory and research. Reading, MA: Addison-Wesley.

Fleiss, J. L., Levin, B., \& Paik, M. C. (2003). Statistical methods for rates and proportions (3rd ed.). Hoboken, NJ: Wiley \& Sons.

George, D. \& Mallery, P. (2003). SPSS for Windows Step by Step: A Simple Guide and Reference. 11.0 Update (4 ed.). Boston, MA: Allyn \& Bacon.

Gire, J. T. (2002). A cross-national study of motives for drinking alcohol. Substance Use \& Misuse, 37(2), 215-223.

Glenewinkel, F., Iffland, R., \& Grellner, W. (1998). Designerdrinks und Modegetränke [Designer drinks and fashionable beverages]. Blutalkohol, 35(1), 36 - 47.

Gmel, G. \& Kuntsche, E. (2007). Alkohol-Intoxikationen bei Jugendlichen und jungen Erwachsenen. Eine Analyse der Schweizer Krankenhausstatistik. Abhängigkeiten, 13(1), 36-49.

Gmel, G. \& Maag, V. (1999). Zunahme des Konsums illegaler Drogen in der Schweiz? Vergleiche der Schweizerischen Gesundheitsbefragungen 1992/ 93 und 1997. Abhängigkeiten, 3, 67-77. 
Gmel, G., Rehm, J., \& Kuntsche, E. (2003). Binge drinking in Europe: Definitions, epidemiology, and consequences. Sucht, 49(2), 105-116.

Gmel, G., Rehm, J., Kuntsche, E. N., Wicki, M., \& Grichting, E. (2004). Das European School Survey Project on Alcohol and Other Drugs (ESPAD) in der Schweiz. Wichtigste Ergebnisse 2003 und aktuelle Empfehlungen. Lausanne: Schweizerische Fachstelle für Alkohol- und andere Drogenprobleme (SFA). Also available http://www.suchtundaids.bag.admin.ch/imperia/md/content/drogen/60.pdf.

Gmel, G., Rehm, J., Room, R., \& Greenfield, T. K. (2000). Dimensions of alcohol-related social and health consequences in survey research. Journal of Substance Abuse, 12(1-2), 113-138.

Goodwin, L. (1990). Social psychological bases for college alcohol consumption. Journal of Alcohol and Drug Education, 36(1), 83-95.

Gotham, H. J., Sher, K. J., \& Wood, P. K. (1997). Predicting stability and change in frequency of intoxication from the college years to beyond: individual-difference and role transition variables. Journal of Abnormal Psychology, 106(4), 619-629.

Gottfredson, D. C. \& Wilson, D. B. (2003). Characteristics of effective school-based substance abuse prevention. Prevention Science, 4(1), 27-38.

Gray, J. A. (1982). The Neuropsychology of Anxiety: An Inquiry Into the functions of the Septo-Hippocampal System. Oxford: Oxford University Press.

Grønbæk, M., Jensen, M. K., Johansen, D., Sørensen, T. I. A., \& Becker, U. (2004). Intake of beer, wine and spirits and risk of heavy drinking and alcoholic cirrhosis. Biological Research, 37(2), 195-200.

Grønbæk, M., Mortensen, E. L., Mygind, K., Andersen, A. T., Becker, U., Gluud, C., \& Sørensen, T. I. A. (1999). Beer, wine, spirits and subjective health. Journal of Epidemiology and Community Health., 53(11), 721-724.

Grube, J. W. (1997). Preventing sales of alcohol to minors: Results from a community trial. Addiction, 92(Suppl. 2), S251-S260. 
Gutjahr, E. \& Gmel, G. (2001). Defining alcohol-related fatal medical conditions for socialcost studies in Western societies: an update of the epidemiological evidence. Journal of Substance Abuse, 13(3), 239-264.

Haden, T. L. \& Edmundson, E. W. (1991). Personal and social motivations as predictors of substance use among college students. Journal of Drug and Alcohol Education, 21(4), 303-312.

Ham, L. S. \& Hope, D. A. (2003). College students and problematic drinking: a review of the literature. Clinical Psychology Review, 23(5), 719-759.

Hawkins, J. D., Catalano, R. F., \& Miller, J. Y. (1992). Risk and protective factors for alcohol and other drug problems in adolescence and early adulthood: implications for substance abuse prevention. Psychological Bulletin, 112(1), 64-105.

Hawks, D., Scott, K., McBride, N., Jones, P., \& Stockwell, T. (2002). Prevention of psychoactive substance use: a selected review of what works in the area of prevention. Geneva: World Health Organization (WHO).

Heaven, P. C. L. (1996). Personality and self-reported delinquency: analysis of the "Big Five" personality dimensions. Personality and Individual Differences, 20, 47-54.

Hibell, B., Andersson, B., Bjarnason, T., Ahlström, S., Balakireva, O., Kokkevi, A., \& Morgan, M. (2004). The ESPAD Report 2003 - Alcohol and Other Drug Use Among Students in 35 European Countries. Stockholm: The Swedish Council for Information on Alcohol and Other Drugs, CAN Council of Europe, Co-operation Group to Combat Drug Abuse and Illicit Trafficking in Drugs (Pompidou Group).

Hingson, R. W., Heeren, T., Zakocs, R. C., Kopstein, A., \& Wechsler, H. (2002). Magnitude of alcohol-related mortality and morbidity among U.S. college students ages 18-24. Journal of Studies on Alcohol, 63(2), 136-144.

Homel, R., Carvolth, R., Hauritz, M., McIlwain, G., \& Teague, R. (2004). Making licensed venues safer for patrons: What environmental factors should be the focus of interventions? Drug and Alcohol Review, 23(1), 19-29.

Hox, J. J. (Ed.). (2002). Multilevel Analysis: Techniques and Applications. Mahwah, NJ: Lawrence Erlbaum Associates. 
Hu, L. \& Bentler, P. M. (1999). Cut-off criteria for fit indexes in covariance structure analysis: conventional criteria versus new alternatives. Structural Equation Modeling, 6, 1-55.

Huang, B., White, H. R., Kosterman, R., Catalano, R. F., \& Hawkins, J. D. (2001). Developmental associations between alcohol and interpersonal aggression during adolescence. Journal of Research in Crime and Delinquency, 38(1), 64-83.

Hughes, K., MacKintosh, A. M., Hastings, G., Wheeler, C., Watson, J., \& Inglis, J. (1997). Young people, alcohol, and designer drinks: quantitative and qualitative study. British Medical Journal, 314(7078), 414 - 418.

Hussong, A. M. (2003). Social influences in motivated drinking among college students. Psychology of Addictive Behaviors, 17(2), 142-150.

Jaccard, J., Turrisi, R., \& Wan, C. K. (1990). Interaction Effects in Multiple Regression. Newbury Park, CA: Sage.

Jackson, K. M., Sher, K. J., Cooper, M. L., \& Wood, P. K. (2002). Adolescent alcohol and tobacco use: onset, persistence and trajectories of use across two samples. Addiction, 97(5), 517 - 531.

James, W. H., Moore, D. D., \& Gregersen, M. M. (1996). Early prevention of alcohol and other drug use among adolescents. Journal of Drug Education, 26(2), 131-142.

Jensen, M. K., Andersen, A. T., Sørensen, T. I. A., Becker, U., Thorsen, T., \& Grønbæk, M. (2002). Alcoholic beverage preference and risk of becoming a heavy drinker. Epidemiology, 13(2), 127-132.

Jerez, S. J. \& Coviello, A. (1998). Alcohol drinking and blood pressure among adolescents. Alcohol, 16(1), 1-5.

Jessor, R., Carman, R. S., \& Grossman, P. H. (1968). Expectantions of need satisfaction and drinking patterns of college students. Quarterly Journal of Studies in Alcohol, 29, 101-116. 
Jessor, R., Graves, T. D., Hanson, R. C., \& Jessor, S. L. (1968). Society, Personality, and Deviant Behavior: A Study of a Tri-Ethnic Community. New York, NY: Holt, Rinehart, and Winston.

Jessor, R. \& Jessor, S. L. (1977). Problem Behavior and Psychosocial Development. A Longitudinal Study of Youth. New York, NY: Academic Press Inc.

Johnson, R. C., Schwitters, S. Y., Wilson, J. R., Nagoshi, C. T., \& McClearn, G. E. (1985). A cross-ethnic comparison of reasons given for using alcohol, not using alcohol or ceasing to use alcohol. Journal of Studies on Alcohol, 46(4), 283-288.

Johnston, L. D. \& O'Malley, P. M. (1986). Why do the nation's students use drugs and alcohol? Self-reported reasons from nine national surveys. Journal of Drug Issues, 16(1), 29-66.

Johnston, L. D., O'Malley, P. M., \& Bachman, J. G. (1984). Drugs and American High School Students 1975-1983. Washington, DC: U.S. Government Printing Office.

Johnston, L. D., O'Malley, P. M., Bachman, J. G., \& Schulenberg, J. E. (2004). Monitoring the Future National Results on Adolescent Drug Use: Overview of Key Findings, 2003 (NIH Publication No. 04-5506). Bethesda, MD: National Institute on Drug Abuse.

Jones, B. T., Corbin, W., \& Fromme, K. (2001). A review of expectancy theory and alcohol consumption. Addiction, 96(1), 57-72.

Jöreskog, K. G. \& Sörbom, D. (2001). LISREL Software Version 8.51. Chicago, IL: Scientific Software International, Inc.

Jung, J. (1977). Drinking motives and behavior in social drinkers. Journal of Studies on Alcohol, 38(5), 944-952.

Kairouz, S., Gliksman, L., Demers, A., \& Adlaf, E. M. (2002). For all these reasons, I do...drink: a multilevel analysis of contextual reasons for drinking among Canadian undergraduates. Journal of Studies on Alcohol, 63(5), 600 - 608. 
Kandel, D. B. (1974). Interpersonal influences on adolescent illegal drug use In E. Josephson \& E. Carroll (Eds.), The epidemiology of drug abuse (pp. 207-240). Washington, DC: Winston.

Kandel, D. B. (1980). Drug and drinking behavior among youth. Annual Review of Sociology, 6, 235-285.

Kandel, D. B. (1996). The parental and peer context of adolescent deviance: An algebra of interpersonal influences. Journal of Drug Issues, 26, 289-315.

Kandel, D. B., Simcha-Fagan, O., \& Davies, M. (1986). Risk factors for delinquency and illicit drug use from adolescence to young adulthood. Journal of Drug Issues, 16, $67-90$.

Kaplan, D. S., Peck, B. M., \& Kaplan, H. G. (1994). Structural relation model of selfrejection, disposition to deviance, and academic failure. Journal of Educational Research, 87(3), 166-173.

Kaplan, H. B. (1975). Self-Attitudes and Deviant Behavior. Pacific Palisades, CA: Goodyear.

Kaplan, H. B. (1980). Deviant behaviour in defense of self. New York: Academic Press.

Karwacki, S. B. \& Bradley, J. R. (1996). Coping, drinking motives, goal attainment expectancies and family models in relation to alcohol use among college students. Journal of Drug and Alcohol Education, 26(3).

Kassel, J. D., Jackson, S. I., \& Unrod, M. (2000). Generalized expectancies for negative mood regulation and problem drinking among college students. Journal of Studies on Alcohol, 61(2), 332-340.

Kjærheim, K., Mykletun, R., \& Halvorsen, T. (1996). Selection into the restaurant business based on personality characteristics and the risk of heavy drinking. Personality and Individual Differences, 21(4), 625-629.

Klatsky, A. L., Armstrong, M. A., \& Kipp, H. (1990). Correlates of alcoholic beverage preference: Traits of persons who choose wine, liquor or beer. British Journal of Addiction, 85(10), 1279-1289. 
Klein, H. (1992). Self-reported reasons why college students drink. Journal of Alcohol and Drug Education, 37(2), 14-28.

Klein, H. \& Pittman, D. J. (1990). Drinker prototypes in American society. Journal of Substance Abuse, 2(3), 299-316.

Klinger, E. (1977). Meaning and void: Inner experience and the incentives in people's lives. Minneapolis, MN: University of Minnesota Press.

Klinger, E. \& Cox, W. M. (2004). Motivation and the Theory of Current Concerns In W. M. Cox \& E. Klinger (Eds.), Handbook of Motivational Counseling (pp. 3-27). Chichester: John Wiley \& Sons.

Kloep, M., Hendry, L. B., Ingebrigtsen, J. E., Glendinning, A., \& Espnes, G. A. (2001). Young people in 'drinking' societies? Norwegian, Scottish and Swedish adolescents' perceptions of alcohol use. Health Education Research, 16(3), 279291.

Komro, K. A. \& Toomey, T. L. (2002). Strategies to prevent underage drinking. Alcohol Research and Health, 26(1), 5-14.

Kuntsche, E. N. (2001a). Mögliche Antezedentien und Konsequenzen eines niedrigen Selbstwerts. In H. Schmid, E. N. Kuntsche \& M. Delgrande (Eds.), Anpassen, ausweichen, auflehnen? Fakten und Hintergründe zur psychosozialen Gesundheit und zum Konsum psychoaktiver Substanzen von Schülerinnen und Schülern (pp. 39-63). Bern: Haupt.

Kuntsche, E. N. (2001b). Radikalisierung? Ein Interpretationsmodell jugendlichen Alkoholkonsums von 1986 bis 1998 in der Schweiz [Radicalisation? An interpretation model of adolescent alcohol use from 1986 to 1998 in Switzerland]. Sucht, 47(6), 393-403.

Kuntsche, E. N. (2004a). Hostility among adolescents in Switzerland? Multivariate relations between excessive media use and forms of violence. Journal of Adolescent Health, 34(3), 230-236. 
Kuntsche, E. N. (2004b). "Ich fühle mich wohl, wenn getrunken wird - ich trinke, um mich wohlzufühlen" - Substanzkonsum Jugendlicher im Kontext von Gesundheit, Wohlbefinden und sozialem Anschluss. In T. Hascher (Ed.), Schule positiv erlegen. Erkenntnisse und Ergebnisse zum Wohlbefinden von Schülerinnen und Schülern (pp. 273-297). Bern: Haupt.

Kuntsche, E. N. (2004c). Progression of a general substance use pattern among adolescents in Switzerland? Investigating the relationship between alcohol, tobacco, and marijuana use over a 12 year period. European Addiction Research, 10(3), 118125.

Kuntsche, E. N. \& Gmel, G. (2004). Emotional well-being and violence among social and solitary risky single occasion drinkers in adolescence. Addiction, 99(3), 331-339.

Kuntsche, E., Gmel, G., Wicki, M., Rehm, J., \& Grichting, E. (2006). Disentangling gender and age effects on risky single occasion drinking during adolescence. European Journal of Public Health, 16(6), 670-675.

Kuntsche, E. N. \& Klingemann, H. (2004). Weapon-carrying at Swiss Schools? A genderspecific typology in context of victim and offender related violence. Journal of Adolescence, 27(4), 381-393.

Kuntsche, E., Knibbe, R. A., Gmel, G., \& Engels, R. C. M. E. (2005). Why do young people drink? A review of drinking motives. Clinical Psychology Review, 25(7), 841-861.

Kuntsche, E., Knibbe, R. A., Gmel, G., \& Engels, R. C. M. E. (2006a). Replication and validation of the Drinking Motive Questionnaire Revised (DMQ-R, Cooper, 1994) among adolescents in Switzerland. European Addiction Research, 12(3), 161-168.

Kuntsche, E., Knibbe, R. A., Gmel, G., \& Engels, R. C. M. E. (2006b). Who drinks and why? A review of socio-demographic, personality, and contextual issues behind the drinking motives in young people. Addictive Behaviors, 31(10), 1844-1857.

Kuntsche, E., Knibbe, R. A., Gmel, G., \& Engels, R. C. M. E. (2007). Drinking motives as mediators of the link between alcohol expectancies and alcohol use among adolescents. Journal of Studies on Alcohol and Drugs, 68(1), 76-85. 
Kuntsche, E. N. \& Meyer, M. (2002). Abschreckung oder Ansteckung? Wenn Kinder der Meinung sind, dass ihre Eltern zu viel rauchen oder trinken [Deterrence or contagation? When children think that their parents smoke or drink too much]. Suchtmagazin, 1, 20-32.

Kuntsche, E., Rehm, J., \& Gmel, G. (2004). Characteristics of binge drinkers in Europe. Social Science and Medicine, 59(1), 113-127.

Kuntsche, E. N., Reitzle, M. \& Silbereisen, R. K. (2001). Selbstabwertung und Substanzkonsum im Jugendalter - die Rolle von Peers, Substanzart und Geschlecht. Abhängigkeiten, 7(2), 44-56.

Kypri, K., Dean, J., Kirby, S., Harris, J., \& Kake, T. (2005). 'Think before you buy under18s drink': evaluation of a community alcohol intervention. Drug and Alcohol Review, 24(1), 13-20.

Kypri, K., Gallagher, S. J., \& Cashell-Smith, M. L. (2004). An internet-based survey method for college student drinking research. Drug and Alcohol Dependence, $76(1), 45-53$.

Labouvie, E. \& Bates, M. E. (2002). Reasons for alcohol use in young adulthood: validation of a three-dimensional measure. Journal of Studies on Alcohol, 63(2), 145-155.

Labouvie, E. W. \& White, H. R. (2002). Drug sequences, age of onset, and use trajectories as predictors of abuse/dependence in young adulthood. In D. B. Kandel (Ed.), Stages and Pathways of Involvement in Drug Use: Examining the Gateway Hypothesis (pp. 19-41). Cambridge: Cambridge University Press.

Lecci, L., MacLean, M. G., \& Croteau, N. (2002). Personal goals as predictors of college student drinking motives, alcohol use and related problems. Journal of Studies on Alcohol, 63(5), 620-630.

Lee, O. K. (1993). Absolute zeroes for reading and mathematics. Rasch Measurement Transactions, 6(4), 245 - 246.

Leeming, D., Hanley, M., \& Lyttle, S. (2002). Young people's images of cigarettes, alcohol and drugs. Drugs: Education, Prevention and Policy, 9(2), 169 - 185. 
Leigh, B. C. (1989). Attitudes and expectancies as predictors of drinking habits: a comparison of three scales. Journal of Studies on Alcohol, 50(5), 432-440.

Leigh, B. C. \& Stacy, A. W. (1993). Alcohol outcome expectancies: scale construction and predictive utility in higher order confirmatory models. Psychological Assessment, 5(1), 216-299.

Lenke, L. (1990). Alcohol and Criminal Violence: Time Series Analysis in a Comparative Perspective. Stockholm: Almquist and Wiksell International.

Lo, C. C. \& Globetti, G. (2000). Gender differences in drinking patterns among Hong Kong Chinese youth: a pilot study. Substance Use and Misuse, 35(9), 1297-1306.

Loukas, A., Krull, J. L., Chassin, L., \& Carle, A. C. (2000). The relation of personality to alcohol abuse/dependence in a high-risk sample. Journal of Personality, 68(6), 1153-1175.

MacAndrew, C. \& Edgerton, R. B. (1969). Drunken Comportment: A Social Explanation. Chicago, IL: Aldine.

MacKinnon, D. P., Lockwood, C. M., \& Williams, J. (2004). Confidence limits for the indirect effect: Distribution of the product and resampling methods. Multivariate Behavioral Research, 39(1), 99-128.

MacLean, M. G. \& Lecci, L. (2000). A comparison of models of drinking motives in a university sample. Psychology of Addictive Behaviors, 14(1), 83-87.

Maggs, J. L. (1997). Alcohol use and binge drinking as goal-directed action during the transition to postsecondary education. In J. Schulenberg, J. L. Maggs \& K. Hurrelmann (Eds.), Health Risks and Developmental Transitions During Adolescence (pp. 345-371). New York, NY: Cambridge University Press.

Masterman, P. W. \& Kelly, A. B. (2003). Reaching adolescents who drink harmfully: Fitting intervention to developmental reality. Journal of Substance Abuse Treatment, 24(4), 347-355. 
McBride, N., Farringdon, F., Midford, R., Meuleners, L., \& Phillips, M. (2003). Early unsupervised drinking-reducing the risks. The School Health and Alcohol Harm Reduction Project. Alcohol Review 22(3), 263-276.

McCabe, S. E. (2002). Gender differences in collegiate risk factors for heavy episodic drinking. Journal of Studies on Alcohol, 63(1), 49-56.

McCarty, D. \& Kaye, M. (1984). Reasons for drinking: motivational patterns and alcohol use among college students. Addictive Behaviors, 9(2), 185-188.

McCrae, R. R., Costa, P. T., Jr., Terracciano, A., Parker, W. D., Mills, C. J., De Fruyt, F., \& Mervielde, I. (2002). Personality trait development from age 12 to age 18: longitudinal, cross-sectional, and cross-cultural analyses. Journal of Personality and Social Psychology, 83(6), 1456-1468.

McCrae, R. R. \& John, O. P. (1992). An introduction to the five-factor model and its applications. Journal of Personality, 60(2), 175-215.

McKeganey, N. (1998). Alcopops and young people: a suitable cause for concern. Addiction, 93(4), 471 - 473.

McKeganey, N., Forsyth, A. J. M., Barnard, M., \& Hay, G. (1996). Designer drinks and drunkenness amongst a sample of Scottish schoolchildren. British Medical Journal, 313(7054), 401.

McNally, A. M., Palfai, T. P., Levine, R. V., \& Moore, B. M. (2003). Attachment dimensions and drinking-related problems among young adults. The mediational role of coping motives. Addictive Behaviors, 28, 1115-1127.

Milgram, G. G. (1993). Adolescents, alcohol and aggression. Journal of Studies on Alcohol, Suppl. No. 11, 53-61.

Miller, W. R. (1996). Motivational interviewing: research, practice, and puzzles. Addictive Behaviors, 21(6), 835-842.

Moffitt, T. E. (1993). Adolescence-limited and life-course-persistent antisocial behavior: a developmental taxonomy. Psychological Review, 100(4), 674 - 701. 
Mohr, C. D., Armeli, S., Tennen, H., Temple, M., Todd, M., Clark, J., \& Carney, M. A. (2005). Moving beyond the keg party: a daily process study of college student drinking motivations. Psychology of Addictive Behaviors, 19(4), 392-403.

Montgomery, R. L., Benedicto, J. A., \& Haemmerlie, F. M. (1993). Personal vs social motivations of undergraduates for using alcohol. Psychological Reports, 73(3 Pt 1), 960-962.

Mulford, H. A. \& Miller, D. E. (1960). Drinking in Iowa. V. Drinking and alcoholic drinking. Quarterly Journal of Studies on Alcohol, 21, 483-499.

Murphy, J. G., Correia, C. J., Colby, S. M., \& Vuchinich, R. E. (2005). Using behavioral theories of choice to predict drinking outcomes following a brief intervention. Experimental and Clinical Psychopharmacology, 13(2), 93-101.

Mushquash, C. J., Stewart, S. H., Comeau, N., \& Conrod, P. J. (2006, November). Psychometric evaluation of the revised drinking motives questionnaire in a high school student sample. Paper presented at the Addictive Behaviors Special Interest Group meeting at the 40th annual conference of the Association for Behavioral and Cognitive Therapies (ABCT), Chicago, IL.

Muthén, L. K., \& Muthén, B. O. (2004). Mplus: Statistical Analysis With Latent Variables User's Guide (3rd ed.). Los Angeles, CA: Muthén \& Muthén.

Nagoshi, C. T., Nakata, T., Sasano, K., \& Wood, M. D. (1994). Alcohol norms, expectancies, and reasons for drinking and alcohol use in a U.S. versus a Japanese college sample. Alcoholism, Clinical and Experimental Research, 18(3), 671-678.

Neff, J. A. (1997). Solitary drinking, social isolation, and escape drinking motives as predictors of high quantity drinking, among Anglo, African American and Mexican American males. Alcohol and Alcoholism, 32(1), 33-41.

Neighbors, C., Larimer, M. E., \& Lewis, M. A. (2004). Targeting Misperceptions of Descriptive Drinking Norms: Efficacy of a Computer-Delivered Personalized Normative Feedback Intervention Journal of Consulting and Clinical Psychology, 72(3), 434-447. 
Newcomb, M. D. \& McGee, D. L. (1989). Adolescent alcohol use and other delinquent behaviors. Criminal Justice and Behavior, 16, 345-369.

Novacek, J., Raskin, R., \& Hogan, R. (1991). Why do adolescents use drugs? Age, sex, and user differences. Journal of Youth and Adolescence, 20(5), 475-492.

Novak, A., Burgess, E. S., Clark, M., Zvolensky, M. J., \& Brown, R. A. (2003). Anxiety sensitivity, self-reported motives for alcohol and nicotine use, and level of consumption. Journal of Anxiety Disorders, 17(2), 165-180.

O'Hare, T. (1997). Measuring excessive alcohol use in college drinking contexts: the Drinking Context Scale. Addictive Behaviors, 22(4), 469-477.

O'Hare, T. (2001). The Drinking Context Scale. A confirmatory factor analysis. Journal of Substance Abuse Treatment, 20(2), 129-136.

Olweus, D. (1993). Bullying at school: What we know and what we can do. Oxford: Blackwell.

Ooteman, W., Koeter, M., Verheul, R., Schippers, G., \& Van den Brink, W. (2006). Development and validation of the Amsterdam Motives for Drinking Scale (AMDS): an attempt to distinguish relief and reward drinkers. Alcohol and Alcoholism, 41(3), 284-292.

Osgood, D. W., Johnston, L. D., O'Malley, P. M., \& Bachman, J. G. (1988). The generality of deviance in late adolescence and early adulthood. American Sociological Review, 53(1), 81-93.

Otten, R., Van den Eijnden, R. J., \& Engels, R. C. (in press). General Parenting, AntiSmoking Socialization And Smoking Onset. Health Education Research.

Oxford University Press. (2001). Oxford Student's Dictionary of English. Oxford: Oxford University Press.

Palmqvist, R. A., Martikainen, L. K., \& vonWright, M. R. (2003). A moving target: Reasons given by adolescents for alcohol and narcotics use, 1984 and 1999. Journal of Youth and Adolescence, 32(3), 195-203. 
Perkins, H. W. (2002). Surveying the damage: a review of research on consequences of alcohol misuse in college populations. Journal of Studies on Alcohol, Suppl. 14, 91-100.

Petraitis, J., Flay, B. R., \& Miller, T. Q. (1995). Reviewing theories of adolescent substance use: organizing pieces in the puzzle. Psychological Bulletin, 117(1), 67-86.

Plant, M. A., Bagnall, G., \& Foster, J. (1990). Teenage heavy drinkers: alcohol-related knowledge, beliefs, experiences, motivation and the social context of drinking. Alcohol and Alcoholism, 25(6), 691-698.

Poikolainen, K., Tuulio-Henriksson, A., Aalto-Setälä, T., Marttunen, M., \& Lönnqvist, J. (2001). Predictors of alcohol intake and heavy drinking in early adulthood: a 5year follow-up of 15-19-year-old Finnish adolescents. Alcohol and Alcoholism, $36(1), 85-88$.

Preacher, K. J. \& Hayes, A. F. (2004). SPSS and SAS procedures for estimating indirect effects in simple mediation models. Behavior Research Methods, Instruments and Computers, 36, 717-731.

Quigley, L. A. \& Marlatt, G. A. (1996). Drinking among young adults: Prevalence, patterns, and consequences. Alcohol Health and Research World, 20(3), 185-191.

Read, J. P., Wood, M. D., Kahler, C. W., Maddock, J. E., \& Palfai, T. P. (2003). Examining the role of drinking motives in college student alcohol use and problems. Psychology of Addictive Behaviors, 17(1), 13-23.

Rehm, J. \& Gmel, G. (1999). Patterns of alcohol consumption and social consequences. Results from an 8-year follow-up study in Switzerland. Addiction, 94(6), 899-912.

Reiss, S., Peterson, R. A., Gursky, D. M., \& McNally, R. J. (1986). Anxiety sensitivity, anxiety frequency and the prediction of fearfulness. Behaviour Research and Therapy, 24(1), 1-8.

Riley, J. W., Marden, C. F., \& Lifshitz, M. (1948). The motivational pattern of drinking based on the verbal responses of a cross-section sample of users of alcoholic beverages. Quarterly Journal of Studies on Alcohol, 9, 353-362. 
Roberts, C., Blakey, V., \& Tudor-Smith, C. (1999). Impact of 'Alcopops' on regular drinking by young people in Wales. Drugs: Education, Prevention and Policy, $6(1), 7-15$.

Romanus, G. (2000). Alcopops in Sweden - a supply side initiative. Addiction, 95(Suppl 4), S609-619.

Room, R. (2001). Intoxication and bad behaviour: understanding cultural differences in the link. Social Science and Medicine, 53(2), 189-198.

Room, R. \& Mäkelä, K. (2000). Typologies of the cultural position of drinking. Journal of Studies on Alcohol, 61(3), 475-483.

Rossow, I., Pape, H., \& Wichstrom, L. (1999). Young, wet \& wild? Associations between alcohol intoxication and violent behaviour in adolescence. Addiction, 94(7), 10171031.

Rutledge, P. \& Sher, K. J. (2001). Heavy drinking from the freshmen year into early young adulthood: the roles of stress, tension-reduction drinking motives, gender and personality. Journal of Studies on Alcohol, 62(4), 457-466.

Sartre, J. P. (1976). L'Être et le Néant. Essai d'ontologie phénoménologique. Paris: Gallimard.

Schmid, H., Delgrande Jordan, M., Kuntsche, E. N., \& Kuendig, H. (2003). Trends im Konsum psychoaktiver Substanzen von Schülerinnen und Schülern in der Schweiz - Ausgewählte Ergebnisse einer Studie, durchgeführt unter der Schirmherrschaft der Weltgesundheitsorganisation (WHO) (Forschungsbericht 39). Lausanne: Schweizerische Fachstelle für Alkohol- und andere Drogenprobleme (SFA).

Schulenberg, J., Wadsworth, K. N., O'Malley, P. M., Bachman, J. G., \& Johnston, L. D. (1996). Adolescent risk factors for binge drinking during the transition to young adulthood: variable- and pattern-centered approaches to change. Developmental Psychology, 32(4), 659-674.

Segal, B., Huba, G. J., \& Singer, J. L. (1980). Reasons for drug and alcohol use by college students. International Journal of the Addictions, 15(4), 489-498. 
Sher, K. J. (2006). Toward a Cognitive Theory of Substance Use and Dependence. In R. W. Wiers \& A. W. Stacy (Eds.), Handbook of Implicit Cognition and Addiction (pp. 473-476). Thousand Oaks, CA: Sage.

Simons, J., Correia, C. J., \& Carey, K. B. (2000). A comparison of motives for marijuana and alcohol use among experienced users. Addictive Behaviors, 25(1), 153-160.

Smart, R. G. (1996). Behavioral and social consequences related to the consumption of different beverage types. Journal of Studies on Alcohol, 57(1), 77-84.

Smart, R. G. \& Walsh, G. W. (1995). Do some type of alcoholic beverages lead to more problems for adolescents? Journal of Studies on Alcohol, 56(1), 35-38.

Smart, R. G. \& Walsh, G. W. (1999). Heavy drinking and problems among wine drinkers. Journal of Studies on Alcohol, 60(4), 467-471.

Smith, E. R. \& DeCoster, J. (2000). Dual process models in social and cognitive psychology: Conceptual integration and links to underlying memory systems. Personality and Social Psychology Review, 4, 108-131.

Smith, M. J., Abbey, A., \& Scott, R. O. (1993). Reasons for drinking alcohol: their relationship to psychosocial variables and alcohol consumption. International Journal of the Addictions, 28(9), 881-908.

Snortum, J. R., Kremer, L. K., \& Berger, D. E. (1987). Alcoholic beverage preference as a public statement: self-concept and social image of college drinkers. Journal of Studies on Alcohol, 48(3), 243-251.

SPSS Inc. (2005). SPSS Base 14.0 User's Guide. Chicago, IL: SPSS Inc.

Stacy, A. W. (1997). Memory activation and expectancy as prospective predictors of alcohol and marijuana use. Journal of Abnormal Psychology, 106(1), 61-73.

StataCorp. (2001). Stata multivariate statistics - Release 7. College Station, TX: Stata Press.

StataCorp. (2005). Stata multivariate statistics - Release 9. College Station, TX: Stata Press. 
Stewart, C. \& Power, T. G. (2002). Identifying patterns of adolescent drinking: A tri-ethnic study. Journal of Studies on Alcohol, 63(2), 156-168.

Stewart, S. H. \& Chambers, L. (2000). Relationships between drinking motives and drinking restraint. Addictive Behaviors, 25(2), 269-274.

Stewart, S. H., Conrod, P. J., Marlatt, G. A., Comeau, M. N., Thush, C., \& Krank, M. (2005). New developments in prevention and early intervention for alcohol abuse in youths. Alcoholism, Clinical and Experimental Research, 29(2), 278-286.

Stewart, S. H. \& Devine, H. (2000). Relations between personality and drinking motives in young adults. Personality and Individual Differences, 29(3), 495-511.

Stewart, S. H., Hall, E., Wilkie, H., \& Birch, C. D. (2002). Affective priming of alcohol schema in coping and enhancement motivated drinkers. Cognitive Behavior Therapy, 31, 63-80.

Stewart, S. H., Karp, J., Pihl, R. O., \& Peterson, R. A. (1997). Anxiety sensitivity and selfreported reasons for drug use. Journal of Substance Abuse, 9, 223-240.

Stewart, S. H., Loughlin, H. L., \& Rhyno, E. (2001). Internal drinking motives mediate personality domain - drinking relations in young adults. Personality and Individual Differences, 30, 271-286.

Stewart, S. H. \& Zeitlin, S. B. (1995). Anxiety sensitivity and alcohol use motives. Journal of Anxiety Disorders, 9(3), 229-240.

Stewart, S. H., Zeitlin, S. B., \& Samoluk, S. B. (1996). Examination of a three-dimensional drinking motives questionnaire in a young adult university student sample. Behaviour Research and Therapy, 34(1), 61-71.

Stewart, S. H., Zvolensky, M. J., \& Eifert G.H. (2002). The relations of anxiety sensitivity, experiential avoidance, and alexithymic coping to young adults' motivations for drinking. Behavior Modification, 26(2), 274-296.

Strack, F. \& Deutsch, R. (2004). Reflective and impulsive determinants of social behavior. Personality and Social Psychology Review, 3, 220-247. 
Suls, J., Martin, R., \& David, J. P. (1998). Person-environment fit and its limits: agreeableness, neuroticism, and emotional reactivity to interpersonal conflict. Personality and Social Psychology Bulletin, 24, 88-98.

Swahn, M. H., Simon, T. R., Hammig, B. J., \& Guerrero, J. L. (2004). Alcoholconsumption behaviors and risk for physical fighting and injuries among adolescent drinkers. Addictive Behaviors, 29(5), 959-963.

Tabachnick, B. G. \& Fidell, L. S. (2001). Using multivariate statistics (4 ed.). Boston, MA: Allyn and Bacon.

Theakston, J. A., Stewart, S. H., Dawson, M. Y., Knowlden-Loewen, S. A. B., \& Lehman, D. R. (2002). Big-Five personality domains predict drinking motives. Personality and Individual Differences, 37, 971-984.

Thombs, D. L., Beck, K. H., \& Pleace, D. J. (1993). Relationship of social context and expectancy factors to alcohol use intensity among 18-22 year-olds. Addiction Research, 1(1), 59-68.

Thush, C. \& Wiers, R. W. (2007). Explicit and implicit alcohol-related cognitions and the prediction of future drinking in adolescents. Addictive Behaviors, 32(7), 13671383.

Tucker, J. S., Orlando, M., \& Ellickson, P. L. (2003). Patterns and correlates of binge drinking trajectories from early adolescence to young adulthood. Health Psychology, 22(1), 79-87.

Turrisi, R., Padilla, K. K., \& Wiersma, K. A. (2000). College student drinking: an examination of theoretical models of drinking tendencies in freshmen and upperclassmen. Journal of Studies on Alcohol, 61(4), 598-602.

Ullman, J. B. (2001). Structural equation modeling. In B. G. Tabachnick \& L. S. Fidell (Eds.), Using Multivariate Statistics (4th ed., pp. 653-771). Boston, MA: Allyn and Bacon.

Vollrath, M. \& Torgersen, S. (2002). Who takes health risks? A probe into eight personality types. Personality and Individual Differences, 32(7), 1185-1197. 
Walters, S. T., Bennett, M. E., \& Noto, J. V. (2000). Drinking on campus. What do we know about reducing alcohol use among college students? Journal of Substance Abuse Treatment, 19(3), 223-228.

Webb, J. A., Getz, J. G., Baer, P. E., \& McKelvey, R. S. (1999). Intentions to use alcohol among fifth and sixth graders: The roles of social and stress/coping motives. American Journal of Orthopsychiatry, 69(4), 541-547.

Weinberger, D. A. \& Bartholomew, K. (1996). Social-emotional adjustment and patterns of alcohol use among young adults. Journal of Personality, 64(2), 495-527.

White, H. R. (1996). Empirical validity of theories of drug abuse: Introductory comments. Journal of Drug Issues, 26(2), 279-288.

White, H. R. (1997). Longitudinal perspective on alcohol use and aggression during adolescence. Recent Developments in Alcoholism, 13, 81-103.

White, H. R., Brick, J., \& Hansell, S. (1993). A longitudinal investigation of alcohol use and aggression in adolescence. Journal of Studies on Alcohol, Supplement 11, $62-$ 77.

White, H. R., Morgan, T. J., Pugh, L. A., Celinska, K., Labouvie, E. W., \& Pandina, R. J. (2006). Evaluating two brief substance-use interventions for mandated college students. Journal of Studies on Alcohol, 67(2), 309-317.

Wicki, M., Gmel, G., Kuntsche, E., Rehm, J., \& Grichting, E. (2006). Is alcopop consumption in Switzerland associated with riskier drinking patterns and more alcohol-related problems? Addiction, 101(4), 522-533.

Wiers, R. W., Bartholow, B. D., van den Wildenberg, E., Thush, C., Engels, R. C., Sher, K. J., Grenard, J., Ames, S. L., \& Stacy, A. W. (2007). Automatic and controlled processes and the development of addictive behaviors in adolescents: a review and a model. Pharmacology Biochemistry and Behavior, 86(2), 263-283.

Wiers, R. W., Hoogeveen, K.-J., Sergeant, J. A., \& Gunning, W. B. (1997). High- and lowdose alcohol-related expectancies and the differential associations with drinking in male and female adolescents and young adults. Addiction, 92(7), 871-888. 
Wiers, R. W., Houben, K., Smulders, F. T., Conrod, P. J., \& Jones, B. T (2006). To drink or not to drink: The role of automatic and controlled cognitive processes in the etiology of alcohol-related problems. In R. W. Wiers \& A. W. Stacy (Eds.), Handbook of Implicit Cognition and Addiction (pp. 339-362). Thousand Oaks, CA: Sage.

Wiers, R. W., van de Luitgaarden, J., van den Wildenberg, E., \& Smulders, F. T. (2005). Challenging implicit and explicit alcohol-related cognitions in young heavy drinkers. Addiction, $100(6), 806-819$.

Wiers, R. W., van Woerden, N., Smulders, F. T., \& de Jong, P. J. (2002). Implicit and explicit alcohol-related cognitions in heavy and light drinkers. Journal of Abnormal Psychology, 111(4), 648-658.

Wild, T. C., Hinson, R., Cunningham, J., \& Bacchiochi, J. (2001). Perceived vulnerability to alcohol-related harm in young adults: independent effects of risky alcohol use and drinking motives. Experimental and Clinical Psychopharmacology, 9(1), 117125 .

Windle, M. (1990). A longitudinal study of antisocial behaviors in early adolescence as predictors of late adolescent substance use: gender and ethnic group differences. Journal of Abnormal Psychology, 99(1), 86-91.

Windle, M. (1996). An alcohol involvement typology for adolescents: convergent validity and longitudinal stability. Journal of Studies on Alcohol, 57(6), 627-637.

Windle, M. (2003). Alcohol use among adolescents and young adults. Alcohol Research and Health, 27(1), 79 - 86.

Windle, M. \& Windle, R. C. (1996). Coping strategies, drinking motives, and stressful life events among middle adolescents: Associations with emotional and behavioral problems and with academic functioning. Journal of Abnormal Psychology, 105(4), 551-560.

World Health Organization (WHO). (1999). Global Status Report on Alcohol. Geneva: WHO, Substance Abuse Department. 
World Health Organization (WHO). (2001). Highlights on health in Switzerland. Copenhagen: WHO Regional Office for Europe.

World Health Organization (WHO). (2002). The World Health Report 2002 - Reducing Risks, Promoting Healthy Life. Geneva: World Health Organization (WHO).

World Health Organization (WHO). (2005). Alcohol and Interpersonal Violence. Policy Briefing. Copenhagen: WHO Europe.

World Medical Association (WMA). (2002). World Medical Association Declaration of Helsinki. Ethical principles for medical research involving human subjects. Ferney-Voltaire: WMA.

Zuckerman, M. (1994). Behavioral Expressions and Biological Bases of Sensation Seeking. New York: Cambridge University Press. 


\section{Curriculum Vitae}

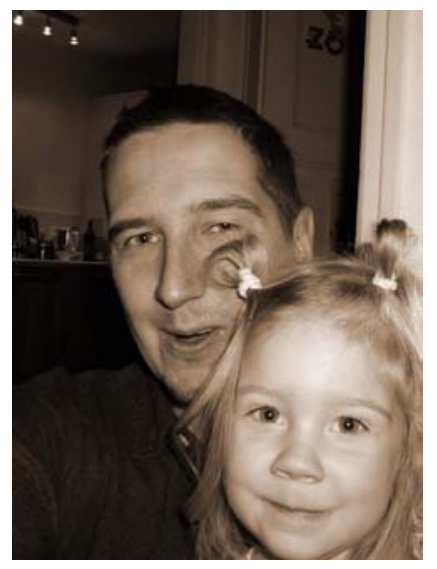

Emmanuel Nicolás Kuntsche was born on August 20, 1972 in Barcelona (Spain). However, he spent most of his childhood in a small town in the Black Forest (Southwest Germany). Shortly after the fall of the Berlin wall in 1992, he moved to Eastern Germany (former GDR) to study Psychology (B.A. in 1994, M.A. in 1999) and Sociology (B.A. in 1997) at the University of Jena. In 1997, he began a psychiatry internship at the Clinique de la Borde in CourCheverny (France). He attended the Essex Summer School in Social Science Data Analysis and Collection (University of Essex, UK) in 1996 first as a student, then in 1998 as a teaching assistant. He accepted the post of junior researcher in the Department of Methods in Empirical Social Research and Structural Analysis in Modern Societies, Institute of Sociology, at the University of Jena before later moving to Switzerland in 1999. Since then, he has been employed in the Swiss Institute for the Prevention of Alcohol and Drug Problems (SIPA), where he has worked primarily on alcohol use and other problem behaviors in adolescence. $\mathrm{He}$ contributed to the large school-based surveys "Health Behaviour in School-Aged Children (HBSC)" and the "European School-Survey Project on Alcohol and Drugs (ESPAD)" and to 13 other research projects. He has published more than 100 peer-reviewed articles, book chapters, research reports and book reviews, and has contributed to more than 50 conferences and scientific meetings. For his presentation of expectancy-motive mediation (cf. Chapter 5) he obtained the 2006 Kettil Bruun Society Early Career Scientist Award. Emmanuel Kuntsche lives with his wife Sandra and their two children, Zoë and Neo, in Lausanne. 


\section{ACKNOWLEDGEMENTS}

\section{Professional acknowledgements}

This doctoral thesis was based on the Swiss participation in the 2003 European School Survey Project on Alcohol and Drugs (ESPAD). I would like to thank everyone - students, teachers, administrators and colleagues - who participated in the project. Without their kindness and help this work would not have been possible.

The 2003 Swiss ESPAD project was mainly funded by the Swiss Federal Office of Public Health (Grant No. 02.000.537). Additional funds for Chapters 4, 5, and 8 were obtained from the Swiss National Science Foundation (Grant No. 101511105481/1). Funding for the analysis in Chapter 6 was provided by the Swiss Foundation for Alcohol Research. Funding for the analysis in Chapter 7 came from the Swiss Federal Office of Public Health Grant No. 02.000.964. The Swiss Institute for the Prevention of Alcohol and Drug Problems supported the writing of Chapters 1 and 9. I am grateful to all. Without their financial support, this work would not have been possible.

I would especially like to thank Michel Graf, Director of the SIPA, as well as my colleagues, such as Marina and Hervé (to name but a few), with whom it has always been a pleasure to collaborate. Without a supportive working environment, this book would not have been possible. 


\section{Personal acknowledgements}

I started working for the Swiss Institute one Friday in October 1999. When I entered the office, the entire research department was deserted. A secretary briefly showed me around my new work place and instructed me on the main administrative procedures. After a while, a strange guy wearing an old sweater and trainers dropped in. Having dispensed with the niceties, he gave me a few words of advice: "Listen, you can either do what you are told to do, please your boss, and have a quiet life - or you can work hard and try to publish and become an expert in the field". I decided to choose the latter option - and I am still trying to reach that goal. His help, support and endurance have enabled me to forge my career. Thank you, Gerhard, for all the beers and verbal bar fights and, most of all, for being a friend.

Thank you, Ronald. You picked me up off the streets (of Berlin) in a moment of black despair. You have been my "good parent": warm, open and responsive, yet firm, organized, and a guiding hand.

Thank you, Rutger, not only for sharing your tremendous knowledge with me but also for providing me with some of your boundless energy and motivation to keep things moving.

Sandra, thank you for being the warm breeze in my life, and for putting up with me in good days and in bad. You have given me the two most wonderful and amazing gifts I could ever have wished for. Their bright cheery faces in the morning give me the strength to cope with whatever the day might bring. 